\title{
Reading
}

3 


\section{Reti Medievali}

\section{E-Book}

Monografie

1. Renato Bordone, Uno stato d'animo, 2002

2. Marina Gazzini, "Dare et habere". Il mondo di un mercante milanese del Quattrocento, 2002

3. Paola Guglielmotti, Ricerche sull'organizzazione del territorio nella Liguria medievale, 2005

Reading

1. "Le storie e la memoria". In onore di Arnold Esch, a cura di Roberto Delle Donne, Andrea Zorzi, 2002

2. Papato e monachesimo "esente" nei secoli centrali del Medioevo, a cura di Nicolangelo D'Acunto, 2003

3. Alto medioevo mediterraneo, a cura di Stefano Gasparri, 2005

\section{Quaderni di Reti Medievali Rivista}

1. Poteri signorili e feudali nelle campagne dell'Italia settentrionale fra Tre e Quattrocento: fondamenti di legittimità e forme di eserci-zio. Atti del Convegno di studi (Milano, 11-12 aprile 2003), a cura di Federica Cengarle, Giorgio Chittolini, Gian Maria Varanini, 2005

2. Ebrei nella Terraferma veneta del Quattrocento. Atti del seminario di studi (Verona, 14 novembre 2003), a cura di Gian Maria Varanini, Reinhold C. Mueller, 2005 
Reti Medievali

\title{
Alto medioevo mediterraneo
}

\author{
a cura di Stefano Gasparri
}

Firenze University Press 2005 
Alto medioevo mediterraneo / a cura di Stefano Gasparri. - Firenze :

Firenze university press, 2005.

(Reti Medievali. E-book, Reading, 3)

http://www.dssg.unifi.it/_RM/e-book/titoli/altomediterraneo.htm

Stampa a richiesta disponibile su http://epress.unifi.it

ISBN 88-8453-129-2 (online)

ISBN 88-8453-130-6 (print)

940.1 (ed. 20)

Storia Medievale-Sec. 5.-11.

Editing e impaginazione di Umberto Coscarelli

(C) 2005 Firenze University Press

Università degli Studi di Firenze

Firenze University Press

Borgo Albizi, 28

50122 Firenze, Italy

http://epress.unifi.it/

Printed in Italy 


\section{Indice}

Stefano Gasparri, Introduzione: da oriente a occidente

Paolo Bettiolo, "Prigionieri dello Spirito". Libertà creaturale ed eschaton in Isacco di Ninive e nelle sue fonti

Héctor R. Francisco, Autoridad carismática y disidencia religiosa. La hagiografia Siria en los siglos Vy VI

Pablo Ubierna, Liturgia y apocalíptica en Bizancio: Notas sobre la leyenda del Trisagion

Jorge Bedoya e Ofelia Manzi, La imagen funeraria tardo-antigua: cristianización de motivos paganos

Hugo Andrés Zurutuza, Ambrosio de Milán y el reclutamento de los "hombres de Iglesia”. Perfíl eclesiástico de Italia del Norte durante el siglo IV

Liliana Pégolo, Relaciones de poder en el epistolario del siglo VI: el Regestum de Gregorio Magno

Hugo Andrés Zurutuza e Horacio Botalla, La Regula benedictina como principio de mutación individual y de resocialización colectiva

Cristina La Rocca, Venanzio Fortunato e la società del VI secolo

Sauro Gelichi, Archeologia longobarda e archeologia dell'alto medioevo italiano: un bilancio critico

Giorgio Ravegnani, Le unità dell'esercito bizantino nel VI secolo tra continuità e innovazione

Stefano Gasparri, La regalità longobarda. Dall'età delle migrazioni alla conquista carolingia

Gian Pietro Brogiolo, Capitali e residenze regie nell'Italia longobarda

Claudio Azzara, “... quod cawerfeda antiqua usque nunc sic fuisset”. Consuetudine e codificazione nell'Italia longobarda 



\title{
Introduzione: da oriente a occidente*
}

\author{
Stefano Gasparri
}

Il titolo di questo libro riflette un dato di fatto, che emerge con chiarezza dai diversi saggi che lo compongono: è possibile individuare una dimensione mediterranea dei primi secoli del medioevo, o, forse ancora meglio, del plurisecolare periodo di transizione fra la tarda antichità e l'alto medioevo. Senza però entrare qui in dispute periodizzanti inutili, si è ritenuto di dare un titolo sintetico per indicare l'ambito cronologico entro la quale si svolgono i fenomeni e i processi presentati nelle pagine che seguono, cui si aggiunge il quadro geografico: il Mediterraneo appunto, con un'accentuazione, a partire dall'Italia, della sua parte orientale, nei secoli che vanno all'incirca dal III all'VIII. Una cornice geo-temporale ma al tempo stesso di civiltà, quella così individuata, di evidente tradizione ellenistico-romana, al cui interno emerge progressivamente una società divisa in due poli, quello orientale, tramite indispensabile per il rapporto con l'antichità, che pian piano si divide fra Bisanzio e l'Islam, e quello occidentale che si va ricostruendo lentamente nelle nuove società barbariche post-romane.

Questo libro è anche il frutto di un incontro fra studiosi diversi, anzi fra due scuole in apparenza molto lontane fra di loro. Da una parte la ricerca altomedievistica italiana, fondata sulle fonti scritte e su quelle archeologiche, queste ultime sostenute da una fortissima esperienza di scavo, dall'altra la ricerca argentina che ha sviluppato un deciso interesse per la tarda antichità, unendo alle fonti scritte l'analisi di quelle artistiche ed iconografiche. E tuttavia questo percorso di studi ha portato necessariamente i colleghi argentini a varcare i secoli dell'altomedioevo, inseguendo personaggi come Benedetto o Gregorio Magno, i mutamenti culturali e quelli religiosi, spirituali e culturali. Di qui l'incontro, che si concretizza in un volume senza alcuna pretesa di completezza tematica, giacché esso riflette semplicemente i diversi percorsi di ricerca dei suoi autori, ma che offre alcune suggestioni di ampio respiro.

\footnotetext{
* Per rispettare le diverse abitudini di citazioni bibliografiche, differenti sia per tradizioni nazionali che per disciplina degli autori, il lavoro di uniformazione redazionale non è stato compiuto fino in fondo.
} 
L'oriente e l'Italia (con la Gallia) sono i due ambiti nei quali si ricompongono i vari saggi. E l'oriente è presente soprattutto come fonte di esperienze e riflessioni religiose. Così, dal profondo della chiesa d'oriente, in bilico fra Bisanzio ed Islam, Paolo Bettiolo ci presenta il pensiero di un monaco siriaco del VII secolo, Isacco di Ninive, che ci introduce nel cuore del dibattito sull'esperienza mistica, affrontando la questione della preghiera pura - non in senso morale, ma metafisico: essa è la deposizione di ogni pensiero, "la preghiera si secca nella bocca dell'orante" -, della natura degli angeli, dei limiti della libertà delle creature, della conseguente inconoscibilità piena della verità divina. Una scuola di grande tradizione, quella siriaca, i cui esponenti, come Teodoro di Mopsuestia, ebbero un ruolo importante nelle più antiche controversie teologiche del cristianesimo mediterraneo: non è un caso che Teodoro stesso si trovi nel cuore stesso del grande dibattito che si ricollega al concilio di Calcedonia e all'eresia monofisita.

Gli echi di questo dibattito, e dei drammatici conflitti che ne seguirono, si colgono anche altrove: ad esempio, l'attesa apocalittica nell'impero di Bisanzio, di cui parla Pablo Ubierna, e che era legata in primo luogo all'esegesi del libro di Daniele - che offriva il quadro storico dei quattro imperi, nel quale l'impero bizantino poteva trovare la sua collocazione - , si concentrò sull'anno 500; ma questa ricerca dell'anno della fine del mondo veniva spesso fatta coincidere proprio con le lotte fra calcedoniani e monofisiti. In realtà, sia nella storiografia propriamente bizantina che in quella siriaca (Malalas, Giosuè Stilita) l'idea apocalittica viene combattuta e i suoi argomenti respinti, nonostante che si registrino tutti i cataclismi apparsi nel periodo "critico". Il monofisita Giovanni Rufo, dal canto suo, utilizza l'interpretazione escatologica degli eventi in chiave anti-calcedoniana. Un'altra manipolazione dell'attesa escatologica, nell'ambito sempre delle polemiche cristologiche, la si può vedere nella leggenda relativa all'arrivo a Costantinopoli della preghiera del Trisagion: una leggenda, che si diffuse a metà circa del secolo $\mathrm{V}$, la cui struttura è escatologica, ma che in realtà ha lo scopo proprio di allontanare l'attesa della fine, provocata da una serie di terremoti avvenuti in quel periodo a Costantinopoli, esprimendo fiducia nel destino dell'impero e della sua capitale. Ma la forza della tradizione apocalittica fa sì che per contrastarla si debba scegliere la stessa forma delle rivelazioni apocalittiche, il messaggio ricevuto tramite un viaggio ultraterreno.

Nel mondo della tarda antichità, che trasformava sempre più nettamente l'età classica sotto la spinta anche delle trasformazioni indotte dal cristianesimo, è caratteristico come - sempre in oriente - la libertà di parola, l'antica parrhesía del cittadino di età classica, giochi ancora un ruolo fondamentale, ma questa volta nell'ambito della relazione che si va instaurando fra il potere carismatico degli "uomini santi", i viri dei delle regioni orientali del Mediterraneo, da una parte, e dall'altra i poteri della gerarchia ecclesiastica 
episcopale, legittimata dallo stato, o i poteri dello stato stesso. Attraverso l'analisi delle opere di due autori, uno greco del V (Teodoreto di Ciro, un altro dei padri di Calcedonia) e uno siriaco del VI (Giovanni da Efeso), Héctor R. Francisco evidenzia questo carisma dell'uomo santo, che, libero da vincoli mondani per la sua scelta ascetica, esercita la sua libertà di parola, autentico dono divino, di fronte al potere politico e religioso, convertendola in pratica ascetica e per estensione in martirio.

La lentezza del passaggio da un'epoca ad un'altra la si coglie anche sfumando i contrasti culturali tra pagani e cristiani: da un punto di vista particolare, lo studio dei motivi iconografici funerari tardo-antichi sviluppato da Jorge Bedoya e Ofelia Manzi suggerisce che il passaggio dal predominio spirituale e culturale dei pagani a quello dei cristiani sia stato tutt'altro che un processo di rottura radicale. I motivi iconografici cristiani riprendevano in modo talvolta anche evidente modelli pagani più antichi (Giona rappresentano come Endimione dormiente, Dio Padre raffigurato come Giove o come un alto funzionario romano, la Croce e il trionfo degli imperatori), mentre sia fra i pagani che fra i cristiani l'accento veniva messo sul superamento della morte, fosse esso parziale - rappresentato per i pagani dal ritorno sulla terra del defunto grazie all'intervento di un eroe - o totale - la salvezza cristiana -, mettendo al contrario fra parentesi le immagini della morte come disfacimento del corpo: nel caso dei cristiani, contarono anche le dispute cristologiche e la conseguente volontà di non presentare la Crocifissione perché ciò poteva sembrare un'accentuazione dell'umanità di Cristo. Qui come altrove, il problema cristologico si presenta come il nodo culturale e spirituale centrale dell'intera età tardo-antica in area mediterranea, quello su cui alla fine si giocherà buona parte del distacco tra occidente ed oriente.

Il tema dei viri dei è quello che può meglio creare un ponte fra oriente ed occidente medieterraneo: il prototipo di essi, in occidente, è Benedetto, della cui Regula Hugo Zurutuza e Horacio Botalla ripercorrono le più antiche vicende. La Regula è presentata come un mezzo per ristabilire le reti di socialità sconvolte dal crollo del mondo romano e per creare nuovi circuiti socioculturali nell'ambito delle comunità monastiche, pur all'interno di una sostanziale modestia culturale delle origini del movimento benedettino; ben diversa invece sarà la portata culturale del progetto carolingio, che utilizzerà la regola come elemento ordinatore e di disciplinamento dell'intera rete monastica dell'impero e dunque, a questo fine, promuoverà un effettivo studio della Regula e delle Sacre Scritture. Ma a questo punto siamo ormai in un quadro che è pienamente medievale. Sempre Zurutuza ci riporta invece nel vivo dell'età tardo-antica analizzando la crescita della rete episcopale in Italia, fra III e IV secolo. In questo lento processo vi è una netta prevalenza dell'Italia suburbicaria rispetto all'Italia annonaria, a conferma delle radici mediterraneee del Cristianesimo e del suo legame con l'oriente. Nel nord 
d'Italia, più povero di episcopati e con ampi vuoti nella rete episcopale, ma asse fra oriente ed occidente, la rete ecclesiastica progredisce da oriente verso occidente: qui è forte lo sviluppo di Vercelli, centro militare e logistico fra Italia e Gallia, a partire dall'episcopato di Eusebio. Al nord c'è però un'influenza alternativa a Roma, quella di Milano, nel IV secolo residenza imperiale che conosce per di più l'episcopato di Ambrogio (374-397). È il periodo della lotta antiariana, e Ambrogio recluta ovunque vescovi e clero niceni, scegliendo per necessità personaggi di estrazione regionale, mostrando loro modalità di comportamento aristocratico, primo fra tutti lo strumento epistolare, e rafforzando il loro livello culturale: si tratta ormai di quadri formati in ambito ecclesiastico, non più derivanti dai ranghi dell'aristocrazia senatoriale (cui invece lo stesso Ambrogio apparteneva), ma espressione di un gruppo sociale autonomo. L'azione delle chiese episcopali si rivolge inoltre ancora solo alle comunità urbane, lasciando ai possessores, soprattutto nel nord-ovest, il compito della conversione dei rustici.

Naturalmente, in questa considerazione della crescita della chiesa italiana tardo-antica, del suo stabilizzarsi, non poteva mancare un'analisi di Gregorio Magno e del suo epistolario, cui si dedica Liliana Pégolo. Quest'analisi consente di svelare la "tecnologia politica" di Gregorio, che - in una gamma di interventi amplissima, che va dall'amministrazione del patrimonio siciliano, alle controversie dogmatiche, alle preoccupazioni militari - offre il suo stesso esempio autobiografico come modello da seguire, come esempio di tensione tra "dentro" (la meditazione, l'ascesi) e "fuori", il mondo e le sue cure: vero punto di cerniera fra tardoantico e medioevo, Gregorio marca la diversità della cristianità occidentale da quella orientale. Egli, inoltre, deve affrontare il problema dei barbari: problema militare, certo, ma non solo. Esiste anche la realtà delle nuove società barbariche, con le quali egli stesso deve fare i conti, nei suoi rapporti stretti con la corte longobarda.

Ecco quindi entrare in campo, in questo lento passaggio da est ad ovest che rappresenta anche una altrettanto lenta transizione epocale - da un oriente saldamente radicato nel mondo romano-ellenistico ad un occidente romano-barbarico -, il vero elemento di novità, le gentes barbariche. Ma queste società nuove si rivelano anch'esse alla ricerca di radici antiche. Valga l'esempio, studiato da Cristina La Rocca, di Venanzio Fortunato, un italiano emigrato nel regno franco (a riprova dei forti legami dei Franchi con il Mediterraneo, dove essi volevano fortemente radicare la loro presenza, in particolare in Italia).

La carriera di Venanzio, da poeta di corte e sodale della regina Radegonda a vescovo di Poitiers, prova come, in una società instabile come quella franca (postromana), divisa fra tradizione e novità, l'opera poetica non si limiti a descrivere la società aristocratica e di corte al cui interno essa è prodotta, ma sia generatrice di modelli e comportamenti aristocratici e costituisca così un 
elemento attivo di sostegno e rafforzamento della posizione dei suoi committenti aristocratici, fornendo loro nuovi elementi da esibire e ostentare nella ricerca del consenso: essa contribuiva dunque a plasmare l'identità delle aristocrazie al pari dei banchetti, della costruzione di chiese o ricostruzione di ville, delle reliquie, dei sepolcri corredati di armi e gioielli, delle politiche matrimoniali. Siano cioè di fronte non all'arcaica barbarie e alle macerie dell'antico, bensì a società che vanno elaborando nuovi modelli di comportamento e codici di valori: così elementi culturali antichi e nuovi possono contribuire insieme a plasmare la nuova identità aristocratica allinterno del mondo franco.

L'Italia comunque rimane un caso particolare, se non altro per la presenza, sul suo territorio, di terre legate direttamente all'impero di Bisanzio. Ce lo ricorda il saggio di Giorgio Ravegnani, che ci offre un quadro minuzioso ed analitico delle varie unità dell'esercito bizantino del VI secolo, in Oriente, in Siria, Palestina, Libano, Egitto, Nord Africa e appunto in Italia. L'esercito bizantino rivela una struttura fortemente tradizionalista, ma è al tempo stesso mobilissimo - secondo le esigenze delle grandi guerre del tempo, in particolare durante l'impero di Giustiniano - e capace di spostare gruppi umani numerosi, composti spesso anche da ex-prigionieri di guerra, da oriente a occidente (Vandali in Persia, Persoarmeni in Italia), dove costoro (ad esempio in Italia) si radicavano finendo per inserirsi nella società locale, insieme ai soldati indigeni. Da una parte si vede la grande forza di un impero vastissimo, capace di convogliare contingenti numerosi soldati sui fronti più caldi e quindi, in Italia, di resistere per due secoli alla pressione dei Longobardi. Dall'altra, sia la barbarizzazione delle forze imperiali, che spesso le rendeva indistinguibili dai loro avversari (favorendo così i passaggi di campo), sia la loro tendenza a radicarsi nei paesi presidiati costituivano alla lunga fattori di debolezza e disgregazione della compagine imperiale.

A questo punto, nella parte conclusiva del libro, sono i Longobardi ad essere in primo piano: la gens al cui dominio viene tradizionalmente attribuita - e non senza qualche ragione - la transizione dalla tarda antichità al medioevo in Italia. Giacché lo studio sull'età longobarda ha ricevuto i suoi più significativi elementi di novità dalle ricerche archeologiche, è proprio dall'archeologia che si deve partire. Sauro Gelichi ricostruisce la lenta e faticosa nascita dell'archeologia medievale in Italia, a partire dalla sua fase più antica, ottocentesca, in cui essa era concepita solo come "archeologia longobarda", legata cioè ad un preciso contesto etnico-culturale visto come estraneo alla penisola ed interpretata a partire esclusivamente dalle sepolture o meglio dai corredi funerari. Solo nel secondo dopoguerra si sono sviluppati in Italia, per influenza di analoghe evoluzioni nel resto d'Europa, filoni di indagine che non solo analizzano i cimiteri cosiddetti barbarici secondo criteri scientifici moderni (metodi stratigrafici, studio dei cimiteri nel loro contesto integrale: 
corredi, topografia del cimitero, tipologia delle sepolture, analisi antropologiche, ecc.), ma che sono rivolti al periodo altomedievale nel suo complesso, analizzando in modo sempre più esteso gli insediamenti: il territorio, ossia le campagne (castelli, popolamento rurale, cristianizzazione), e le città (le trasformazioni della città tardo-antica). Un'evoluzione importante, conclude Gelichi, in conseguenza della quale - giustamente - i Longobardi come entità etnica sono un po' scomparsi, ma in compenso la conoscenza del periodo altomedievale ha fatto molti importanti progressi. Non paia contraddittoria questa conclusione: infatti è l'età longobarda nel suo complesso che va studiata, non i Longobardi come gruppo etnico chiuso e separato dal resto della popolazione, giacché quest'ultima circostanza si verificò forse solo per un breve periodo, e comunque, oggi, non è più possibile sostenere l'idea di una precisa identità "germanica" (etnica e culturale) dei Longobardi (o di altre gentes barbariche). Lo avevamo già implicitamente suggerito a proposito del regno dei Franchi e di Venanzio Fortunato.

Di questo mondo longobardo-italico gli ultimi tre saggi del volume presentano aspetti importanti. In quello da me scritto si tenta di costruire un profilo della regalità longobarda attento all'evoluzione delle basi ideologiche del potere, che ne mette in luce le componenti romane e non romane e l'aspirazione, imperfetta ma costante, all'ereditarietà. In effetti, è un unico gruppo familiare allargato, quello ricollegabile alla regina Teodolinda, che, tenuto insieme prevalentemente per via femminile, governa per buona parte dell'età del regno indipendente. Solo negli ultimi decenni prima della conquista di Carlo Magno si affermò al potere un gruppo familiare regionale, quello friulano (o friulano-veneto), la cui saldezza avrebbe potuto forse competere con i Carolingi, se non fosse arrivato troppo tardi a installarsi sul trono. La conquista franca significò la trasformazione della regalità longobarda, pur già saldamente cattolica, secondo parametri culturali nuovi, che sottolineavano il ruolo della militia sovrana - simboleggiata dal cingulum e dalla spada - al servizio della chiesa e del popolo, in un contesto nel quale si era ormai affermato il concetto tipicamente carolingio di connubio fra regnum e sacerdotium.

Gian Pietro Brogiolo esamina invece le varie "capitali" dell'Italia longobarda, mettendo in evidenza le diverse motivazioni (militari, politiche, religiose) che stanno dietro le scelte dei sovrani. Mette in luce quali sono i simboli che costituiscono una capitale, dal palazzo, alle chiese (prima ariane, poi cattoliche), ai luoghi e ai riti della morte, alle residenze regie suburbane, infine alle chiese-mausoleo espressione di un potere ormai pienamente cristiano; sottolinea la scarsa ricaduta della presenza pubblica sul tessuto socioeconomico delle città capitali. Il regno longobardo dunque, a lungo ritenuto nella storiografia uno dei più restii ad accogliere l'eredità romana, si rivela al contrario profondamente permeato da essa - e del resto, in un contesto come 
quello italiano non poteva essere diversamente. E lo stesso dato emerge pure dal saggio di Claudio Azzara, che fa una rapida messa a punto del sistema normativo e giuridico del regno longobardo, mettendone in luce la complessità. All'interno di tale sistema, che risente anche di usi locali probabilmente improntati al diritto romano, il codice di leggi scritte, più volte continuato dai sovrani longobardi per adeguarlo anche empiricamente alla realtà del regno, non è che un elemento di un meccanismo non solo giuridico ma sociale più ampio, che prevede largamente il ricorso, per la risoluzione dei conflitti, alla tradizione consuetudinaria e a pratiche arbitrali e concordate fra le parti. Tra cawerfeda e diritto romano, locale o di livello alto (come nel prologo di Rotari), e - aggiungo - ispirazione cristiana sempre più evidente, il corpus delle leggi longobarde rappresenta un'altra prova della complessità di quella società. Così come complesso e multiforme è l'intero mondo tardoantico $\mathrm{e}$ altomedievale mediterraneo, del quale, in maniera assolutamente non completa (manca del tutto, ad esempio, la Spagna visigotica), si è cercato di dare conto, per affondi significativi, nelle pagine che seguono. 



\title{
"Prigionieri dello Spirito". Libertà creaturale ed eschaton in Isacco di Ninive e nelle sue fonti*
}

\author{
Paolo Bettiolo
}

Sugli Angeli: "Aiutano Dio a fare i suoi lavori. Non lavorano perché hanno il sole negli occhi "

1. È del 1932 la pubblicazione di un breve, sapido saggio di I. Hausherr, il cui titolo recita: Par delà l'oraison pure grâce à une coquille. A propos d'un texte d'Evagre ${ }^{2}$. Lo studioso, già autorevole, era allora nella prima, fervida

\footnotetext{
* Saggio già apparso in "Annali di scienze religiose", 4 (1999), pp. 343-363.

${ }^{1} \mathrm{La}$ frase, di cui è autore un bimbo, scolaro a Reggio Emilia, è segnalata da A. Sofri, che ringrazio per l'indicazione, in una nota datata "Martedì 23 settembre 1997", ora in Piccola posta, Palermo 1999, 87. Riassume bene, nella sua semplicità, alcuni temi trattati nelle pagine che seguono. Per non appesantire le note successive, do notizia qui delle edizioni e traduzioni delle opere di Isacco che verranno utilizzate in questo saggio. Come si sa, i suoi testi (trattati, lettere, centurie, raccolte di preghiere o altro) sono divisi in almeno "due parti": la "prima", che comprende 82 scritti, si trova edita ad opera di P. Bedjan in Mar Isaacus Ninivita, De perfectione religiosa, Paris-Leipzig 1909; se ne ha una versione inglese, integrale, a cura di A.J. Wensinck, Mystic Treatises by Isaac of Nineveh, Amsterdam 1923 (ristampa anastatica: Wiesbaden 1969); una versione italiana degli opuscoli I-XXXVIII, da cui solo cito dove possibile, si legge in Isacco di Ninive, Discorsi ascetici/1 - L'ebbrezza della fede, a cura di M. Gallo e P. Bettiolo, Roma 1984 - di seguito gli scritti di questa parte sono citati facendo precedere da B l'indicazione, in cifra romana, dell'opuscolo cui si rinvia, cui segue l'indicazione della pagina del testo, preceduta da (t), e quindi quella della pagina della traduzione, italiana o inglese che sia, preceduta da (tr). La "seconda parte", invece, comprensiva di 41 scritti e non integralmente edita, si legge, nel testo siriaco, per la sezione pubblicata, in Isaac of Nineveh (Isaac the Syrian), 'The Second Part', Chapters IV-XLI, S. Brock ed., CSCO 554, Lovanii 1995 (tr. inglese: CSCO 555; alcuni opuscoli di questa sezione della "seconda parte" sono stati tradotti in italiano in Isacco di Ninive, Discorsi spirituali e altri opuscoli, a cura di P. Bettiolo, Magnano (BI) 1990). Di seguito, rinvierò agli scritti reperibili in questa edizione facendo seguire al nome dell'editore (Brock) il numero del trattato, in cifra romana, e quello del paragrafo, al suo interno, che ospitano la citazione, accompagnati dal numero della pagina del testo, preceduto da (t), e, infine, della traduzione inglese, preceduto da (tr); qualora si dia una versione italiana del passo, al numero della pagina della traduzione inglese sarà fatto seguire, fra parentesi, quello della corrispndente pagina della traduzione italiana). Alla sezione inedita di questa "seconda parte", che ospita soprattutto le quattro centurie dei Capitoli della conoscenza, in seguito citati utilizzando la sigla KG, si rinvia, quanto al testo, a quello restituito dal ms di Oxford Bodl syr 7 (X-XI secolo), in cui compaiono ai ff. $10 v^{\circ}$ - $11 \mathrm{or}^{\circ}$; quanto alla traduzione, a quella pubblicata da chi scrive in Isacco di Ninive, Discorsi spirituali. Segnalo, infine, che nel corpo del saggio la versione di tutti i passi citati è mia.

2 Edito in Revue d'Ascétique et Mystique 13 (1932), 184-188, si legge anche in una raccolta di studi del p. gesuita dal titolo Hésycasme et prière, Roma 1966, 8-12, da cui qui si cita.
} 
stagione della sua produzione, e lo scritto riflette bene ad un tempo compiuta conoscenza dei testi, sagacia interpretativa e giovanile (ma pure "europea" e "romana", si direbbe) sicurezza e anche sufficienza nei giudizi - un agio, una signorilità e compiacenza, quasi, mirabili nel trattare di autori semiti, il cui temperamento, passata la stagione in cui era trattenuto dalla "semplicità evangelica", avrebbe evidenziato, a contatto con la filosofia greca, "trop capiteuse pour eux", "des signes inquiétants d'intempérance intellecuelle", inducendoli ad "aberrations" e a opere estreme, geniali talora, ma certo sempre pericolose e, il più delle volte, eretiche 3 .

Non sono però i grandi frutti della speculazione mistica di area siriaca del VI secolo a interessare il p. Hausherr in queste pagine; non "Dionigi" né Stefano bar Sudaili ne sono il centro, ma le più tarde meditazioni di Isacco di Ninive, di cui scrive che poté "encore faire œuvre originale" applicandosi ad un tema decisivo del vivere cristiano, pur ritenendo di non riesporre, nei propri opuscoli, che "la plus claire pensée évagrienne" 4

La questione è quella della "preghiera pura", vertice dell'esperienza del credente, tale non per mera purezza di cuore e d'intenzione. La "filosofia" di Alessandria, infatti, aveva aggiunto un senso "metafisico" a quello immediatamente morale dell'espressione, nota lo studioso gesuita: la purezza esigeva non solo virtù, ma anche "deposizione" di ogni pensiero. Unicamente l'intelletto silente, nudo, prega l'Indicibile, l'Impredicabile - Colui per il quale non v'è immagine, nome, intellezione. Recita una sentenza evagriana: "Preghiera è lo stato dell'intelletto prodotto dalla luce della santa Trinità" 5 , mondo di ogni altra, creaturale luce. "Prodotto", traducevo, ma il testo reca, alla lettera: "divenuto" - divenuto secondo quel divenire che Dio muove e sostiene, divenendo, infine, lui stesso, nel Cristo. In questa semplificazione e unificazione di sé, che è spogliazione di tutto, la creatura perviene al proprio compimento, vi sosta e sta: qui, e qui solo, prega, propriamente.

Ma Isacco nega si dia una preghiera "spirituale", nega che la preghiera, pur pura, sia opera del Regno, abbia dignità escatologica. Egli sa che i Padri, e non solo gli eretici, i messaliani, nota Hausherr, hanno parlato e scritto di una tale preghiera ${ }^{6}$, ma scorge e denuncia in ciò un'imprecisione, comprensibile, forse, ma certo del tutto inopportuna ${ }^{7}$. Infatti, scrive, la preghiera è

3 Ivi, 8.

4 Ivi, 9 .

5 Il testo, trentesima sentenza del cosiddetto Supplemento alle Centurie di Evagrio, edito nella sua versione siriaca da W. Frankenberg in Euagrius Ponticus, Berlin 1912, 454, è citato, nell'originale greco, da Hausherr, Par delà l'oraison pure, 11. Si legge ora in J. Muyldermans, Note additionnelle à: Evagriana, in Le Muséon 44 (1931), 369-383, 377, come $27^{\circ}$ capitolo degli Skemmata evagriani ivi pubblicati.

6 Hausherr, Par delà l'oraison pure, 9 e 12.

7 Isacco, nel XXII opuscolo della Prima parte dei suoi scritti, avente per titolo Sulle numerose 
sempre "pensieri belli, $<\ldots>$ moti psichici"8; l'uomo vi si dispone e raccoglie "con forza", e per questo essa è posta sotto il segno della lotta, sempre9. La preghiera pura, che ne è l'estremo frutto, certo introduce al limite, è, anzi, il limite dell'umano agire, dell'umana attenzione: "tutti i suoi movimenti e le sue forme conducono fin qui l'intelligenza, nel potere della loro libertà"10 fino al "fuoco dell'ardore, dalla cui gioia l'uomo è umiliato nei suoi pensieri fino agli abissi"; fino ad "uno sguardo non soggetto a inclinazione rivolto a nostro Signore", cui allora "sembra quasi di essere vicin(i) anche nel corpo"; fino al punto, ancora, in cui "la preghiera si secca nella bocca (dell'orante) ed egli cessa assolutamente da ogni moto e, nella sua anima e nel suo corpo, giunge ad un silenzio immobile" 1 ... "Ma oltre questo termine/limite, da allora è lo stupore, non la preghiera": "il potere dell'intelletto $<\ldots>$ ha campo fino alla purezza della preghiera, ma quando giunge qui, o si volta indietro o smette la preghiera"12. Oltre, infatti, "la libertà della natura è tolta", "la natura non ha (più) dominio su se stessa"; "da allora essa è condotta, e non conduce", "è condotta da un'altra potenza dove non sa", "perché in quell'ora sulla natura regna una prigionia" ed essa "non ha volontà", e "neppure sa di sé"13. Lo Spirito allora la governa e guida, e la preghiera, l'atto estremo della creatura, ne è più che impedita, spezzata: "come dice Evagrio: <La preghiera è la condizione dell'intelletto che solo è recisa dalla luce della santa Trinità, tramite la meraviglia>"14.

Questa testimonianza, osserva Hausherr, è decisiva per Isacco; questo "seul mot d'Evagre", che si oppone alla tradizione e risuona, così, unico nella scrittura stessa del monaco pontico, lo induce ad una dottrina "nuova", che espone con ostinazione, in un periodare faticoso - un "amphigouri", dice Hausherr -, segno di una sua difficoltà a raggiungere, esprimere la posizione

distinzioni della preghiera e sui limiti del potere dell'intelletto, qui (t) 169; (tr) 208, scrive, introducendo, di fatto, una citazione del De divinis nominibus del "santo Dionigi": "Dunque, l'esattezza nelle designazioni si pone per le realtà di qui. Non v'è, invece, vero nome per le realtà del mondo nuovo, ma una scienza una, semplice, che (sta) oltre ogni nome e segno e figura e colore e forma e designazione composti”.

8 Desumo questa citazione da un opuscolo della cosiddetta Seconda parte degli scritti di Isacco, Sui vari santi fremiti e sul limpido corso che ci sono regalati dalla clemenza di nostro Signore nel momento della preghiera, qui Brock XXXII.4, (t) 131; (tr) 143 (218).

9 Cf l'opuscolo XXII della Prima parte degli scritti di Isacco, già citato, qui (t) 173 e 166; (tr) 212 e 206. Sulla preghiera in Isacco rinvio, sommariamente, a quanto scrive E. Khalifé-Hachem nella prima parte di un articolo su cui dovremo tornare, dato che ospita una correzione delle tesi di Hausherr: La prière pure et la prière spirituelle selon Isaac de Ninive, in Mémorial Mgr G. Khouri-Sarkis (1898-1968), Louvain 1969, 157-172, qui 157-163.

10 Cf B XXII, (t) 165; (tr) 206.

11 Cf Brock XXXII.1 e 2, (t) 130-131; (tr) 142 (217).

12 Cf B XXII, (t) 166 e 169; (tr) 206 e 209.

13 Ivi, (t) 170; (tr) 209.

14 Ivi, (t) 174; (tr) 212. 
assunta15. Questa sola testimonianza lo muove, ma essa è fallace! Si sarà infatti riconosciuta, nella citazione, la sentenza evagriana più sopra riportata sulla "produzione" della preghiera pura da parte della luce della Trinità. La preghiera pura è stato escatologico, non condizione che vada trascesa, recisa dalla grazia. "La malencontreuse distraction d'un traducteur lisant temnomene au lieu de ginomene", "cet accident" ha indotto Isacco a sviluppare un’intelligenza "originale" della vita nuova nel Regno ... "Tout cela pour l'amour d'un mot qu'il croit d'Evagre. C'est la morale de cette petite histoire: quelle ne devait pas être - conclude Hausherr - l'autorité d'un docteur dont un seul mot inspire tant de respect qu'on le préfère au langage très clair des autres Pères, et que, plutôt que d'oser le discuter (car il n'était pas, pour le moins, très certain), on se lance dans de telles virtuosités dialectiques pour lui rester fidèle", reinterpretando o giustificando maldestramente, con delle "niaiseries", la tradizione tutta16?

15 Hausherr, Par delà l'oraison pure, 10 e 11.

${ }^{16}$ Ivi, 12. Né Hausherr né gli altri studiosi che avremo occasione di menzionare si sono soffermati sulla lettura che la tradizione monastica della chiesa d'oriente forniva del testo "corretto" di Evagrio. Tuttavia, la questione merita una pur fugace trattazione, agevolata dal fatto che il Supplemento evagriano alle Centurie, come si è già ricordato, fu edito da Frankenberg, come le Centurie stesse, entro il commento fattone da Babai il grande, decisivo rielaboratore delle prospettive teologiche e "spirituali" della Persia cristiana tra fine VI, inizi VII secolo. Babai, dunque, così glossa il testo evagriano: "Questa è la preghiera beata, che l'uomo prega assolutamente - il suo intelletto e i suoi sensi rivolti ad una visione elevata, senza che alcunché lo recida (da essa) o lo impedisca mentre si leva nel suo stato naturale, in cui è l'immagine, magnifica per bellezza, della Signoria adorabile -, (e) che lo separa da ogni moto mormorante e turbamento innaturale: solo tramite la meraviglia ammirata e indicibile, tramite la luce della santa Trinità, che rifulge sull'anima, (questa) è recisa da ogni congiunzione che la offenda e turbi, da ogni impronta materiale, ed è unita a Dio, in un (solo) spirito, nella visione della sua luminosa bellezza, datrice di ogni delizia che arrechi gioia" (454.8-14). Il commento al capitolo precedente, che recita: "La preghiera è lo stato dell'intelletto distruttivo di tutti i pensieri terreni", e l'introduzione a quello del capitolo successivo aiutano ad intendere il senso di queste righe. Nel primo testo Babai aveva evidenziato che "la preghiera spirituale, incorporea, che libera da ogni distrazione," si produce quando "tutti i pensieri che, (insistendo) sulle cose terrene, sono soliti meditare vanità, sono distrutti da qualsiasi (umana) visione tramite il raccoglimento da ogni dispersione e la luce che rifulge sulla mente orante" (454.3.4-6); nel secondo, ricapitolando l'insegnamento dei precedenti capitoli, scrive che Evagrio lì ha trattato della "preghiera che (procede) dalla grazia, tramite la luce che sorge sull'anima" (454.16). Essa, aggiunge, "non (procede) solo dal lavoro o dalla meditazione, dalla sollecitudine e volontà dell'uomo, (ma) è opera di quella datrice di beni [ la grazia, dunque ] che riverbera nella sua anima lo splendore beato e illumina la sua mente con la sua delizia", quand'egli si levi nel suo "stato naturale" e nella "purezza che acquisisce tramite i lavori e la liberazione dalle passioni" (454.16-20). Babai, dunque, non interpreta la "recisione", di cui parla il testo, come sospensione della preghiera per l'irruzione della luce divina, ma come allontanamento, separazione da tutto quanto è innaturale e terreno, materiale, in un raccoglimento di sé volontario, certo, ma poi, e più decisivamente, involontario, frutto di un'operazione della grazia: allora, e solo allora, la preghiera è spirituale, "incorporea", non più "recidibile" dall'orante. Ad un certo livello la discontinuità con l'esegesi di Isacco è evidente, ma si potranno poi cogliere anche i punti di contatto tra le due letture, assai più convergenti di quanto non appaia a prima vista. 
2. In un saggio del 1975, S. Brock, cui molto si deve in ordine alla conoscenza dei testi e dell'insegnamento di Isacco, sottolineava nuovamente la peculiarità delle tesi del solitario del Qatar sulla preghiera, quel "cessare" del suo "movimento" "as the soul receives the same sanctification as do the Brad and Wine at the Epiklesis", e aggiungeva: "This actually touches on a paradox that has long puzzled readers of Isaac: at the very height of prayer, prayer ceases to exist"17. Si tornerà sull'accenno all'eucarestia contenuto in queste note, in relazione ad un ulteriore, successivo saggio dello studioso inglese, su cui pure sarà opportuno sostare ${ }^{18}$. Prima, seguendo la sua indicazione relativa alle difficoltà patite dagli interpreti a motivo del paradosso ospitato nelle pagine di Isacco, si devono menzionare e brevemente esaminare almeno due studi tesi a contestare la lettura che ne ha proposto Hausherr: il già citato saggio di E. Khalifé-Hachem su La prière pure selon Isaac de Ninive, pubblicato nel $1969^{19}$, e, ancora, la sezione, dedicata allo stesso problema, dell'ampia tesi di dottorato discussa nel 1974 a Parigi da R. Beulay su L'enseignement spirituel de Jean de Dalyatha ${ }^{20}$.

Il punto su cui vertono questi studi non è quello del riconoscimento o meno del debito di Isacco nei confronti di Evagrio, o, se si vuole, di uno pseudo-Evagrio che gli avrebbe offerto "la formulation la plus tranchée" della sua dottrina ${ }^{21}$. Il punto è la dimostrazione del fatto che una tale indubbia ripresa si inscrive in una elaborazione del tutto originale e coerente, cui presta solo una sintetica ed efficace espressione, certo migliore di quella rinvenibile in una distinzione, troppo piana e anche fuorviante, tra preghiera "attiva" e "passiva", quale quella suggerita da Hausherr: "ces termes abstraits", nota

17 Cf S. Brock, St. Isaac of Nineveh and Syriac Spirituality, ora in Studies in Syriac Spirituality, Poona 1988, 99-108, qui 104.

18 Il rinvio all'eucaristia è motivato dalla presenza, nel testo di Isacco cui Brock fa riferimento, una sezione del suo XXII trattato Sulle numerose distinzioni della preghiera, già più volte citato, di una sua esplicita menzione. Nel giustificare l'uso dei Padri di designare col nome, improprio, di "preghiera spirituale" i "doni grandi e ineffabili" dello Spirito, Isacco osservava che appunto "nel momento della preghiera lo sguardo dell'intelligenza si fissa solamente in Dio", così che sensatamente " anche la misericordia di Dio doveva sgorgare da questo momento, in cui un solo pensiero è presente nell'anima”, consentendo di estendere alla condizione instaurata dal suo irrompere il nome dello stato in cui la creatura si era raccolta per esso. Isacco poi aggiungeva: "Vediamo, infatti, che anche il dono dello Spirito discende su quest'offerta manifesta che offriamo, sul pane e sul vino che disponiamo sull'altare, quando tutti sono pronti e si tengono in preghiera" ((t) 171 e 172; (tr.) 210 e 211). Osservo che anche Khalifé-Hachem insiste su questo parallelo. Scrive, infatti: "Isaac compare cette descente de l'esprit dans l'âme durant la prière, à la descente de l'Esprit sur le pain et le vin eucharistique qui, elle aussi, survient pendant que l'assitence prie" (La prière pure, 166).

19 Cf supra, n. 9.

${ }^{20}$ La tesi, parzialmente rielaborata, si trova ora edita, per la sezione che qui interessa, sotto il titolo di L'enseignement spirituel de Jean de Dalyatha, mystique syro-oriental du VIII ${ }^{e}$ siècle, Paris 1990.

21 così Beulay, L'enseignement, 216. 
Beulay, "eussent été concrètement moins riches que le paradoxe accepté par Isaac, et surtout ils n'auraient pas indiqué avec autant de force la transcendance de la $<$ prière spirituelle $>$ qui $<$ n'est pas une prière $>$ par rapport à celle de l'homme"22. È opportuno tenere a mente queste osservazioni. Ma è pure bene cogliere, seguendo l'indicazione di Khalifé-Hachem, il nesso che lega la prospettiva di Isacco a quella di un precedente testimone e autore del monachesimo siriaco, Giovanni il solitario, la cui originalità proprio il p. Hausherr, in un suo più tardo saggio, aveva contribuito a evidenziare ${ }^{23}$. Giovanni, è bene ricordare, aveva connesso la distinzione, già tradizionale in ambito siriaco, tra giustizia e perfezione a quella, antropologica (e paolina), tra corporeità, psichicità e spiritualità, termini volti a significare le tre distinte stazioni o stature della vita cristiana, i tre diversi gradini della via, del cammino proposti ai credenti. Se corporeità e psichicità ricapitolano, infatti, le condotte dell'uomo esteriore e interiore, la custodia dei sensi e dei pensieri, la purezza, infine, cui obbliga la giustizia ${ }^{24}$, l'ordine della spiritualità o del "mondo

\footnotetext{
22 Ivi, 219.

23 Cf I. Hausherr, Un grand auteur spirituel retrouvé: Jean d'Apamée, in Orientalia Christiana Periodica 14 (1948), 3-42, o, ora, nella raccolta di studi del padre gesuita pubblicata con il titolo di Etudes de spiritualité orientale, Roma 1969, 181-216. Vorrei ricordare che il p. Hausherr, soprattutto nell'introduzione alla sua traduzione di alcuni scritti di Giovanni, Jean le Solitaire (Pseudo - Jean de Lycopolis), Dialogue sur l'âme et les passions des hommes, Roma 1939, 15-16, ha riconosciuto il debito di Isacco nei confronti di questo suo predecessore. Noto anche che mantiene pure qui un giudizio quantomeno perplesso sul monaco del Qatar, sottolineandone "le manque de clarté" e il concordismo ingenuo (anzi: "le plus ingénu") che avrebbe praticato fra le sue diverse fonti $(I v i, 15)$.

Su Giovanni i contributi più accorti sono ancora quelli dovuti a A. De Halleux, La christologie de Jean le Solitaire, in Le Muséon 94 (1981), 5-36, e Le milieu historique de Jean le Solitaire, in III Symposium Syriacum 1980, R. Lavenant éd., Roma 1983, 299-305. De Halleux, nel primo dei due saggi citati, su cui mi soffermerò, sottolinea bene l'arcaismo della cristologia di Giovanni, già preoccupata, tuttavia, di contrastare quella antiochena, ai suoi occhi troppo divisiva, per eccesso di volontà di indagine del mistero, come spiega utilizzando un topos della letteratura antiariana. De Halleux, inoltre, parla del "caractère encore fruste" del suo vocabolario (17), e, benché lo riconosca "plus philosophe" di Efrem (19), sa che è un monaco "qui fait passer l'expérience spirituelle avant la théologie rationnelle" (21). Egli sottolinea anche, però, che uno studio puntuale della sua "doctrine spirituelle" resta da fare, e talora attesta, in relazione a ciò, qualche perplessità circa l'unitarietà del corpus dei suoi scritti: in n. 59, 20-21, ad esempio, si chiede se il De oratione edito da Brock e da chi scrive sia autentico, e più oltre, in n. 92, 28-29, segnala una certa distanza, sul tema del silenzio, tra quello stesso opuscolo e il Dialogo sulle passioni, da una parte, e le lettere che studia, dall'altra. Del resto il suo saggio evidenzia, nei testi che analizza, alcuni svolgimenti singolari, tali da indurlo, nella pagina finale, a parlare di "quelques traits inquiétants, chez un auteur peut-être crédité d'orthodoxie à trop bon compte par le P. Hausherr" (36). Ricordo queste osservazioni per invitare a prudenza nella lettura delle note che seguono.

24 Una precisazione va fatta: come scrive P. Harb, Doctrine spirituelle de Jean le Solitaire (Jean d'Apamée), in Parole de l'Orient 2 (1971), 225-26o, qui 230, per Giovanni "l'homme corporel est tout simplement celui <qui s'adonne aux convoitises de la nature du corps>”, restando schiavo del peccato. In questo senso per il solitario propriamente "la pratique ascétique 'corporelle' [ quella che disciplina la condotta esteriore ] se trouve dans l'ordre "psychique" - osserva R.
} 
nuovo", situato oltre ogni creaturale limpidezza, è un ordine, uno "stato" istituito "dall'alto", da Dio, dal suo Spirito, appunto. Per Giovanni, "comme pour Isaac - scrive Khalifé-Hachem -, l'étape spirituelle dépasse la possibilité de la nature et ne sera donnée que dans la vie d'après la résurrection" 25 . Isacco quindi, prosegue lo studioso maronita, affiancando il lessico evagriano a quello di Giovanni26, ripensa il lascito del primo nei termini dell'eredità del

Beulay, in La lumière sans forme. Introduction à l'étude de la mystique chrétienne syro-orientale, Chevetogne s.d. (1987), n. 34 a p. 285. Tuttavia, il solitario talora parla anche di uomini "corporali" "qui sont encore travaillés par leurs penchants mauvais et leurs passions diverses sans commettre le mal, en traduisant ces penchants en 'actes"', giungendo così ad essere prossimi all'ordine degli uomini "psichici", aggiungeva Harb, Doctrine, 232, e questo spiega perché "ses disciples nestoriens" collocheranno l'ascesi stessa, nella sua prima cura, rivolta al controllo dei sensi, "dans l'ordre corporel lui même" (Beulay, Lumière sans forme, n. 34 a p. 285).

25 Khalifé-Hachem, La prière, 170. Registro qui un'interessante osservazione di Hausherr, che in Un grand auteur, 214, accostando Giovanni a Marco eremita, scrive: "C'est contre la tendence pélagienne de ces mêmes messaliens qu'ils insistent l'un et l'autre sur la nécessité de la grâce, jusqu'à paraître nier le mérite de non œuvres" (corsivo nel testo).

26 Vorrei ricordare, a proposito dell'accostamento di questi due autori, che De Halleux, in Christologie, 20 e, soprattutto, ivi n. 57, sulla base della ricorrenza, negli opuscoli di Giovanni, di alcuni termini propri della versione siriaca dei testi evagriani, osserva che "une influence éventuelle de l'évagrianisme mitigé de la version syriaque commune des Centuries gnostiques sur la protologie et l'eschatologie du Solitaire mériterait d'être prise en considération". Del resto, il passo del commento alle centurie evagriane di Babai, cui si affida l'identificazione di Giovanni con Giovanni d'Apamea, affianca la testimonianza di quest'ultimo a quella di Evagrio, in modo assai interessante. Babai sta spiegando un capitolo del testo evagriano, il sesto della seconda centuria, che recita: "L'anima pratica, che per grazia di Dio ha ben progredito ed è migrata dal corpo, giunge in quelle regioni della conoscenza cui le ali della sua impassibilità l'hanno fatta pervenire". Dopo aver sottolineato che "l'esodo dell'anima dal corpo", di cui Evagrio parla, non è la morte, "ma l'esodo dall'uomo vecchio", secondo le parole di Paolo, egli aggiunge: "Anche Giovanni il solitario, che è dei dintorni di Apamea (e) che era, lui pure, addentro a questi misteri, dice così in uno dei suoi trattati: 'Dopo il suo esodo dalle passioni, allora uno è reso degno di entrare nella regione della vita, che è la carità di Dio, in cui riceve, in rivelazione, la visione dei suoi misteri. E - continua - quando sia giunto alla (matura) pace della carità, la sua anima esulta nel placarsi delle battaglie nascoste"”. Fin qui Giovanni, in un passo della seconda lettera edita da L.G. Rignell in Briefe von Johannes dem Einsiedler mit kritischem Apparat, Einleitug und Übersetzung, Lund 1941, qui, nel testo, 80.18 - 81.4, ma Babai prosegue, parafrasando il testo del capitolo che commentava: "A questo modo anche il santo Evagrio dice: L'anima pratica, quella che ha praticato le virtù secondo il comandamento del suo Signore e con il soccorso della grazia che (procede) da lui ha ben progredito in tutti i suoi lavori ed è migrata dal corpo in un'ascensione spirituale, né legata né vincolata da quanto è suo, $<\ldots>$ tramite la purezza e grazie alle ali dell’impassibilità, che (quella) tramite le virtù ha fatto spuntare in lei, è volata (via) dalla corporeità e da tutto quanto è suo ed è giunta, nella (sua) ascensione, ad innalzarsi fino all'altezza delle (realtà) celesti, come ha detto il divino Paolo: La pratica che ci è propria è in cielo (Fil 3, 20) - in quelle stanze e regioni dei diversi modi di conoscenza cui le ali dell'impassibilità la fanno pervenire" (Frankenberg, Euagrius, 132.28 - 134.15). Dunque, per Babai v'è perfetta conformità tra testo giovanneo e testo evagriano, così come entrambi concordano coi versetti paolini citati; tale consonanza, aggiungo, è rilevata proprio nella valutazione dello stacco che si produce tra condotta umana e conoscenza spirituale: se il lavoro della virtù, se l'impassibilità che l'anima così acquisisce sono condizione della conoscenza, pure questa è frutto di rivelazione, appartiene ad un altro ordine, non creaturale. Certo, queste troppo frettolose note abbisognano di molte preci- 
secondo, di cui "reste le disciple", assai fedelmente ${ }^{27}$. È dunque una linea interna al monachesimo siriaco quella da lui sviluppata; una linea, si deve insistere, che ha una sua forte coerenza, pur nutrendosi di apporti molteplici e forse, in taluni casi, pure esterni ai suoi più decisivi accenti.

Il quadro tracciato da queste note può essere tuttavia ulteriormente arricchito. Quando Khalifé-Hachem, infatti, insiste su "l'état de passivité totale à l'égard de l'action de l'Esprit" in cui consisterebbe la preghiera "spirituale"28, cita, tra gli altri, un passo del solitario nestoriano in cui questi afferma che allora "l'intelletto è assorbito dalla meraviglia $<\ldots>$ e i suoi movimenti sono immersi in una profonda ebbrezza ed (esso) non è (più) in questo mondo"; poco prima Isacco aveva scritto, similmente, che i santi, nel mondo nuovo, l'intelletto "assorbito" dallo Spirito, dimorano "nello stupore"29. Ora v'è un luogo delle sue centurie in cui il vocabolario dello stupore, della meraviglia, è connesso a ben individuati versetti biblici, che assumono valenza paradigmatica in relazione al "raccoglimento dell'intelletto", al suo "escatologico" raccoglimento. Si tratta di $G n$ 2, 21 e 15, 12, utilizzati in un capitolo conclusivo dell'opera, in una sezione che medita sulla "condotta spirituale", in termini che ci consentiranno di riesporre sinteticamente i molti e diversi materiali fin qui raccolti, anticipandone di nuovi.

Recita dunque il testo di KG 4.9530: "Ma uno domanderà: In che è il pensiero in quei momenti (d'estasi), nel suo sublime raccoglimento? Secondo quel che ha detto il Libro: La quiete cadde su Abramo $(G n$ 15, 12), e, come ha detto di Adamo: Il Signore Iddio gettò la quiete su Adamo (Gn 2, 21). Il greco al posto di quiete dice stupore, e il beato Interprete, spiegando il mistero dello stupore, dice: <Chiama stupore il fatto che uno sia fuori dall'ordine con-

sazioni, ma è importante cogliere la lunga elaborazione che precede talune affermazioni, alla cui novità, pure, nulla così si intende togliere... Ma su questo si avrà occasione di tornare.

Qui, tuttavia, si consenta un ultimo richiamo. V'è infatti un altro luogo del testo di Babai in cui questi accosta Giovanni ad Evagrio, almeno secondo la lettura di A. Guillaumont, Les "Kephalaia gnostica" d'Evagre le Pontique et l'histoire de l'origénisme chez les grecs et chez les syriens, Paris 1962, 269 (in particolare ivi, n. 269) e 317, n. 48: si tratta dell'introduzione al Commento, nella sezione che dà ragione dell"'oscurità" del testo evagriano. Il monaco pontico viene qui menzionato con Giovanni, appunto, e Teodoro di Mopsuestia quale dottore che ha insegnato "toute la vie spirituelle", pratica e conoscenza, ai credenti tutti. Ma, mentre Teodoro è, nel suo discorrere "manifesto", chiaro, maestro di dottrina cristiana per coloro che "non hanno ancora conosciuto le (cose) nascoste", e guida alle "battaglie che (si combattono) in (modo) manifesto", i due "solitari", invece, educano non solo alla virtù, ma anche al "discernimento delle impronte e dei moti che (si producono) nel nascondimento, nelle stanze (più) fonde dell'anima"; sono entrambi - non il solo Evagrio, come riassume Guillaumont - maestri "par excellence de la doctrine ascétique et mystique", di quanto conduce e istruisce, nella misura del possibile, all'esperienza del "mondo nuovo".

27 Khalifé-Hachem, La prière, 169.

28 Ivi, 165 .

29 B XXII, (t) 174 e 170; (tr) 212 e 209.

$30 \mathrm{Cf}(\mathrm{t}) \mathrm{ff} .108 \mathrm{v}^{\circ}-109 \mathrm{r}^{\circ} ;(\operatorname{tr}) 192$. 
sueto e fuori dalla percezione umana>. I Padri solitari, invece, lo chiamano $<$ raccoglimento dell'intelletto che (procede) dalla grazia $>$ e $<$ primizia delle delizie del mondo nuovo $>$ "31.

L'atto creatore di Dio, la sua rivelazione si producono, dunque, in un istupidimento, in un torpore, quasi, dell'uomo - in una sospensione dei suoi "pensieri consueti". È Teodoro il primo, autorevole testimone di questa dottrina/esegesi, almeno nell'ambito della tradizione della chiesa d'oriente, come confermano alcune osservazioni di Brock. Questi, infatti, in relazione ad un ulteriore opuscolo di Isacco, da lui edito, scrive, in margine alla sua traduzione, commentando un passo che fa menzione della "quiete" e dello "stupore" prodotti dalla rivelazione di Dio: "for the close relationship between stillness and wonder see especially Keph. IV.95 [ il capitolo sopra citato, dunque ] where he [ Isacco ] points out that at Gen. 2:21 and 15:12 the Greek (which he knows through Theodore's Commentary) has temha (i.e. ekstasis) whereas the Peshitta has shelya"; poco oltre, poi, in una nota al secondo paragrafo di questo stesso testo, ove Isacco prega di esser reso degno, con tutti, "of delight at the good things which are to come", egli commenta: "the phrase derives from Theodore of Mopsuestia", adducendo alcuni interessanti paralleli32.

Isacco, tuttavia, in KG 4.95 portava a compimento una meditazione sul "raccoglimento del pensiero" e i "doni grandi" che accompagnano la "terza età" della vita solitaria, quella che altrimenti chiama "la condotta spirituale", iniziata alcuni capitoli prima, in 4.92. Due citazioni ospitate in questa sezione, meritano qui un'ulteriore considerazione.

Innanzi tutto, in 4.93, in relazione alla "seconda età - che è il lavoro della psichicità -", Isacco osservava che il "raccoglimento del pensiero" vi può aver luogo solo per brevi momenti, "come testimonia anche il beato Giovanni d'Apamea: <Il suo pensiero si raccoglie per poco tempo, e questo perché egli

${ }^{31}$ Per quanto concerne i modi in cui i "Padri solitari" chiamano lo stupore, qui rilevati, cf, per il primo, la nota 3 apposta da Brock, nella sua versione della sezione della Seconda parte degli scritti di Isacco, a XV.5, 85, ove si enumerano una serie di ulteriori sue ricorrenze nei testi del solitario nestoriano e di autori a lui più o meno prossimi, quali Simone di Taybuteh, Sahdona, Nilo, Evagrio ed Efrem; per il secondo, cf, nello stesso corpus di opuscoli, VII.2 (t) 19-20; (tr) 24, ove ricorre l'espressione "the pledge of the New World"; X.40, (t) 41-42; (tr) 51, ove si legge: "a pledge from this world of those things which are to come" (in nota 3 alla traduzione Brock scrive: "compare Narsai <...> rahbona da-'tidata" - "primizia delle (realtà) future") e, soprattutto, XII.1 e 2, su cui torneremo subito. Qui osservo ancora che lo studioso inglese, in XIV.5, (tr) n. 2 a p. 67, rinvia, per l'espressione "spiritual delight (bussama ruhana)", a Giovanni il solitario, in una sezione della Quarta conversazione edita da S. Dedering in Johannes von Lykopolis, Ein Dialog über die Seele und die Affekte des Menschen, Leipzig-Uppsala-Haag 1936, 80-93, qui 91. 12-16: "La sete dei misteri spirituali è la delizia della vita nuova. Come infatti la delizia corporale è che uno non si riempia dei cibi eccellenti di (questo) mondo, così che uno non si sazi della sapienza di quel mondo è la delizia spirituale che acquieta e rende gioioso l'uomo interiore". $3^{2}$ Cf XII.1, (tr) n. 10 a p. 64, e 2, (tr) n. 1 a p. 64. 
non è affatto puro da (ogni) vagare >". Mi pare questa sia l'unica citazione esplicita di Giovanni, almeno come Giovanni d'Apamea, negli scritti di Isacco. Il testo è quello del primo dei trattati pubblicati da Dedering, ove si legge: "Colui che è psichico nel suo pensiero ha (sì) amore per l'insegnamento, però abbisogna di molta lotta per (riuscire a) raccogliere il suo pensiero nella preghiera. Il raccoglimento del suo pensiero, poi, è di breve durata: in modo puro (non dura) neppure un attimo. Udite perché. Poiché l'anima è (trattenuta) nei moti del vagare o nella meditazione delle conoscenze (plurali) o nel mondo del corpo, per questo anche al momento della preghiera queste (cose) si agitano in lei. Non è possibile che (quell'uomo) guardi a Dio in modo raccolto, dato che il suo intelletto vaga di sembiante in sembiante" 33 . Dunque, si conferma la presenza del lascito giovanneo in punti decisivi della meditazione di Isacco.

In secondo luogo, KG 4.92 e 93 ospitano entrambi una stessa allusione a $L c$ 1, 35: quando il solitario entra nella terza età della condotta monastica, "lo ricopre la grazia dello Spirito", si legge, ovvero "quella potenza lo ricopre pienamente".

Ora, la ricorrenza di questo verbo (aggen, "ricoprire") ci consente di dar seguito ad un motivo precedentemente appena accennato. Sempre S. Brock, in un contributo del 1988 dedicato all'uso del termine maggnatuta negli scritti dei mistici della Siria orientale, e in particolare in quelli di Isacco, aveva avanzato alcune importanti considerazioni sull'uso di tale verbo ${ }^{34}$. Maggnatuta, sostantivo derivato da aggen, appunto, è termine attestato solo a partire dalla fine del V secolo, vi si legge, e sembra essere stato da subito usato, in un senso assai ristretto, quasi tecnico, "in the context of divine activity, in particular the action of the Word and the Holy Spirit"35. Del resto, già il verbo da cui derivava, si osserva, ricorreva in contesti in cui si esaltava una "divine activity of a salvific nature" 36 , traducendo, in $G v 1,14$ e $L c 1,35$, appunto, due diversi verbi greci, riferiti rispettivamente al Figlio e allo Spirito.

Ora, nota Brock, Isacco distingue accuratamente, nel suo uso del termine, "two quite distinct modes of maggnanuta: one effects sanctification, the other is a source of protection" 37 . Nel primo senso, quello più innovativo, nell'applicazione che egli ne fa alla vita cristiana, il termine, e il verbo che ne è

33 Cf Johannes, Ein Dialog, 14.11-18.

34 Cf S. Brock, "Maggnanuta": a Technical Term in East Syrian Spirituality and its Background, in Mélanges Antoine Guillaumont - Contributions à l'étude des christianismes orientaux, Genève 1988, 121-129.

35 Ivi, 121.

36 Ibid.

37 Ivi, 122. 
all'origine, trovano al meglio corrispondenza nell'uso che ne è attestato nell'epiclesi eucaristica, ove indicano la consacrazione del pane e del vino compiuta dallo Spirito; il loro divenire, per la sua discesa, corpo e sangue di Cristo. Brock ritiene, pur non potendolo dimostrare ${ }^{38}$, che proprio in questa accezione il vescovo di Ninive, e con lui un altro solitario del Qatar a lui più $o$ meno contemporaneo, Dadisho', utilizzino il vocabolo, probabilmente entrambi indotti a ciò dall'uso di $L c$ 1, 35 nelle omelie dello pseudoMacario 39.

È importante questa nota, sia per l'accostamento all'eucaristia che suggerisce, sia per il rinvio alla discesa/dimora dello Spirito che attesta: la vita del mondo nuovo, di cui qui si ha solo rara e momentanea prova, è posta sotto il segno del venire dello Spirito, del suo operare su e in noi, trasfigurandoci, transustanziandoci, direi quasi, se il termine non fosse troppo greve - certo facendoci, in corpo e anima, nuova creatura, anzi: più che creatura ${ }^{40}$.

Con il suo studio, dunque, Brock offre indirettamente una spiegazione (una spiegazione in più, si dovrebbe dire) per la dottrina di Isacco sulla preghiera: è l'insistenza "macariana" e siriaca sull'esperienza spirituale, confrontata al mistero eucaristico, a dar ragione del suo concentrarsi su quell'errata versione del testo evagriano.

Macario, Giovanni d'Apamea, la prassi eucaristica delle chiese d'oriente, alcune esegesi di Teodoro: tutte queste fonti si sono potute fin qui addurre a conforto delle tesi di Isacco sull'impossibilità di ogni preghiera nell'eschaton. Altre, tuttavia, ne vorrei ora indicare, legate al lavoro esegetico delle scuole cristiane della Persia.

3. "Dio è veramente padre per gli esseri dotati di ragione che ha generati per grazia affinché divenissero gli eredi della sua gloria nel tempo futuro, per mostrare loro la sua ricchezza, a loro inseparabile delizia": così Isacco apre il suo "primo discorso sulla conoscenza" 41 . Il quarto ed ultimo si chiude, poi, sulle stesse note, sussunte, a quel punto, entro un canto di gloria e un'invocazione ardente: "Chi ti glorificherà come (ne) sei degno, Dio, Padre di tutto, datore di beni senza richiesta? Mio Signore, non venga meno dai nostri cuori la speranza di te $\langle\ldots\rangle$. Colui che per la speranza di tutto il mondo hai innal-

38 Cf Ivi, 129: "although Isaac himself never uses these terms in a Eucharistic context, he can hardly have been unaware of this, and it seems likely that his use of maggnanuta in the sanctifying sense intentionally had Eucharistic resonances".

39 Ivi, 128-129. C. Stewart, tuttavia, in "Working the Earth of the Heart" - The Messalian Controversy in history, Texts, and Language to AD 431, Oxford 1991, 214 n. 226, registra già in Efrem questa operazione di Dio e dello Spirito in noi affidata al verbo aggen.

$4^{0} \mathrm{Cf}$, per questo appunto conclusivo, l'ultimo testo citato più oltre, in n. 45 .

${ }^{41} \mathrm{KG} 1.1$, (t) f. $20 \mathrm{v}^{\circ}$; (tr) 51. 
zato da tutto presso di te, sia lui per te la pienezza di questa lode, a nostro favore. Mio Signore, non venir meno, sulla terra, ad alcuno di coloro che rivestono la sua carne e le sue ossa, ma attiralo alla parte che è nei cieli, e lì ti glorificherà la totalità del mondo, gioendo nel suo Principio, con quel nuovo gloria che non pronunzia una lingua di carne. Amen"42.

La paternità escatologica di $\mathrm{Dio}^{43}$; la grazia di una generazione alla gloria del mondo futuro, luogo della rivelazione della ricchezza del Padre, speranza, affatto imprevedibile speranza di tutto - di ogni carne e di ogni intelligenza; la lode che, perfetta, solo l'uomo assunto proferisce e sostiene: questi i termini che delimitano la meditazione di Isacco. Ma subito un secondo tema irrompe nel testo, quasi un controcanto teso ad evidenziare per contrasto il motivo iniziale, solo nell'eschaton compiuto: quello della "distanza", della "grande distanza" dal Creatore in cui si trova gettata la creazione tutta, nel suo stesso inizio. "La Verità è celata nel suo essere a tutto quanto ha creato", recita infatti il secondo capitolo della prima centuria, e se poi il precedente motivo induce Isacco ad affermare: "nel tempo opportuno" essa "si rivelerà da se stessa, secondo quel che le parrà bene", subito però aggiungerà: “(ma) la sua fine no, nient'affatto; la sua fine, infatti, è celata nella sua Essenza"44.

È una distanza intransitabile quella che così separa la creatura dal Creatore. Certo, lui, da sé, quando vorrà, la colmerà, in qualche modo ${ }^{45}$, ma gli stessi eredi nel regno non saranno mai capaci di sostenere tutta la sua ricchezza: v'è un'ignoranza intrascendibile; v'è un arcano di Dio sottratto pure a colui che egli ha "toccato", rapendolo nella sua gloria.

E se così è nell'eschaton per i figli, per il Figlio stesso, nella sua umanità, tanto più i divenuti sono in sé, nella loro creaturalità, lontani, esterni ed

42 KG 4.100, (t) f. $110^{\circ}$; (tr) 193-194.

$43 \mathrm{Cf}$, ancora, KG 3.71, qui (t) $75^{\circ}$; (tr) 141: "Se Dio è davvero Padre, lui che ha generato tutto per grazia; (se) gli esseri dotati di ragione (sono) figli $<\ldots>$ ".

$44 \mathrm{KG} \mathrm{1.2,} \mathrm{(t)} \mathrm{f.} 20 \mathrm{v}^{\mathrm{o}}$; (tr) 51.

$45 \mathrm{Cf} \mathrm{KG} \mathrm{4.79-81,} \mathrm{(t)} \mathrm{f.} 104 \mathrm{r}^{\mathrm{o}}-\mathrm{v}^{\mathrm{o}}$; (tr) 185 , il cui testo recita, rispettivamente: "Una è la causa dell'esistenza del mondo e della venuta del Cristo nel mondo: la rivelazione della grande carità di Dio, che ha mosso entrambi [ intendi: mondo e Cristo ] ad esistenza"; "Specchio della veemenza della carità di Dio per la creazione è la venuta del Cristo nel mondo. Specchio della carità di questi, i modi della sua umiliazione", e, infine: "Come Dio ha fatto conoscere la sua altissima carità, con cui ha fatto venire ad esistenza i mondi, nell'economia del Cristo, nel suo ripetersi per noi, così, quanto a (questo) suo ripetersi nel Cristo, ha mostrato che ne mostrerà chiaramente il significato agli esseri dotati di ragione nel mondo futuro". Questi capitoli, che ho richiamati anche in un saggio di alcuni anni fa, "Avec la charité comme but”: Dieu et création dans la méditation d'Isaac de Ninive, in Irénikon 63 (1990), 323-345, evidenziano la dinamica, ancora incompiuta (almeno nell'ordine della manifestazione), dell'economia divina, del ripetersi/confermarsi dell'atto creatore di Dio in Cristo, in cui "la creazione è divenuta Dio", come Isacco osa affermare in un opuscolo della "terza parte" dei suoi scritti, per cui rinvio a Isacco di Ninive, Scritti spirituali, 6, per informazioni sul breve trattato, inedito, e, per la traduzione, 241-245, qui 242. 
estranei a Dio. "Parola e pensiero", siano d'uomo o d'angelo, sono "al di sotto di quel che (Lui) è", trattenuti da un "limite", un confine, oltre il quale non possono mai muovere ${ }^{46}$. La creatura, quale che sia, giunta a quel limite "deve $\langle\ldots\rangle$ tornare indietro, rivestit(a) di timore e dubbio" 47 . L'uomo, sicuramente, ma anche l'angelo, ripeto, ed è proprio la meditazione sulla creazione "spirituale", "incorporea", ad offrire spunti di grande interesse per il tema che queste note intendono svolgere. Le pagine di Isacco, infatti, serbano frequenti tracce di un'attenzione volta al mondo angelico, termine estremo della potenza creaturale, suo paradigma, che è opportuno cogliere nel suo orientamento, negli esiti cui perviene, nella tradizione da cui è sostenuta e che liberamente ripropone.

Ora, una prima indicazione relativa all'angelo si legge già in KG 1.8, ove Isacco osserva che "le nature dotate di ragione hanno imparato a servirsi del suono sensibile della parola dapprima dal Creatore, e il suo primo uso è stata la glorificazione offerta al Creatore dalle (sue) opere, com'è scritto in Giobbe" 48 . V'è dunque una parola dell'angelo, una parola che risuona a partire da una parola divina a lui indirizzata, essa pure in qualche modo sensibile; una parola di lode, aggiungo, che dice, nomina per lodare, in rendimento di grazie.

La tesi non è punto nuova, e consente di saggiare da subito la qualità del debito di Isacco nei confronti dei suoi maggiori. La prima autorità che è doveroso introdurre è, anche in questo caso, quella di Teodoro di Mopsuestia. Basti ricordare qui un passo del suo Commento alla Genesi, ove, in riferimento a Gn 1, 1-2, si legge: "Per questo, infatti, il beato Mosé non (pre)pose alle (cose) che furono create per prime le parole: Dio disse, ma (scrisse) semplicemente: In principio Dio fece il cielo e la terra, perché la sua volontà sola le creò, senz'uso di parola, dato che non v'era chi avesse bisogno di imparare alcunché dalla sua parola. Ma, a proposito di quel che segue, disse che la parola precedette la sua esistenza, perché di fatto allora v'erano quelli che avrebbero dovuto imparare (qualcosa) sul Creatore attraverso la parola, dato ch'egli, nella sua natura, era nascosto. Secondo la sua volontà, quindi, la parola precedette (la creazione), mentre l'opera seguiva la parola, (e) quest'insegnamento su Colui che, col suo comando, aveva creato la creazione fu (rivolto) alle nature dotate di ragione ed invisibili.

Dunque, (Dio) non prepose la parola alle cose che furono create per prime, né cessò di dire nel (creare) quelle che furono poi, perché qui essa era assolutamente necessaria, dato che v'era un insegnamento (da dare) a dei discenti, mentre lì non v'era chi avesse bisogno di imparare - e questo Dio lo

46 Cf KG 1.3, (t) ff. $20 v^{\circ}-21 r^{\circ}$; (tr) 51.

47 Ibid.

48 (T) f. $21 v^{\circ}$; (tr) 52. 
fa conoscere al beato Giobbe dicendo: Mentre creavo la stella, acclamarono ad alta voce tutti i miei angeli e mi glorificarono $(G b 38,7)$ " 49.

Questo testo lascia chiaramente intendere la dipendenza di Isacco dall'Interprete. Dipendenza semplice, forse; forse però mediata da altre fonti, come già si suggeriva e sembra più probabile 50 . Narsai, innanzi tutto, con-

49 Cf Theodori Mopsuesteni Fragmenta syriaca, Ed. Sachau ed., Lipsiae 1869, (t) 4.14 - 5.7. Il testo greco di questo passo è parzialmente ricostruibile a partire dalla citazione/parafrasi che ne fa Giovanni Filopono: cf R. Devreesse, Essai sur Théodore de Mopsueste, Roma 1948, n. 2 a p. 8. $5^{\circ} \mathrm{L}$. Van Rompay ha espresso a più riprese il suo convincimento relativo al fatto "qu'il ne faut pas trop insister sur le caractère novateur de l'introduction de l'exégèse de Théodore dans le monde syriaque", dato il raccordo da sempre esistente tra tradizioni antiochene ed edessene, documentabile puntualmente, a livello esegetico, fin dagli inizi del IV secolo (cf ad esempio Quelques remarques sur la tradition syriaque de l'œuvre exégétique de Théodore de Mopsueste, in IV Symposium syriacum 1984, H.J.W. Drijvers, R. Lavenant, C. Molenberg and G.J. Reinink eds., Roma 1987, 33-43, qui 33). Egli, inoltre, sulla base di un celebre passo di un autore della fine del VI secolo, Barhadbshabba, ha sottolineato l'esistenza, a quella data, di almeno due decisivi e distinti livelli d'esegesi: nell'un caso, scrive, "il s'agit d'une transmission souvent orale des interpretations de diverses autorités, interprétations qui, souvent anonymes, devenaient la propriété de chacun, se prêtaient facilement à des adaptations et à des élargissements, et donnaient continuellement lieu à de nouvelles synthèses", miranti, di fatto, alla volgarizzazione della dottrina cristiana $(I v i, 41)$. Si tratta, qui, di una corrente interna alle chiese di Siria, presentata dai suoi elaboratori come "tradition de l'école", tout court, "apostolica" nelle sue origini e certo, comunque, erede delle proposte "pastorali" di un Efrem o di un Narsai. Nell'altro caso, invece, quello dell'esegesi in senso stretto, si è di fronte a "un commentaire écrit, de nature savante", indirizzato ad un pubblico colto, limitato, dovuto ad un autore individuabile e conforme, di massima, al lavoro dell'esegeta per eccellenza della chiesa d'oriente, Teodoro (ivi).

Ora, questi due distinti livelli, quello del lavoro interpretativo sulle Scritture e quello dell'elaborazione "omiletica" (e parenetica) dell'annuncio cristiano, tradito nelle diverse chiese, tendono a influenzarsi vicendevolmente, come testimonia eccellentemente, ad esempio, sul versante della "tradizione", il saggio, su cui torneremo, che W. Macomber ha dedicato a The Theological Synthesis of Cyrus of Edessa, an East Syrian Theologian of the Mid Sixth Century, pubblicato in Orientalia Christiana Periodica 30 (1964), 5-38 e 363-384, se assunto nella prospettiva indicata da Van Rompay nelle ultime pagine del suo saggio.

Isacco, in questo contesto, si situa alla confluenza delle due correnti: non solo una delle due vite che lo concernono afferma che nel Qatar era stato pure "dottore", e che era parente di un grande esegeta attivo a Seleucia Ctesifonte intorno alla metà del VII secolo (su ciò cf complessivamente L. Van Rompay in Le Commentaire sur Genèse-Exode 9, 32 du manuscrit (olim) Diyarbakir 22, CSCO 484, Lovanii 1986, XXVII-XXXII), ma taluni suoi, pochi, sì, ma non trascurabili, puntuali rinvii, in ordine all'approfondimento di singoli problemi, a opere esegetiche di Teodoro sembrano confermare, da parte sua, una conoscenza anche tecnica dell'interpretazione delle Scritture quale era praticata nelle scuole del suo tempo (Isacco cita espressamente, del dottore antiocheno, che Van Rompay in Quelques remarques, 43, afferma non essere stato poi troppo letto "après l'apogée de la littérature syriaque", tra V e VI secolo, suppongo, il Commento alla Genesi, in B XIX, (t) 155; (tr) 195, e L, (t) 358; (tr) 240, nonché in KG 4, 95, sopra citato; il Commento a Giobbe, in B XIX, (t) 155 e 160; (tr) 195 e 199; il Commento ai 12 profeti, in B XIX, (t) 156; (tr) 195; il Commento a Matteo, in B XIX, (t) 156; (tr) 195, e LIX, (t) 418; (tr) 280, nonché in Brock VIII. 21, (t) 25; (tr) 31-32; il Commento agli Atti, in B XIX, (t) 156; (tr) 195). D'altra parte, numerose sue pagine, come quelle qui in esame, si inscrivono bene nell'ambito della più vasta "tradizione" sopra descritta. E a questo proposito è utile richiamare un'ultima osservazione di Van Rompay: egli adduce sia in Quelques remarques, $41 \mathrm{n}$. 25, sia in Le Commentaire, XXI n. 13, un passo di Timoteo I (fine IX secolo) volto a riconoscere la molteplicità delle esegesi relative ai versetti delle Scritture, del tutto legittima e solo coerente alla diver- 
vinto assertore dei meriti dell'esegesi antiochena e fondatore della scuola di Nisibi, riprende e sviluppa più volte l'interpretazione del vescovo di Mopsuestia. Scrive, ad esempio: "Una grande quiete posava su tutto, quand'Egli costituì il tutto, / ed erano tranquille le nature, quelle dotate di parola ${ }^{51}$ e le silenti. // Per dodici ore protrasse la quiete sul tutto / e quando fu compiuta, fece udire una voce: Sia la luce! (Gn 1, 3)// Una voce nuova fece risuonare nella creazione il Signore della creazione, / e furono scosse dalla sua gran voce le schiere dei celesti. // Come tromba fece squillare la sua voce entro il cosmo, / e gli spirituali si raccolsero e vennero ad ascoltarla. // Per loro fece udire una voce Colui che non ha voce, / per insegnare loro che il suo Cenno aveva costituito loro e tutto. // Tramite un suono rese sapienti i possessori di parola, / perché sapessero che lui aveva costituito il tutto dal nulla"52. Qui e altrove Narsai, forse consapevole del rifiuto e della derisione, anche, con cui simili tesi erano accolte in ambienti latamente "alessandrini", insiste sul paradosso di questa voce di Colui che trascende ogni voce, sulla natura "economica" di una voce "che non somiglia alla voce corporea" 53 , che è solo funzionale all’istruzione, all'alfabetizzazione, quasi, degli angeli: Dio

sa intelligenza di ciascuno. È questa una affermazione importante, perché indica bene l'orizzonte entro cui si colloca la sintesi di Isacco, se ve n'è una - quello de "la transmission d'un héritage commun (...), dont chacun peut disposer, en le résumant ou en l'amplifiant, et en l'adaptant à ses propres idées", liberamente (Le Commentaire, XXXIV).

$5^{1}$ Qui e altrove, in questo testo, rendo con "dotato di parola" il termine siriaco, corrispondente al greco loghikos e come quest'ultimo unico, che più comunemente traduco: "dotato di ragione", data la coincidenza dei due vocaboli in entrambe queste lingue. In italiano la variazione è giustificata dal contesto, che ora, e più abitualmente, accentua la valenza intellettuale della parola, ora la sua, più originaria, determinazione "materiale", di suono articolato, dotato di senso.

$5^{2}$ Cf Homélies de Narsaï sur la création, P. Gignoux éd., PO 34/3-4, Paris 1968, qui II. 229-240, (t) 570. Sull'angelologia di Narsai e sui rapporti della sua esegesi dei primi versetti di $G n$ con quella di Teodoro, cf le note di Gignoux, Ivi, 453-457 e 478-482.

53 Cf Ivi, V.72, (t) 642. Narsai aveva scritto, in V.65-66, (t) 642: "Nell'ora mattutina udirono una voce che non (era) voce, / perché era emessa per l'ascolto dei loro intelletti”. Le tesi relative all'inclusione dell'angelo in cielo e terra, così come quella dell'insegnamento in qualche modo sensibile indirizzato da Dio all'angelo avevano trovato pronta contestazione da parte di scrittori non antiocheni. W. Wolska, studiando in La Topographie chrétienne de Cosmas Indicopleustès. Théologie et science au $\mathrm{VI}^{e}$ siècle, Paris 1962, i rapporti che legano Cosma alle tradizioni esegetiche e teologiche della scuola di Nisibi (e cf, ad esempio, Ivi, 81, soprattutto n. 6, la menzione della lettera di Giorgio, che più sotto utilizzeremo, in relazione al commento di $G n$ 1, 3), sosta a lungo anche sulla confutazione che l'insegnamento di Teodoro aveva ricevuto in Alessandria, nella prima metà del VI secolo, da parte di Filopono. Si veda, in particolare, per il tema dell'angelo inscritto nel mondo, Ivi, 179, o anche, nel recente volume di C. Scholten, Antike Naturphilosophie und christliche Kosmologie in der Schrift <De opificio mundi $>$ des Johannes Philoponos, Berlin-New York 1996, 147 ss.

A minima testimonianza della discussione relativa alla "voce" udita all'atto della creazione della luce rinvio, per la tradizione siriaca, alle righe che vi dedica Mosè bar Kepha (IX sec.) nel suo "esamerone": cf L. Schlimme, Der Hexaemeronkommentar des Moses bar Kepha. Einleitung, Übersetzung und Untersuchungen I, Wiesbaden 1977, II.5.4, 221-222 (esposizione della posizizione antiochena: 1l.164-167; sua critica: 1l.176-181). 
infatti "insegnò loro una scrittura nuova, che non conoscevano; // come per dei fanciulli scrisse un suono al posto delle lettere dell'alfabeto, / e li fece meditare sui libri dell'esistenza della luce" 54 .

Ma oltre Narsai, è tutta la tradizione dei commenti della chiesa d'oriente a riflettere, variandola, questa lettura 55 . Basti citare le tarde annotazioni di un Teodoro bar Koni (fine VIII secolo) o di un Isho'dad di Merv († circa 850). Il primo, nel suo Libro degli scoli, alla domanda: "Perché la creazione ha principiato ad essere dalla tenebra e non dalla luce?”, risponde, tra l'altro: “In secondo luogo, ad insegnamento degli angeli, perché era necessario imparassero a riguardo del loro autore. Bene dapprima li avvolse e serrò come con fasce per la durata di dodici ore, e poi creò la luce - e per la sua bellezza gli angeli acclamarono il loro autore, come è detto in Giobbe"56. Il secondo, più ampiamente, ma in taluni punti riprendendo le stesse parole, gli stessi periodi presenti in Teodoro, ad indicare la comune dipendenza da una stessa fonte, scrive: "Come ad insegnamento degli angeli, perché era necessario imparassero a riguardo del loro autore. Bene, quando essi la sera del primo giorno della settimana, che è il principio della creazione, furono creati con le sei [altre creature dell'in principio] in silenzio, dapprima (Dio) li avvolse e serrò come con fasce per la durata di dodici ore, perché si affaticassero nell'indagine e la loro razionalità avesse sete di suggere il latte dell'infanzia - ed essi erano dubbiosi e riflettevano su di dove fossero venuti all'esistenza e su chi li avesse fatti e su come fossero divenuti -, poi, al momento del mattino, udirono un'alta e stupenda voce: Sia la luce!, e subito tutto il mondo rilucette, e per la sua bellezza adorarono e acclamarono il loro autore: Gloria a Colui che ha creato la luce!, secondo l'espressione di Giobbe: Mentre creavo la stella del mattino - cioè la luce diffusa - tutti i miei angeli a voce alta (mi) hanno acclamato e mi hanno esaltato $(\mathrm{Gb} 38,7)$ " 57 .

Questi testi sicuramente bastano a illustrare antichità, permanenza e variazioni dei motivi esegetico-dottrinali presenti nelle pagine di Isacco. Tuttavia, prima di procedere all'individuazione di pochi, ulteriori temi della sua meditazione sull'angelo, mi sembra utile segnalare un'ultima variante a questa tradizione, che si legge in un testo di quel cattolico Giorgio che l'aveva conosciuto monaco nel Qatar e quindi condotto con sé in Babilonia, dove l'aveva consacrato vescovo di Ninive, per dispensarlo poi dall'episcopato

54 Cf Homélies sur la création, II.250-253, (t) 570.

$55 \mathrm{Su}$ questi commenti, la loro successione e i loro vicendevoli rapporti, si veda almeno la sommaria presentazione offerta da Van Rompay in Le Commentaire, XL-LII.

$5^{6}$ Cf Theodorus bar Koni, Liber scholiorum, A. Scher ed., CSCO 55, Paris 1910 (edizione anastatica: Louvain 1960), 35.7-8 e 12-17.

57 Cf Commentaire d'Isho'dad de Merv sur l'Ancien Testament - I. Genèse, J.M. Vosté et C. Van Den Eynde éd., CSCO 126, Louvain 1950, 15.25 - 16.11 (il corsivo nel testo è mio, ad evidenziare i passi che questo commento ha in comune con quello di Teodoro bar Koni). 
dopo appena cinque mesi di ministero. Gli atti sinodali della chiesa d'oriente serbano infatti una sua lettera databile probabilmente ai primi mesi del 680 (e dunque ad appena quattro anni dal suo incontro con Isacco), indirizzata ad un "presbitero e corepiscopo nella terra dei persiani" di nome Mina, "sulla divinità del Cristo e sulla sua umanità", in cui si attesta "che non (è vero), come hanno pensato i distruttori dell'ortodossia della chiesa, che Dio Verbo abbia subito mutamento e sia divenuto carne nella sua ipostasi” 58 . Qui non interessa seguire l'argomentazione di Giorgio; basti dire che lì dove inizia a replicare a quanti parlano male "dell'economia del nostro vivificatore e nostro Dio, Gesù Cristo" 59 , egli comincia la sua esposizione ricordando l'atto creatore di Dio, per poi ripercorrere i grandi momenti della vicenda umana e dell'agire divino in essa. Si legge così, al principio di questa sezione: "Il nostro eterno, buon Dio, che (è) da sempre, senza principio, quando volle condurre a manifestazione la bontà del (suo) volere, fece venire ad esistenza la creazione, che non era affatto, con un cenno potente del suo volere: dico il cielo, di sopra, e la terra, di sotto, i due limiti estremi della creazione, il vaso che racchiude tutti i divenuti. Al loro interno, subito creò e stabilì con potenza, ad un cenno del suo volere, l'acqua, l'aria, il fuoco e la tenebra, insieme agli angeli, che sono viventi e dotati di ragione e d'intelletto. E per dodici ore le nature spirituali rimasero nella tenebra, con tutte le nature create. Come ad insegnamento degli spirituali il nostro buon Dio disse: Sia la luce! $(G n 1,3)$, e immediatamente, in uno con la voce fu la natura stupenda della luce, e le nature spirituali stupirono e furono mosse alla gloria di Colui che aveva creato la luce, come Dio ha detto ad edificazione del giusto Giobbe: Mentre creavo le stelle dell'aurora, tutti i miei angeli (mi) acclamarono e mi glorificarono $(G b 38,7)$ "60.

Trascuro per un attimo queste indicazioni, di impressionante evidenza, per tornare ai testi di Isacco e cogliere da un ulteriore capitolo delle sue centurie un secondo e ultimo tratto di quella stessa vicenda dell'in principio relativa all'angelo. In KG 3, 8o, infatti, si legge: "Dapprima la creazione degli spirituali, pur essendo nell'inclinazione, non conosceva la malizia che da essa sgorgava; ma, mentre tutti erano fiduciosi e si levavano, essi videro improv-

58 Il testo della lettera si legge in J.B. Chabot, Synodicon Orientale ou Recueil de synodes nestoriens, in Notices et Extraits des Manuscrits de la Bibliothèque Nationale 37, Paris 1902, (t) 227245, qui Titolo, 227.1-6.

59 Ivi, 229.25.

60 Ivi, 229.29 - 230.7. Il testo di Giorgio, come l'insieme della sua vicenda (su cui cf la breve voce di D. Bundy, Georges Ier de Kaphra, in Dictionnaire d'Histoire et de Géographie ecclésiastique 20 (1983), 625-627), non hanno ancora ricevuto grande attenzione. Vi fa cenno Wolska, come segnalato in n. 53, o Beulay, in Lumière sans forme, 194, in un importante paragrafo dedicato a L'influence de la théologie dogmatique nestorienne sulla letteratura monastica della chiesa d'oriente tra VII e VIII secolo, ove i temi qui trattati si trovano riassunti alle pp. 192-194. 
visamente uno di loro cadere dalla gloria in cui erano - un capo di moltitudini, e molti con lui. In tutti caddero tremore e timore, e la loro creazione fu mossa dalla paura che entrò ed abitò in essa. E di qui, (da) allora ha abitato in loro il timore del Creatore, quasi disperassero di se stessi, perché pensavano che dunque sarebbero caduti tutti; di qui hanno ricevuto notizia della grandezza del suo vigore e hanno quindi saputo che tutti erano stati suscitati dal suo cenno. Questo timore di fatto ha fatto loro acquisire una grande vigilanza. Da allora in poi, dunque, vedendo in sé l'inclinazione che possedevano e la caduta che ne (era conseguita), (e) che si era prodotta per molti di loro, erano quieti in se stessi - tutta la creazione degli angeli -, senza sapere che vi sarebbe stato un tempo in cui ne sarebbero stati liberati”.

Anche su questa vicenda la tradizione presenta interessanti paralleli. Certo, ad esempio, il peccato dell'angelo è talora connesso alla gelosia che parte almeno degli spirituali patirono nei confronti di Adamo. Per citare il solo Giorgio, nella sua lettera si legge, appunto, che, mentre, alla vista dell'uomo, molti angeli ancor "più ammirarono la sapienza di Dio e gioirono dell'onore (e gloria) della sua immagine", "ve ne furono tra loro (altri) che $<\ldots>$ furono mossi da invidia e malizia e inclinarono a volgersi all'abisso dell'orgoglio e dell'odio per l'uomo e a cadervi" ${ }^{61}$. Tuttavia, saldo è, comunque, il motivo, tipicamente antiocheno, della vertibilitas, dell'inclinazione cui sempre è soggetto l'angelo, del timore, quindi, in cui sempre versa, circa sé, il proprio futuro, e da cui è liberato solo dal Cristo ${ }^{62}$. Ad illustrarlo, vorrei qui utilizzare un ulteriore testimone, la cui importanza è stata precedentemente ricordata solo in nota: si tratta di Ciro d'Edessa, qui citato in un luogo della sua Causa sulla Resurrezione, ove afferma, a proposito del giorno in cui ebbe luogo la resurrezione: "Poiché, infatti, ebbe luogo nel primo giorno la costituzione della prima creazione - dico del cielo, della terra, degli angeli e delle restanti (cose) che con loro, ad un unico cenno, vennero ad esistenza, (realtà) che poi, dopo la trasgressione del comandamento (da parte) del padre di tutti, Adamo, furono travagliate da molta fatica: La creazione - è scritto infatti - fu asservita alla vanità non di sua volontà, ma a motivo di Colui che (ve) l'asservì in ordine alla speranza $(R m 8,29)$-, giustamente in quello (stesso) giorno in cui questa costituzione sensibile aveva avuto inizio parve (bene) al nostro adorabile Iddio, affatto sapiente, di disporre daccapo la liberazione per tutto l'universo, tramite nostro Signore, il Cristo, per far sapere così che è uno stesso (sia) la causa della sua esistenza sia Colui che ora (lo) incorona"63.

61 Cf Chabot, Synodicon, 230.31 e 32-34. Beulay, in Lumière sans forme, 194, cita un passo parallelo a questo di Giuseppe Hazzaya, altrimenti assai vicino a Isacco.

62 Cf, per questo, in particolare Macomber, The Theological Synthesis, 12-13.

63 Cf Six Explanations of the Liturgical Feasts by Cyrus of Edessa - An East Syrian Theologian of the Mid Sixth Century, W.F. Macomber ed., CSCO 355, Louvain 1974, 3.3, 106.29 - 107.11. 
4. È tempo di abbandonare questa esposizione dei testi di Isacco fittamente e forse anche faticosamente intervallata dalla citazione di luoghi ad essi paralleli. Penso sia ormai evidente la compattezza della tradizione esegetica, omiletica, monastica entro cui si colloca e cui va restituita la sua scrittura ${ }^{64}$. Certo, sarebbe possibile e utile, credo, addurre ulteriori testimonianze, sia a partire dalle fonti fin qui utilizzate, sia introducendo, su altri punti, materiali desunti da diversi autori - e penso in particolare a Evagrio e allo pseudo-Dionigi65. Ma qui, ora si deve insistere, infine, su quell'aspetto di questa complessa meditazione sull'angelo che consente di gettare nuova luce sull'insegnamento di Isacco relativo alla preghiera e di evidenziarne ancor più l'interna coerenza, la stessa punta di novità.

Si torni, dunque, alle tesi desumibili dai pochi capitoli relativi all'angelo fin qui citati. Si noterà, allora, la modestia di questa creatura. La sua intelligenza, curiosa, attiva, nella tenebra dell'inizio si interroga su sé senza trovare risposta alcuna. Solo la rivelazione spezza questa ignoranza. Per rapporto a Teodoro e ad altri autori che ne riprendono le tesi, Isacco sembra trascurare quanto all'angelo riesce comunque di intendere a partire dalla creazione sensibile66: della propria creaturalità, davanti a Dio, egli sa da Dio stesso, attraverso la creazione della luce ${ }^{67}$. Creazione, si noti: la luce è creata da nulla, è creazione assoluta, nuova, come nuova, non deducibile da alcunché di anteriore é la conoscenza che la rivelazione che l'accompagna schiude all'angelo ... E ad essa l'angelo corrisponde levandosi, innalzandosi, levando e innalzando un suono, una parola - di cui pure è capace solo a partire dalla rivelazione di Dio: suono e parola di lode, si diceva.

Ma ecco: alcuni, improvvisamente precipitano. Isacco non segue la tradizione, ampiamente attestata, cui si è fatto cenno, che coglie nell'incomprensione nei confronti della creazione di Adamo l'occasione del peccato dell'angelo. È nell'innalzarsi concitato e lieto di quel primo mattino che la caduta si

\footnotetext{
64 Se se ne volesse avere ulteriore prova, suggerisco di leggere il saggio di S. Brock, Some Use of the Term "Theoria" in the Writings of Isaac of Nineveh, in Parole de l'Orient 20 (1995), 407-419. 65 Sarebbe utile anche meglio correlare tra loro le testimonianze addotte, definendo con la maggiore precisione consentita l'elaborazione delle diverse riformulazioni della comune tradizione: per temi più legati a singole tesi cristologiche e teologiche e per un autore più tardo, Giovanni di Dalyatha, questo è un lavoro esemplarmente schizzato da Beulay in L'enseignement.

$66 \mathrm{Si}$ veda, esemplificativamente, quanto Teodoro scrive all'inizio della parte che ci è tradita dell'introduzione al suo Commento alla Genesi: "Non era possibile, infatti, che le nature dotate di ragione ed invisibili, che avevano ricevuto una vita immortale, conoscessero le cose belle che possedevano, se non avessero appreso ciò dalla comparazione con le altre (creature) $<\ldots$. " (Theodori Mopsuesteni Fragmenta, (t) 1.13-15).

67 Ricordo che Teodoro bar Koni attribuisce all'Interprete stesso una lettura di Gn 1, 3, di cui abbiamo pure ulteriori attestazioni, prive però della menzione della fonte che citano, secondo cui sarebbe stato Dio stesso a dire: Dio dice: La luce sia!, facendo così conoscere all'angelo il suo nome (cf Liber scholiorum, 22.24 - 23.9, in particolare 23.1-9).
} 
produce - e non ve n'é ragione ${ }^{68}$. Per l'uomo, ripetendo la tradizione, Isacco scriverà: "Non siamo mortali perché pecchiamo, ma perché siamo mortali siamo stati spinti al peccato" 69 . Neppure qui v'è un motivo - il capitolo, infatti, prosegue: "La potenza della libertà, posta nel mezzo, ha fatto (sì) che essa venisse in uso o per la vita o per la morte" 70 -, pure si indica una condizione di particolare sollecitazione al peccato, per così dire: mortale, l'uomo sembra quasi "spinto", appunto, ad "aggrapparsi" al suo vivere caduco, diffidando dell'invisibile, trascurando la parola/promessa ... Ma l'angelo? Non è corruttibile la sua sostanza, così che dalla sua instabilità, dall'evidenza della sua dissoluzione ricavi una vertigine che lo confonda. Si levavano nell'acclamazione, fiduciosi, quando improvvisamente alcuni caddero. E da allora, scrive Isacco, la paura abitò in loro, "quasi disperassero di se stessi, perché pensavano che dunque sarebbero caduti tutti" 1 .

Incorruttibile, l'angelo non è però privo d'inclinazione, non è in sé immutabile. Creatura, ospita un'indecisione mai perfettamente persuasa, in nessun momento sottratta alla possibilità di una diversa risoluzione: il caso (l'Ereignis, direbbero taluni moderni) può scompigliare la sua determinazione, per quanto consolidata. E il mistero di questa defettibilità entro la gioia stessa del volgersi al Dio che si è rivelato, dinnanzi a Lui, sciolti dal cruccio della propria originaria ignoranza; il mistero di questa dimensione ultima, che eccede ogni consapevolezza, acceso in uno con la coscienza di sé - questo

68 In un ulteriore capitolo, invero, Isacco sembra indicare una ragione. In KG 3. 87, infatti, scrive: "Sappiate, fratelli miei, di dove è accaduta la determinazione del male nelle nature dotate di ragione. Quella stella mattutina che è sorta dall'aurora (Is 14, 12 LXX), poiché era sminuente ai suoi occhi essere soggetta ad una regola, secondo la determinazione delle creature, per questo fu abbandonata dalla potenza che la (sos)teneva e cadde come una folgore $(L c 10,18)$ dalla sua gloria" ((t) f. $79 r^{\circ}$; (tr) 146). Il capitolo successivo, poi, inizia ribadendo: "Dal desiderio di libertà è cominciato il pensiero della malizia nelle creature", e prosegue insistendo su questo "amare la libertà e uscire da sotto la regola e la legge", in cui consiste il principio del peccato (KG 3.88, (t) f. $79 \mathrm{r}^{\circ}-\mathrm{v}^{\mathrm{o}}$; (tr) 146-147).

La ragione indicata è dunque la libertà, che situa la creatura oltre sé, oltre il suo affatto creaturale limite. È la sua stessa potenza, che le si rivela in uno con il manifestarsi di Dio, a travolgerla - ma non necessariamente, dato che, vediamo, alcuni, anzi molti, pur scossi, non cadono. Più oltre, nel testo, si dirà di questa sofferenza della creatura, chiamata, paradossalmente, a trascendenza di sé senza poter da sé compiere questo trascendimento; chiamata ad agonia, fino alla rivelazione del Cristo, che mostra la perfetta agonia e il suo compimento dall'alto; qui basti dire che la ragione prospettata da Isacco non è tale, almeno secondo i criteri del "mondo": quel sapere, infatti, è per lui un sapere della fede, l'unico rapporto con l'altro in cui la libertà, esercitandosi, si sappia - altrimenti v'è solo la sua rabbiosa negazione, lo "strisciare nell'abisso", come recita KG 3.88, del tutto prigioni di sé e della propria mortale brama. Sul radicamento di queste riflessioni nella letteratura siriaca mi permetto di rinviare, esemplificativamente, ad un mio saggio di prossima pubblicazione su Adamo in Eden e la liturgia celeste: stili ecclesiali nella Siria del IV secolo, tra Afraate e il "Liber graduum".

$69 \mathrm{KG} 3.2$, (t) f. $59 \mathrm{v}^{\circ}$; (tr) 119.

70 Ibid.

${ }^{71} \mathrm{Cf} \mathrm{KG} \mathrm{3.80,} \mathrm{qui} \mathrm{(t)} \mathrm{f.} 77 \mathrm{v}^{\circ}$; (tr) 144. 
spaventa e modera e intristisce la creazione angelica. "Vedendo l'inclinazione che avevano (in sé) e la caduta che ne (era proceduta)"72, gli angeli si acquietano, vigili, addolorati - di un dolore che li appesantisce, che non portano gioiosamente. Perché la creatura fatta ricettiva di Dio, che ha ricevuto il gusto di Lui, non può in alcun modo sciogliere, trascendere il proprio paradosso, se non in una condotta, affatto insoddisfacente, anche se del tutto lucidamente assunta, di attenta, violenta custodia di sé. Il che riesce all'angelo, sembra il più delle volte, almeno; ma lo lascia necessariamente inquieto, sofferente.

Solo Cristo libera le schiere angeliche da questo sordo dolore, dando loro premonizione, se non conoscenza, dell'eschaton. "Le nature intelligibili scrive Isacco in KG $3.79^{73}$ - sono divenute infinitamente più eccellenti in conoscenza a partire da ciò che hanno compreso nel Cristo, nostro Signore cose che prima non conoscevano; in lui, che è venuto per la liberazione e il compimento loro e nostro". Di qui, alla "notizia della liberazione futura", "il loro dolore fu dissolto" 74 ... Ma non perché non sia più, ora. "Una natura soggetta a inclinazione - si legge in un opuscolo posto sotto il titolo: Contro coloro che dicono: Se Dio è buono, perché fa questo? - non è in grado di ricevere qui (in questo mondo) la pienezza della verità divina o di conoscere tutta la volontà divina relativa al genere degli esseri dotati di ragione, $\langle\ldots>$ finché l'inclinazione non sia stata tolta di mezzo, così che la natura non declini da questa percezione"75. E più oltre Isacco ribadisce questa impossibilità: "se una natura soggetta a inclinazione ricevesse qui l'esatta verità, morrebbe per la veemenza dell'inclinazione"76.

Dunque, l'inclinazione, condizione della libertà creaturale, ospita una "veemenza", un'irruenza, un impetus, che la rende indisponibile alla conoscenza di Dio, almeno ad una conoscenza immediata di Lui. La rivelazione tende, esaspera, parrebbe, la creatura; se eccessiva, attiva in lei, in modo che la sorprende e le risulta incontrollabile, una volontà e potenza che induce morte, che non consente che morte. Per questo essa - la rivelazione, dico - è soggetta a limite, sempre. Un limite incessantemente spostato, variato; un limite che, nel suo mutare, avanzare o ritrarsi, sulla via certo non diritta che così traccia77, educa e "abitua" al Dio umile (Dio, ma, inattesamente, proprio

\footnotetext{
72 Ibid.

73 (T) f. $77 \mathrm{v}^{\circ}$; (tr) 144 .

$74 \mathrm{KG} 3.80$, qui (t) f. $78 \mathrm{r}^{\circ}$; (tr) 144 .

75 B XXVI, qui (t) 192.18 - 193.1; (tr) 231.

76 Ivi, (t) 193.5-6; (tr) 231.

77 Questo incessante mutare di Dio in funzione dell'istruzione umana è tratto centrale di buona parte della meditazione siriaca: cf, a minimo esempio, in relazione ad Efrem, i capitoli iniziali del volume di S. Brock, The Luminous Eye, Roma 1985. I rinvii più frequenti sono quelli alla condotta del padre o della madre nei confronti del figlio e alla cura del maestro per lo scolaro. Se ne veda, per Isacco, un esempio in B XXIX, qui (t) 205.12-15 e 206.6-8; (tr) 243 e 244: "Il Padre
} 
come tale, perché tale, umile); abitua ad umiltà, unico principio di pace perché solo l'umiltà, appunto, veste di Dio e riverbero del suo mistero ${ }^{78}$, modera e quasi vince la veemenza, la febbre della creatura esposta al Creatore, la converte già qui a quel pur momentaneo "sguardo non soggetto a inclinazione rivolto al nostro Signore" crocifisso, cui sembra allora di essere vicini "anche nel corpo", di cui si è già detto, e che è perfetta anticipazione del Regno ${ }^{79}$.

La croce, specchio della carità di Dio, ci rende così, infine, perfettamente "prigionieri della sua carità, tramite (quel) la nostra sovrabbondante carità" che procede dalla sua visione80; ci dispone a quella resa che acconsente, coscienti - passati per la prova e in essa mondati -, al proprio morire, lo invoca. Non il morire spezzati dal proprio impeto, ma il morire spezzati da Dio, in lui assolutamente fidando - il solo risanatore, il solo vivificatore, che toglie ogni inclinazione, a chi voglia, e, infine, come che sia, si mostra.

Certo la preghiera qui cessa, anch'essa spezzata, recisa. In questo, però, non vedo alcuna ottusa, "pasticciata” fedeltà ad un'altrui parola, per quanto autorevole; piuttosto, l'esito coerente del vasto sforzo di organico ripensamento di una tradizione di condotte e studi, saggiata, provata in anni di lavoro, meditazione, confronti, visione. Un ripensamento e una proposta di vita, ad un tempo, che forse possono apparire talora troppo urtanti, troppo poco "dialettici"81, certo non sempre, per tutti soddisfacenti - ad iniziare dai con-

della verità conversa variamente con i suoi figli. Per il profitto dei suoi figli si guarda dall'uguaglianza, che (è) esibizione di un unico volto in ogni tempo; piuttosto, per la (loro) istruzione (talora) cela furtivamente la sua carità. $<\ldots>$ Non chiedere ad un amico sapiente una carità insipida: chi uccide il proprio figlio con un nutrimento di miele non è diverso da chi (lo) uccide con un coltello", o in B XXXVI, qui (t) 273.12 - 274.1; (tr) 303, ove della potenza di Dio si dice: "Essa li istruisce [ si intenda: gli uomini ] come uno che insegni nuoto ad un bimbo piccolo. Quando (questi) inizia ad affondare, (quello) lo tira su, perché il bimbo si tiene a galla sulle mani del suo maestro. Quando il bambino inizia a perdersi d'animo per timore d'affondare, quello che lo sostiene con le sue mani gli grida: <Non temere! Ti tengo su io>. O, ancora, (li istruisce) come una madre che insegna al suo figlioletto a camminare. Lo pone lontano da sé e lo chiama. Quando il bimbo inizia a venire verso sua madre sui suoi piedi piccoli e malcerti, (questi) per la loro tenerezza tremano. Ma quando il bimbo comincia a cadere, sua madre corre e lo solleva sulle sue braccia. Così la grazia di Dio sostiene e istruisce gli uomini <...>”.

78 B LXXXII, che reca come titolo: Su quanto onore possegga l'umiltà e quanto grande sia il suo grado, testo tutto dedicato al tema dell'umiltà, inizia con una confessione che è utile riportare. Scrive, dunque, Isacco: "Sono pieno di paura, come uno che è consapevole che nella trattazione del suo argomento tratterà di Dio: essa infatti è la veste della Divinità, perché il Verbo che si è fatto uomo, lei ha rivestito e in lei ha parlato con noi" ((t) 574.6 e 8-11; (tr) 384). L'umiltà, del resto, è eccellenza nuova, propriamente cristiana, per Isacco - che pure ne indica la profezia in taluni luoghi messianici delle Scritture d'Israele. Scrive infatti: "Quale delle creature non riverirà la vista di un umile? Tuttavia, finché la gloria dell'umiltà non fu manifestata al tutto, la (sua) vista piena di santità era disprezzata" ((t) 576.5-8; (tr) 385).

$79 \mathrm{Cf}$ supra, n. 11.

80 Cf KG 4.78, qui (t) f. $102 v^{\circ}$; (tr) 183.

${ }^{81} \mathrm{Mi}$ sembra che anche in questo Isacco sia erede di quella stessa ampia tradizione le cui mol- 
temporanei. Ma Isacco, il cui insegnamento è ben più articolato e complesso di quanto qui non sia possibile anche solo suggerire, richiama con chiara intelligenza e mite forza all'ineludibilità del paradosso che l'uomo, ogni intelligente potenza è a sé; alla "mondana" 82 insolubilità di questo paradosso, che tutti peraltro inquieta, e modera e ingentilisce, anche, appena un po' lo si sostenga - e tutti così pone sulla via che conduce all'eschaton mostrato da Cristo, eschaton di carità e resurrezione. Evagrio, l'autore prediletto, nelle sue Centurie del resto lo indicava non dissimilmente, scrivendo: "Spetta all'intelletto nudo [ spoglio e silente - mite ed umile, quindi ] dire quale sia la sua natura, ma a questa domanda [ cui l'intelletto non può non lavorare, incessantemente ] ora non v'è risposta. Da ultimo, poi, neppure vi sarà la domanda" 83 - nella chiarezza e nella gioia del compimento.

teplici voci si sono più volte pur frammentariamente citate. Vorrei qui, pur con qualche cautela, riportare alcune felici righe di un recente studio su Teodoro (P. Bruns, Den Menschen mit dem Himmel verbinden. Eine Studie zu den katechetischen Homilien des Theodor von Mopsuestia, CSCO 549, Lovanii 1995, qui 120), che recitano: "Aus der Inkommensurabilität von göttlichem und menschlichem Sein folgt auch eine wesensmäßige Unerreichbarkeit des göttlichen Wesens für das kreatürliche Erkennen. Eine <rein natürliche> Gotteserkenntnis ohne Glauben, der sich auf die Autorität Gottes und der Kirche als Glaubensgemeinschaft gründet, ist schwer möglich. Kritiker sprechen deshalb vom < Hang zum Agnostizismus $>$ in der Theologie Theodors, doch ist dies eher als eine Überreaktion auf den arianischen Rationalismus zu verstehen. Zudem darf man den mystischen Weg der Gotteserkenntnis nicht außer acht lassen, der auch von späteren nestorianischen Theologen und Gottsuchern wie etwa Isaak von Ninive immer wieder beschritten worden ist".

82 "Mondano" intendo, al modo d'Isacco, un mondo "dimezzato", privo di profondità e trascendenza, tutto fantastico, frutto di menti "passionate", avide, invide e accidiose, che pure sono sorprese e travolte da casi che ne sospendono i pregiudizi - e le inquietano.

83 Cf Les six centuries des "Kephalaia gnostica" d'Evagre le Pontique, A. Guillaumont éd., PO 28/1, Paris 1958, 3.70126 e 127 (in questo caso la sentenza è sostanzialmente la stessa in entrambe le recensioni che ci hanno trasmesso l'opera in siriaco). 


\section{Bibliografia}

Bedjan P. (ed.), Mar Isaacus Ninivita, De perfectione religiosa, Paris-Leipzig 1909

Bettiolo P. "Avec la charité comme but": Dieu et la création dans la méditation d'Isaac de Ninive, in Irénikon 63 (1990)

Bettiolo P. (a cura di), Isacco di Ninive, Discorsi spirituali e altri opuscoli, di Magnano (BI) 1990

Beulay R., La lumière sans forme. Introduction à l'étude de la mystique chrétienne syro-orientale, Chevetogne s.d. (1987)

Beulay R., L'enseignement spirituel de Jean de Dalyatha, mystique syrooriental du VIIIe siècle, Paris 1990

Brock S., The Luminous Eye, Roma 1985

Brock S., "Maggnanuta": a Technical Term in East Syrian Spirituality and its Background, in Mélanges Antoine Guillaumont - Contributions à l'étude des christianismes orientaux, Genève 1988 Brock S., St. Isaac of Nineveh and Syriac Spirituality, in Studies in Syriac Spirituality, Poona 1988

Brock S. (ed.), Isaac of Nineveh (Isaac the Syrian), 'The Second Part', Chapters IV-XLI, CSCO 554 (t); 555 (v), Lovanii 1995

Brock S., Some Use of the Term "Theoria" in the Writings of Isaac of Nineveh, in Parole de l'Orient 20 (1995)

Bruns P., Den Menschen mit dem Himmel verbinden. Eine Studie zu den katechetischen Homilien des Theodor von Mopsuestia, CSCO 549, Lovanii 1995

Bundy D., Georges Ier de Kaphra, in Dictionnaire d'Histoire et de Géographie ecclésiastique 20 (1983)

Chabot J.B., Synodicon Orientale ou Recueil de synodes nestoriens, in Notices et Extraits des Manuscrits de la Bibliothèque Nationale 37, Paris 1902

Dedering S. (ed.), Johannes von Lykopolis, Ein Dialog über die Seele und die Affekte des Menschen, Leipzig-Uppsala-Haag 1936

De Halleux A., La christologie de Jean le Solitaire, in Le Muséon 94 (1981)

De Halleux A., Le milieu historique de Jean le Solitaire, in III Symposium Syriacum 1980, R. Lavenant éd., Roma 1983

Devreesse R., Essai sur Théodore de Mopsueste, Roma 1948

Frankenberg W. (ed.), Euagrius Ponticus, Berlin 1912

Gallo M. e Bettiolo P. (a cura di), Isacco di Ninive, Discorsi ascetici/1 L'ebbrezza della fede, Roma 1984

Gignoux P. (éd.), Homélies de Narsaï sur la création, PO 34/3-4, Paris 1968 
Guillaumont A. (éd.), Les six centuries des "Kephalaia gnostica" d'Évagre le Pontique, PO 28/1, Paris 1958

Guillaumont A., Les "Kephalaia gnostica" d'Evagre le Pontique et l'histoire de l'origénisme chez les grecs et chez les syriens, Paris 1962

Harb P., Doctrine spirituelle de Jean le Solitaire (Jean d'Apamée), in Parole de l'Orient 2 (1971)

Hausherr I., Par delà l'oraison pure grâce à une coquille. A propos d'un texte d'Evagre, in Revue d'Ascétique et Mystique 13 (1932)

Hausherr I. (a cura di), Jean le Solitaire (Pseudo-Jean de Lycopolis), Dialogue sur l'âme et les passions des hommes, Roma 1939

Hausherr I., Un grand auteur spirituel retrouvé: Jean d'Apamée, in Orientalia Christiana Periodica 14 (1948)

Hausherr I., Hésycasme et prière, Roma 1966

Hausherr I., Etudes de spiritualité orientale, Roma 1969

Khalifé-Hachem, La prière pure et la prière spirituelle selon Isaac de Ninive, in Mémorial Mgr G. Khouri-Sarkis (1898-1968), Louvain 1969

Macomber W., The Theological Synthesis of Cyrus of Edessa, an East Syrian Theologian of the Mid Sixth Century, in Orientalia Christiana Periodica 30 (1964)

Macomber W.F. (ed.), Six Explanations of the Liturgical Feasts by Cyrus of Edessa - An East Syrian Theologian of the Mid Sixth Century, W.F. CSCO 355, Louvain 1974

Muyldermans J., Note additiommelle à: Evagriana, in Le Muséon 44 (1931) Rignell L.G., Briefe von Johannes dem Einsiedler mit kritischem Apparat, Einleitug und Übersetzung, Lund 1941

Sachau E. (ed.), Theodori Mopsuesteni Fragmenta syriaca, Lipsiae 1869

Scher A. (ed.), Theodorus bar Koni, Liber scholiorum, CSCO 55, Paris 1910 (edizione anastatica: Louvain 1960)

Schlimme L., Der Hexaemeronkommentar des Moses bar Kepha. Einleitung, Übersetzung und Untersuchungen I, Wiesbaden 1977

Scholten C., Antike Naturphilosophie und christliche Kosmologie in der Schrift $<$ De opificio mundi> des Johannes Philoponos, Berlin-New York 1996

Sofri A., Piccola posta, Palermo 1999

Stewart C., "Working the Earth of the Heart" - The Messalian Controversy in history, Texts, and Language to AD 431, Oxford 1991

Van Rompay L., Quelques remarques sur la tradition syriaque de l'Euvre exégétique de Théodore de Mopsueste, in IV Symposium syriacum 1984, H.J.W. Drijvers, R. Lavenant, C. Molenberg and G.J. Reinink eds., Roma 1987

Van Rompay L., Le Commentaire sur Genèse-Exode 9, 32 du manuscript (olim) Diyarbakir 22, CSCO 484, Lovanii 1986

Vosté J.M. et Van Den Eynde C. (éd.), Commentaire d'Isho'dad de Merv sur l'Ancien Testament - I. Genèse, CSCO 126, Louvain 1950 
Wensinck A.J. (a cura di), Mystic Treatises by Isaac of Nineveh, Amsterdam 1923 (ristampa anastatica: Wiesbaden 1969)

Wolska W., La Topographie chrétienne de Cosmas Indicopleustès. Théologie et science au VIe siècle, Paris 1962 


\title{
Autoridad carismática y disidencia religiosa. La hagiografia Siria en los siglos V y VI
}

\author{
Héctor R. Francisco
}

\section{Introducción}

La aparición del fenómeno monástico en la Antigüedad tardía puede ser entendida como la resolución transitoria del problema de la autoridad espiritual en la Iglesia. Desde el siglo I dC. la competencia entre el poder episcopal, basado en la transmisión burocrática de la autoridad a través de la sucesión apostólica; y la autoridad carismática, la que ciertos individuos adquieren a partir de un estilo de vida que los separa del mundo; tuvo su resolución en el siglo VI dC. con la incorporación definitiva de los monjes dentro de la Iglesia. Al mismo tiempo, esto permitió, al monopolizar la sucesión episcopal, la preeminencia del estamento monástico como grupo por sobre el clero secular ${ }^{1}$. Los Concilios de los siglos IV a VI permitieron esta evolución en la medida que la disidencia religiosa al imperio solo pudo ser sustentada a partir de una autoridad carismática, debido a que el clero episcopal no podía sostenerse sin el apoyo imperial. Nuestro objetivo será analizar un aspecto de esta interacción entre poder carismático y poder episcopal dentro del marco el lenguaje político en la Antigüedad tardía. Centraremos nuestro interés en las formas en que la libertad de palabra, asociada al concepto clásico de parrhesía adquiere nuevos significados en el contexto de las disputas cristológicas en el estado tardorromano. Partimos de la definición clásica del término, asociada a las prerrogativas del ciudadano, luego, veremos su desarrollo en el contexto del mundo tardoromano, cuando las tradiciones municipales clásicas se incorporan a los estados autocráticos en el mundo oriental. Allí adquieren nuevas significaciones gracias a su apropiación por parte del discurso cristiano tanto en griego como en siríaco. Partimos de la premisa que esta nueva definición obedece a las transformaciones sociales que se desarrollan en el mediterráneo oriental entre los siglos III y VI y que se reflejan en la ambigüedad del discurso cristiano en su apropiación de los espacios de poder polí-

${ }^{1}$ Sobre el desarrollo de la autoridad en el cristianismo primitivo: Vide Van Copenhausen, Hans Ecclesiastical Authority and Spiritual Power in the Church of the first 3 centuries. Londres, 1997. 
tico. Esta definición no pretende ser exhaustiva ni concluyente, sino que lo iniciamos como primer paso hacia una investigación más extensa de las estrategias de construcción de la estructura (o estructuras) de poder dentro de la Iglesia oriental desarrollada entre los siglos V y VI. Nuestro énfasis en el discurso político dentro del contexto religioso del imperio romano oriental obedece a dos factores. Por una parte la intrínseca relación entre estado y religión que se verifica en el mundo tardorromano oriental y protobizantino; y por otro la transformación del clero provincial en voceros de las elites locales. Esto nos obligará a proyectar las prácticas políticas del clero como hombres públicos sin dejar de lado los aspectos teológicos. En particular, queremos analizar el desarrollo del concepto de parrhesía que se refiere a la libertad de palabra. A través de un análisis de dicho concepto, intentaremos demostrar como en distintos contextos políticos y culturales, adquiere nuevos significados, siempre adaptados a la constitución de una nueva elite que intenta transformarse en interlocutor con el estado. Para esto, debemos recordar que no existe un discurso cristiano monolítico sino una serie de discursos siempre en estado de adaptación y reajuste y siempre listos para absorber de manera oportunista cualquier cosa que pueda ser útil del vocabulario retórico. Gran parte del éxito del cristianismo radica en su capacidad efectiva de crear su propio imaginario que se apoya en la capacidad de resignificación de elementos derivados de la cultura clásica, utilizándolos para sus propios fines².

\section{La parrhesía en el mundo clásico y en Antigüedad tardía}

Para definir el papel de las formas discursivas en las prácticas políticas de la Antigüedad debemos hacer referencia al lugar ocupado por la paideia (como ámbito de cultura compartida por la elite clásica) en la determinación del acceso al poder. Este término, fue generalizado por el filósofo Alemán Werner Jaeger ${ }^{3}$ y se ha convertido en sinónimo de lo que los estudiosos consideran la "cultura clásica", esto es, aquellas manifestaciones del alto mundo intelectual en lengua griega que desde por lo menos el siglo VIII a.C. se desarrollaron en la cuenca del mediterráneo oriental y se extendieron a partir del siglo III a.C. al occidente latino. Este sistema educativo (como lo define

2 Cameron, Averil Christianity and the rhetoric of Empire. Londres, 1991.

3 Jaeger, Werner Paideia. México, 1993 (1933). Idem Cristianismo primitivo y Paideia Griega. México, 1993 (1961). El concepto de párrhesía es utilizado por primera vez en el siglo V aC. y recorre todo el mundo clásico hasta el bizantino. Dicho término surge de la raíz pan-rêma, literalmente decir todo, hablar claramente y en consecuencia el hablante da una explicación completa de aquello que tiene en mente. 
Jaeger) se basaba en una tradición literaria-filosófica de matriz urbana que se remontaba a los poemas homéricos y se había convertido en el símbolo de la unidad cultural de las elites de las ciudades griegas primero, y luego del mundo romano-helenístico. Esta definición cultural del mundo clásico se asocia directamente con las prácticas políticas desarrolladas en el mundo de la paideia clásica y el desarrollo de la palabra como herramienta. La parrhesía (libertad de palabra, hablar con libertad, confianza, claridad de palabra) es un elemento constitutivo de la paideia en tanto es parte de la práctica del discurso político. Así, adquiere especial relevancia en relación con la definición del hombre como zoon politikón que predica la verdad (aletheia) ${ }^{4}$. Para Michel Foucault, la parrhesía como ejercicio verbal de la verdad sin adorno es esencialmente el uso de la crítica a un interlocutor socialmente superior y por la cual, y desde una posición subordinada, se asume el riesgo de irritarlo con el ejercicio de ésta; sin embargo, el parrhesiastés es un hombre libre (ciudadano) y tiene el deber de expresar esa verdad. Por lo tanto, la parrhesía establece una relación íntima entre el que habla y aquello que es dicho ${ }^{5}$. Así podemos distinguir un doble uso clásico del término:

a) En primer lugar un uso más amplio y positivo de la parrhesía como una actividad verbal en donde se establece una correspondencia entre opinión y verdad, es decir, que existe una estrecha conexión entre el hablante y el hablado y por lo tanto se distingue de la retórica.

b) En segundo lugar, un uso despreciativo del término, que el autor asocia a Platón y la tradición cristiana que se definiría como "charlatanería" que impide la contemplación 6 .

Nuestro objetivo es, de aquí en adelante, describir la función de la parrhesía en el contexto del Estado autocrático romano oriental desde dos perspectivas: Por un lado, en la relación entre el Estado y una estructura jerárquica en formación (la Iglesia) y por otro, las relaciones internas de poder y solidaridad en esa estructura en formación y diversificación.

En el siglo III dC. el estado romano ha devenido en una estructura burocrática centralizada en la figura autocrática del emperador. Este proceso es

4 L. Spina, Il cittadino alla tribuna. Diritto e libertà di parola nell'Atene democratica. Nápoles, 1986, pp. 25-6o.

5 ...il parlante rende manifestamente chiaro e ovvio il fatto che ciò che egli dice è la sua personale opinione (...) Nella parresia il parlante sottolinea il fatto che egli è contemporaneamente il soggetto dell'enunziazione e dell'enunciandum, cioè che egli stesso è il soggetto dell'opinione a cui si sta riferendo. Foucault, Michel Discorso e verita nella Grecia antica. Roma, 1997, p 4. 6 Platón La República 577b, Fedro 240e, Las Leyes 649b, 671b. Vide: Bartelink, G.J.M. Quelques observations sur la Parresia dans la littérature paléochrétienne. En: Latinitas Christianorum primaeva, III, pp. 44-45. 
paralelo a la erosión de las viejas tradiciones municipales del Mediterráneo oriental 7 . Dicha erosión se asentaba en la tendencia a la ruralización de las elites provinciales que huían de las pesadas cargas de la política municipal minando el modelo clásico de política forense y dejando lugar a la conformación de una nueva elite compuesta por burócratas imperiales y obispos locales. Éstos conciben una nueva forma de acceso al poder, dejando a la carrera eclesiástica o la burocracia imperial como únicas alternativas de ascenso social a los hijos de la elite provincial8.

Este proceso llega a un punto de maduración cuando, en el año 408, asciende al trono de Oriente Teodosio II. En su reinado se inicia una etapa de enfrentamiento entre teólogos alejandrinos y antioqueños en torno a la relación entre las naturalezas humana y divina de Cristo. Sin embargo, esta disputa no se limitaba a un mero debate teológico; a un nivel más profundo se debate la definitiva formación de una estructura jerárquica dentro de la Iglesia marcada por la lucha de los dos mayores obispados cristianos por el control del emergente obispado de la nueva Roma9 . Estos debates provocan una a serie de concilios que se abren con Éfeso I (431), Éfeso II (449), y Calcedonia (451); dónde se sanciona tanto la fórmula cristológica de "en dos naturalezas sin confusión”, como la estructura jerárquica del canon 28 del concilio de Calcedonia, donde queda definitivamente consolidada la identidad entre estado e Iglesia en el oriente bizantino (en oposición al ecumenis-

7 Jones, A.H.M. The later Roman Empire. Oxford 1964. Morrisson, Cécile \& Sodini, Jean Pierre The Sixth Century Economy. en Laiou, Angeliki (ed.) The Economic history of Byzantium. Vol. 1. Washington DC, 2002, pp. 171-220

8 Véase las amargas quejas de Libanio frente a la decadencia de la retórica forense en Festugiére, A.J. Antioche païene et chrétiene. Libanius, Chrysóstome et les moines de Syrie. París, 1959. Brown, Peter El mundo en la antigüedad tardía. De Marco Aurelio a Mahoma. Madrid, 1989 (1971). Idem Power and persuation in late antiquity. Towards a Christian Empire. Winsconsin, 1992.

9 El debate giró en trono a la resolución del problema del nexo de unión de las naturalezas humana y divina de Cristo El detonante de la controversia será la posición del Patriarca de Constantinopla Nestorio, que rechazó el término theotokos aplicado comúnmente a la virgen María. La negativa a aceptar esta palabra se debía a que suponía el cambio en la physis divina. Durante el concilio de Éfeso los antioqueños aceptaron bajo presión esta palabra aunque muchos (entre ellos Teodoreto) prefirieron el término anthropotokos. Fueron Diódoro de Tarso y Teodoro de Mopsueste los formalizadores de esta escuela teológica. Sus obras nos son sólo en parte conocidas en especial las doctrinas sobre la encarnación del segundo quien fue objeto de ataque de monofisitas y neocalcedonianos en el siglo VI. Durante los siguientes veinte años se cerrará un caso de definición teológico y jurídico que cristalizará la estructura jurisdiccional que prevaleció en la iglesia ortodoxa por mil quinientos años. No nos detendremos en los vericuetos de la discusión cristológica, a nuestro lector recomendamos para conocer una visión actualizada de los debates cristológicos la serie de artículos publicados en Istina XL, 1995. Vide Sozómeno Historia eclesiástica VII, 29. Amman, E. Théodore de Mopsueste. En: DTC, Vol. XV, París, 1946. Quasten, Johannes Op. cit. Vol. 2. pp. MPL LXXVI, Col. 76. Guinot, Jean Noël L' exégese de Cyrille d' Alexandrie et de Théodoret de Cyr: un lieu de conflit ou de convergence? En: Cassiodorus. 4 (1998). pp. 47-82. ibidem La exegese de Théodoret de Cyr. TH 100. París,1995. 
mo cristiano de occidente) ${ }^{10}$. Tanto Teodosio II como sus sucesores jugaron un papel fundamental en estas controversias, buscando diversas salidas, ya sea por el consenso, ya sea por medio de medidas que fueron decididamente coactivas $^{11}$. En consecuencia, el papel del emperador tardorromano como guardián de la ortodoxia eleva a los debates doctrinales del s. V dC. al estatus de "cuestión de Estado"12.

Nuestra intención particular es analizar el papel de la parrhesía en el vocabulario de dos importantes colecciones hagiográficas. Primero la Historia Religiosa de Teodoreto de Cirros, compuesta en griego en los años previos al Concilio de Calcedonia y luego, las Vidas de los Santos Orientales compuesta en siríaco por el monofisita Juan de Éfeso en la década del 580. A pesar del abismo teológico, cronológico y lingüístico que separa ambos autores, tienen en común su conocimiento de primera mano del ascetismo sirio y una posición protagónica en los debates cristológicos en campos diametralmente opuestos. Por lo tanto, justificamos nuestra elección en el hecho de que el concepto de libertad de palabra juega un rol fundamental en el esquema eclesiológico de ambos autores, aunque de manera diferente, determinado por los distintos contextos en que los autores escriben sus obras. En segundo lugar, podremos analizar brevemente la helenización del cristianismo siríaco que alcanza su punto más alto en el siglo VI dC. para decaer en el siglo siguiente con la lenta, pero inexorable, imposición del árabe como lengua franca del oriente ${ }^{13}$.

\footnotetext{
10 No abundaremos en las diferencias en la construcción de las iglesias medievales en occidente y oriente, recomendamos al lector los siguientes títulos introductorios: Castellan, Angel A. La idea de Imperio y la idea de Iglesia en torno a los problemas planteados por el canon 28 del Concilio de Calcedonia (451). En: Anales de Historia Antigua y Medieval, Facultad de Filosofía y Letras, UBA, 1950, pp. 59-84.

${ }^{11} \mathrm{El}$ emperador Zenón con el edicto de unión o Henoticón (482) y el movimiento neocalcedoniano del siglo VI intentaron resolver la distancia entre calcedonianos y monofisitas eludiendo toda alusión al conflicto; en cambio Heraclio, en el siglo VII apoyó las doctrinas monoenergistas o monothelitas que buscaron un punto medio que asegurara el consenso. En cambio, Justino y Justiniano aplicaron varias medidas restrictivas a la difusión de tendencias heterodoxas eliminando a los adeptos mas extremos del diofisismo que se refugiarán en la Iglesia sasánida o persiguiendo (infructuosamente) a los monofisitas.

12 Debemos notar que es imposible entender el desarrollo de las estrategias políticas durante las controversias cristológicas sin incluir mecanismos mucho menos sutiles como la movilización de la plebe urbana o los temibles monjes rurales, sin embargo, dejamos de lado esta cuestión por haber sido ampliamente estudiada. Frend. W.H.C. The rise of monophysite movement. Cambridge, 1972. ibidem The monks and the survival of the east roman empire in the fifth century. En: Past and Present. 54 (1972) pp. 3-24. y Cameron, Alan Circus factions: Blues and greens at Rome and Byzantium. Oxford 1976, Gregory, Th. Vox Populi: Violence and Popular involvement in the religious controversies of the $V$ century $A D$. Ohio, 1979. Teja, Ramón La 'tragedia' de Éfeso (431): Herejía y poder en la Antigüedad tardía, Santander, 1995. Idem La violencia de los monjes como instrumento de política eclesiástica: el caso del Concilio de Éfeso (431). En: Bádenas, Pedro; Bravo, Antonio; y Pérez Martín, Inmaculada (eds.) EPIGEIOS URANÓS El cielo en la tierra. Estudios sobre el monacato bizantino. Madrid, 1997, pp. 1-19.

13 Sobre la interacción del siríaco y el griego: Vide Brock, Sebastián From antagonism to assimi-
} 
Ambos autores reflejan las nuevas formas de acceso al poder establecidas por los Hombres de Iglesia y, en consecuencia, se transforman en figuras de transición entre la cultura tardorromana y la bizantina. Por lo tanto los consideramos como una invaluable fuente de información para el período de las disputas cristológicas. Al analizarlos desde un nuevo punto de vista abrimos el interrogante acerca de los elementos culturales que caracterizan la relación entre una autoridad eclesiástica que define su estructura de poder, la burocracia administrativa y los notables de la corte y las provincias.

Antes de empezar nuestro análisis debemos realizar una advertencia. Repetidas veces se ha hecho hincapié en la carencia de la literatura tardoantigua y bizantina de cualidad expresiva y originalidad. Ciertamente, los escritores del período no expresan sus propios sentimientos ni su mundo psicológico sino mas bien tratan con tópicos y clichés retóricos extraídos de la literatura bíblica o clásica. Así, la retórica en la Antigüedad tardía se presenta como cristalizada y repetitiva y por esto ha sido interpretada como una producción carente de valor ${ }^{14} \mathrm{o}$, como la definiera P. Lemerle una literatura sin público ni problemas ${ }^{15}$. Sin embargo, dichos estereotipos eran una elección conciente del autor, que cumplían importantes funciones estéticas y políti$\operatorname{cas}^{16}$. En primer lugar, era un signo de elegancia que los conectaba con un pasado glorioso (ya sea clásico o bíblico) que legitimaba el discurso del autor, en segundo recreaba el clima de estabilidad que moldeaba la sociedad de su época. Además, los clichés retóricos funcionaban como herramientas políticas en un mundo de aparente inmutabilidad gobernada por una autoridad autocrática (el emperador) y en la cual los débiles lazos sociales entre los individuos se expresaban en un sistema de comportamiento pautado por la amistad (philía) entendida como la relación que nace a partir de los intereses comunes de los individuos, ya sea la cultura común o, en un sentido religioso la tradición. Su educación, su origen familiar y la posición de patronos de sus ciudades - a través de las obras evergéticas - confiere a los interlocutores el prestigio suficiente para legitimar su poder y ser objeto de la obediencia de quienes gozaban de su protección. Estos eran los pilares, junto con la posesión de amplias extensiones de tierra, sobre los que la elite de la Antigüedad tardía sustentó su posición en la sociedad proyectando el ideal de intermediarios entre el soberano y los súbditos. En este juego retórico, los

lation Syriac attitudes to Greek learning. En: Syriac Perspectives on Late antiquity. Aldershot, 1984. pp. 17-34; idem Syriac Culture in the Seventh Century. En: Aram 11989 pp.; idem From Ephrem to Romanos: Interactions between Syriac and Greek in Late Antiquity, Aldershot, 1998. 14 Por ejemplo es la opinión de Marshall F.H. Byzantine literature en Baynes, N.H. y Moss, H. Byzantium. Oxford, 1948, p. 221. o Runcimann, S. Byzantine Civilization. Londres, 1961 p. 240. 15 Lemerle, P. Prolégomènes à une édition critique et comentée des "conseils et Récits" de Kékauménos. Bruselas, 1960, p. 95.

16 Kazhdan A., Constable, G. People and power in Byzantium. Washington, 1982. Cap. 2 
topoi literarios aportan coherencia y legitimidad al discurso, generando un lazo solidario entre emisor y receptor. La asimilación de los elementos retóricos de la parrhesía, es un elemento crucial de la capacidad del discurso cristiano de influir en diferentes niveles, dependiendo del receptor de su discur$\mathrm{so}^{17}$. En este caso, podemos adelantar que la estrategia discursiva del obispo se adapta a cada contexto variando el uso y la connotación del término parrhesía. De esta manera establece diferentes categorías de receptores y, con ellas, diferentes usos del lenguaje con el objetivo es garantizar, a través de éste, una red de intermediación, patronzago o solidaridad.

\section{La parrhesía en la Historia Religiosa}

Ahora, nos corresponde establecer los diferentes usos del término parrhesía para definir su función como topos retórico dentro del primero de los autores. Un análisis de las cartas de Teodoreto de Cirros confirma que esta palabra es parte fundamental de su defensa durante su exilio y deposición en el primer Concilio de Éfeso (449) ${ }^{18}$. El lugar asignado a la libertad de palabra se circunscribe a la nobilitas romana. El linaje, el rango y la cualidad cultural del receptor (que lo coloca en pie de igualdad al emisor) lo convierten en el intermediario necesario frente a la autoridad. Al invocar este ámbito de cultura compartida el autor no sólo promueve la solidaridad con un miembro de la corte, en virtud de una identidad común, sino que también consolida el mayor legado de la antigüedad clásica; el derecho de los ciudadanos a dirigirse abiertamente al poder, lo que constituye la más poderosa arma de persuasión que detenta la elite frente al soberano y funcionarios imperiales. Si bien la retórica, como señala Peter Brown se había transformado a lo largo de la Antigüedad tardía en un lenguaje cristalizado y carente de originalidad, seguía constituyendo la forma de comunicación entre elite y la administración imperial en la que tanto los gobernantes como los gobernados alegaban, con persistencia saber como dirigirse unos con otros como "compañeros servidores de las musas" ya que ambas partes hacían uso del mismo código para conservar la autoridad. Si las peticiones y los consejos iban a ser tomados en cuenta si se hacían en la forma correcta, entonces una orden, si se encuadra-

17 Cameron, Averil, op. cit. Introducción.

18 En las cartas dirigidas a los miembros de la administración imperial y provincial Teodoreto se dirige a sus interlocutores desde el punto de vista de un miembro de la elite al otro. Como consecuencia de esta estrategia, el receptor se constituye como un intercesor frente a la autoridad superior, en calidad de los valores compartidos.Héctor Francisco, Mantente dispuesto a tiempo y fuera de tiempo. Los usos del concepto de parrhesia en las Epístolas de Teodoreto de Cirros, trabajo presentado en el $\mathrm{I}^{\circ}$ Encuentro Argentino de Estudios Bizantinos y del Cercano Oriente Medieval. Buenos Aires 19-21 de Septiembre 2002. 
ba en el mismo tono, debía ser cumplida ${ }^{19}$. En efecto, el obispo esperaba del soberano, a través del cortesano, la sensibilidad ante sus peticiones en virtud de lo que unía a aquellos que, cómo él, compartían la parrhesía según el modelo platónico del "rey filósofo" transformando a la retórica en un control de la violencia. Este acceso al poder se traducía en el derecho a la libre expresión de la elite, la parrhesía a la cual se accedía por la amistad que unía a sus miembros en tanto comunes portadores de la paideia y que otorga la posibilidad de hablar con franqueza frente a los poderosos 20 .

Sin embargo, en la Historia Religiosa desarrolla una concepción de la libertad de palabra basada en un criterio distinto, expresando nuevas situaciones y con ellas nuevos significados. La cultura no es la única manera de ejercer la libertad de palabra, había un personaje que, a través del abandono del mundo, se convertía en el espíritu libre que la ejercía por sí mismo. Esta figura es el filósofo que adquiría, por su superioridad moral, el derecho de ejercer la libre expresión frente al poder ${ }^{21}$. Sus herederos en el mundo cristiano son los "Hombres Santos" como miembros marginales de la sociedad y detentadores del carisma que, en virtud de tales, pueden enfrentar las decisiones del emperador. Teodoreto enfatiza este paralelo entre el "Hombre Santo" y el filósofo y define su vida como un arte (tekhnê) y una filosofía ${ }^{22}$. En este caso la parrhesía deviene el derecho del especialista que puede enfrentar al soberano en su calidad de poseedores de un conocimiento ${ }^{23}$. El "Hombre Santo" que ha abandonado el mundo por su voluntad y la gracia divina adquiere el derecho de asumir el peligro como un nuevo martirio enfrentando el poder temporal a costa de su vida. Apoyado en la legitimidad que supone este abandono de las necesidades y restricciones que atan a la sociedad humana el "Hombre de Iglesia" vuelve a la comunidad debido a un fin más elevado que la simple contemplación. Esta forma de ejercicio de la palabra como virtud ascética tiene como consecuencia el recrear la pasión divina en su defensa de la fe. Notemos que la libertad de palabra en tanto es una virtud ascética tiene su raíz en el dualismo cuerpo-alma típica de la noción ascética de Teodoreto que se basa en la tradición cristológica antioqueña. La voluntad del hombre (como la voluntad de la humanidad de Cristo)

\footnotetext{
19 Brown, Peter op. cit. 1992.

20 Sin embargo, no nos debemos engañar por este modelo ideal ya que la política del imperio romano tardío estuvo lejos de ser ingenua cortesía y detrás de las cristalizadas formas de comunicación entre poder y elite se esconde una intrincada red de influencias que unían al estado con las elites urbanas donde las grandes distancias que separaban la corte imperial. de las provincias creaban y complejo juego de equilibrio entre los intereses de los funcionarios centrales y la elite. Vide Brown, Peter, op. cit. 1992

${ }^{21}$ Brown, Peter, op. cit. 1992.

${ }^{22}$ Los santos cristianos son especialistas (tekhnitai) que, como los atletas, corredores, actores de tragedia, marineros, constructores y médicos ejercen un arte HR Prol. 1-2 y XXXI, 11-15

23 Brown, Peter, op. cit. 1992
} 
se une a la sabiduría divina sin perder su propia individualidad, proyectando los modelos cristológicos a los antropológicos ${ }^{24}$. Esta concepción del "Hombre Santo" como especialista no se circunscribe a la obra hagiográfica de Teodoreto sino que responde a la tradición antioquena iniciada en los discursos de Juan Crisóstomo ${ }^{25}$. Esta idea de la libertad del especialista puede apreciarse en la vida de Afraates, que describe un episodio durante la intervención de los "Hombres Santos" contra los arrianos en Antioquia. Según Teodoreto, Afraates fue uno de los discípulos que recurrieron al anciano Julián durante la disputa ${ }^{26}$. Afraates junto al obispo de Antioquia Flaviano y Diódoro (futuro obispo de Tarso de Cilicia) líderes del clero niceno acuden a los discípulos de Julián quienes viajan hasta el desierto para convencer al anciano de intervenir en la ciudad en defensa de la ortodoxia. Acacio utiliza este discurso:

“...Te mostraré, dijo Acacio, cómo rendirle un mayor servicio que no le has prestado hasta ahora, y te lo diré, no recurriendo a solo un razonamiento sino a través de la enseñanza que ÉL nos ha dado. Pues le preguntó a Pedro si él lo amaba más que a los otros y sabiendo la respuesta a la pregunta antes de la palabra de Pedro. 'Tu sabes bien, Señor que te amo’, él le muestra eso que debía hacer por él para hacerle un servicio: `Si me amas, dijo, haz pastar a mi rebaño y alimenta mis corderos'27. Esto es lo que también falta ser hecho, padre, pues corre riesgo de ser devorado por los lobos, el rebaño que te quiere y quiere tanto, y es propio de los amantes hacer lo que al bien amado plazca" 28 .

Por otra parte, Afraates llega a enfrentar al mismo emperador herético haciendo gala de la parrhesía. La anécdota transcurre en un diálogo sobre las obligaciones de los ascetas. El emperador reprende al anacoreta por haber abandonado la vida solitaria luego de haber hecho profesión de vida monástica. El monje le contesta:

“...Dime, respondió, oh emperador, si fuera una virgen encerrada en el tálamo, si viera que alguno encendiera fuego en la casa de mi padre, ¿qué me aconsejarías hacer, cuando viera la llama encendida y la casa incendiada? ¿Permanecer en el interior y despreciar la casa consumida por el fuego? Pero ¿No me convertiría yo también en presa del fuego? Si, en cambio me dijeses que corriera y llevara el agua, ir de arriba abajo para apagar las llamas; no me censures, emperador, si actúo de la misma manera, pues lo mismo que acon-

24 Para una mas detallada del desarrollo del ascetismo de Teodoreto como extensión de la cristología antioqueña. Vide Drijvers, Han Hellenistic and Oriental origins. En: Hackel, Sergei (Ed.)

The Byzantine saint. Birmingham, 1981. pp. 25-33.

25 Juan Crisostomo Adversus oppugnatores vitae Monasticae.MPG 47, col. 323-384.

${ }^{26}$ HR II, 15-17

27 Jn.21, 15-17

${ }^{28}$ HR II, 16, 27-38. 
sejarías a la virgen encerrada en el tálamo, estoy obligado a hacer a pesar de hacer profesión de vida monástica. Pero si me reprochas de abandonar la soledad repróchate de haber encendido el fuego en la casa de Dios y no a mí por esforzarme en apagarlo"29.

El sentido de la anécdota reside en presentar al lector un modelo de comportamiento. Éste no se define por elementos mundanos (cultura, rango) sino por algo de carácter superior. El "Hombre Santo", como el filósofo, por sus sufrimientos (ya sean voluntarios o no) y a través de su constancia (kartería) se libera de las ataduras del mundo terrenal y asciende a una categoría superior que lo libera de las pasiones que limitan al resto de los hombres. Este patrón se repite en la Historia Religiosa donde el abandono del mundo y el sometimiento de las pasiones en un equilibrio cuerpo-alma incorpora a cierta categoría de hombres entre los notables y les confiere la libertad de palabra. En estos casos se revela un nuevo discurso, en el que los clichés retóricos evidencian un uso del término contrapuesto al anterior. Para describir esta nueva aristocracia espiritual el autor escribe:

\footnotetext{
“...No les ha dado la victoria su naturaleza, pues esta es mortal y llena de múltiples pasiones, pero su voluntad atrae la gracia divina. Amantes y ardientes de la belleza divina ..... ellos han soportado generosamente la insurrección de las pasiones, han soportado vigorosamente las avalanchas de golpes que les propinó el diablo y, diciendo como el apóstol, ellos han mortificado sus cuerpos y lo han reducido a la esclavitud ${ }^{30}$, y así, han calmado el fuego del apetito irracional y obligado a mantenerse tranquila a la furia del apetito. Habiendo dormido así las pasiones por la abstinencia, el descansar en el suelo aplacar sus sobresaltos, ellos han obligado al cuerpo a pactar con el alma y poner un término a su lucha que es parte de la naturaleza"31.
}

La vida ascética se transforma en el paralelo a la vida ciudadana ya que el monasterio constituye un paralelo a la ciudad y se coloca frente vida urbana como una comunidad alternativa, construida sobre principios evangélicos. Teodoreto señala la distinción radical que separa el espíritu de uno y otro tipo de vida, mientras que la vida de la polis se rige por las leyes humanas, la vida ascética se define por el amor a Dios y la renuncia al mundo para asegurar las condiciones más favorables para alcanzar el fin fijado a los cristianos por el bautismo. Por ejemplo, en la Vida de Jacobo de Nísibis refiriéndose al crecimiento espiritual del santo alude a sus poderes taumatúrgicos explicándolos desde el punto de vista de su influencia ante la corte celestial:

${ }^{31}$ HR: Prol., 5. 
“...y así, su libertad de palabra hacia Dios día a día y como pedía a Dios aquello que deseaba pedir, él lo obtenía de inmediato”32.

La metáfora política del poder taumatúrgico de los santos cumple la funcionalidad de legitimar la autoridad carismática e individual que se adquiere por medio de la ascesis. La asociación entre milagro y libertad de palabra ante Dios es el tópico dominante en la HR ${ }^{33}$. En cambio, son escasas las referencias a la libertad de palabra en un sentido estrictamente político. Si bien son numerosos los episodios en los que los santos se enfrentan a los poderes civiles, sólo en tres episodios alude claramente a la autoridad espiritual del santo. Los dos primeros aparecen en la biografía del anacoreta de la montaña adyacente a Antioquia, Macedonio. El primero de ellos es la divertida descripción de la furia del santón por su ordenación forzada por el obispo de Antioquia $^{34}$. Teodoreto siente la necesidad de explicar el comportamiento del anacoreta (que resulta contradictorio con el plan general de la obra, que describe un ascetismo perfectamente subordinado a la jerarquía episcopal) y lo enmarca en la simplicidad de espíritu.

A diferencia del uso clásico del término, la libertad de palabra del santo es fruto de su misma falta de cultura y de una sabiduría espiritual opuesta a la paideia. Por otra parte, el término se asocia a topoi bíblicos que establecen modelos de conducta. Estos modelos son los héroes de la historia bíblica: los patriarcas, los profetas y los apóstoles. La tipología bíblica es el fundamento de este modelo de parrhesía en tanto práctica ascética y testimonio del carisma divino: la libertad de palabra frente a Dios es asociada en varias oportunidades a los patriarcas y profetas y por extensión lógica a los santones y obispos contemporáneos, continuadores de un modelo histórico. Los paradigmas bíblicos cumplen un papel fundamental en una filosofía de la historia presente en los trabajos históricos de Teodoreto y que se proyectan a sus propias estrategias retóricas epistolares. De esta manera, tanto en el Antiguo Testamento como en el Nuevo se prefiguran todos los aspectos del ascetismo tal como lo concibe Teodoreto y, en consecuencia, la vida ascética constituye una vida no sólo angélica sino también una vida bíblica y cumple fines pedagógicos ${ }^{35}$.

Podemos observar que la parrhesía del "Hombre Santo" es efecto y a la vez causa de su ubicación en la periferia de la sociedad. Tanto ante Dios como frente al poder temporal, la libertad de palabra es un atributo de la Gracia divina y de la libre voluntad del individuo y se extiende como derecho. El "Hombre

32 HR, I, 3, 8-9

33 Vide $H R$, III, 9, 1-2; HR, VII, 3, 22-23; VIII, 9-15; HR, IX, 7, 5-7; HR, XVIII, 4, 13

$34 \mathrm{HR}, \mathrm{XIII}, 4$

35 Krueger, Derek Typological figuration in Theodoret of Cyrrhus Religious History and the art of postbiblical Narrative. En: JEChS 5:3 (1998) pp. 393-419. 
de Iglesia" ejerce esa libertad frente a los poderes terrenos y la convierte en práctica ascética (y extensión del martirio) desde el momento que se arriesga la vida y en consecuencia se adquiere la libertad de palabra ante Dios por esa misma causa. Estos motivos claramente hagiográficos tienen, una presencia notable en las obras históricas: el ejercicio de la libertad de palabra del "Hombre Santo" es la imitatio Christi, esto es, revivir la vida angélica de Cristo y los apóstoles en el presente. El santo, en tanto es libre de las pasiones mundanas y ha adquirido, por imitación, el carisma divino, adquiere el derecho de defender la "verdadera doctrina" aún si las condiciones son adversas.

\section{La parrhesía en Juan de Éfeso}

Compuestas casi 120 años después de la muerte de Teodoreto, las Vidas de los Santos orientales escrita por Juan de Éfeso (507?-589?) retoma el problema de la libertad de palabra del "Hombre Santo" incorporando vívidos testimonios de las persecuciones a los disidentes religiosos durante los reinados de Justino y Justiniano. Por lo tanto, las Vidas nos proveen importante información acerca de las estrategias de resistencia en los círculos monásticos de Siria y Mesopotamia a la imposición de la definición de dos naturalezas sin separación ni confusión. Las historias, compuestas en un estilo más crudo y menos protocolar que sus contemporáneos, fueron escritas en un Siríaco que evidencia la creciente helenización de la literatura siríaca durante los siglos $\mathrm{V}$ y VI ${ }^{36}$. Esta colección de retratos de los monjes anticalcedonianos están compuesta siguiendo un criterio similar a la Historia Religiosa aunque en un estilo menos sereno y donde la polémica teológica es el centro articulador del relato. Por esta razón, Juan incluye con mayor frecuencia discursos de sus héroes y las historias se desarrollan en un contexto político mas preciso donde la libertad de palabra se tiñe de un tono polémico.

Juan fue educado en un monasterio sirioparlante de alta Mesopotamia aunque adquirió un buen dominio del griego, lo que le valió su posición de portavoz del partido anticalcedoniano en la corte de Justiniano bajo la protección de la emperatriz Teodora. Como dijimos, el lenguaje de la Vidas de los Santos Orientales evidencia un alto grado de helenización, en especial en el vocabulario y la sintaxis, resultando un relato por momentos arduo y de difícil lectura. Sin embargo, la elección de mantener el siríaco para la composición puede ser explicado por razones políticas. En efecto, Juan escribe en el momento en que los acontecimientos impiden cualquier reconciliación entre ambos partidos, y en el momento en que una estructura episcopal anticalce-

${ }^{6}$ Ashbrook Harvey, Susan Ascetism and Society in Crisis. John of Ephesus and the Lives of the Eastern Saints. Berkeley, 1990, pp. 34-37. 
doniana se ha fortalecido (aunque de manera clandestina) en Siria, Mesopotamia y Egipto, pero que ha sido prácticamente erradicada de las zonas grecoparlantes ${ }^{37}$. Por lo tanto, Juan escribe en la lengua de sus partidarios en los monasterios de las áreas rurales, lejos de la corte o las grandes ciudades (donde el clero monofisita apenas sobrevive). Es este alto grado de penetración del vocabulario griego el que nos interesa. Mucho del vocabulario ascético o político de la hagiografía griega se encuentra presente en Juan, a pesar de poder recurrir a equivalentes siríacos ${ }^{38}$. Es precisamente en las Vidas donde el término parrhesía adquiere una importancia mayor. Se halla simplemente transliterado (parhesya'), sin embargo, la utilización como término político se halla mucho más extendido, contrapuesto a la idea de ' $n n q$ ' (anankê) (en el sentido de obligación o compulsión, falta de libertad). Esquemáticamente, comprende los siguientes campos semánticos:

1. Confianza ante Dios de los santos

2. Libertad de lenguaje frente a la autoridad civil

3. Familiaridad o confianza con líderes monásticos

De estos tres usos de la libertad de lenguaje, es el tercero el que provoca menos problemas de interpretación; indicando la confianza del discípulo frente al maestro ${ }^{39}$. En cambio, en los dos primeros usos, la incorporación del término griego adquiere una significación más rica al entrar en juego con términos de origen semítico. Este juego permite a Juan desarrollar su concepción del carisma de los santos, en el que la libertad de palabra es, en primer lugar, un don divino que se adquiere a través de la simpleza, la práctica ascética y la constancia en la recta fe:

\footnotetext{
“...Incluso las cosas que hemos repetido lo hemos repetido por la gloria de Dios, y como el amor de Dios hacia los que lo aman y cumplen sus mandamientos puede ser conocido a nosotros ordinarios ( hdywt') y simples (pshytt'), y cuan grande libertad de palabra (parhesia') da Dios ante él a sus servidores (l`abdwhy)" ${ }^{40}$.
}

En este caso, nos encontramos de nuevo frente a la oposición sabiduría del mundo frente a la sabiduría espiritual del santo. Los simples (pshytt' equivalente del griego aploos) y ordinarios (hdywt' idiotês) son términos propios del vocabulario hagiográfico para calificar a los monjes, simples y rústicos, y,

37 Ashbrook Harvey, Susan, op. cit. pp 40-42.

38 Enumeramos algunos términos en una lista que, si bien no es completa, sí es indicativa.Del vocabulario político: swnqlytws, 'cswry', pwlyty', nmws', mtwny', 'gwn', 'nnq', prswp', t'wry'.

39 Vide, por ejemplo Juan de Éfeso, op. cit. p. 163.

40 Juan de Éfeso, op. cit. p. 72. 
como tales, opuestos a las formas artificiosas de la vida en el mundo. Por lo tanto, los poderes taumatúrgicos concedidos a los santos se inscriben en el simbolismo de la corte celestial donde Dios, en tanto es monarca concede la libertad de dirigirse abiertamente a los hombres que son sus servidores ('abde’). Juan remarca la fuerza del discurso de los santos frente a la artificialidad del discurso de los herejes que apelan al discurso elegante para difundir sus doctrinas. Un ejemplo de esta concepción es la vida de Z`ura, donde los monofisitas de Constantinopla se enfrentan a los obispos imperiales en un debate frente al emperador.

\begin{abstract}
“...Y cuando el anciano y los que estaban con él entraron, y las doctrinas que fueron condenadas fueron expresadas de manera elegante (mshyn'yt) aquellos que estaban en lo correcto expresaron de nuevo heroicamente con lenguaje llano por el bien de los creyentes a través del bendito hombre con la libertad de palabra de su Señor(bparhesia' dmoreh) y la confianza (twcln') que enfrenta a la muerte, mientras que el bendito procedía de esta manera de acuerdo a lo que esta escrito que el rey de Edom ordenó: ' No debatirás ni con grande ni con pequeño salvo con el rey de Israel' ${ }^{11}$ pues el no dirigió su debate ni a grandes ni a pequeños sino a aquel que rugía como un león, y buscaba a quién devorar” 42 .
\end{abstract}

Este fragmento deja en claro las diferencias entre los teólogos imperiales y el santo. Mientras que los primeros utilizan palabras elegantes y sutíles, el santo dirige su discurso directo al emperador que es asociado a un león furioso, enfrentando el peligro de muerte. Para Juan, la libertad de palabra no pertenece al santo, y mucho menos al emperador sino a Dios. Por otra parte, el valor y constancia del santo (justificada, como es debido, desde el punto de vista de tipología bíblica) se opone a la furia del rey, quién teme castigar la temeridad del santo:

“...Cuando el rey a causa del temor hacia él (Dios) tuvo miedo de poner su mano sobre el hombre bendito a causa de la libertad de palabra divina (parhesia' 'alohto' ) que poseía, se excitó por la ira"43.

Juan deja en claro a su lector que el origen de la libertad del santo no es su propia temeridad sino Dios mismo, que le concede gracias a su condición espiritual. Por la misma razón el emperador, a pesar de su ira, no se atreve a castigar al santo. Este juego de oposiciones (discurso artificioso de los calcedonianos, ira del emperador, libertad del santo) permite percibir al lector la autoridad del santo que se inserta en la historia bíblica a través de la tipolo-

${ }^{41}$ I Reyes 22:31

42 Juan de Éfeso Vidas de los Santos Orientales. PO 17 p. 23

43 Juan de Éfeso, op. cit. p. 23 
gía y prueba su autoridad espiritual. Más adelante, la autoridad del santo no se detiene en la mera defensa de una doctrina contra los teólogos imperiales sino en los signos producidos en la persona misma del emperador. En un episodio que tiene su correlato en Procopio ${ }^{44}$, Justiniano es atacado por la locura y la misma emperatriz Teodora ruega al santo su oración. La intercesión del santo restablece la cordura del emperador quién concede la libertad de palabra a los creyentes.

\footnotetext{
“...cesó aquella violencia y los maltratos, mientras el poder de la oración del anciano dio de ahí en mas libertad de palabra a todos los creyentes en toda ciudad y lugar, y realizaron asambleas abiertamente (knwshye' gly'yt ..." ${ }^{\prime 45}$.
}

Otro de los tópicos preferidos por Juan es la intervención de los santos en los conflictos suscitados dentro de la sociedad. Esta característica propia de la hagiografía oriental durante el siglo VI dC. ha sido estudiada con detenimiento por Susan Ashbrook Harvey ${ }^{46}$ en su trabajo sobre Juan de Éfeso. Mientras Teodoreto apenas menciona este tipo de intervenciones, Juan repite una y otra vez cómo los santos castigan terratenientes y magistrados por sus abusos. Harvey ha mostrado claramente (aunque de manera superficial) la influencia de los momentos críticos vividos por el norte de Siria y Alta Mesopotamia durante el siglo VI (las guerras con los persas, las catástrofes naturales y la asfixiante presión del estado romano sobre las elites provinciales) en la obra de Juan de Éfeso. Pero a la vez, Juan expresa la necesidad de crear una nueva base de poder para una facción que ha perdido gran parte de su sustento en la corte y los magistrados imperiales, y ha sido excluida de la sucesión episcopal. Esta crisis del mundo rural es la que llevó a Peter Brown a describir la función de los santos en la Antigüedad tardía como "patronazgo" 47 ejercido por las elites eclesiásticas en el contexto de la disolución de las estructuras sociales del mundo oriental. Del análisis de las biografías de Juan podemos incluir esta visión parcial del "Hombre Santo" en la perspectiva más amplia de la construcción de una autoridad que, excluida de la sucesión episcopal controlada por la jerarquía calcedoniana, construye su autoridad desde la intervención carismática de los santos en la sociedad.

Para Juan, a diferencia de Teodoreto, el centro de la atención se ha movido de la práctica ascética a la constancia en la ortodoxia. En ambos autores la

44 Hist. Arc. XII, 23. H.B. Dewing (ed.) Loeb Classical Library, Nueva York y Londres 1914-35. Vol. 2

45 Juan de Éfeso, op. cit. p. 25-26

46 Ashbrook Harvey, Susan Ascetism and Society in Crisis. John of Ephesus and the Lives of the Eastern Saints. Berkeley, 1990.

47 Brown, Peter The rise and function of the Holy man in Late antiquity. En: JRS 61, 1971, pp.80101. reimpr. Brown, Peter, op. cit. 1982, pp. 103-152. 
tensión entre la imposición del retiro monástico y la participación en el mundo se resuelve por la legitimidad carismática de los monjes aunque por distintas razones. Tanto el obispo grecoparlante de Cirros como el sirioparlante de Éfeso reconocen en los monjes el centro de la resistencia contra la herejía. Tanto los anacoretas del siglo $\mathrm{V}$ como las grandes comunidades del VI funcionaron como reductos de disidencia teológica en la conformación de la ortodoxia, y, por esto, eran los únicos capaces de exhibir autoridad cuando el Estado abrasaba la herejía. Sin embargo, ambos autores escriben sus colecciones en contextos diferentes. El primero centra su interés en la incorporación del movimiento ascético sirio dentro de los límites de la Iglesia imperial, mientras que el segundo dentro de una jerarquía en descomposición (fruto de la persecución estatal) que busca nuevas fuentes de legitimidad en el poder taumatúrgico y su participación activa dentro de la sociedad. Por eso, el sentido de las historias de las Vidas es una forma de construir un poder sobre bases diferentes. Las biografías de Juan de Tella ${ }^{48}$ y Jacobo Burdoyo ${ }^{49}$ expresan con mas claridad esta necesidad mediante las ordenaciones masivas del clero anticalcedoniano, pero éste carece de la legitimidad del clero Imperial, ¿cuál es la solución? El poder carismático.

\section{Conclusión}

Hemos intentado mostrar que la libertad de palabra juega un papel fundamental en la relación entre el poder carismático (de los santos) y los poderes políticos (tanto religiosos como civiles) en las estrategias de acomodación del discurso cristiano dentro de las esferas de poder del Imperio tardío. Además, a través de dos textos hagiográficos hemos visto la multiplicidad de significados que adquiere el término a través de la utilización de topoi y clichés que dan sentido al discurso. En el mundo clásico, la parrhesía era el derecho del ciudadano a usar la palabra en la comunidad de iguales, en la Antigüedad tardía establece lazos de comunicación verticales entre los miembros de la elite y los poderes superiores del estado. En cambio, la hagiografía expresa una comprensión particular de la libertad de palabra como práctica ascética unida a la idea de autoridad carismática. Los hagiógrafos del siglo V y VI (tanto en griego como en siríaco) conciben la parrhesía unida a la práctica ascética y a la libertad espiritual que conlleva. Sin embargo, el relativamente estable contexto del siglo V contrasta con las convulsiones teológicas y sociales del VI . Dicho cambio de clima volcará el equilibrio hacia un concepto político asociado a la libertad de los disidentes a expresar su verdad frente al poder temporal.

48 Juan de Éfeso, op. cit. Cap. 24.

49 Juan de Éfeso, op. cit. Cap. 49. 


\section{Bibliografia}

Ashbrook Harvey S., Ascetism and Society in Crisis. John of Ephesus and the Lives of the Eastern Saints. Berkeley, 1990

Bartelink G.J.M., Quelques observations sur la Parresia dans la littérature paléochrétienne. En: Latinitas Christianorum primaeva, III

Brock S., From antagonism to assimilation Syriac attitudes to Greek learning. En: Syriac Perspectives on Late antiquity. Aldershot, 1984, pp. 17-34

Brock S., From Ephrem to Romanos: Interactions between Syriac and Greek in Late Antiquity, Aldershot, 1998

Brock S., Syriac Culture in the Seventh Century. En: Aram 11989

Brown P., El mundo en la antigüedad tardía. De Marco Aurelio a Mahoma. Madrid, 1989 (1971)

Brown P., Power and persuation in late antiquity. Towards a Christian Empire. Winsconsin, 1992

Cameron A., Christianity and the rhetoric of Empire. Londres, 1991

Cameron A., Circus factions: Blues and greens at Rome and Byzantium. Oxford 1976

Castellan A.A., La idea de Imperio y la idea de Iglesia en torno a los problemas planteados por el canon 28 del Concilio de Calcedonia (451). En: Anales de Historia Antigua y Medieval, Facultad de Filosofía y Letras, UBA, 1950, pp. 59-84

Drijvers H., Hellenistic and Oriental origins. En: Hackel S. (Ed.) The Byzantine saint. Birmingham, 1981, pp. 25-33

Festugiére A.J., Antioche païene et chrétiene. Libanius, Chrysóstome et les moines de Syrie. París, 1959

Foucault M., Discorso e verita nella Grecia antica. Roma, 1997

Francisco H., Mantente dispuesto a tiempo y fuera de tiempo. Los usos del concepto de parrhesia en las Epístolas de Teodoreto de Cirros, trabajo presentado en el $\mathrm{I}^{\circ}$ Encuentro Argentino de Estudios Bizantinos y del Cercano Oriente Medieval, Buenos Aires 19-21 de Septiembre 2002

Frend W.H.C., The monks and the survival of the east roman empire in the fifth century. En: Past and Present. 54 (1972), pp. 3-24

Frend W.H.C., The rise of monophysite movement. Cambridge, 1972

Gregory Th., Vox Populi: Violence and Popular involvement in the religious controversies of the $V$ century AD. Ohio, 1979

Guinot J.N., L'exégese de Cyrille d'Alexandrie et de Théodoret de Cyr: un lieu de conflit ou de convergence? En: Cassiodorus. 4 (1998). pp. 47-82

Guinot J.N., La exegese de Théodoret de Cyr. TH10o, Paris, 1995 
Jaeger W., Paideia, México, 1993 (1933)

Jaeger W., Cristianismo primitivo y Paideia Griega. México, 1993 (1961)

Jones A.H.M., The later Roman Empire. Oxford 1964

Kazhdan A., Constable G., People and power in Byzantium. Washington, 1982

Krueger D., Typological figuration in Theodoret of Cyrrhus Religious History and the art of postbiblical Narrative. En: Jecks 5:3 (1998), pp. 393-419.

Lemerle P., Prolégomènes à une édition critique et comentée des "conseils et Récits" de Kékauménos. Bruselas, 1960

Marshall F.H., Byzantine literature en Baynes N.H. y Moss H., Byzantium, Oxford, 1948

Morrisson C. \& Sodini J.P., The Sixth Century Economy. en Laiou, Angeliki (ed.) The Economic history of Byzantium. Vol. 1. Washington DC, 2002, pp. 171-220

Runcimann S., Byzantine Civilization. Londres, 1961

Spina L., Il cittadino alla tribuna. Diritto e libertà di parola nell'Atene democratica. Nápoles, 1986

Teja R., La 'tragedia' de Éfeso (431): Herejía y poder en la Antigüedad tardía, Santander, 1995

Teja R., La violencia de los monjes como instrumento de política eclesiástica: el caso del Concilio de Éfeso (431). En: Bádenas P., Bravo A. y Pérez M.I., (eds.) EPIGEIOS URANÓS El cielo en la tierra. Estudios sobre el monacato bizantino, Madrid, 1997, pp. 1-19

Van Copenhausen H., Ecclesiastical Authority and Spiritual Power in the Church of the first 3 centuries. Londres, 1997 


\title{
Liturgia y apocalíptica en Bizancio: Notas sobre la leyenda del Trisagion
}

\author{
Pablo Ubierna
}

Las ideas cristianas sobre el fin del mundo, los alcances sociales y políticos de las "esperanzas" contenidas en los textos de la tradición apocalíptica y la forma en que los poderes institucionalizados, jerarquías eclesiásticas e imperiales, se relacionaron con ellos es uno de los aspectos más sobresalientes de la historia intelectual de la Antigüedad Tardía?.

Textos de esperanza apocalíptica, crónicas y anales, exégesis de la Escritura, calendarios y cómputos fueron todos ensayos tendientes a administrar un tiempo, el de la historia humana, siempre fugitivo.

En el caso de la tradición occidental las exégesis del apocalipsis y los cambios en el cómputo de la historia tendieron a hacer del discurso apocalíptico un elemento menor dentro de una visión de la historia marcada por un fuerte saber eclesiológico ${ }^{2}$. En Bizancio el libro del Apocalipsis tuvo una aceptación controvertida por lo cual su circulación fue restringida y tuvo pocos comentadores $^{3}$. La exégesis pro-imperial de la tradición apocalíptica se cen-

\footnotetext{
${ }^{1}$ La bibliografía al respecto es inmensa y se acrecienta día a día. Nos permitimos referir al lector a un artículo propio. $C f r$. Pablo Ubierna, «Fin de los tiempos, milenio y exégesis del Apocalipsis en el cristianismo tardo-antiguo y bizantino», Byzantion Nea Hellás 19-20 (2000-2001), pp. 189-211.

${ }^{2}$ Con la conversión al cristianismo el imperio (que todavía pagano había sido ya entendido en términos providencialistas por hombres como Orígenes y Melitón de Sardes) cesó en su persecución al cristianismo. Ese imperio, otrora «typo» de la bestia descripta en el Apocalipsis de NT devino en el centro de una nueva interpretación. El «reino» anunciado en el controvertido capítulo XX del Apocalipsis fue entendido, en una exégesis que comenzó con el donatista Ticonio y fue universalizada por san Agustín como «la iglesia ya existente entre nosotros», interpretación que no requería el final de un régimen político devenido protector de los cristianos. Cfr. R. Landes, «Millenarismus absconditus. L'historiographie augustinienne et le millénarisme du haut Moyen Âge jusqu'à l'an mil», Le Moyen Âge 1992, 3-4; pp. 355-377 y 1993, 1; pp. 5-26. Sobre la «edades del mundo", ver en primer lugar el trabajo ya clásico de A. Luneau, L'histoire du salut chez les Pères de l'Église. La doctrine des âges du monde (Théologie Historique 2), Paris, 1964.

$3 \mathrm{El}$ texto muchas veces fue copiado junto a otros apócrifos. En comparación con occidente el número de comentarios hasta el siglo X es muy breve. Conservamos aquellosde Ecumenio a principios del siglo IV (ed. M. de Groote, Oecumenii Comentarius in Apocalypsim, Lovaina, 1999), Andrés de Cesárea, a fines del siglo VI, (ed. J. Schmid, Studien zur Geschichte des griechischen Apokalypse Textes, 2 vols, Munich, 1955) y de Aretas, en el siglo X (ed. J. Schmid, op.cit.).
} 
tró, entonces, en los textos relativos a Daniel. El libro de Daniel ofrece un cuadro histórico, el de los "cuatro imperios" en el que el último será seguido, antes del Juicio, por el Reino eterno de Dios${ }^{4}$. La "escatología imperial” bizantina se encontraba ligada a un esquema cuya validez era acentuada por el paso de los siglos 5 .

En relación con los sistemas de cómputo del tiempo, el cristianismo griego estableció su era mundi (AM) en los primeros siglos de nuestra era (ca. 100250)6 . El cristianismo latino hizo dos revisiones mayores de su sistema de datación entre el 250 y el 850, antes de abandonar AM a favor del Annus Domini 7 . Si bien la tradición griega no cambió su sistema de datación, la cercanía del annus mirabilis $6000^{8}$ supuso grandes esfuerzos explicativos que hacían caer esa fecha desde el 492 hasta el 508. Esta "esperas escatológicas" alrededor del año $500^{9}$ fueron brillantemente estudiadas por Wolfram Brandes ${ }^{10}$ y el resultado de sus investigaciones nos obligan a matizar o abandonar las aseveracio-

4 Cfr. en primer lugar G. Podskalsky, Byzantinische Reicheschatologie, Munich, 1972; P. Alexander, The Byzantine Apocalyptic Tradition, Los Angeles, 1985 y A. Pertusi, Fine di Bisanzio e fine del mondo, Roma, 1988.

5 Hasta el definitivo fin del imperio, claro está. La decadencia y posterior caída de Constantinopla potenció, empero, una literatura apocalíptica por lo general signada por una lectura negativa de la alianza con los latinos. Cfr. G. Podskalsky, «Der Fall Konstantinopels in der Sicht der Reicheschatologie und der Klagelieder», Archiv für Kulturgeschichte 57 (1975), pp. 71-86; J.L. van Dieten, «Politische Ideologie und Niedergang im Byzanz der Palaiologen», Zeitschrift für Historische Forschung 1979, 1, pp. 1-35; A. Argyriou, Les exégèses grecques de l'Apocalypse à l'époque turque (1453-1821), Salónica,1982 (primera edición en griego, 1979) y finalmente los diversos artículos contenidos en B. Lellouch y S. Yerasimos, eds, Les traditions apocalyptiques au tournant de la chute de Constantinople (Varia Turcica XXXIII), Paris, 1999.

6 La obra clásica es la de H. Gelzer, Sextus Julius Africanus und die byzantinische Chronographie, Leipzig, 1880, reimpr. Nueva York, 1967. Ver también V. Grumel, La Chronologie, Paris, 1958 y W. Adler, Time Immemorial. Archaic History and its sources in christian chronography from Julius Africanus to George Syncellus, Washington, 1989.

7 Cfr. R. Landes, «Lest the Millenium be fulfilled. Apocalyptic expectations and the pattern of Western Chronography 100-800 CE», en W. Verbecke et alii, eds, Use and Abuse of Eschatology in the Middle Ages, Lovaina, 1988; pp. 137-211.

8 En la Epístola de Bernabé aparecen ya mencionados los textos que serán la base de la cronografía cristiana : Dios terminó su obra en seis días (Génesis 1) y para Dios, un día es como mil años (Salmo 89/90). Dado que al séptimo día, Dios descansó, el universo llegará a su fin al término de 6000 años. Cfr. P. Prigent y R. Kraft, eds, L'épître de Bernabé (SC 172), Paris, 1971, pág. 185. La semana cósmica también aparece en Ireneo, Adv. Haer., V, 28, 3 y en Hipólito, In Dan., IV, 23, 1-6. Cfr. P. Ubierna, op. cit, pp. 190-197.

9 en esos años podemos datar la redacción de numerosos textos apocalípticos como la VII Visión de Daniel (ca. 480) de la que conservamos una traducción armenia de un original griego hoy perdido (Gr. Kalemkiar, «Die siebente Vision Daniels», Wiener Zeitschrift für die Kunde des Morgenlandes VI (1892); 109-136 (texto) et 227-240 (traducción).)o el Oráculo de Baalbek (ed. P. Alexander, The Oracle of Baalbek, Washington, 1967) escrito hacia el 502. Incluso el De Cursu Temporum de Hilariano, escrito hacia el 397, esperaba el fin del mundo en el 498 (ed. K. Frick, Chronica Minora, Leipzig, 1893).

10 W. Brandes, «Anastasios O Dikoros: Endzeiterwartung und Kaiserkritik», Byzantinische Zeitschrift, 1997-1, pp. 24-63. 
nes de generaciones precedentes de investigadores para quienes la espera del fin del mundo no había tenido lugar en el mundo bizantino ${ }^{11}$.

Pero apocalipsis y cómputos del tiempo no fueron los únicos textos en los que se vieron reflejadas estas tensiones. Tanto la historiografía bizantina como la siríaca se hicieron eco de esa búsqueda hermenéutica. Es el caso de la obra de Malalas hacia el $530^{12}$ con una constante actualización de las fechas relativas al problemas de las "edades del mundo"13. Preocupación semejante encontramos en su contemporáneo, Josué el Estilita quien presenta en su crónica siríaca los temores relacionados con la llegada del año $6000^{14}$. Malalas era consciente de la importancia de ciertas fechas en relación con las angustias escatológicas, sobre todo bajo el reinado de Anastasio ${ }^{15}$. El fin del milenio en tiempos de Anastasio era también esperado, como ya hemos dicho, entre otros, por el Oráculo de Baalbek ${ }^{16}$. Ecos de esto encontramos todavía en la crónica siríaca del 846. La historiografía siríaca en particular parece haber dado una gran importancia escatológica a las catástrofes naturales debidas, de acuerdo con los textos, a la controversia cristológica entre calcedonianos y monofisitas ${ }^{17}$.

Pero la importancia de estas "esperas escatológicas" debemos sin duda buscarla por debajo del fárrago de apologías destinadas a combatirlas. Malalas tiene mucho cuidado en intentar refutar los argumentos sobre las que parecían estar fundadas ${ }^{18}$.

\footnotetext{
${ }^{11}$ A. Vasiliev, «Medieval Ideas on the End of the World: East and West», Byzantion 16:2 (19423); p. 469.

${ }^{12}$ Cfr. Elizabeth Jeffreys, Michael Jeffreys y Roger Scott, The Chronicle of John Malalas (Byzantina Australiensia 4), Melbourne, 1986. Cfr. también A. Jeffreys, «The attitude of Byzantine Chroniclers towards Ancient History», Byzantion 49 (1979), pp. 199-238; Roger Scott, «Malalas, the Secret History and Justinian Propaganda», Dumbarton Oaks Papers 1985, pp. 99-109 y E. Jeffreys, Studies in John Malalas (Byzantina Australiensia 6), Sydney, 1990.

13 Cfr. E. Jeffreys, «Malalas' use of the Past» en Reading the Past in Late Antiquity, Graeme Clarke, ed. Melbourne, 1990.

14 William Wright, ed, The Chronicle of Joshua the Stylite, Cambridge, 1882 (reimpr. Amsterdam, 1968).

15 Malalas, Chronographia, ed. L. Dindorf, Bonn, 1831 (reimpr. PG 87), pp. 392-409 para el reinado de Anastasio (año 491) y para el reinado de Justiniano (años 528-29).

${ }^{16} \mathrm{El}$ texto fue redactado durante el reinado del emperador Anastasio (491-518), bajo la impresión deprimente que produjo la derrota de los ejércitos bizantinos durante los dos primeros años de la guerra contra el monarca persa Kawad I, lo que sitúa la redacción hacia el 503/504. El contexto literario es el de los oráculos o profecías clásicas atribuídas a la Sibila Tiburtina y su autor era originario de la región de Heliópolis-Baalbek en Siria. El texto fue editado por Paul Alexander, The Oracle of Baalbek. The Tiburtine Sibyl in Greek Dress, Washington, 1967. Una versión latina fue editada por E. Sackur en sus Sibyllinische Texte, p. 177 y ss. y otra por G. Waitz, Vaticinium Sibyllae, MGH, Scrp., XXII, p. 375 y ss. Ver también C. Capizzi, «L'imperatore Anastasio I e la Sibilla Tiburtina», Orientalia Christiana Periodica, 36 (1970), pp. 377-406.

17 Cfr. Susan Ashbrook Harvey, «Remembering Pain: Syriac historiography and the Separation of the Chuch», Byzantion 58 (1988), pp. 295-308.

18 Por ejemplo el excursus cronológico que Malalas (cfr. Malalas, op. cit., p. 391) inserta al
} 
Josué es Estilita, por su parte, escribió durante el reinado de Anastasio y a pedido de un tal Sergio, abad de un monasterio cerca de Edesa, una "Crónica" sobre los últimos siglos de la historia humana. En variadas oportunidades, Josué recuerda a sus lectores el hecho de que Dios envió una serie de cataclismos aparecidos durante esos años para castigar a los hombres por sus pecados y obligarlos a enmendar sus conductas. Lo que a Josué le interesa es subrayar el carácter moralizador de la aparición de dichos cataclismos. Pero no se trataba, se encarga también de subrayar, del fin del mundo. El carácter anti-escatológico de su relato nos permite inferir los temores de unos clérigos, entre ellos el tal abad Sergio quien le encomendó la crónica, en relación con las corrientes de pensamiento escatológicas entre los fieles. En el 818 (= 6006) Josué hace una esmerada descripción de todas las catástrofes que cayeron sobre el mundo y que fueron consideradas, en cada oportunidad, como anunciadoras del fin comienzo del fin ${ }^{19}$.

Otro autor que debemos tener en cuenta, para la misma época, fue Juan Rufo. Personaje fundamental en la historia espiritual del cercano oriente en la segunda mitad del siglo V, Juan Rufo, fue uno de los grandes opositores al Concilio de Calcedonia ${ }^{20}$. Junto con una Vita de Pedro el Íbero escrita después de la muerte del personaje en 491, es autor de las Pleroforías, un conjunto de anécdotas (en el sentido casi aforístico de los Apotegmas, de la Historia Lausíaca de Paladio o de la Historia Religiosa de Teodoreto de Cirros $^{21}$ ) anticalcedonianas redactadas hacia el $512^{22}$. Cada una de las anécdotas hagiográ-

relatar la muerte del emperador Zenón, quien habría muerto en el año 600o, de acuerdo a la «era mundial protobizantina» o de la que Grumel llama, «era mundial bizantina» (cfr. V. Grumel, La Chronologie, p. 244). En la estructura de tiempo establecida por Malalas el primer año del reinado de Anastasio comenzó una vez sobrepasado el año 60oo. Debe nuestro autor, entonces, asegurar a sus lectores en el hecho de que el año 600 había efectivamente quedado atrás en el momento de hacer su relato del reinado de Justiniano ( $c f r$. Malalas, op. cit., p. 428). Sobre este último punto, cfr. Elizabeth Jeffreys, "Chronological Structures in Malalas' Chronicle», p. 118 : «Despite this problem, the thrust of the passage is nevertheless plain: Malalas is concerned to argue that the sixth millenium has passed, by whatever system of calculation one operates. While, however, it is clear why a passage of millenial speculation should once have been included at A.D. 491 on Zeno's death, it is not clear why A.D. 528-9 should be significant. It may be that, by reckoning we can lo longer trace, some sect (perhaps syrian) had calculated that the millenium was to end at that time».

19 Josué el Estilita, op. cit., pp. 36-7, sobre un terremoto en Jerusalém, por ejemplo.

20 Junto con Pedro el Íbero y Zacarías Escolástico. Sobre el hombre y la obra, ver la reciente tesis de Jan-Eric Steppa, John Rufus and the World Vision of Anti-Chalcedonian Culture (Gorgias Dissertations. Ancient Christian Studies 1), Pisscataway, 2002.

${ }^{21}$ Sobre el contexto intelectual de la construcción del ideal monástico a partir de textos hagiográficos, ver el reciente artículo de Héctor Francisco, «Fronteras políticas y culturales en la Siria Tardorromana. El caso de Teodoreto de Cirros y la Historia Religiosa», en H. Zurutuza y H. Botalla, Centros y Márgenes Simbólicos del Imperio Romano. $2^{\circ}$ Parte, Buenos Aires, 2001; pp. 137-163. El género se continuará con obras como las Vidas de los Santos de Oriente de Juan de Éfeso y el Prado Espiritual de Juan Mosco.

22 E. Nau, Jean Rufus, évêque de Maïouma, Plérophories. Témoignages et révélations contre 
ficas de las Pleroforías incluye una condena divina de Calcedonia, expresada de formas y maneras muy diversas.

Muchas de esas condenas tienen la forma de visiones y revelaciones que dan el tono general a la obra como transmisora de los argumentos teológicos del autor, sobre la divinidad, la creación y también sobre acontecimientos escatológicos ${ }^{23}$. La mayoría de estas visiones, con todo, son profecías ex even$t u^{24}$ que anticipan la aparición de la "herejía" calcedoniana y la persecución de los fieles ${ }^{25} \mathrm{y}$, posteriormente relacionan el advenimiento de su observancia, como decíamos, con la aparición de signos anunciadores del fin ${ }^{26}$.

Pero, más allá de la tradición computista y de crónicas como las de Malalas y Josué el Estilita, o de compendios visionarios y hagiográficos como el de Juan Rufo, a fines del siglo $\mathrm{V}$ podemos también encontrar otros intentos de manipular las esperas escatológicas ligadas a los signos que anunciaban un fin del mundo con la llegada del año $6000^{27}$. Junto con las interpretaciones escatológicas de acontecimientos políticos o terremotos, encontramos la leyenda, anti-escatológica, relativa a la llegada a Constantinopla de la oración del Trisagion ${ }^{28}$.

le concile de Chalcédoine, Patrologia Orientalis 8.1, Paris, 1911. La mención de «obispo de Maiuma», puerto de Gaza, que se encuentra en el título no pareciera tener demasiado sustento. Cfr. J.-E. Steppa, op. cit., p. 15-24. El sentido de la obra es dar "plena seguridad» (pleroforía) a los creyentes en su negación del concilio de Calcedonia.

23 Momento que sobrevendrá, esperablemente, a causa de los pecados contra el dogma trinitario que conlleva la aceptación de Calcedonia.

24 El título anuncia que la obra trata de «testimonios» (sohdûte) y «revelaciones» ( $g^{e}$ lîne), señalando, desde el principio la unión de los géneros visionarios y hagiográficos en la construcción de una identidad.

25 Como en Pleroforías, II (ed. Nau, pp. 13-14) en las que Pelagio de Edesa, monje y profeta anuncia, unos siete años antes del concilio la persecución que sufrirán bajo el emperador Marciano. Análoga predicción se encuentra en boca del sacerdote alejandrino Juan de Bet Tatiano en Pleroforías VII, (ed. Nau, pp. 18-20) y de abba Zenón, en Kefar Se'arta en Palestina, Pleroforías VIII, (ed. Nau, pp. 20-21).

${ }^{26}$ Pleroforías X (ed. Nau, pp. 23-27) sobre la oscuridad que se abatirá sobre la tierra en tiempos de la apostasía del emperador Marciano. En Pleroforías, XXVI (ed. Nau, pp. 63-67), el concilio de Calcedonia es relacionado con la aparición del anticristo anunciada por el apóstol Pablo en II Thes., II, 3-10.

27 Hecho favorecido, en la visión anticalcedoniana, como hemos visto, por los pecados de los seguidores del Concilio.

28 La fórmula Hágios ho Theós, hágios isxyrós, hágios athánatos, eléêson hêmâs, [«Dios Santo, santo (y) poderoso, santo (e) inmortal, ten piedad de nosotros»] estuvo en el centro de una gran polémica. El Trisagion aparece explicitamente durante el concilio de Calcedonia, recitado por los metropolitas orientales al finalizar la primera sesión. Pero podemos considerar que su existencia es anterior ya que tenemos testimonios indirectos de su utilización durante el concilio de Éfeso. Sobre este último punto, cfr. Acta conciliorum oecumenicorum (ACO), I, vol. i, pars 7 , p. 72 y J.-M. Hanssens, Institutiones liturgicae de ritibus orientalibus, t. III, Roma, 1971; V. S. Janeras, «Les byzantins et le Trisagion Christologique» en Miscellanea Liturgica in onore de Sua Eminenza il Cardinale Giacomo Lercaro, vol. 2, Roma, 1967, pp. 469-499. Para la tradición siríaca, $c f r$. S. Brock, "The thrice-holy hymn in the Liturgy», en ib, Studies in Syriac 
La aparición y utilización de la oración del Trisagion fue siempre estudiada en relación con las controversias cristológicas que opusieron a monofisitas y calcedonianos 29 . Sin embargo, creemos que la "leyenda" sobre la aparición del Trisagion en Constantinopla reviste un fuerte carácter antiescatológico.

Uno de los hechos fundamentales es la leyenda sobre el origen y oportunidad de la aparición de la oración en la Capital. De hecho la fórmula/oración del Trisagion habría llegado a Constantinopla para contrarrestar las esperas escatológicas derivadas de una serie de terremotos sucedidos en Constantinopla ${ }^{30}$. Más aún, se utilizó un texto que tiene la estructura de un apocalipsis, esto es, una revelación recibida por un mensajero durante un viaje ultraterreno, con la intención de aportar esperanza a una comunidad en tribulación ${ }^{31}$.

Spirituality (The Syrian Churches Series 13), Poona, 1988, pp. 21-29 y para la tradición armenia, G. Winkler, «Das Gloria in Excelsis und Thrisagion und die dem Jovhannes Ojnec'i zugeschriebene Konziliengeschichte», en E. Carr et alii, eds, Eu)lo/ghma. Studies in Honor of Robert Taft, S.J. (Studia Anselmiana 110-Analecta Liturgica 17), Roma, 1993, pp. 536-569.

29 Las diferencias teológicas podían ponerse de manifiesto en una liturgia que presentaba entonces muchas diversidades regionales. Pedro el Batanero, patriarca de Antioquía, insertó hacia el 469-470 en la fórmula conocida del Trisagion, la mención «crucificado por nosotros» [stavrotheis di'hêmâs], incorporada al Trisagion en tiempos de Pedro el Batanero como Patriarca de Antioquía fue prohibida por el Concilio In Trullo en 691 ya que si bien podía entenderse en un sentido calcedoniano, al insistir en la crucifixión de Dios en el Cristo se prestaba a una interpretación monofisita. Cfr. S. Janeras, «Le Trisagion: une formule brève en liturgie comparée», p. 534-554. Cfr. también E. Schwarz, Publizistische Sammlungen zum Acacianischen Schisma, p. 242 y ss. junto con su Introducción a las ACO, vol. III, Collectio Sabbaitica contra acephalos et origenistas destinata, insunt acta synodorum Constantinopolitanae et Hierosolymitanae a. 536, Berlin, 1940, pp. XI-XII. El aspecto trinitario de la controversia sobre el Trisagion, tal vez uno de los fundamentales en la obra de Juan Rufo, tiene eco en Pleroforías XXXVII (ed. Nau, pp. 85-87) en la que Pedro el Íbero tiene una visión en la cual el misterio de la Trinidad le es manifestado por el apóstol Pedro.

30 Para las relaciones con los acontecimientos históricos ver B. Croke, «Two early byzantine earthquakes and their liturgical commemoration», Byzantion 51 (1981), pp. 121-147. A lo largo del siglo VI, los intelectuales bizantinos continuaron ocupándose de los terremotos, en un ejercicio intelectual que partía la herencia helénica para unirse con la tradición bíblica, en un deslizamiento intelectual, en la interpretación de los sismos, que los condujo de la noción aristotélica de causa a la noción de signos enviados por Dios. Cfr. G. Dagron, «Quand la terre tremble... », Travaux et Mémoirs 8 (Mélanges P. Lemerle), 1981, pp. 87-103.

${ }^{31}$ Desde los días de K. Kautzsch y R. H. Charles a principios del siglo XX el desarrollo de los estudios sobre la literatura apocalíptica bíblica y post-bíblica han sido muy numerosos. Nos permitimos remitir a la oportuna, y relativamente reciente, definición de John Ashton, que suscribimos en general : "An Apocalypse is a narrative, composed in circumstances of political, religious, or social unrest, in the course of which an angelic being discloses heavenly mysteries, otherwise hidden, to a human seer, either indirectly, by interpreting a dream or vision, or directly, in which case the seer may believe that he has been transported to heave in order to receive a special vision", John Ashton, Understanding the Fourth Gospel, Oxford, 1991, p. 386. La definición de Ashton supera en mucho la aportada en 1979 por la Society of Biblical Genres Project, cfr. J. J. Collins, ed: Apocalypse. The Morphology of a Genre, Semeia 14, Missoula, 1979. 
La Narratio de Rebus Armeniae, redactada hacia el año 700 y que se conserva en una versión griega del siglo X, menciona que el Trisagion fue introducido y aceptado en la Iglesia después del Concilio de Éfeso, siendo Proclo Patriarca de Constantinopla (434-446) con la intención de obtener el perdón de Dios después de un terremoto ${ }^{32}$. Si bien la oración pudo existir con anterioridad, pudiera haberse difundido en la capital durante esos años.

Sin embargo, hacia fines del siglo V, según lo relatado en una carta del Papa Félix III (483-492) al Patriarca monofisita de Antioquía, el mencionado Pedro el Batanero, aparece por primera vez el relato sobre el viaje al más allá de un niño que allí recibe una revelación. El niño escucha durante una hora a los habitantes de las mansiones celestiales cantar la fórmula del Trisagion y fue encargado de transmitir al pueblo de Constantinopla que debían cantar el dicho himno para que desaparecieran los terremotos ${ }^{33}$. Si bien el contexto de la controversia cristológica es claro en lo relativo al contenido de la leyenda (Félix intentaba demostrar a Pedro que el himno, tal cual ser lo recitaba en Constantinopla, había sido aceptado por Dios, e incluso tenido en Él su origen), el hecho de que se trate de una "revelación" es muy importante en relación con la historia de los apocalipsis bizantinos ya que la leyenda del niño elevado a los cielos para recibir allí una revelación que, transmitida a su pueblo, debía otorgarles esperanza frente a lo que se creía eran tribulaciones escatológicas (como los terremotos), signos anunciadores del fin de los tiempos. Y esa es la forma literaria y el sentido de un apocalipsis ${ }^{34}$.

Pero más allá de la negación del carácter escatológico de los movimientos telúricos, el hecho de aparecer en Constantinopla dentro de un mensaje apocalíptico, hace de la leyenda sobre el origen de Trisagion, un contra-discurso escatológico a favor no sólo de una tradición religiosa y política, ligada al destino del Imperio en un momento álgido de la discusión sobre la recepción de Calcedonia ${ }^{35}$ sino también a favor de una ciudad, Constantinopla, en la que la tradición "patriográfica" (cuyos textos provienen del siglo VIII pero transmitiendo y estabilizando una tradición que se origina en esta época) ${ }^{36}$ de erudición y leyendas sobre los orígenes y el des-

$3^{2}$ G. Garitte, La Narratio de Rebus Armeniae (CSCO 134), Lovaina, 1967, p. 28. La tradición bizantina se centra en esta datación en tiempos del Patriarca Proclo, lo que contradice el testimonio indirecto que sitúa el origen del Trisagion durante el Concilio de Éfeso.

33 Felix, Ep. III, PL 58, cols. 909-910.

34 La leyenda sobre el origen del Trisagion se encuentra también en la Crónica de Teófanes (ed. C. de Boor, p. 93) y en el Menologion de Basilio II (ii. 65). Cfr. B. Croke, «Two Early Byzantines Earthquakes», p. 128.

$35 \mathrm{Y}$ de lo que esto significaba en términos tanto políticos (el posicionamiento por encima de Alejandría, entre otros aspectos) como de resignificación de la vida religiosa en la que sobresalen la creciente oposición entre la jerarquía eclesiástica y un monacato carismático cuya tradición interpretaba la fe a través del prima de la vida ascética.

$3^{6}$ Es es caso, por ejemplo de las «Breves noticias históricas» (Parastáseis syntomoi jronikai) 
tino de la ciudad, "leía" su futuro y el del imperio en las estatuas y monumentos clásicos de la que estaba plagadas las calles y plazas de la capital. Ya a principios del siglo XX, Charles Diehl llamó la atención sobre la importancia de los Patria en la pervivencia de creencias escatológicas ${ }^{37}$. Posteriormente, Paul Alexander, retomó el valor de esta tradición, en una obra que no tuvo posterior desarrollo dentro de sus estudios sobre la tradición apocalíptica ${ }^{38}$. Paul Magdalino, más recientemente nos ha recordado que "de la misma manera que las Parastaseis, la Diegesis de Hagio Sophia y los Patria nos presentan una imagen de Constantino, de Justiniano y de Constantinopla inversa a la que ofrecen los panegíricos de la corte (...), las profecías populares, en su pesimismo, contrarrestan el optimismo de la escatología imperial"39.

La leyenda sobre el origen del Trisagion puede, entonces, ser entendida como parte de la estrategia imperial a nivel escatológico, de dos maneras concurrentes. En relación con la discusión alrededor de Calcedonia ${ }^{40}$ por un lado y en relación con las discusiones sobre el destino de la propia capital, por el otro. Dentro de esa estrategia, la elección de una revelación, que podemos considerar apocalíptica, recibida durante un viaje ultraterreno, para hacer llegar el mensaje antiescatológico de esperanza a una comunidad atribulada nos parece un hecho significativo en el plano retórico de la confrontación y que a la vez señala la fortaleza de la tradición apocalíptica.

cuyos textos provienen del siglo VIII pero transmitiendo y estabilizando una tradición que se origina en esta época. Los Patria de Constantinopla se redactan finalmente en el siglo X sobre la base de toda una serie de textos, entre ellos una Historia universal, obra de Hesyjio de Mileto que terminaba con la muerte del emperador Anastasio en 518. Cfr. G. Dagron, Constantinople Imaginaire. Études sur le Recueil des "Patria", Paris, 1984.

$37 \mathrm{Ch}$. Diehl, «De quelques croyances byzantines sur la fin du monde», Byzantinische Zeitschrift 30 (1929-30), pp. 192-196.

$3^{8} \mathrm{P}$. Alexander, "Historiens byzantins et croyances eschatologiques», Actes du XII Congrès International des Études Byzantins (Belgrado, 1964), reeditado en sus Religious and Political Thought in the Byzantine Empire, Londres, 1978, XV).

39 P. Magdalino, «The history of the future and its uses: prophecy, policy and Propaganda» en R. Beaton y R. Roueché, The Making of Byzantine History, Aldershot, 1993, p. 3o. Para nuestra época conservamos el panegírico de Anastasio escrito por Procopio de Gaza, (ed. C. Kempen, Procopii Gazaei: In Imperatorem Anastasium panegyricus, Bonn, 1918. Sobre el contexto retórico de los panegíricos imperiales en Bizancio, cfr. H. Hunger, "Aspekte der griechischen Rhetorik von Gorgias bis zum Untergang von Byzanz ", en Sitzungberichte der Österreichischen Akademie der Wissenschaften, Philosophisch-historische Klasse, t. 277, 3 (1972), pp. 1-27; G. L. Kustas, Studies in Byzantine Rhetoric, Tesalónica, 1973.

40 Y no hay que olvidar que la discusión con los grupos anticalcedonianos revestía, también, un carácter escatólogico. Cfr. S. Ashbrook Harvey, op. cit. 


\section{Bibliografia}

Adler W., Time Immemorial. Archaic History and its sources in christian chronography from Julius Africanus to George Syncellus, Washington, 1989

Alexander P., The Byzantine Apocalyptic Tradition, Los Angeles, 1985

Alexander P., The Oracle of Baalbek, Washington, 1967

Alexander P., The Oracle of Baalbek. The Tiburtine Sibyl in Greek Dress, Washington, 1967

Alexander P., «Historiens byzantins et croyances eschatologiques», Actes du $X I I^{e}$ Congrès International des Études Byzantins (Belgrado, 1964), reeditado en sus Religious and Political Thought in the Byzantine Empire, Londres, 1978, XV

Argyriou A., Les exégèses grecques de l'Apocalypse à l'époque turque (14531821), Salónica, 1982 (primera edición en griego, 1979)

Ashbrook Harvey S., «Remembering Pain: Syriac historiography and the Separation of the Chuch», Byzantion 58 (1988)

Ashton J., Understanding the Fourth Gospel, Oxford, 1991

Brandes W., "Anastasios O Dikoros: Endzeiterwartung und Kaiserkritik», Byzantinische Zeitschrift, 1997-1

Brock S., "The thrice-holy hymn in the Liturgy», en $i b$, Studies in Syriac Spirituality (The Syrian Churches Series 13), Poona, 1988

Collins J. J., ed: Apocalypse. The Morphology of a Genre, Semeia 14, Missoula, 1979

Croke B., «Two early byzantine earthquakes and their liturgical commemoration», Byzantion 51 (1981)

De Groote M., Oecumenii Comentarius in Apocalypsim, Lovaina, 1999

Dagron G., Constantinople Imaginaire. Études sur le Recueil des "Patria", Paris, 1984

Dagron G., «Quand la terre tremble... ", Travaux et Mémoirs 8 (Mélanges P. Lemerle), 1981

Diehl, «De quelques croyances byzantines sur la fin du monde», Byzantinische Zeitschrift 30 (1929-30)

Francisco H., «Fronteras políticas y culturales en la Siria Tardorromana. El caso de Teodoreto de Cirros y la Historia Religiosa», en Zurutuza H. y Botalla H., Centros y Márgenes Simbólicos del Imperio Romano. $2^{\circ}$ Parte, Buenos Aires, 2001, pp. 137-163

Frick K., Chronica Minora, Leipzig, 1893

Garitte G., La Narratio de Rebus Armeniae (CSCO 134), Lovaina, 1967 
Gelzer H., Sextus Julius Africanus und die byzantinische Chronographie, Leipzig, 1880, reimpr. Nueva York, 1967

Grumel V., La Chronologie, Paris, 1958

Hanssens J.M., Institutiones liturgicae de ritibus orientalibus, t. III, Roma, 1971

Hunger H., "Aspekte der griechischen Rhetorik von Gorgias bis zum Untergang von Byzanz ", en Sitzungberichte der Österreichischen Akademie der Wissenschaften, Philosophisch-historische Klasse, t. 277, 3 (1972)

Janeras V. S., «Les byzantins et le Trisagion Christologique» en Miscellanea Liturgica in onore de Sua Eminenza il Cardinale Giacomo Lercaro, vol. 2, Roma, 1967

Jeffreys A., «The attitude of Byzantine Chroniclers towards Ancient History», Byzantion 49 (1979)

Jeffreys E., Jeffreys M. y Scott R., The Chronicle of John Malalas (Byzantina Australiensia 4), Melbourne, 1986

Jeffreys E., «Malalas' use of the Past» en Reading the Past in Late Antiquity, Graeme Clarke, ed. Melbourne, 1990

Jeffreys E., Studies in John Malalas (Byzantina Australiensia 6), Sydney, 1990

Kalemkiar Gr., «Die siebente Vision Daniels», Wiener Zeitschrift für die Kunde des Morgenlandes VI (1892)

Kempen C., Procopii Gazaei: In Imperatorem Anastasium panegyricus, Bonn, 1918

Kustas G. L., Studies in Byzantine Rhetoric, Tesalónica, 1973

Landes R., "Lest the Millenium be fulfilled. Apocalyptic expectations and the pattern of Western Chronography 100-80o CE», en Verbecke W. et alii, eds, Use and Abuse of Eschatology in the Middle Ages, Lovaina, 1988

Landes R., «Millenarismus absconditus. L'historiographie augustinienne et le millénarisme du haut Moyen Âge jusqu'à l'an mil», Le Moyen Âge 1992

Lellouch B. y Yerasimos S., eds, Les traditions apocalyptiques au tournant de la chute de Constantinople (Varia Turcica XXXIII), Paris, 1999

Luneau A., L'histoire du salut chez les Pères de l'Église. La doctrine des âges du monde (Théologie Historique 2), Paris, 1964

Magdalino P., «The history of the future and its uses: prophecy, policy and Propaganda» en Beaton R. y Roueché R., The Making of Byzantine History, Aldershot, 1993

Malalas, Chronographia, ed. Dindorf L., Bonn, 1831

Nau E., Jean Rufus, évêque de Maïouma, Plérophories. Témoignages et révélations contre le concile de Chalcédoine, Patrologia Orientalis 8.1, Paris, 1911

Podskalsky G., Byzantinische Reicheschatologie, Munich, 1972

Podskalsky G., «Der Fall Konstantinopels in der Sicht der Reicheschatologie und der Klagelieder», Archiv für Kulturgeschichte 57 (1975) 
Pertusi A., Fine di Bisanzio e fine del mondo, Roma, 1988

Prigent P. y Kraft R., eds, L'épître de Bernabé (SC 172), Paris, 1971

Schmid J., Studien zur Geschichte des griechischen Apokalypse Textes, 2 vols, Munich, 1955

Schwarz E., Publizistische Sammlungen zum Acacianischen Schisma, p. 242 y ss. junto con su Introducción a las ACO, vol. III, Collectio Sabbaitica contra acephalos et origenistas destinata, insunt acta synodorum Constantinopolitanae et Hierosolymitanae a. 536, Berlin, 1940

Scott R., «Malalas, the Secret History and Justinian Propaganda», Dumbarton Oaks Papers 1985

Steppa J.E., John Rufus and the World Vision of Anti-Chalcedonian Culture (Gorgias Dissertations. Ancient Christian Studies 1), Pisscataway, 2002

Ubierna P., «Fin de los tiempos, milenio y exégesis del Apocalipsis en el cristianismo tardo-antiguo y bizantino», Byzantion Nea Hellás 19-20 (20002001)

Van Dieten J.L., «Politische Ideologie und Niedergang im Byzanz der Palaiologen», Zeitschrift für Historische Forschung 1979, 1

Vasiliev A., «Medieval Ideas on the End of the World: East and West», Byzantion 16: 2 (1942-3)

Winkler G., «Das Gloria in Excelsis und Thrisagion und die dem Jovhannes Ojnec'i zugeschriebene Konziliengeschichte», en E. Carr et alii, eds, Eu)lo/ghma. Studies in Honor of Robert Taft, S.J. (Studia Anselmiana 110-Analecta Liturgica 17), Roma, 1993

Wright W., ed, The Chronicle of Joshua the Stylite, Cambridge, 1882 (reimpr. Amsterdam, 1968) 



\title{
La imagen funeraria tardo-antigua: cristianización de motivos paganos
}

\author{
Jorge Bedoya - Ofelia Manzi
}

El estudio de la iconografía funeraria presente en los sarcófagos tardoantiguos permite señalar la existencia de continuidades en las prácticas cultuales de la época. Estas obras son, en la mayoría de los casos, producto de un trabajo en serie cuyos modelos iconográficos y formales están fijados por la tradición pero que, en su reiteración, sufren sutiles resignificaciones vinculadas con la intencionalidad de las comunidades a las cuales están destinadas. En este período, los grupos cristianizados utilizaron el repertorio romano pletórico de significados heroicos y místicos para comunicar su mensaje.

En el mundo romano, los elementos figurativos que aparecen en altares funerarios, urnas cinerarias y sarcófagos constituyen ejemplos donde, por medio de un simbolismo rico y variado, se alude al mundo del más allá. Así, las figuras de Meleagro, Hipólito, Endimión, Dionisos, Orfeo o Persefone, acompañados por nereidas y centauros, sirven para indicar la beatitud después de la muerte o aquellas de Hércules y Teseo a los cuales sus hazañas y sufrimientos han transformado en héroes. Estos tema suelen acompañarse con diversos elementos decorativos tales como guirnaldas, bucraneos, grifos y victorias que sirven para exaltar las significaciones portadas por las imágenes. En el prolongado desarrollo del arte romano, deben señalarse tanto las variaciones en la conformación de los repertorios iconográficos como las transformaciones en la composición y en las formas que dieron su carácter a las diferentes épocas ${ }^{1}$.

Hacia finales del siglo I, los sarcófagos van desplazando a las urnas funerarias utilizadas en períodos anteriores, lo cual constituye uno de los indicios de cambio de costumbres que tienen su correlato en el ritual mortuorio. Por

\footnotetext{
${ }^{1}$ J. Elsner, Imperial Rome and Christian Trimph, Oxford, 1998, p. 1-23. D. Strong, Roman Art, Yale, 1995, p. 108-126; J. Alvar, y C. Blánquez, "Recorridos por la religión, el sexo y la muerte", en J. Alvar, C. Blánquez y C.G. Wagner (eds.), Sexo, muerte y religión, Madrid, 1994, p. 1-10; R. Bianchi Bandinelli, Roma, centro del poder, Madrid, 1969, p.51-106 y 223-342 / Del Helenismo a la Edad Media, Madrid, 1981, $2^{\circ}$ parte /... y M. Torelli, El arte de la Antigüedad Clásica: Etruria-Roma, Madrid, 2000, p. 95-136.
} 
otra parte, por lo menos hasta la mitad del siglo II, coexistieron la cremación y la inhumación volviéndose ésta última corriente un siglo después. En cuanto a la iconografía, el contenido narrativo y simbólico que presentan los sarcófagos, no es sustancialmente diferente del que poseían las urnas.

Los sarcófagos producidos en la península itálica, al estar destinados a colocarse dentro de un nicho, presentan el frente y los laterales decorados mientras su cubierta, que asume la forma de un tejado, incluye también motivos esculpidos. Se ha señalado que, probablemente, los sarcófagos con guirnaldas se ubican en tiempos de Trajano mientras que los decorados con relieves figurados, pertenecen a la época de su sucesor Adriano, momento en el cual se establecieron, en distintos lugares del Imperio, los talleres destinados a su fabricación².

El sarcófago con escenas de la historia de Teseo y Ariadna (mármol, c. 125-138, Metropolitan Museum of New York) tiene distribuidos en su frente y costados ocho Eros, que sostienen sobre sus hombros una larga guirnalda formada por diversos tipos de ramas, hojas, flores y frutos. En la pared frontal, las curvaturas del adorno vegetal dejan lugar para tres escenas que muestran, de izquierda a derecha, a Teseo recibiendo de Ariadna el ovillo de hilo que lo guiará para salir del Laberinto, al héroe matando al Minotauro y su posterior partida de Naxos mientras ella duerme. Esta sucesión de escenas, expresión del sentido narrativo típico del arte romano, sirve para indicar como el designo divino otorga el premio a quienes han ayudado a sus protegidos. La postura de Ariadna en su sueño expresa la espera anhelante del encuentro con la divinidad, Dionisos, que la conducirá al país de los dioses. La presencia en la caja del sarcófago de las diferentes figuras de Eros se completa con la talla, en la pendiente de la tapa, de otros que se encuentran alistando carros tirados por osos, leones, toros y jabalíes. Esta acción se desarrolla entre dos metas, figuradas en los ángulos, y con la palma del triunfo emplazada en el centro de la composición. Las plantas, que aparecen en el fondo y entre los corredores, permiten deducir que las imágenes de Eros simbolizan, de izquierda a derecha, la Primavera, el Verano, el Otoño y el Invierno. De esta manera, el ciclo de las estaciones y la experiencia humana se incluyen en el juego dialéctico vida-muerte que, guiado por el poder de Eros, alcanza su culminación en el encuentro místico de la durmiente Ariadna con el dios oculto ${ }^{3}$.

2 D. Strong, op.cit., p. 141-196; R. Bianchi Bandinelli, Roma centro del poder, Madrid, 1969, p. 302-307; T. Hölscher, Il linguaggio dell'arte romana, Torino, 1993, p. 67-108; G. Becatti, El arte romano, México, 1964, p.61-84.

3 J. R. Mertens, The Metropolitan Museum of Art. Greece and Rome. New York, 200o, p. 132 (figs. 101- 102); Vid. P. Grimal, Diccionario de mitología griega y romana, Barcelona, 1994, p. 51, 505-510; R. Graves, Los mitos griegos, Buenos Aires, v.1, 1993, 88f, 9ob, 95, 98. 
El mito dionisiaco es complejo y, en su construcción, han intervenido aspectos vinculados con su acción civilizadora en el mundo griego y otros ámbitos, con el vino y el delirio místico, con el descenso a los Infiernos y el ascenso, luego de múltiples trabajos cumplidos entre los hombres, a los cielos para integrar la asamblea divina. Los escultores se inspiraron, a través del tiempo, en diversos aspectos del relato que lo tiene como protagonista y, en este escrito a modo de ejemplo se señalan dos sarcófagos que lo muestran en diferentes contextos. En el primero (mármol, c. 200, Walters Art Gallery, Baltimore), Dionisos, embriagado por el vino y el placer sexual, aparece en el centro de la escena sostenido por un sátiro mientras Eros solicita su atención tirando de la piel de pantera que apenas lo cubre mientras con la otra mano, en un gesto imitado por Pan, le señala a Ariadna dormida. Diferentes dioses y criaturas de la naturaleza se encuentran presentes contemplando la epifanía del dios. En la otra pieza (mármol, c. 260-270, Metropolitan Museum of New York), se unen el tema de las estaciones con el triunfo de Dionisos en la India. Aquí, el dios aparece sentado sobre una pantera, que mientras avanza vuelve su cabeza hacia el protagonista, y rodeado por ménades, sátiros y animales. Esta marcha triunfal se encuentra enmarcada por las estaciones figuradas por cuatro efebos de pie, que ofrecen los frutos típicos de cada una de ellas. En esta pieza, con sus extremos redondeados porque su forma se inspira en las cubas donde fermentaba el vino, se destaca la morbidez de los cuerpos y la flexibilidad de la vegetación que, por una parte, acentúan rítmicamente la estructura compositiva y, por otra, expresan la sensualidad generada por la presencia del dios ${ }^{4}$.

En otras piezas funerarias aparecen diversos actores que, en distintas circunstancias de sus vidas, han estado en contacto con la Divinidad y el más allá. Puede así señalarse el sarcófago con el mito de Meleagro (mármol, c.180, Palacio Doria Pamphili, Roma) uno de los, aproximadamente, doscientos existentes que desarrollan este tema. La vida de este personaje está cruzada por enojos, maldiciones, venganzas y muertes. La presencia del feroz jabalí que asolaba Calidón fue obra de Artemisa debido a que el rey Eneo, padre de Meleagro, la olvidó en el sacrificio ofrecido a todas las divinidades. Las diversas versiones del mito señalan luchas después de la muerte del jabalí por la posesión del trofeo de caza. En unas, la lucha se produce entre los etolios y curetes, los dos pueblos que habían participado en la cacería mientras, en otras, lo constituye la entrega de los despojos del animal a la joven Atalanta participante de la cacería y de quien el héroe se había enamorado. En ambos casos, la situación despierta la ira de Meleagro y las consecuentes matanzas

4 M. Detienne, Dioniso a cielo abierto, Barcelona, 1997, p. 17-57, 115-127; J. Elsner, op. cit. p. 150-151 (fig.100); Vid. P. Grimal, op. cit., p. 139-141; R. Graves, op. cit. v. 1, 125 y 135. 
lo cual lleva a su madre, Altea, a cumplir la maldición, formulada el día de su nacimiento, que provocará su muerte. Más tarde cuando Altea recobra la cordura y se da cuenta de lo ocurrido se suicida. En otro relato, se dice que la muerte del invulnerable Meleagro, que aparece como hijo de Ares y Altea, la provocó una flecha de Apolo, que había luchado en el bando de los curetes. Esta versión es contada en la Ilíada por Fénix para impresionar a Aquiles, quien en su obstinación se asemejaba a Meleagro cuando, ante la maldición de su madre por la muerte de sus tíos, se había retirado de la lucha provocada por la posesión de la piel y la cabeza del jabalí y, solamente volvió a ella, ante los ruegos de su mujer Cleopatra-Alcione la cual se suicidará cuando muera el héroe. Este desarrollo del mito relacionaría a Meleagro con la figura emblemática de Aquiles y la guerra de Troya mientras el encuentro de su sombra con Heracles, cuando éste baja al Hades en busca del perro Cerbero, lo conecta con el ciclo del héroe argivo. Este complicado relato, donde los héroes deben deponer su hybris y aceptar castigos y trabajos para alcanzar su salvación, es el punto de partida para la realización de los relieves del sarcófago que lo tiene como protagonista. En el centro de la cara frontal de la pieza que se está analizando, aparece Meleagro, rodeado por otros cazadores, matando al jabalí de Calidon mientras Atalanta, que a diferencia de los hombres se muestra vestida y calzada con botas, se representa dos veces, una detrás del héroe y otra a su lado, atacando el jabalí. En la pendiente de la cubierta, se muestra a los compañeros de cacería llevando en procesión el cuerpo del héroe muerto mientras que, en el ángulo superior derecho su madre Altea se suicida 5 .

El sarcófago con la historia de Orestes (mármol, 130-134, Museos Vaticanos, Depósito del Museo Laterano) fue hallado junto con otros dos en una tumba, cercana a Porta Viminalis, construida con ladrillos fechados en los años 132 y 134 lo cual ha permitido la datación de las obras halladas en ella. Los temas presentes en las otras cajas fúnebres, son la dramática muerte de los Nióbidas (mármol, 130-134, Museos Vaticanos, Depósito del Museo Luterana) y el mito de Diana, que aparece enmarcado por guirnaldas sostenidas por mujeres (mármol, 130-140, Museo del Louvre, París). En las tres obras se cuentan historias trágicas relacionadas con el designio de los dioses. Los relieves del sarcófago de Orestes pueden ser interpretados en términos de vida y muerte ya que los trabajos del héroe simbolizarían la lucha por la vida y su eventual triunfo sobre la muerte bajo la guía de las deidades protectoras. Puede señalarse otra pieza con el mito de Orestes (mármol, 130-140, Palacio Giustiniani, Roma) con similares características simbólicas y donde se ha empleado, para las figuras principales, el modelo utilizado para la obra

5 Homère, Iliade / ed. Paul Mazon /, París, 1956, IX, 529 y ss.; J. Elsner, op. cit. p. 5-7, (fig.3). Vid. P. Grimal, op. cit. p. 343-345; R. Graves, op. cit. v. 1,80, v.2, 134c, 141d, 142a, 148i, 162 d. 
depositada en los Museos Vaticanos mientras que se han simplificado los personajes secundarios lo cual habla del funcionamiento de los talleres peninsulares y de las relaciones entre productores y clientes ${ }^{6}$.

Un sarcófago proveniente de la Campaña (mármol, finales del 200, British Museum, London) muestra una figura masculina reclinada, que es posible identificar con Endimion, acompañado por Eros recolectores y músicos que revolotean y trabajan a su alrededor. Según las diferentes versiones, este personaje era hijo o nieto de Zeus y de la ninfa Cálice, y reinaba en Ëlide. Su esposa, a la cual se la designa con diferentes nombres, le dio cuatro hijos y Selene, desesperadamente enamorada de él, cincuenta hijas.

Endimión dormía en una cueva cuando Selene lo vio por primera vez y besó sus ojos cerrados. Más tarde, este rey, que suele representarse como pastor, volvió a la cueva y cayó en un sueño eterno conservándose siempre joven y hermoso. Las narraciones difieren en este punto pero sea que Zeus le produjera el sueño a pedido de la diosa o lo solicitara, por temor a envejecer, el mismo Endimión, su destino fue diferente al que tuvo Titono para quien Eos pidió la inmortalidad pero, olvidándose de reclamar la juventud para él, envejeció y terminó, puesto que la diosa se cansó de cuidarlo, convertido en cigarra. Algunas versiones dicen que fue durante este sueño feliz cuando Selene se enamoró del durmiente y concibió su numerosa descendencia.

Ciertos estudiosos señalan que el mito de Endimión se relaciona no sólo con relatos vinculados con los ciclos de la naturaleza sino también con acciones de conquista, que tienen como resultado el casamiento del jefe invasor con sacerdotisas de cultos matriarcales. Al terminar su ciclo, el rey era sacrificado y se instituía su culto porque había alcanzado la categoría de héroe. En el sarcófago analizado, resulta interesante la figuración de Endimión porque aparece, como en algunos otros ejemplos, con los ojos abiertos ${ }^{7}$. Tal vez, esta forma de representación se encuentre vinculada con cultos mistéricos en los cuales el sueño feliz se genera por la contemplación de la divinidad.

El llamado sarcófago Velletri (mármol, c. 190, Museo Nazionale Romano, Roma) presenta sus lados divididos en dos registros cuya organización está inspirada en la arquitectura teatral. En la zona superior se ubican las figuras de Hipodamia, Protesilao, Alcestes y Hércules mientras que, en la inferior, diversos atlantes soportan la figuración arquitectónica y, entre ellos, se desarrollan varias escenas entre las cuales se encuentra el rapto de Proserpina,

6 Para la datación de los sarcófagos hallados en la tumba cercana a Porta Viminalis ver R. Bianchi Bandinelli, Roma centro del poder, Madrid, 1969, p. 275-279; D. Strong, op. cit., p. 190 (fig. 123). Vid. P. Grimal, op. cit. p. 389-393; R. Graves, op. cit. v. 2, 112d, g, l, 113-117, 160, .169. 7 J. Elsner, op. cit., p. 152-153, (fig. 101). Cf. nota 4: sarcófago de Dionisos con la imagen de Ariadna dormida que muestra como ciertas representaciones de Endimión pueden derivar de ella. Vid. P. Grimal, op. cit. p. 155-156; R. Graves, op. cit. v. 1, $40 c, 64$. 
un tema vinculado con la renovación de la naturaleza y el mundo infernal. Esta compleja figuración se completa con los doce trabajos del héroe más popular en el mundo romano, Hércules, y al cual el descenso al Hades y el posterior regreso lo convertían en un paradigma tal como lo expresa Séneca ${ }^{8}$ en uno de sus diálogos mientras que Palladas9 ${ }^{9}$ presenta a la vida como un escenario donde se aprende a jugar con dignidad o se soportan las penas del existir. En la decoración del sarcófago, el Hades aparece como fondo de la acción y está indicado por medio de personajes identificados con esa región tales como Caronte, Sísifo, Tántalo, las Danaides mientras que las moradas celestiales se presentan a través de las figuras de Caelus, la Luna y el Sol ubicados en los frontones, que cobijan a las personificaciones emplazadas en la zona superior. Por su simbolismo, este sarcófago se convierte en una importante expresión de las ideas que, sobre la vida y la muerte, tuvieron los romanos ya que sus relieves hablan del descenso y del retorno, del castigo al malvado y de la beatitud en el más allá y su simbolismo presenta elementos en común con expresiones contenidas en los sarcófagos cristianos del siglo IV10.

El sarcófago de Euhodos describiendo la muerte de Alcestes (mármol, 150-175, Museo Chiaramonti, Museos Vaticanos) ofrece las imágenes de Admeto y Alcestes representando al muerto Euhodus y a su mujer Metilia Acte. Este tipo de sustituciones fueron, en época de los Antoninos, características y estaban relacionadas con la moda del retrato a la manera clásica. El matrimonio de Admeto y Alcestes fue considerado como modelo de amor conyugal porque ella aceptó morir en lugar de su marido. Según una versión del relato, Perséfone, impresionada por la abnegación de Alcestes la envió al mundo de los vivos mientras que, de acuerdo a otra, Hércules se precipitó a los infiernos y la restituyó, más joven y más hermosa, a la tierra. De esta manera, en este mito se exaltaba la fidelidad conyugal, se expresaba la existencia de otra vida después de la muerte y los iniciados en las religiones mistéricas sentían que él contenía la promesa de una recompensa. De esta manera, la intervención directa de los dioses y de los héroes, ejecutores de sus mandatos, señalaba la presencia de un orden universal en el cual se insertaba el hombre ${ }^{11}$. En la sala $\mathrm{N}$ del Hipogeo de la Vía Latina entre diferentes

8 (...) "Ulyssem et Herculem (...) stoici nostri sapientes pronuntiaverumt, invictos laboribus, contemptores voluptalis et victores omnium terrarum", Seneca, "De Constantia Sapientes II", en Oeuvres Complètes de Sénèque, Le Philosophe / ed. M.Nisard /, París, 1858, p. 226.

9 Palladas, Antología Palatina X, LXII, / ed. F. Dübner /, París, 1888.

10 D. Strong, op. cit., p. 188-196, (fig. 122). Vid. P. Grimal, op. cit.. p. 239-257; P. Graves, op. cit. v.2, 103, 111,122-134, 143,242-143,. a

${ }^{11}$ D. Strong, op. cit., p. 128-200, (fig. 130); R. Bianchi Bandinelli, Roma centro del poder, p. 302-302, (fig. 342); E. D’Ambra, Roman Art, Cambridge, 1998, p. 124-125. (fig. 84); A. Grabar, El Primer Arte Cristiano (200-395), Madrid, 1967 (fig. 251). Vid. P. Grimal, op. cit. p. 18; P. Graves, op. cit. v.1, 69, 106, 6, 134 (4, 8), 155. 
escenas con los trabajos de Hércules se puede destacar la que lo muestra a conduciendo a Alceste fuera del Hades y a ésta proponiendo a Admeto darle su vida. Por la elección de éste y otros episodios es posible observar al héroe evocado como "salvador" de los humanos vinculándolo con aquellas creencias cristianas en otra vida. El ciclo artístico de las "salvaciones" bíblicas y evangélicas, desarrollado en las catacumbas durante el siglo III, y textos de diverso origen sirven de base para las imágenes, ubicadas en las distintas salas de este hipogeo y que se expresan a través de elaboradas relaciones intertextuales ${ }^{12}$.

El surgimiento de las primeras imágenes cristianas, hecho que se produce a partir del siglo III dentro del marco histórico del imperio romano, ofrece uno de los testimonios más concluyentes para el estudio de las tensiones creadas entre la perduración de las creencias tradicionales y los cambios propuestos por la nueva religión; entre la permanencia de la memoria y el surgimiento de diferentes formas de elaboración del pasado, sin olvidar la problemática coexistencia de diversas identidades (cristianos, paganos y judíos). De esta manera, el repertorio iconográfico elaborado y utilizado por el cristianismo resulta un tema propicio para reflexionar sobre el imaginario, entendido como elemento referencial en el vasto sistema simbólico que produce toda comunidad y, a través del cual, designa su identidad; crea una representación de si misma, que incluye las posiciones sociales de sus integrantes; impone determinadas creencias comunes; conserva y modela los recuerdos; y proyecta al futuro temores y esperanzas ${ }^{13}$.

El conjunto de imágenes generado en relación con un nuevo contexto teórico que, merced a la difusión de la doctrina, se extiende por áreas ajenas a su génesis, necesita de la resignificación y/o creación de motivos capaces de canalizar una comunicación eficiente en cuya resolución formal debieron intervenir referentes fuertemente establecidos en el medio helenístico romano. El reconocimiento de las formas es uno de los requisitos para conseguir afianzar el fenómeno de la comunicación.

La nueva doctrina impuso el protagonismo de personajes nuevos, cuya existencia visual dependió de arquetipos consagrados por la tradición y que

\footnotetext{
12 A. Grabar, op. cit. p. 225- 236. Vid. P. Bourdieu, "Campo intelectual y proyecto creador", en J. Pouillon et alt., Problemas del Estructuralismo, México, Siglo XXI, 1967, p. 135-182 / Las reglas del arte, Barcelona, Anagrama, 1995, p. 419-479.

13 B. Baczko, Los imaginarios sociales. Memorias y esperanzas colectivas, Buenos Aires, 1991, p. 11-32. Vid. C. Castoríadis, "La institución imaginaria de la sociedad", en C. Colombo (comp.), El imaginario social, Montevideo, 1989; J. Le Goff, El orden de la memoria. El tiempo como imaginario, Barcelona, 1991, $2^{\circ}$ parte; P. Brown, The world of Late Antiquity, Londres, 1982; $\mathrm{H}$. A. Zurutuza, "Paganismo y cristianismo. Revisitando las culturas campesinas en la Galia de los siglos VI y VII", en H. A. Zurutuza y H. Botalla (comps.), Paganismo y Cristianismo. Pervivencias y mutaciones culturales (siglos III-IX), Rosario (Argentina), 1995, p.111-121.
} 
fueron sustentados en una intencionada selección de los textos referenciales. La relación entre la escritura y la imagen configuraron un mensaje cuya intencionalidad dependió de las diferentes instancias de la historia interna de la Iglesia y marcaron su ascenso al poder.

El análisis de la producción de imágenes en los primeros siglos del cristianismo presenta la particularidad de comprobar la utilización de un repertorio iconográfico y formal que tuvo que tomar en cuenta la existencia de formas de pensamiento estructuradas en torno a determinados temas y a ciertas resoluciones plásticas que, por su larga existencia, se habían integrado plenamente a aquéllas.

El primer aspecto que surge del estudio de esa primera producción iconográfica, es el hecho de que se encuentra circunscripta a un ámbito funerario: cementerios y sarcófagos constituyen el soporte de las figuras que sirvieron como vehículo para expresar el mensaje que se expresó en las épocas anteriores a la paz de la iglesia.

Durante el transcurso de los siglos III, IV y V, independientemente del cambio de situación del cristianismo en el imperio, se privilegiaron determinados contenidos de las escrituras que constituyeron la base del mensaje de salvación. Acorde con esta propuesta, un recorrido por los repertorios de imágenes de esa época, permite advertir que está ausente toda referencia al sufrimiento y a la muerte. Si bien a partir de la segunda mitad del siglo IV, se impone una temática triunfal, acorde con un proceso de ascenso al poder, en el III, en medio de una situación de notoria precariedad, las escenas traducidas en imágenes configuran un conjunto homogéneo y reiterado, en el que diferentes situaciones separadas por el tiempo y el espacio, resultan unidas por un hilo conductor: todos los protagonistas, de un modo u otro, acceden a la salvación. El mensaje transfiere, igualmente, los intereses vitales hacia una esfera que resulta sustraída de la experiencia terrenal y contribuye a exaltar una dimensión extra humana como meta final del hombre.

En este contexto, una imagen como la del Buen Pastor en la que se conjuga la tradición helenístico-romana del Moscóforo y la enunciación de Juan XI, 1, presenta al protagonista privilegiado de la nueva doctrina transformado en un personaje cuya misión es la de proteger y finalmente salvar. La existencia de imágenes en las que además el personaje porta un recipiente con alimento, refuerza su significación ${ }^{14}$ en el sentido descrito. La juventud del pastor, su cabellos rizados, su rostro lampiño, demuestran hasta qué punto los modelos helenísticos se encuentran presentes y articulan un mensaje nuevo, pero a partir de elementos visuales cuya significación está fuertemente fijada.

Este caso constituye un primer paso en dos direcciones, por un lado la resignificación de un motivo plástico, por el otro la selección intencional

14 Tal como la imagen que aparece en la Cripta de Lucina, Catacumba de Calixto, Roma. 
de un pasaje evangélico coincidente con el núcleo fundamental de aquello que se pretende destacar.

La distribución de las figuras es otro de los aspectos a considerar. Herederas, de algún modo, de los sistemas narrativos romanos, las imágenes que expresan visualmente los contenidos de las escrituras, aparecen organizadas de acuerdo con una estructura narrativa generada a partir de ideas rectoras según las cuales el relato se expresa mediante la juxtaposición de episodios. La necesidad de destacar algunos temas determina la existencia de conjuntos - que con ciertas diferencias mantienen una relativa homogeneidad - que podemos considerar característicos de la retórica en imágenes de los siglos III y IV.

El esquema difundido a partir de la obra de Quintiliano ${ }^{15}$ de acuerdo con el cual la división del texto y la marcación del mismo, constituían valiosos recursos para favorecer la memorización, se aplica a la cultura escrita resultante de la difusión del cristianismo. Las recomendaciones de este autor cuyo conocimiento en la Tardía Antigüedad se debió a la obra de Julius Victor y a la de Marcianus Capella - proporcionaron una determinada cantidad de prescripciones de acuerdo con las cuales fue factible organizar la lectura del libro. El contenido, dividido en diversas unidades, debería contar con palabras o imágenes dispuestas en los márgenes que facilitaban la memorización. Si tenemos en cuenta que este sistema domina la Tardía Antigüedad y los primeros siglos de la Edad Media, podemos entender la selección a la que fueron sometidas las Escrituras como una forma de organización textual con el objetivo de posibilitar la memorización de episodios considerados fundamentales para la comprensión de la doctrina. Este tipo de uso de la palabra escrita la transforma en el eje de una elaboración intelectual, al tiempo que supedita al texto todo un aparato conceptual orientado hacia la comunicación, en la que la memorización desempeña un rol fundamental.

Si aplicamos estos conceptos a la producción de las imágenes cristianas, podemos encontrar, por un lado los recursos intelectuales de acuerdo con los cuales se produjo la primera exégesis textual de las Escrituras y por el otro descubrir los mensajes que se priorizaron de acuerdo con las circunstancias que rodearon la creación de los conjuntos iconográficos.

La elaboración de un mensaje más complejo, tanto por la resolución plástica cuanto por la creación de una determinada iconografía, se advierte en los numerosos ejemplos contenidos en sarcófagos fabricados - frecuentemente en serie - para satisfacer las necesidades de la comunidad cristiana en constante crecimiento. Ese tipo de producción de un objeto cotidiano favoreció la repetición de motivos de modo que es posible advertir el esta-

15 Cf. J.P. Antoine, "Mémoire, lieux et invention spatiale dans la peinture intalienne des XIIIe et XIV siécles", en Annales, París, nov. dic. 1993, pp. 1447 y ss. 
blecimiento de un modelo iconográfico reiterado, incluso en zonas de producción geográficamente muy alejadas.

En la decoración de los sarcófagos existe una determinada cantidad de escenas que se reiteran sin un orden preestablecido, pero que conservan estrictamente su relación con textos que han sido seleccionados de acuerdo con ideas rectoras.

El estudio de piezas conservadas en diversas colecciones ${ }^{16}$ permite comprobar la existencia de esa temática, la que aparece igualmente, en las pinturas realizadas en las catacumbas y - luego del Edicto de Milán -, en la decoración de los muros de los edificios cultuales. Estos temas comprenden ciertos temas contenidos en el Antiguo Testamento tales como la Historia de Jonás, Los tres hebreos que se salvan de las llamas del horno, Daniel en el foso de los leones, El sacrificio de Isaac, Las penurias de Job. También se representa frecuentemente el Pecado original encarnado en las figuras de Adán y Eva, tema que condiciona cronológicamente las diversas situaciones dado que constituye un punto de partida, cuya culminación está en la encarnación y a través de ésta, en la salvación eterna. A su vez, la temática veterotestamentaria aparece vinculada con ciclos del Nuevo Testamento de los cuales la Infancia de Cristo (Anunciación, Visitación, Natividad, Epifanía) son los que cuentan con mayor cantidad de ejemplos. En la misma línea significativa se cuentan, los milagros de Cristo (preferentemente la resurrección de Lázaro) y el ciclo de la Pasión, en el que durante mucho tiempo se evita toda referencia visual a la crucifixión.

Un sarcófago que se conserva en el Museo de Letrán realizado en talleres romanos durante el último cuarto del siglo III, puede considerarse paradigmático, no sólo por la iconografía, sino también por la relación que ésta presenta con temas consagrados por la mitología greco-romana. El sarcófago tiene como tema principal la Historia de Jonás que es una de las más frecuentemente representadas. La figura del monstruo que engulle en sus fauces al protagonista ocupa un lugar preponderante en la composición, tanto por su ubicación central, como por su tamaño en relación con las demás figuras. La secuencia del relato está representada por la caída de Jonás desde una barca, la presencia de una figura monstruosa que lo engulle y el protagonista que descansa bajo un follaje luego de su milagroso regreso a la vida. En esa última escena, se advierte - hecho que por otra parte se reitera en la mayor parte de los relieves y pinturas que contienen este tema - la influencia de la iconografía desarrollada ampliamente en sarcófagos romanos, de la historia de Endimion. El cuerpo yacente de lado con la mano derecha plegada sobre la cabeza, y el rostro de perfil reiteran la postura del joven que duerme acaricia-

16 Cf. A. Grabar, El primer arte cristiano, Madrid, 1967, pp. 239-278. A. Grabar, Las vías de la creación en la iconografía cristiana, Madrid, 1980. T. Mattews, The clash of gods, Princeton, 1993. 
do por los rayos lunares. Si bien en esta época temprana (siglos III a V) las figuras, particularmente las que son representadas desnudas, conservan aún un marcado naturalismo procedente de la tradición helenística, en este ejemplo Jonás está tratado con marcado realismo. Dado que el episodio del Antiguo Testamento guarda una relación significativa con la historia del joven que obtiene la juventud y la inmortalidad, la solución plástica otorgada a ambos personajes, demuestra hasta qué punto se utilizaban modelos comunes. La identificación de uno u otro personaje resulta de la identificación de la pieza en que se desarrollan las imágenes y del contexto en el que se las incluye.

El interés de estas piezas radica, igualmente, en la forma en que se elabora la narración vinculando episodios diversos que resultan conectados por un mensaje que es el que se privilegia: superar situaciones merced a la intervención divina e incluso regresar de la muerte. El que logró esto último es, por antonomasia, Lázaro, que en este sarcófago aparece representado en el ángulo superior izquierdo acompañando al milagro que Moisés (o Pedro) producen al hacer surgir agua de la roca. Por sobre la figura de Jonás, está el patriarca Noé quien recibe a la paloma. Esta última figura queda situada justo encima del monstruo que engulle a Jonás con lo que la significación opuesta que encarnan ambos animales, resulta especialmente destacada. Las figuras que se encuentran en extremo derecho de la composición no responden a un texto determinado, pero el hecho de que se trate de hombres y un ave que pescan en el mar del que ha salido incólume Jonás, permite integrarlas al relato a través de la presencia del agua. Estos últimos personajes configuran un marco de realidad para enmarcar las acciones representadas.

En otras piezas es frecuente encontrar las figuras de orantes intercaladas entre diversos episodios. La imagen, masculina o femenina, con los brazos elevados hacia el cielo, expresa el acto mediante el cual se propicia la acción reparadora de la divinidad 17 .

En un ejemplar conservado en la iglesia de San Salvador de Brignoles, Provenza, la decoración presenta, mediante un estilo característico de piezas producidas en los siglos III y IV en la región, una serie de motivos vinculados por la figura de la orante. La figura sedente del centro, seguramente la del fallecido está mutilada y los restantes personajes están dispuestos a ambos lados. En el extremo izquierdo un rostro representado en busto podría ser una personificación cuya identidad se hace difícil determinar. Junto a ella aparece un pescador que tiene a su lado tres ovejas que descansan junto a un ancla. En ese lado izquierdo, la composición se completa con la figura de la orante cuyos brazos desmesuradamente grandes expresan, mediante el gesto,

17 Cf. entre otros el Sarcófago conservado en el Foro romano, reproducido en A. Grabar, Las vías de la creación en la iconografía cristiana (1980), fig. 10. Los ejemplos son numerosos. 
el poder otorgado a la oración. El árbol y el ave que completan esa parte de la composición, configuran un conjunto en el que la simbología de la conversión expresada mediante la pesca y el rebaño, encuentra en la oración su proyección hacia la trascendencia. En el lado derecho el Buen Pastor se aproxima a un árbol en el que existe un ave semejante a la representada en el otro lado. La figura más interesante del conjunto la constituye el personaje situado en el extremo izquierdo. Se trata de una representación heredera de las de Júpiter-Zeus (anciano barbado, con el torso desnudo que porta una vara en su mano derecha). Por sus características iconográficas y por la significación que se puede otorgar al conjunto, esa figura podría ser identificada con una temprana representación de Dios Padre que aparecería, entonces junto a su hijo. Según esta interpretación, el ave situada muy junto a la mano del anciano, podría encarnar al Espíritu Santo. De todos modos, aún cuando este último significado podría ser dudoso, lo incuestionable es la elaboración de un relato mediante alegorías que contienen un mensaje que traducido en palabras expresa de qué manera las almas ganadas mediante la oración se convierten en el objeto preciado de la salvación tal como la ejerce el Pastor que protege al rebaño.

Un ejemplar del siglo III, conservado en Santa María Antigua en Roma, presenta una interesante elaboración del mensaje de salvación mediante la yuxtaposición de escenas y personajes. El milagro de la salvación de Jonás evocado mediante una imagen en la que se destaca el tratamiento clásico del cuerpo del protagonista, flanquea la figura de la orante. El centro está ocupado por la representación del muerto, sentado en actitud de leer un rollo. A la derecha el Buen Pastor y la escena del bautismo de Cristo, establecen significativamente el sentido general de la representación. La oración de la mujer, evoca ante el fallecido, los episodios de las Escrituras que sirven como camino de su propia salvación. El antecedente veterotestamentario adquiere una dimensión actual por la presencia del dios encarnado y del sacramento del bautismo.

En el período posterior al Concilio de Nicea se advierte una mayor elaboración en los programas iconográficos en los que es posible advertir las huellas de la fijación doctrinaria producidas a partir de esa época. En el sarcófago conocido como "dogmático" que fue hallado en la basílica de San Pablo y que actualmente se conserva en los Museos Vaticanos, el conjunto de imágenes genera un relato visual mediante el cual Antiguo y Nuevo Testamento se unen a través del significado de la salvación.

En el frente de esta pieza, dispuestas en dos registros, las figuras evocan momentos arquetípicos de la historia sagrada. En el centro, colocados en un clípeo, aparecen las imágenes del difunto y su esposa. Las vestimentas y peinados denotan su alta condición social. A derecha e izquierda se desarrolla el relato en el que se hilvanan escenas diversas dispuestas a modo de narración 
continúa. En el extremo derecho superior la creación del mundo realizada por Dios Padre representado con los atributos de un funcionario romano: sentado en una cátedra usa dalmática y toga. Es interesante el hecho de que dos figuras barbadas flanqueen a la central configurando un cuadro relacionado con la forma de presentación de los emperadores o altos dignatarios que aparecen rodeados por otros funcionarios. Este rasgo denota la adopción de formas cortesanas en la iconografía cristiana, la asimilación de sus protagonistas a las dignidades civiles, constituye un paso en el ascenso al poder de la Iglesia. La escena siguiente es la de la expulsión del Paraíso. Adán y Eva desnudos aunque con el sexo cubierto flanquean a un Dios-Cristo igualmente vestido al modo romano y cuyo rostro conserva los elementos esenciales de la iconografía del Buen Pastor. A la derecha del clípeo central, sin solución de continuidad se presentan tres milagros de Cristo: la Bodas de Canáan, la multiplicación de los panes y la resurrección de Lázaro.

En el registro inferior, de izquierda a derecha, la Epifanía en la que María aparece asimilada por vestimenta y gesto a una matrona romana. Detrás de la cátedra que ocupa el personaje femenino, aparece la figura de Balaám. La narración prosigue con la curación del ciego, en el centro Daniel en el foso de los leones y a su lado la negación de Pedro, el prendimiento del mismo y finalmente el milagro en el que Moisés-Pedro hacen brotar el agua de la fuente.

La elaboración iconográfica utiliza por lo tanto, pasajes pertenecientes a varios libros del Antiguo Testamento y del Evangelio, entre los cuales se establece una relación conceptual en la cual la Creación-Caída, se supera - milagro mediante - por la Salvación emergente de la encarnación. Predomina la temática neotestamentaria y el acento está puesto en la intervención de Cristo como taumaturgo capaz de alterar el curso de los acontecimientos venciendo aún a la misma muerte.

Este sarcófago que puede ser fechado entre el 320 o el $340^{18}$ constituye un antecedente de la pieza conocida con el nombre de Sarcófago de Junio Basso (Museo de las Grutas Vaticanas, Roma) datado en el 359 y considerado como la obra más importante entre las de su especie en esa época. En este caso las escenas del Antiguo y Nuevo Testamento se encuentran encuadradas en nichos coronados por tímpanos triangulares y semicirculares en el registro inferior y por un arquitrabe en el superior. Las escenas, al igual que en el caso analizado precedentemente, obedecen a una elaboración simbólica centrada en la presentación de la salvación como bien supremo.

Un caso especial es la representación del ciclo de la Pasión de Cristo y dentro de éste la escena culminante de la crucifixión. La falta casi total de imágenes de este hecho en los primeros siglos constituye un elemento de parti-

18 R. Bianchi Bandinelli y M. Torelli, El arte de la antigüedad clásica. Etruria-Roma, Madrid, Akal, 2000, Fig. 199. 
cular interés. Las extensas controversias generadas a partir de la definición de la "naturaleza de Cristo", determinaron que se evitara representar un tema que podía ser interpretado como enfatizar su condición de hombre. Hasta que las conclusiones del Concilio de Calcedonia del 451 no establecieron el principio de "Un Cristo en dos naturalezas" o "una persona que actúa en dos personas inseparables, pero inconfundibles cada una según su peculiaridad"19 no aparece el desarrollo de esa iconografía y se la soslaya mediante la introducción de imágenes triunfales vinculadas con la resurrección.

En un sarcófago conservado en el Museo de Letrán (Roma, siglo IV) las escenas del ciclo de la Pasión culminan en imágenes que representan la superación de la muerte mediante el milagro de la resurrección. La cara frontal aparece dividida en cinco compartimentos mediante columnillas que generan una secuencia narrativa integrada por las diversas escenas que componen el ciclo. Estas se distribuyen en dos grupos a ambos lados de la figura central y contienen, de izquierda a derecha, la portación de la cruz, el prendimiento de Cristo, Cristo conducido ante Pilatos y el lavado de manos de éste. Las figuras, originadas en el vasto repertorio de representaciones de soldados y funcionarios, están dotadas de una gestualidad medida y carente por completo de todo dramatismo. El núcleo del relato se encuentra en la imagen central en la cual aparece la cruz sobre la cual campea una corona triunfal que enmarca las letras que componen el monograma de Cristo. El motivo inspirado en la iconografía de las escenas de triunfo de los emperadores que se representan junto a los vencidos, en este caso está reemplazado por la de los dos soldados custodios del sepulcro, que son los primeros en advertir el milagro de la resurrección. De este modo la combinación de elementos provenientes de la tradición romana y los resultantes de trasladar a la imagen un pasaje del texto evangélico, configuran un conjunto en el que se destaca el milagro que produce la salvación. La cruz, elemento supremo de la pasión, al no contener la figura del Cristo muerto, reafirma su carácter simbólico y soslaya toda alusión a la destrucción física. "Las armas de los soldados al pie de la cruz resultan tan impotentes para impedir la resurrección victoriosa de Cristo, como lo eran la de los bárbaros ante los ejércitos imperiales”20.

La búsqueda de recursos "propagandísticos" que expresan, de un modo u otro, la existencia de una posibilidad de soslayar, aunque sea de manera temporaria a la muerte - el héroe que regresa del más allá, el hombre que es milagrosamente salvado - constituye uno de los tantos elementos culturales

19 Con esta doctrina quedaron condenadas por igual las teorías nestoriana y monofisista. El dogma de las naturalezas inseparables iba en contra del nestorianismo. La fórmula de las naturalezas inconfundibles e inalterables contra los monofisistas.

20 A. Grabar, op. cit. (1980), pp.113-114. 
que permiten interpretar a la época tardo antigua, como un período en el cual las tensiones entre paganos y cristianos, fueron menores de lo que apareció en una visión historiográfica tradicional ${ }^{21}$. El tema que en este caso ha sido tomado en cuenta, demuestra la existencia de ciertos elementos comunes instalados en el imaginario colectivo y que, como no podía ser de otro modo, pretenden superar la instancia suprema, presentándola bajo el velo protector del mito, de la doctrina y del ritual propiciatorio. Aún cuando la dimensión de salvación eterna propuesta por el cristianismo supera, por su proyección trascendente al mensaje heroico de la tradición greco-romana, la conformación del repertorio iconográfico se realiza mediante la utilización de ciertos elementos comunes que otorgan a la temática de la elusión de la imagen de la muerte como destrucción progresiva y abyecta del cuerpo, un carácter emblemático en la conformación del pensamiento de la época.

21 A. Momigliano, Conflicto entre paganismo y cristianismo, Madrid, 1986. La historiografía actual plantea la convivencia e interrelación de paganos y cristianos que tuvieron que compartir un espacio geo-político y cultural. Vid. P. Brown, The Rise of Western Christendom. Triunph and Diversity Ad. 200 - 1000, Massachusetts, 1997. / Society and the Holy in Late Antiquity, Berkeley, Londes, 1982. 


\section{Bibliografia}

Alvar J., y Blánquez C., "Recorridos por la religión, el sexo y la muerte", en Alvar J., Blánquez C. y Wagner C.G. (eds.), Sexo, muerte y religión, Madrid, 1994, pp. 1-10 Antoine J.P., "Mémoire, lieux et invention spatiale dans la peinture intalienne des XIIIe et XIV siécles" en Annales. París, nov. dic. 1993, pp. 1147 y ss

Baczko B., Los imaginarios sociales. Memorias y esperanzas colectivas, Buenos Aires, 1991

Becatti G., El arte romano, México, 1964

Bianchi Bandinelli R., Roma, centro del poder, Madrid, 1969

Bianchi Bandinelli R. y Torelli M., El arte de la antigüedad clásica. Etruria-Roma, Madrid, Akal, 2000

Bourdieu P., "Campo intelectual y proyecto creador", en J. Pouillon et alt. Problemas del Estructuralismo, México, Siglo XXI, 1967, pp. 135-182

Brown P., Society and the Holy in Late Antiquity, Berkeley, Londes, 1982

Brown P., The Rise of Western Christendom. Triunph and Diversity Ad. 200 - 10oo, Massachusetts, 1997

Brown P., The world of Late Antiquity, Londres, 1982

Castoríadis C., "La institución imaginaria de la sociedad", en C. Colombo (comp.), El imaginario social, Montevideo, 1989

D’Ambra E., Roman Art, Cambridge, 1998

Detienne M., Dioniso a cielo abierto, Barcelona, 1997

Elsner J., Imperial Rome and Christian Trimph, Oxford, 1998

Grabar A., El Primer Arte Cristiano (200-395), Madrid, 1967

Grabar A., Las vías de la creación en la iconografía cristiana, Madrid, 1980

Graves R., Los mitos griegos, Buenos Aires, v.1, 1993

Grimal P., Diccionario de mitología griega y romana, Barcelona, 1994

Hölscher T., Il linguaggio dell'arte romana, Torino, 1993

Le Goff J., El orden de la memoria. El tiempo como imaginario, Barcelona, 1991, $2^{\circ}$ parte

Mattews T., The clash of gods, Princeton, 1993

Mertens R., The Metropolitan Museum of Art. Greece and Rome, New York, 2000

Momigliano A., Conflicto entre paganismo y cristianismo, Madrid, 1986

Strong D., Roman Art, Yale, 1995

Torelli M., El arte de la Antigüedad Clásica: Etruria-Roma, Madrid, 2000

A. Zurutuza, "Paganismo y cristianismo. Revisitando las culturas campesinas en la Galia de los siglos VI y VII", en H. A. Zurutuza y H. Botalla (comps.), Paganismo y Cristianismo. Pervivencias y mutaciones culturales (siglos III-IX), Rosario (Argentina), 1995, p.111-121 


\section{Ambrosio de Milán y el reclutamento de los "hombres de Iglesia". Perfíl eclesiástico de Italia del Norte durante el siglo IV}

Hugo Andrés Zurutuza

El perfil eclesiástico de Italia del Norte durante el siglo IV aparecía definido por las relaciones episcopales que se organizaban para contener las tensiones existentes en un espacio sociocultural complejo, cruzado por localismos e ideologías en pugna. Planteamos que al no poder establecerse con ajuste el panorama eclesiástico regional, y especialmente la génesis de algunos de sus obispados, nos limitaremos a destacar aquellas dinámicas generadas por las prácticas políticas de la época que influyeron en su configuración, señalando la especificidad que presentaba el área septentrional con respecto al resto de la península².

Intentaremos elaborar un análisis de los mecanismos de selección de los cuadros eclesiásticos considerando aquellos factores socioculturales y presiones políticas que gravitaron en dicha selección y como consecuencia, observar el cambio generado en el reclutamiento de los "hombres de Iglesia" de Italia del Norte en particular. Esta mutación fue el resultado de una práctica episcopal que contemplaba con atención las realidades políticas de ese período y que simultáneamente desarrolló acciones adecuadas para satisfecer los nuevos requerimientos. Estas acciones pautaron modos y frecuencias en el proceso de cooptación de aquellos actores sociales que se instalarían en las sedes episcopales locales. Destacamos, en convergencia de criterios con otros tardoanti-

\footnotetext{
${ }^{1}$ El presente trabajo está basado en la ponencia presentada en el II Coloquio de Historia Antigua (2-4 junio 2003) organizado por la Facultad de Filosofía y Letras de la Universidad de Zaragoza (España), Fronteras étnicas e identidades religiosas en los "hombres de Iglesia" de Italia del Norte durante el siglo IV.

2 Guyon, J., I primi secoli della missione cristiana in Italia, en: De Rosa, G.; Gregory, T.; Vauchez, A., Storia dell'Italia religiosa 1. L'Antichità e il Medioevo. Bari, 1993, pp. 79-110. Cf Lanzoni, F., Le diocesi d'Italia dalle origini al principio del secolo VII (an. 604), I-II. Faenza, 1927; Hefele, C.F.; Leclercq, H., Histoire des conciles, I-III. Paris, 1907-1910; Lizzi, R., Vescovi e strutture ecclesiastiche nella cità tardoantica (L'Italia annonaria nel IV-V secolo d.C:) (Athenaeum 9). Como, 1989; Pietri, Ch., Roma Christiana: Recherches sur l'Église de Rome, son organisation, sa politique, son idéologie de Miltiade à Sixte III (311-44O), I-II. Roma, 1976.
} 
quistas, que el momento central de esta transformación es la época correspondiente al veintenio (374-397) del episcopado de Ambrosio de Milán ${ }^{3}$.

En la búsqueda de antecedentes sobre la densidad de la trama episcopal de la península una carta de Cornelio, obispo de Roma, dirigida a Fabio, prelado de Antioquía - a mediados del siglo III - diseña un cuadro que puede considerarse como representativo de su comunidad eclesiástica. Roma en aquel tiempo contaba con "cuarenta y seis sacerdotes, siete diáconos, siete subdiáconos, cuarenta y dos acólitos, un grupo de cincuenta y dos compueso de exorcistas, lectores y ostiarios, y también mil quinientas viudas e indigentes, a todos lo cuales sostiene la gracia y el amor del Señor para con los hombres" sin olvidar al obispo, que ocupa el primer puesto en la lista ya "que debe ser único en la Iglesia universal"4. Esta es una circunstancia más que demuestra que el cristianismo, para la época de la persecución de Decio y sus consecuencias en los grupos dirigentes cristianos, había dejado de ser un fenómeno marginal en la sociedad romana. Esta situación que era representativa para Roma podría valer también para una gran parte de Italia.

En Roma, en el año 251, luego de la elección de Cornelio como obispo de la ciudad se reunió un sínodo para considerar la medidas enviadas por Cipriano de Cartago y los obispos reunidos en torno a él, relativas a los lapsi y al cismático Novato que pertenecía a una facción rigorista enfrentada con la del episcopo romano. Eusebio de Cesárea en su Historia Eclesiástica nos hace conocer esta convocatoria que reunió a sesenta obispos - de los cuales desafortunadamente no precisa la sede de ninguno ${ }^{5}$ - y señala además la presencia de los presbíteros y diáconos que acompañaban al grupo episcopal.

3 Cracco Ruggini, L., La fisonomia sociale del clero e il consolidarsi delle instituzioni ecclesiastiche nel Norditalia (IV-VI secole), en: Morfologie sociali e culturali in Europa fra Tarda Antichità e Alto Medioevo, II (Settimane di Studii XLV). Spoleto, 1998, pp. 852-853.”...io mi limiterò invece a riflettere qui, basandomi su di un certo numero di esempi ben documentati e significativi, sui ritmi e sui modi con cui ebbe luogo in questi secoli una radicale mutazione nel reclutamento dei quadri ecclesiastici del Norditalia, parallela a un risplasmarsi delle estrutture stesse. Essa fu fortemente segnata, si capisce, dai cambiamenti allora in atto sul piano politico, e conferi a questo clero una fisonomia particolare, nell'insieme assai diversa -pur nella varietà delle situazioni- da quella riscontrabile in altre aree cronologicamente in paralello (per esempio in quelle galliche, a thut'oggi le meglio studiate). Ma, per lo meno in un momento-chiave del IV secolo, tale mutazione fu anche il portato de una strategia ecclesiastica che delle realtà politiche in movimiento ebbe lucida consapevolezza e che, di conseguenza, operò scelte mirate e precise. A mio modo de vedere, questa svolta decisiva ebbe luogo durante l'episcopato ventennale di Ambrogio di Milano (374-397 d.C.)". $C f$ Sotinel, C., Le recrutement des evêques en Italie aux IVe. et Ve. siècles. Essai d'enquête prosographie, en: Vescovi e pastori in epoca teodosiana. I (Studia Ephemeridis Augustinianum 58). Roma, 1997, pp. 191-204.

4 Durante la mitad del siglo III, dos personajes están fuertemente influídos por las grandes persecuciones contra los cristianos extendidas a todo el imperio durante el gobierno de Decio y Valeriano, nos referimos a Cecilio Cipriano Tascio, obispo de Cartago y Novato, presbítero y obispo cismático de Roma. Acerca de Novato y su herejía. Cf EUS. Hist. Eccles. VI, 43.

5 EUS. Hist. Eccles., 42, 2. Los obispos, ancianos (presbíteros) y diáconos se convirtieron en la 
Considerando la historia sucesiva de la difusión del cristianismo podemos inferir que la Italia suburbicaria debió haber tenido una presencia mayoritaria en este sínodo, mientras que en Italia del Norte la penetración cristiana era todavía esporádica. En este período Milán y Aquileia tendrían probablemente obispos, puede que también Ravena, Verona y Brescia, pero la presencia episcopal en otras ciudades de la región es considerada problemática.

El desarrollo de las redes episcopales, difícil de abarcar con precisión, muestra una dimensión del fenómeno, en una perspectiva que abarca tres siglos, desde la mitad del siglo III a las invasiones longobardas. Observamos un acrecentamiento que va desde una sesentena de sedes en tiempos de Cornelio a más de doscientos obispados en la mitad del siglo IV ${ }^{6}$. En este siglo el número de las sedes episcopales se había prácticamente cuadruplicado, hasta reunir un número cercano a doscientos cincuenta, con una fuerte disparidad regional. Sólo un quinto de estos obispados estaban en efecto ubicados en Italia del norte, donde no todas las ciudades tenían un obispo mientras que en el área suburbicaria el organigrama eclesiástico reproducía casi exactamente las densidades de las civitates.

Este panorama refleja, más allá de la vitalidad de una Iglesia misionera, la existencia de situaciones regionales, la mayor parte de las cuales explicarían las causas de la creación de las nuevas cátedras episcopales. Esta creación se debió ciertamente al ejercicio de un fuerte pragmatismo por parte de los obispos frente a diversas coyunturas que alteraban la estabilidad del espacio sagrado, como las complicadas relaciones jerárquicas establecidas entre ellos mismos agudizadas por los conflictos ideológicos que los escindían poniendo en permanente riesgo la unidad episcopal.

En la Italia suburbicaria todas las sedes episcopales dependían de Roma que ejercitaba un estricto control no sólo en el momento de la ratificación de los obispos electos sino también a través de los concilios reunidos durante el siglo IV, aunque la acción del obispo de Roma no siempre había encontrado la obediencia deseada. La jurisdicción romana parecía acotarse a partir de ciertos límites, ya que la Italia del Norte dependía, al menos desde finales del siglo IV, de una influencia alternativa a Roma, en particular la de Milán. Esta ciudad fue durante el siglo IV residencia de la corte imperial y adquirió en la época de Ambrosio una influencia proporcional a la de su obispo.

jerarquía de un clero profesional organizado, a cada uno de cuyo grado correspondían distintas funciones espirituales y administrativas. El obispo flanqueado por los ancianos (presbíteros), presidía la asamblea desde un estrado (solium) sentado en un sillón como un magistrado romano. La congregación se sentaba fuera de este presbiterio, supervisada por los diáconos y dispuesta en un orden establecido. $C f$ Krautheimer, R., Arquitectura paleocristiana y Bizantina. Madrid, 1996, pp. 27-29.

${ }^{6}$ Guyon, J. I primi..., p. 109, n.45. 
Las modificaciones observadas en esta topografía eclesíastica fueron consecuencias de las reacciones de los "hombres de Iglesia" frente a la intromisión del poder imperial. A partir del concilio de Nicea (325) el cristianismo había comenzado a proyectar sus debates internos en el espacio público, siendo los sucesores de Constantino emperadores cristianos que pretendían representar cada uno la ortodoxia religiosa en discusión y que, por lo tanto, intervenían frecuentemente en los conflictos eclesiásticos, incluso con prácticas violentas. Es así como la disputa sobre el arrianismo se convertía en el gran problema del siglo IV7.

Si bien las consecuencias del debate teológico generaron todo tipo de dificultades por las conductas imprevistas adoptadas por los emperadores divididos entre nicenos y arrianos, no debemos dejar de señalar que el favor oscilante de estos gobernantes hacia el cristianismo había permitido a los hombres de una "Iglesia triunfante" dar forma a un paisaje eclesiástico de irregulares contornos religiosos. Para consolidarlo era necesario entonces elaborabar estrategias para cubrir los vacíos episcopales existentes.

Además destacamos que paralelamente las circunstacias políticas enunciadas favorecieron la conformación y fortalecimiento de un orden vertical al interior de la Iglesia modificando así su primitiva distribución horizontal para cumplir con las exigencias de las nuevas élites cristianas.

La cristianización en el último cincuentenio del siglo IV había estado ampliamente difundida, por los menos en las grandes ciudades. Se tiene la impresión de que en sus dinámicas y modalidades, sea posible reconocer el condicionamiento del cuadro geográfico y las huellas de presencias culturales múltiples. El hilo conductor común de la historia regional durante este período está constituído por la función mediadora del eje padano entre Oriente y Occidente, África y el mundo greco-oriental (ilírico, anatólico-capadocio, sirio-palestinense, egipcio), las escalas adriáticas y la presión de Roma.

El número de diócesis episcopales seguras, o casi, en los años ‘60 y ‘70 del siglo IV era todavía exiguo en Italia septentrional, si se compara con aquel de la Italia peninsular directamente controlado por Roma. Podemos ubicar una

\footnotetext{
7 Esta centuria que fue caracterizada por la historiografía tradicional como el período más representativo del emblemático conflicto entre paganismo y cristianismo, ha sido revisitada en los ultimos años y los enfoques más actuales han trasladado el problema central de la época al espacio de poder cristianizado, al conflicto entre ortodoxos y herejes. $C f$ Zurutuza, H., Emperadores, burócratas, magos y astrólogos, en: Zurutuza, H.; Botalla, H. (comps.), Centro y márgenes simbólicos del Imperio Romano. Buenos Aires, 1998, p. 179. "Nuestra hipótesis de trabajo destaca que el conflicto entre paganismo y cristianismo no ocuparía en realidad un lugar de relieve durante el siglo $I V$, porque los cristianos estaban empeñados en dificiles debates internos (escritos antiheréticos y anticarismáticos, etc.) y en la construcción de un espacio de poder en el que operaban los nuevos políticos convertidos o filocristianos, junto a funcionarios ambiciosos y epíscopos de ambigua definición dogmática...El encuentro paganismo-cristianismo aparece de manera definitiva con una nueva dimensión, entendido en clave conciliatoria."
} 
trama fuertemente descompensada hacia el sector oriental y adriático integrada por Aquileia, Verona, Trento, Padua, Brescia, Milán, Pavia, Vercelli y Génova, próxima al tejido más denso de los diócesis emilianas: Faenza, Parma, Imola/Forum Cornelii, Claterna, Bolonia, Módena, Piacenza, Voghenza/Vicohabentia ${ }^{8}$.

Mientras la Italia annonaria era requerida por su estructura socioeconómica y se iba convirtiendo en el centro de gravedad del nuevo imperio burocrático en vías de cristianización, también las iglesias locales intentaban consolidarse.

Destacamos en particular la situación del sector occidental donde Vercelli, ciudad que se estaba adecuando a sus nuevas funciones, se ubicaría como centro estratégico y logístico entre Milán y Galia. Se transformó en diócesis autónoma con el nombramiento como obispo de Eusebio 9 , pocos años antes de su exilio (335-361/362). La población local parecía aceptar de buen grado a este extranjero, un sardo de familia acomodada, culto y poseedor de la lengua griega que había viajado a Oriente y se había formado como sacerdote en Roma $^{10}$. Hay coincidencia en aceptar que la fisonomía militarizada que Vercelli estaba asumiendo como lugar de escala y concentración de las milicias comitatenses, con predominio ilirio-danubiano y especialmente arrianas, haya sido un motivo determinante para su promoción como sede de diócesis. Coincidimos con Cracco Ruggini ${ }^{11}$ que esta acción fue más bien dirigida por Roma que desde Milán, ya que en la antigua ciudad capital dejada de lado desde hacía tiempo por los emperadores, estaba instalado desde 352 el papa Liberio ${ }^{12}$, de intransigente posición ortodoxa, defensor de la fe nicena. Esta filiación determinaría su posterior exilio en Tracia al ser sancionado por Constancio II en 355. En cambio desde la sede milanesa un emperador filoarriano podía ejercitar un condicionamiento ideológico mucho más efectivo y

8 Cracco Ruggini, L., La fisonomia..., esp. 855 .

9 EVSEBIVS 1, episcopus Vercellencis., en: Prosographie Chrétienne du Bas- Empire, 2 Italie (313-604) I, pp. 692-696 (Se citará P.C.B.E. 2, I-II )

10 HIERON., De vir. inl., XCVI.

11 Siniscalco, P., Gli imperatori romani e il cristianesimo nel IV secolo, en: Gaudemet, J.; Siniscalco, P.; Falchi, G.L., Legislazione imperiale e religione nel IV secolo (Sussidi Patristici 11). Roma, 2000, p. 101. "Costanzo si schiera decisamente con una parte della cristianità, quella ariana, e non fa mistero di una tale sua scelta. Ispiratori della politica religiosa da lui perseguita sono alcuni vescovi illirici filoariani, Valente di Nursa, Ursacio di Singidunum, Germinio di Sirmio, veri prelati palatini. I suoi protetti sono sempre della medesima sua parte: da Giorgio ad Alessandria d'Egitto, a Leonzio ad Antiochia, ad Ausenzio a Milano, a Felice a Roma, a Saturnino ad Arles, a Potamio a Lisbona. I suoi avversari, che divengono nemici, sono per lo più i 'niceni': in primo luogo Atanasio di Alessandria, e poi Dionigi di Milano, Eusebio di Vercelli, Lucifero di Cagliari, Ilario di Poitiers, Rodanio di Tolosa, Ossio di Cordova..."

12 LIBERIVS 1, diaconus, puis évêque de Rome, en: P.C.B.E. 2, II, pp. 1297-1298. Liberio, obispo de Roma niceno (352-366, 355-358 exiliado) al regresar de exilio debió compartir el gobierno eclesiástico con el obispo arriano Felix II. 
peligroso. Por lo tanto la vinculación de Eusebio con el clero de Roma parece justificar su elección como obispo.

De la decisión de elevar como sede episcopal a Vercelli salía robustecida la tutela tanto de la comunidad ortodoxa de la ciudad como así también de un número de plebes ya existentes y diseminadas en un área extensa: Dertona/Tortona, Novaria/Novara, Eporedia/Iurea, Augusta Pretoria/Aosta, Augusta Taurinorum/Torino, Industria/Monteu da Po, Agaminae in Palatium/Ghemme hasta Ebredunum/Ebrum más allá de los Alpes ${ }^{13}$.

Observamos la configuración de una frontera virtual como línea de resistencia antiarriana, antioriental e incluso anticonstantinopolitana. Mientras la orientalizante Aquileia, con su obispo africano Fortunaciano ${ }^{14}$, permanecía inclinada a los arrianos, en Vercelli, Eusebio se mantenía firme en su ciudad, resistiendo a la milicia reclutada en el Ilírico y Oriente, importante soporte de la herejía arriana. Debió ser por lo tanto Vercelli el primer polo itálico septentrional en el que el contraste entre católicos nicenos y arrianos se fue agravando hasta un conflicto abierto, estimulado por los sectores que respondían a Constancio II.

Este emperador era considerado como un "oriental" en Italia según la información que suministra una carta de Liberio a Eusebio poco antes del concilio de Milán del $355^{15}$. En este concilio participará el obispo de Vercelli junto a aquellos epíscopos que más abiertamente se oponían a la condena de Atanasio de Alejandría. Recordemos que la política de Constancio II se caracterizó en este período por una serie de defenestraciones de las sedes episcopales ortodoxas, y sobre todo, por la instalación de arrianos, reclutados especialmente entre personajes de origen oriental, en aquellos sitios que habían quedado vacantes. La formación de un partido de obispos heréticos ligados al emperador resultaba operativo para sus propósitos de lograr una hegemonía sobre el cuerpo eclesiástico ${ }^{16}$. La situación religiosa de la Italia padana después del concilio filoarriano del 355, es bien conocida pero merece ser revisada. Constancio II quería condenar a Atanasio ${ }^{17}$ y amenazaba a los obispos de Italia para que rompieran su alianza con el prelado de Alejandría. La convocatoria de trescientos obispos de Occidente en Milán, no resolvió la crisis y como consecuencia fueron exiliados Eusebio de Vercelli - primero en Scythopolis (Palestina) y luego en Capadocia y la Tebaida superior -,

13 Cracco Ruggini, L.,La fisonomia..., esp. 856. Cf Lanzoni, F., Le diocesi d'Italia, op.cit.

14 FORTVNATIANVS, episcopus Aquilensis, en: P.C.B.E. 2, I, pp. 856-857. Cf HIERON. De vir. inl.. XCVII

$15 C f$ LIBER., Ep. 1,1,2.

16 Cecconi, G.A., Vescovi e maggiorenti cristiani nell'Italia centrale fra IV e V secolo, en: Vescovi e pastori in epoca teodosiana, vol.I (Studia Ephemeridis Augustinianum 58). Roma, 1997, p. 207.

17 El conflictivo episcopado de Atanasio se desarrolló entre los años 328 y 373 . Período durante el cual estuvo cinco veces en exilio: 335-337, 339-346, 356-362, 362/63, 365/366. 
Dionisio de Milán ${ }^{18}$ - también en Capadocia - y Lucifer de Cagliari19 - en primera instancia en Germanicia de Commagene y después en otras dos localidades orientales: Eleuthéropolis (Palestina) y coincidiendo con Eusebio de Vercelli, la Tebaida superior.

Ante el vacío de la cátedra milanesa los arrianos propusieron a Ausencio (355-373)20, un capadocio arriano, que había sido sacerdote en Alejandría y que debió aprender latín sin llegar a integrarse durante los veinte años de gestión en la comunidad de Milán. Mientras tanto los obispados de Vercelli y Cagliari fueron probablemente dados a episcopos arrianos y el mismo papa Liberio fue exiliado en Tracia, lejos de sus amigos y compañeros de infortunio. Un año después Hilario de Poitiers lo fue en Frigia (356) ${ }^{21}$ en tanto Osio, en Sirmium ${ }^{22}$.

La llegada al poder de Valentiniano I (364-375) iba a permitir a Occidente un cierta estabilidad religiosa que le facilitaría permanecer fiel al símbolo niceno hasta que un conflicto en la misma Roma asumió el perfil de una guerra civil entre dos partes irreconciliables. En 366 a la muerte del papa Liberio, el emperador había sostenido el partido del obispo Dámaso $(366-375)^{23}$ contra el del diácono Ursino ${ }^{24}$. El objetivo de este apoyo fue un intento de buscar la unidad ideológica entre los epíscopos partidarios de la fe nicena. Por lo tanto, años más tarde en 373 Dámaso apoyaría, luego de la muerte del arriano Ausencio, la elección por parte de la comunidad milanesa del obispo atanasiano Aurelio Ambrosio25, ya consular en Emilia y Liguria. De origen senatorial romano su padre había sido prefecto del pretorio de la Galia bajo Constantino II.

La actividad desarrollada por Ambrosio para organizar el reclutamiento de obispos y clérigos próximos a la Iglesia nicena, al estar en gran parte condicionada por la contingencia de las ofertas existentes para cubrir sedes periféricas, lo obligó a poner la atención en los sectores sociales de extracción regional. Es así como contribuyó a la instalación de una red episcopal diseñada en función de un modelo de cooptación que favorecía una promoción social sostenida desde Milán a través de una adecuada práctica epistolar.

18 DIONYSIOS 1, episcopus Mediolanensis, en: P.C.B.E. 2, I. pp. 563-565.

19 LUCIFER 1, episcopus Calaritanus, en: P.C.B.E.2, II, pp. 1324-1328.Cf HIERON. De vir. inl., XCV; A.A.V.V., La figura e l'opera di Lucifero di Cagliari. Una revisitazione. Atti del I Convegno Internazionalee. Cagliari, 5-7 dicembre 1996 (Studia Ephemeridis Augustinianum 75). Roma, 2001.

20 AVXENTIVS 1, episcopus ecclesiae Mediolanensium, en: P.C.B.E. 2, I, pp. 238-241.

${ }^{21}$ Fue exiliado a Frigia después del concilio de Béziers (356). Cfr HIERON. op.cit., C.

22 Cfr la obra fundamental para la problemática arriana: Simonetti, M., La crisi ariana nell IV secolo (Studia Ephemeridis Augustinianum 11). Roma, 1975.

23 DAMASVS, diaconus, puis presbyter, en: P.C.B.E. 2, I, p. 530.

24 VRSINVS 1, diaconus, antipape, en: P.C.B.E. 2, II, pp. 2356-2358.

25 Cf Mazzarino, S.,Storia sociale del vescovo Ambrogio. Problemi e ricerche di storia antica 4. Rome, 1989. 
Las cartas enviadas por Ambrosio a sus colegas de Italia septentrional, recientemente promovidos al episcopado, manifiestaban un claro proyecto de buscar la unificación a través de la religión y la cultura. El prelado milanés parecía querer comunicar además de las directivas pastorales algunos criterios formales, los mismos que de alguna manera habían regulado las relaciones entre los miembros de la aristocracia senatorial, de divulgar el uso del instrumento epistolar ${ }^{26}$. Este ideal aristocrático representó en la sociedad tardoantigua la matriz de comportamiento que debía uniformar también a los que no eran específicamente de origen noble, a los idóneos funcionarios que querían o debían entrar en contacto con los miembros de la élite. Este programa contemplaba la formación cultural de los obispos que involucraba tanto el servicio político como el eclesiástico, en definitiva la necesidad de integrarlos a ambos sistemas de control social. Elevar el nivel cultural de los obispos serviría para reforzar el frente unitario ortodoxo contra enemigos de fe diversa. El grupo niceno debía confrontarse tanto con el nuevo interés suscitado en la intelectualidad pagana por la tradición judía 27 , como resistir la reivindicación que hacían los arrianos de pretender ser ellos los interpretes más relevantes de las Sagradas Escrituras e incluso dialogar con los mismos grupos ortodoxos donde la discusión o debate veterotestamentario se intensificaba para profundizar el desarrollo de la cultura religiosa.

Las relaciones establecidas por el obispo milanés, que intentaban conciliar la dispersión geográfica con los ritmos impuestos por las presiones políticas a su gestión episcopal, proveen una información que ofrece definiciones específicas. Había organizado una red eclesiástica de control social y religioso que permitía articular la zona de influencia milanesa con áreas periféricas.

El cuadro de las jerarquías eclesiásticas del Norte de Italia parece revelar durante la segunda mitad del siglo IV una evolución que en muchos aspectos permite especular una similitud con la seguida por los funcionarios imperiales encuadrados en la administración provincial y regional ${ }^{28}$. Con el transcurrir del siglo IV, en particular en la segunda mitad, los funcionarios comienzan a ser sustituidos por personajes de origen más oscuro, local, en una sociedad articulada por una presencia imperial más frecuente y prolongada. Con una tendencia análoga, en relación a las necesidades y motivaciones especialmen-

\footnotetext{
26 AMBR. Ep. 47, 1, 2; De Off. 1, 67.

27 Esta influencia se dió sobre todo después del 382 cuando el paganismo dejó cesó de existir como religión oficial del Estado. Algunas eminentes familias senatoriales emprendieron la defensa de los valores ético-religiosos y de los propios privilegios sobre el culto de las tradiciones, en oposición a cualquier innovación. Nace en esta atmósfera reivindicativa una nueva atención a la tradición judía por su carácter arcaico, conservador y ritual. $C f$ Cracco Ruggini, L., Pagani, ebrei e cristiani: odio sociologico e odio teologico nel mondo antico, en: Gli ebrei nell'Alto Medioevo (Settimane di Studi XXVI). Spoleto, 1980, pp. 3-117.

28 Cracco Ruggini, L., La fisonomia..., p. 884.
} 
te políticas, en la jerarquía eclesiástica regional detectamos que la red episcopal integrada por prelados extrarregionales - obispos romanos como Ambrosio de Milán, africanos como Fortunaciano de Aquileia ${ }^{29}$, Zenón de Verona $^{30}$, Marcelino de Embrun ${ }^{31}$ (en la Moriana), sardos como Eusebio de Vercelli, orientales como Juliano de Parenzo ${ }^{32}$ (con un discutido origen istriano), e incluso el capadocio Ausencio, predecesor arriano de Ambrosio -, hacia el final de la centuria se abre a nuevos obispos reclutados entre sectores emergentes locales y provenientes de familias dedicadas al servicio eclesiástico.

Observamos entonces como la estrategia clerical "ambrosiana" buscaba incorporar al clero actores sociales de procedencia local, que se manifestaban más confiables y respetuosos de la ortodoxia, pero pertenecientes a niveles de extracción cultural más heterogénea ${ }^{33}$, porque la situación política inestable llevaba a formalizar alianzas con redes de parentesco regionales de segundo rango ${ }^{34}$. El cursus clerical podía posibilitar un ascenso social puesto que estos provincianos, educados según las normas eclesiales, tenían las competencias necesarias para desempeñar de manera idónea sus funciones. La institución estaba desarrollando aptitudes para producir sus propios cuadros, evitando recurrir a la aristocracia tradicional. Las familias locales constituirán el reservorio de los nuevos obispos. Sus miembros se convertirán en específicos "hombres de Iglesia" con identidad propia, más que representantes de un grupo social determinado, puesto que los eclesiásticos durante mucho tiempo se habían sentido confundidos con las jerarquías sociales de su época.

Como exponentes de este nuevo conjunto de obispos y clérigos locales podemos mencionar el caso de Cromacio de Aquileia ${ }^{35}$ y de su hermano Eusebio, probablemente primer obispo de Concordia ${ }^{36}$, o el de Flavio Latino, que accede al episcopado de Brescia en los últimos años de su vida, después de haber recorrido un cursus eclesiástico: exorcista, praesbiter, episcopus, y cuyo hijo Flavio Macrino era lector en la misma ciudad a la muerte de su padre ${ }^{37}$, o todavía más tarde, el sacerdote Marcelino, que formó parte del clero de Vercelli y cuyo carmen sepulcral constata un origen local, en el terri-

29 FORTVNATIANVS, episcopus Aquileiensis, en: P.C.B.E. 2, I, pp.856-857.

30 ZENO, episcopus Veronensis, en: P.C.B.E. 2, II, pp. 2376-2377.

$3^{1}$ Es discutida su identificación. Cfr MARCELLUS 3 , episcopus, en: P.C.B.E. 2, II, pp. 1375-1376.

32 IVLIANVS 2 bis, Parentinae urbis episcopus, en: P.C.B.E. 2,I, pp. 1173-1174.

33 Lizzi, R., Vescovi e strutture..., p. 31, Cf AMBR. De Off.

34 Matthews, J.F., Western Aristocracies and Imperial Court A.D. 364-425. Oxford, 1990 (1975).

35 CHROMATIVS, episcopus Aquileiensis, en: P.C.B.E. 2, I, pp. 432-436.

36 EVSEBIVS, 2, episcopus, en: P.C.B.E. 2, I, pp. 697-698. Está extendida la opinión que fue el primer obispo de Concordia (Venecia), basándonos en CHROM., Sermo 26.

37 Personajes conocidos por vía epigráfica: $C I L, \mathrm{~V}, 4846$ (Brixia-Regio X):

FL . LATINO . EPISCOPO

AN . III . M . VII . PRAESB .

AN . XV .EXORC . AN . XII 
torio de $\mathrm{Bessa}^{38}$. Otros ejemplos provienen de la elección directa de Ambrosio como metropolitano 39 .

La sucesión de nombramientos de frecuencia creciente para la ordenación sacerdotal muestra que Ambrosio tenía un rol activo o por lo menos un decisiva supervisión de los mismos. Constancio devino obispo probablemente en Claterna hacia 379. Juliano, de origen istriano o acaso oriental, que ya había sido monje en Jerusalén, fue obispo de Parenzo en la época ambrosiana y estuvo alineado con la política devocional de difusión de las reliquias apostólicas en Italia septentrional, gravitando especialmente en la búsqueda aquilense de clerici locales, de la cual salieron nuevos obispos como los ya mencionados Cromacio - obispo de Aquileia a la muerte de Valeriano en el 388/389 - y el archidiácono Eusebio - hermano de Cromacio, probable obispo de Concordia en torno al 390 - junto al archidiácono Jovino ${ }^{40}$, promovido a la cátedra episcopal de una sede que podría ser identificada con Padua.

En torno a los años 385/388 Vigilio ${ }^{41}$ fue consagrado también por Ambrosio como obispo de Trento, siendo probablemente de origen local pero con ascendencia o por lo menos educación romana. Entre 386 y 390 consagró también a Félix ${ }^{42}$, primer obispo de Como, a Gaudencio de Brescia ${ }^{43}$, discípulo de Filastrio, que asumió bajo fuerte presión política a la muerte de éste en 396/397, a Basiano ${ }^{44}$, primer obispo de Lodi, a Máximo45, de origen por lo menos regional, propuesto especialmente por Ambrosio para la creación de la sede episcopal de Turín; poco después devendrían también sedes epis-

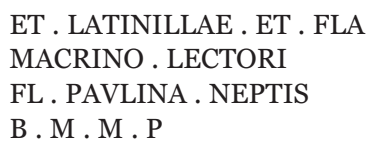

$3^{8} C I L$, V, 6733. $C f$ Roda, S., Religiosità popolare nell'Italia nord-occidentale attraverso le epigrafi cristiane nei secoli IV-VI, en: Religiosità popolare nel cristianesimo antico (Augustinianum XXI). Roma, 1981, p. 256, n. 51. El autor recurre al repertorio epigráfico carmina epigrafici vercellesi.

39 SABINVS 2, episcopus Placentinus, en: P.C.B.E. 2, II, pp. 1969-1973.

Ambrosio mantiene una especial relación con Sabino, obispo de Piacenza, hombre que había adquirido un gran cultura durante las delicadas misiones desempeñadas en Oriente, además de haber demostrado una clara adversión al arriano Ausencio de Milán. Sabino era uno de los diáconos que separado de la tendencia herética impuesta en la sede de Milán, estaban agrupados en torno de Filastrio de Brescia, y que en 374 habían sostenido con firmeza la candidatura de obispos ortodoxos. Suponemos que si en esos años Sabino ya no era la cabeza de los cristianos de Piacenza, Ambrosio mismo habría tenido buenos motivos para proponerlo a la cátedra episcopal de aquella ciudad. $C f$ AMBR. Ep.47, 1,2,3.

40 IOVINVUS 1, episcopus, en: P.C.B.E. 2, I, pp. 1152-1153.

41 VIGILIVS 1, episcopus Tridentinae ecclesiae, en: P.C.B.E. 2, II, pp. 2296-2297.

42 FELIX 8, en: P.C.B.E. 2, I, pp. 771-772.

43 GAVDENTIVS 3, évêque de Brixia, en: P.C.B.E. 2, I, pp. 887-890.

44 BASSIANVS, episcopus Laudensis, en: P.C.B.E. 2, I, pp.269-270.

45 MAXIMVS 10, episcopus Taurinensis ecclesiae, en: P.C.B.E. 2, II, pp. 1468-1469. 
copales las plebes de Aosta, Ivrea y Novara, limitando así la extensión de la diócesis de Vercelli. La última consagración del obispo milanés fue la del sucesor de Evencio en Pavía probablemente Profuturus ${ }^{46}$, en los inicios de 397, poco antes de caer enfermo y morir.

\section{Centros y periferias}

La actividad y acción pastoral de estos obispos se situaba en un contexto particular: es a las comunidades urbanas, y sólo a ellas que se dirigen Ambrosio y sus contemporáneos ${ }^{47}$. Los campos quedaban en un segundo plano, por lo tanto la evangelización del Piamonte tuvo también como punto de partida la ciudad, en particular Turín/Augusta Taurinorum. Pero si bien la frontera entre paganismo y cristianismo coincidía con la existente entre campo y ciudad, ambos polos no constituían realidades independientes debido a la situación socio-económica regional, manteniéndose en estrecha dependencia. Exístia una economía esencialmente agrícola con una fuerte presencia de terratenientes que vivían en las ciudades dirigiendo desde allí la administración y la especulación de los productos de sus propias tierras, mientras la carga directa de la producción recaía en los campesinos indigentes. Esta polaridad social coincidía con la división cultural y religiosa entre "domini y rustici”, cristianos y paganos.

La actividad y acción pastoral de Máximo de Turín se situaba en este contexto espacial y temporal particular, en un período de la historia social y político-militar del mundo tardoantiguo entre fines del siglo IV y comienzos del siglo V. Máximo se centraba en la ciudad, dirigiéndose a una comunidad de fieles de reciente conversión, de neófitos, que se encontraban en los márgenes de una región todavía por evangelizar ${ }^{48}$. En cierto sentido estaban ubicados en tierra de misión, esa misión desarrollada, como se ha señalado, por el impulso de Ambrosio y sus conteporáneos. La Iglesia, más preocupada por la gestión urbana y la elaboración de las redes episcopales regionales, había delegado la conversión del campo a los possessores, los grandes propietarios que tenían la misión de extirpar las creencias paganas de sus dependientes. La prédica de Máximo se desenvolvía especialmente en un punto conflictivo, en un

46 ** PROFVTVRVS, en: P.C.B.E. 2, II, pp. 1851. Cf PAUL., Vita Ambr., 45.

47 Lizzi, R. Ambroise's contemporaries and the Christianisation of Northern Italy, Journal of Roman Studies 80, 1990, pp. 156-173. Cf Cantino Wataghin, G., Christianisation et organisation ecclésiastique des campagnes: L'Italie di Nord aus IVe.-VIIIe. siècles, en: Brogiolo, G.P.; Gauthier, N.; Christie, N. (eds.), Towns and their territories between Late Antiquity and the Early Middle Ages. Leiden-Boston-Köln, 2000, p. 211.

$48 \mathrm{Cf}$. Devoti, D., Massimo di Torino e il suo publico, en Religiosità popolare nel cristianesimo antico (Augustinianum XXI). Roma, 1981, pp. 153-167. 
lugar de la frontera religiosa donde más fuerte era la resistencia al cristianismo, en una confusa demarcación que separaba la religión cristiana de las viejas prácticas paganas. La síntesis de un diálogo pastoral unitario, totalizante e interclasista se confrontaba con formas de religiosidades subalternas, configuradas por la supervivencia pagana de tradición romana o incluso prerromana, sugeridas o modeladas por la presión de situaciones económicas y socioculturales locales. Este análisis regional incorpora la zona que se extendía, grosso modo, desde las regiones alpinas occidentales hasta las augustas regio IX, regio XI occidental, regio VIII noroccidental, que presentaba las características de un tierra periférica de tardía y no muy profunda romanización, con notables persistencias culturales célticas e incluso precélticas. La articulación de su estructura social era un tanto limitada pero al mismo tiempo, en cuanto zona de intenso tránsito hacia los pasos transalpinos, aparecía abierta y permeable a influjos de variadas matrices culturales y religiosas ${ }^{49}$.

Las inscripciomes funerarias constituyen la traza más precoz y más evidente de una presencia cristiana. La distribución espacial de la epigrafía cristiana define tanto la dirección este-oeste de donde procedía la penetración cristiana, irradiando desde los centros urbanos a través de las principales arterias de comunicación de la zona, como el carácter mayoritariamente urbano del cristianismo local. La máxima concentración epigráfica se encuentra en las ciudades de más antigua influencia cristiana ${ }^{50}$ como en primer lugar, Vercelli51, luego de acuerdo a una escala de frecuencias que corresponde a niveles de cristianización destacamos centros como Dertona ${ }^{52}$, Eporedia ${ }^{53}$, Augusta Taurinorum ${ }^{54}$, etc.

Algunas áreas como las alpinas y la faja de la llanura comprendida entre los ríos Tánaro y Po representan márgenes refractarios a la cristianización y era el contexto generador de las preocupaciones de Máximo, obispo de Turín. Sin embargo al mismo tiempo se empezaba a detectar la existencia de un difuso cristianismo rural que parecia desarrollarse entre aquellos sectores sociales subalternos dónde mas fuerte se había considerado siempre la conservación del paganismo.

Sergio Roda sostiene que la abundante documentación epigráfico-cristiana de Dertona, dispuesta en un arco cronológico que se desarrolla al menos desde $454^{55}$ hasta la mitad del siglo VI ${ }^{56}$, muestra la existencia de una comu-

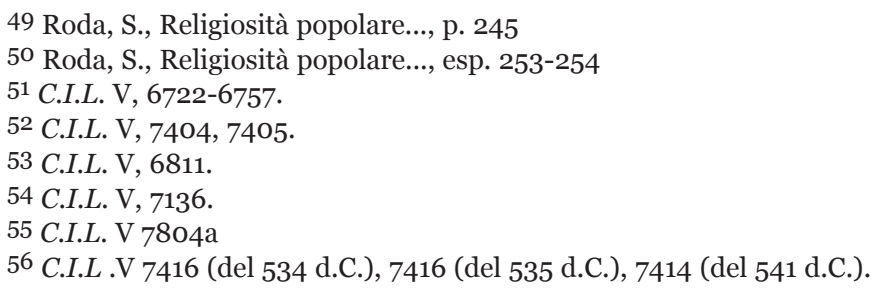


nidad cristiana de nivel sociocultural no elevado, contrastando esta situación local con la de las ciudades limítrofes como Vercelli o Turín, donde el perfil social del cristianismo local parecía decididamente privilegiar a sectores más elevados de la comunidad urbana ${ }^{57}$.

Entonces se puede señalar que en esta región no existía una única identidad cristiana urbana de los possessores contrapuesta al error gentilitates de los rustici de los latifundia, sino también un cristianismo de los rustici que convivía o coexistía con el paganismo de otros rustici, a través de una acomodación en la que las tensiones religiosas eran probablemente moderadas por la homogeneidad de los intereses sociales de ambos en un contexto donde se conjugaban la necesidad de sobrevivir a la inestabilidad política con la resistencia a las penetraciones externas (herejes, bárbaros, etc.).

A modo de conclusión podemos señalar que nuestra investigación ha analizado algunas de las cuestiones más significativas del contexto político-ideológico que modificaron los espacios centrales y periféricos y que terminaron afectando la composición misma del cuadro eclesiástico de Italia septentrional durante el siglo IV.

El modelo de organización eclesiástico original fue redefinido por las nuevas posibilidades previstas para el reclutamiento de sus integrantes a nivel regional. Este perfil se puede explicar tanto a partir de una revisión de las redes episcopales organizadas especialmente durante el período ambrosiano como a través de la consideración de aquellos elementos que configuraron el espacio social entre diversidades étnico-culturales, identificadas tanto con paganismos y cristianismos locales como con corrientes heréticas exógenas.

Es en este contexto de mutaciones que la Iglesia, ante la variedad de situaciones a resolver, desarrolló estrategias que trasgredieron algunas de sus reglas tradicionales con el objetivo de seleccionar un personal eclesiástico específico y adecuado a los requerimientos de las nuevas realidades políticas y socioculturales. 


\section{Bibliografia}

A.A.V.V., La figura e l'opera di Lucifero di Cagliari. Una revisitazione. Atti del I Convegno Internazionale. Cagliari, 5-7 dicembre 1996 (Studia Ephemeridis Augustinianum 75), Roma, 2001

Cantino Wataghin G., Christianisation et organisation ecclésiastique des campagnes: L'Italie di Nord aus IVe.-VIIIe. siècles, en: Brogiolo G.P., Gauthier N., Christie N. (eds.), Towns and their territories between Late Antiquity and the Early Middle Ages, Leiden-Boston-Köln, 2000, pp. 209-234

Cecconi G.A., Vescovi e maggiorenti cristiani nell'Italia centrale fra IV e V secolo, en: Vescovi e pastori in epoca teodosiana, vol.I (Studia Ephemeridis Augustinianum 58), Roma, 1997, pp. 205-225

Cracco Ruggini L., La fisonomia sociale del clero e il consolidarsi delle instituzioni ecclesiastiche nel Norditalia (IV-VI secole), en: Morfologie sociali e culturali in Europa fra Tarda Antichità e Alto Medioevo, II (Settimane di Studii XLV), Spoleto, 1998, pp. 851-901

Cracco Ruggini L., Pagani, ebrei e cristiani: odio sociologico e odio teologico nel mondo antico, en: Gli ebrei nell'Alto Medioevo (Settimane di Studi XXVI), Spoleto, 1980, pp. 3-117

Devoti D., Massimo di Torino e il suo publico, en Religiosità popolare nel cristianesimo antico (Augustinianum XXI), Roma, 1981, pp. 153-167

Guyon J., I primi secoli della missione cristiana en Italia, en: De Rosa G., Gregory T., Vauchez A., Storia dell'Italia religiosa 1. L'Antichità e il Medioevo, Bari, 1993, pp. 79-110

Hefele C.F., Leclercq H., Histoire des conciles, I-III, Paris, 1907-1910

Krautheimer R., Arquitectura paleocristiana y Bizantina, Madrid, 1996

Lanzoni F., Le diocesi d'Italia dalle origini al principio del secolo VII (an. 604), I-II. Faenza, 1927

Lizzi R., Ambroise's contemporaries and the Christianisation of Northern Italy, Journal of Roman Studies 8o, 1990, pp. 156-176

Lizzi R., Vescovi e strutture ecclesiastiche nella cità tardoantica (L'Italia annonaria nel IV-V secolo d.C:) (Athenaeum 9), Como, 1989

Matthews J.F., Western Aristocracies and Imperial Court A.D. 364-425, Oxford, 1990 (1975)

Mazzarino S., Storia sociale del vescovo Ambrogio. Problemi e ricerche di storia antica 4, Rome, 1989

Pietri Ch., Roma Christiana: Recherches sur l'Église de Rome, son organisation, sa politique, son idéologie de Miltiade à Sixte III (311-44O), I-II, Roma, 1976 
Roda S., Religiosità popolare nell'Italia nord-occidentale attraverso le epigrafi cristiane nei secoli IV-VI, en: Religiosità popolare nel cristianesimo antico (Augustinianum XXI), Roma, 1981, pp. 243-257

Simonetti M., La crisi ariana nell IV secolo (Studia Ephemeridis Augustinianum 11), Roma, 1975

Siniscalco P., Gli imperatori romani e il cristianesimo nel IV secolo, en: Gaudemet J., Siniscalco P., Falchi G.L., Legislazione imperiale e religione nel IV secolo (Sussidi Patristici 11), Roma, 2000, pp. 67-120

Sotinel C., Le recrutement des evêques en Italie aux IVe. et Ve. siècles. Essai d'enquête prosographie, en: Vescovi e pastori in epoca teodosiana. I (Studia Ephemeridis Augustinianum 58), Roma, 1997, pp. 191-204

Zurutuza H., Emperadores, burócratas, magos y astrólogos, en: Zurutuza H., Botalla H. (comps.), Centro y márgenes simbólicos del Imperio Romano, Buenos Aires, 1998, pp. 175-232 



\section{Relaciones de poder en el epistolario del siglo VI: el Regestum de Gregorio Magno}

Liliana Pégolo

La preocupación ética, que se constituye en el eje motivador del discurso y el pensamiento de San Gregorio Magno, lo relaciona particularmente con los hombres del Tardoantiguo, en la medida que no puede resolver, sino a través de diferentes soportes textuales, la tensión dicotómica que escinde su ansia de santidad entre el poder seglar y la austeridad del monasterio. En ese contexto personal Gregorio Magno elabora un modelo eclesiástico que se sostiene en el ejercicio del poder pastoral y en la compasiva capacidad de la cura animae, es decir el ars artium que permite el gobernar condescendientemente a los espíritus y llevar a los hombres hacia la indagación de la palabra divina.

La utilización del género epistolográfico como medio dialéctico para la contención de los ánimos, es producto de la cotidianidad del pastor que halla en el ejercicio del ministerio sacerdotal una puesta en práctica del texto sagrado. Gregorio en la mediatez del mensaje epistolar, anuncia su propia experiencia en la persecución del télos de la vida cristiana, es decir, el fin del exilio interior del monje que lo asimila con la vida angélica. Al mismo tiempo que la epístola ficcionaliza la dialéctica conversacional de la confesión, se inscribe en el terreno de la tipología hagiográfica, ya que Gregorio se vale de su pasado monástico y su presente inscripto en el mundo, como un testimonio pasional de pugna entre dos topografías espirituales que responden a nuevas exigencias religiosas, culturales y de política eclesiástica.

A través de una selección, efectuada sobre el extenso epistolario del santo y en particular del Libro I, se examinará la interacción peculiar con diferentes y elegidos remitentes, y la recurrencia a la simbología de la "fuga del mundo para la salvación del alma" que expone su política vocación predicadora y al mismo tiempo, la solución a su propio conflicto interior. La condescensio le permite trascender el debate introspectivo entre la "exclusión" en el espacio monacal y la "inclusión” en los asuntos gregarios del Estado. A través de esta metodología, Gregorio construye una imagen viva del cristiano fundada en la veracidad autobiográfica. 
1. Las matrices socio-políticas y culturales que influyeron sobre el Imperio cristiano, antes y durante el papado de Gregorio Magno (590-604), provocaron una serie de controversias en lo que se refiere al ejercicio del poder por parte del emperador y al desarrollo de ideologemas teológicos que inficionaron la unidad dogmática de la Iglesia. Aún, los diferentes contextos de la parte oriental y occidental acrecentaban las diferentes modalidades de gobierno: por una parte la impetuosidad ${ }^{1}$ del Estado de Oriente, a lo largo del siglo VI, que se enfrentaba a la vida profana de las ciudades; mientras que en Occidente, el obispado urbano se consolidaba en los espacios citadinos que habían sobrevivido al avance de un proceso de ruralización creciente.

Por otra parte el campesinado oriental se tornó devotamente cristiano y apegado a la búsqueda afanosa de la salvación, que se instaló sobre la base de la oposición desierto-mundo; en cambio las características del vir Dei en Occidente se resolvieron a partir del concepto agustiniano de que la actitud angélica propia del monje, se desarrollaba dentro de la sociedad misma; es decir que los varones santos eran llamados a convertirse en líderes de la Iglesia católica ${ }^{2}$. No se opone para P. Brown, la santidad con la vocación política dentro del marco eclesiástico occidental 3 ; la ruptura con el sedentarismo secular podía hallarse en modo ejemplar entre los santos ya muertos ${ }^{4}$ y no entre quienes, recluidos en tópoi no-urbanos, se entregaban a la recuperación del paraíso perdido.

No obstante, en una y otra parte del Imperio, a pesar de sus diferencias, los hombres se enfrentaban a múltiples preocupaciones, aún cuando fueron grandes los propósitos que alimentaron los sueños de encumbramientos efímeros. El siglo VI vio el surgimiento de Pedro Sabacio Justiniano, un outsider como lo califica Brown ${ }^{5}$, que a través de un sistema autocrático, pretendió imponer un poder ilimitado como representante de Dios en la tierra, ante el cual la Iglesia y el estado debían doblegarse ${ }^{6}$. Justiniano, que asumió en el año 527, sería el emperador que extendería nuevamente las posesiones imperiales hasta España, ya que se consideró a sí mismo como el propulsor de la renovatio o recuperatio imperii ${ }^{7}$.

La instauración de un poder universal suponía para Justiniano, la unificación del estado político con el eclesiástico de carácter ortodoxo. Al igual que

\footnotetext{
${ }^{1}$ Brown, Peter: El primer milenio de la cristiandad occidental. Barcelona, 1997. Segunda Parte, Cap. Siete, p. 107.

2 Idem (1), p. 108.

3 Idem (1), p. 109.

4 Idem (3): Obsérvese el ejemplo que da Brown sobre Gregorio de Tours.

5 Idem (1), pp. 111-112.

6 Maier, Franz: Las transformaciones del mundo mediterráneo. Siglos III-VIII. México, 1989, Vol. 9. Cap. 3, p. 178.

7 Idem (6), p. 179.
} 
Constantino, dos siglos antes, necesitó doblegar posturas heréticas que azotaban la unidad político-religiosa. Su concepción de un Imperium Romanum Christianum, de tipo absolutista, requería de actitudes intolerantes hacia todo aquello que hiciera peligrar sus pretensiones de soberanía este-oeste. Hacia el año 555, después de casi dos décadas de campañas militares, Justiniano había logrado que el Mediterráneo fuera un mar romano-bizantino; pero, como afirma F. Maier, los éxitos del emperador sufrían la discrepancia entre ideología y realidad ${ }^{8}$.

Las guerras desangraron el Imperio que requería de una política impositiva cada vez más asfixiante para equilibrar su balanza interna; a pesar de la importante reforma administrativa llevada a cabo por Justiniano, la burocracia instalada hacía funcionar lentamente la maquinaria imperial; por último el problema monofisita9 lejos de calmarse, se agravaría aún más durante los reinados que siguieron al de Justiniano.

Las administraciones de sus sucesores ${ }^{10}$, hombres avezados en la milicia y severamente ortodoxos, no hicieron más que acrecentar la crisis de un estado jaqueado por enemigos internos y externos. Ante los deseos de autonomía de las noblezas territoriales - proceso que caracterizó a Occidente -, el emperador Mauricio (582-602) obró con sagacidad política creando el sistema de exarcados ${ }^{11}$ con los que unificó en una misma figura, el poder civil y militar.

A pesar de estas decisiones, Italia pasó a ocupar un segundo lugar durante la era de Justiniano y los emperadores subsiguientes; sus fronteras comenzaron a tornarse inseguras ante el avance de los diferentes pueblos que forzaban día a día la penetración por el norte. Según P. Brown, Roma era la más desolada y descuidada ${ }^{12}$ de las grandes ciudades del Imperio; en el año 568 los lombardos destruyeron la unidad italiana reconquistada por Justiniano, al dominar el valle del Po hasta Spoleto y Benevento, pasando a controlar la cadena de los Apeninos. A pesar de esto, Ravena seguía sostenida por el poder virreinal del exarca bizantino y se irguió sobre las poblaciones bárbaras con la imagen de la sancta res publica ${ }^{13}$; Roma, bajo el poder de los

\footnotetext{
8 Idem (6), p. 237.

$9 \mathrm{El}$ monofisismo es una posición herética que sostiene una única naturaleza en Cristo, la divina; por lo tanto la carne del Lógos es distinta a la humana en esencia. Esta postura fue condenada durante el sínodo patriarcal celebrado en Constantinopla, en el año 448. Hubo un nuevo intento por acabar con las posturas alejandrinas del monofisismo, al convocarse el cuarto concilio de Calcedonia, en el 451.

${ }^{10}$ Los emperadores que le sucedieron a Justiniano hasta acabr el siglo VI, fueron Justino II (565578), Tiberio I (578-582) y Mauricio (582-602).

${ }^{11}$ En Ravena y Cartago, el emperador Mauricio inició el proceso de militarización del aparato administrativo.

12 Idem (1), Cap. Ocho, p. 121.

13 Idem (12) y Zurutuza, Hugo: "Los "hombres de Iglesia" en la Umbria Tardoantigua. La discretio como criterio de ordenamiento de la comunidad monástica", en Umbria cristiana. Dalla
} 
papas, cuidaba el llamado "patrimonio de San Pedro" con el fin de mantenerse y reubicar a los refugiados del centro de Italia y pagar las guarniciones militares imperiales ${ }^{14}$.

Aunque los obispos occidentales cumplían actividades de abastecedores y administradores de las ciudades italianas bajo el dominio bizantino, la Iglesia de esta parte del mundo había iniciado ya en el siglo $\mathrm{V}$, un proceso de centralización y de política autónoma que tenía a Roma como centro dominante. Hasta el momento, los terratenientes romanos, que se vanagloriaban de su pertenencia al antiguo Senado, mantenían sus relaciones territoriales con el resto de la península hasta que acabaron aislados y arruinados durante las guerras de expansión de Justiniano.

La llegada de los lombardos a Italia sería el hecho que consolidaría el ascenso del papado ya que se ablandaría la sujeción política del papa por parte de los delegados bizantinos, para quienes el obispo de Roma sólo era el patriarca de Occidente ${ }^{15}$. A partir de la formación de un nuevo estado en la península itálica que modificó el espacio de poder entre los lombardos recién llegados y los dominios orientales, la sede del obispado romano ampliaba su deseo de autonomía y para esto, la asunción como papa de Gregorio, sería un verdadero hito en la instauración de su existencia política.

2. La importancia que se le asigna al papado de Gregorio, obedece al hecho de que en él se sintetizaron diversas concepciones ideológicas y religiosas, que en apariencia contradictorias entre sí, representaron un punto de inflexión en el proceso de cristianización de Occidente, entendiéndose por dicho proceso aquello que define Zurutuza como no solamente la adhesión doctrinal sino el ejercicio de determinadas prácticas, conductas y modos de concebir la autoridad ${ }^{16}$. En Gregorio se ejemplificó la pertenencia a dos estados religiosos disímiles: su aceptación de la vida clerical con preocupaciones seglares, cuando marchó hacia la corte bizantina, en el año 572, como praefectus urbi y su separación posterior de lo "mundano" cuando eligió la vida monástica, hacia el año 574.

Esta dualidad de santidad y participación en los asuntos de estado - característica del Occidente cristiano -, no era ajena para quienes pertenecían a las clases aristocráticas y veían en las turbaciones de los hechos contemporáneos, un peligro inminente del "fin de los tiempos" ante los cuales la "áscesis" aseguraba la salvación. Como afirma S. Pricoco, en el monasticismo occidental

diffusione del culto al culto del santi (secc. IV-X). Spoleto, 2001, p. 906.

14 Idem (13).

15 Idem (6), pp. 250-251.

16 Idem (12), p. 905. 
había una fuerte presencia aristocrática ya desde las primeras comunidades, en muchas de las cuales, los nobles se retiraban con su servidumbre para continuar con un estilo de vida en el que la comunión con las lecturas bíblicas y su reflexión, no significaba más que una transformación del otium clásico ${ }^{17}$.

Ya Juan Casiano, perteneciente a una familia rica y religiosa, mediando el siglo IV, había peregrinado por Palestina para ejercitarse en la militia spiritualis y más tarde, en el $\mathrm{V}$, propugnó reformas en el monasticismo de Occidente, a partir de la austeridad del oriental y el retorno a los temas apostólicos ${ }^{18}$. Casiodoro, un contemporáneo de Gregorio, que luego de defender los intereses de los reyes ostrogodos en Constantinopla, regresó a Italia y fundó en sus heredades un monasterio que pretendió convertir en una civitas $\mathrm{Dei}^{19}$. Al igual que estos, Gregorio pertenecía a una familia poderosa ${ }^{20}$ en la que se combinaba la pertenencia al "mundo" y el afán de reclusión; es por ello que tras renunciar a su cargo de prefecto, se hizo monje transformando la mansión de su padre en el Aventino, en un monasterio.

En cuanto a su formación, todos ellos gozaron del conocimiento del pasado como verdaderos eruditos del período tardorromano ${ }^{21}$ y en consecuencia hicieron de sus espacios de retiro, un "continente" para la evocación de los poetas clásicos por los que se sentía atraído, particularmente por Virgilio, como es el caso de Casiano ${ }^{22}$; lugares de copia, distribución de textos cristianos clásicos en latín y traducción de fuentes griegas, tal como sucedió con Casiodoro ${ }^{23}$. Este impulsó un trabajo equilibrado de meditación religiosa y filológica que también fue desarrollado por Benito de Nursia, quien en el año 529 fundó el monasterio de Montecassino donde sentaría las bases definitivas del monacato latino.En el caso de Gregorio, el establecimiento de un centro de riguroso estudio y reflexión ascética significó una radicalización de las reglas establecidas por Benito24, en particular aquellas que impulsaban el estudio de las letras profanas. Maier recuerda un caso, que tuvo a Gregorio

\footnotetext{
17 Pricoco, Salvatore: "Le trasformazioni del monachesimo occidentale fra Tarda Antichità e Alto Medioevo" en Morfologie sociale e culturali in Europa fra Tarda Antichità e Alto Medioevo. Spoleto, 1998, T. Secondo, pp. 787-788.

18 Pastorino, Agostino: "I "temi spirituali" della vita monastica in Giovanni Cassiano". Civiltà Classica e Cristiana. Anno I, N 1, Aprile 1980, pp. 125-126.

19 Idem (12), p. 125.

20 Zurutuza en idem (13) recuerda la relación de la familia de Gregorio con los poderosos Anicii, un clan cristiano de cuño aristocrático, caracterizados por su apoyo a las letras y las artes, durante los siglos anteriores.

21 Idem (19).

22 Idem (18).

23 El Vivarium, fundado por Casiodoro, era un centro de estudios de aspecto monacal en donde se proponía a sus miembros el estudio de la teología y de las ciencias profanas. Véase Maier, F: Idem (6), p. 209.

24 Idem (19).
} 
como protagonista, cuando amonestó al obispo Desiderio de Viena porque se ocupaba más de la gramática que de la teología 25 .

Estos ejemplos de conductas paralelas en las que incluso, se advierten ciertas diferencias, permiten afirmar la existencia de tensiones ideológicas sobre el ejercicio de las funciones de monjes y clérigos y, en particular, sobre el modo de acercamiento a los textos. La iglesia al igual que las clases aristocráticas, eran las patrocinadoras de la vida espiritual e intelectual de la época; pero no existía un acuerdo, en especial entre las diversas reglas monásticas, acerca de la consideración de textos profanos, a excepción de los testamentarios.

S. Pricoco afirma que la única y verdadera "regla" de la vida monacal, es la Sagrada Escritura y su fundamento estriba en la predicación apostólica, ejemplificada en el Nuevo Testamento26; por lo tanto la instauración de la meditatio benedictina que incluía la lectura y reflexión sobre los textos, implicaría la equilibrada "conversión" de los monasterios occidentales en focos de ciencia y literatura ${ }^{27}$ donde se trabajaría en la transcripción de códices y en la conservación del pensamiento y la literatura clásica de la Antigüedad. Gregorio, embuido del contexto religioso de la "fuga del mundo" pero dispuesto a ocupar los espacios seculares del poder terrenal, mostraría en su producción textual, las contradicciones de su época, que animaron su propia existencia: el labor del político y la ausencia de las curae mundanas que avivaron "con ardor lírico" sus escritos ${ }^{28}$.

Antes de ser consagrado papa, en el año 590, Gregorio se dedicó, al mismo tiempo que desempeñaba sus funciones de legado pontificio en Constantinopla, a explicar a la manera que lo haría un "abad" con sus monjes, el meollo de su pensamiento moral. El mismo fue contenido en el titulado Moralia in Iob, un texto de carácter exegético en los que se tratró un problema muy antiguo, ya considerado desde la época de Séneca: el problema del poder y de las obligaciones y turbulencias que este provoca ${ }^{29}$.

El resto de su obra se centró en la expresión de su pensamiento inquieto que no resolvía las antinomias políticas y religiosas del siglo VI: la Regula

25 Idem (6), p. 225. Contrariamente a esta afirmación, Alejandro Holgado Ramírez y José Rico Pavés en la Introducción a La regla pastoral de Gregorio Magno. España, 1993, p. 31 y 128-131, sostienen que no se puede discutir la formación clásica de Gregorio y que la amonestación a Desiderio obedece al hecho de que el clérigo debía anteponer a las artes humanas, las Sagradas Escrituras.

26 Idem (17), p. 761.

27 Idem (6), p. 210.

28 Cremascoli, Giuseppe: "La Bibbia nella Regola Pastorale di San Gregorio Magno". Vetera Christianorum. Anno 6, 1969. Fasc. 1-2, p. 47.

29 Idem (12), p. 126. Siempre se estimó que la redacción del texto no se habría concluido hasta el año 595 cuando se la envió a Leandro, el obispo de Sevilla. Sin embargo la crítica más reciente considera que en el 597 estaría retocando aún el libro 27. Véase idem (25), pp. 82-83, n. 156. 
pastoralis, escrita en el año 593 e inspirada en la concepción agustiniana ${ }^{30}$, concentró la experiencia religiosa contemporánea, partiendo de la doble "vida" llevada por Gregorio en la reclusión del monasterio ${ }^{31}$ y en la inclusión del saeculum. En la Regula, el santo se situó en el ejercicio del poder abacial32 para desempeñar su labor de "padre" y "pastor", centrándose en una discusión sobre el carácter del poder que debía ser universal y perdurable.

Por otra parte Gregorio, a partir del modelo paulino, que era su ideal de hombre contemplativo pero no indiferente a la problemática de la Iglesia como institución terrenal, mantuvo una muy nutrida correspondencia donde reflejó su gestión de gobierno. Su Regestum, es decir, su archivo de correspondencia cuidado y revisado por él mismo para su selección y publicación, refleja su preocupación por los asuntos de Estado y la necesidad de mantener una comunicación fluida que estableciera de manera permanente, las relaciones verticales entre el pastor y su grey33. Como ya se señaló, el uso del género epistolográfico como dispositivo dialéctico para el control de los ánimos, manifiesta el esfuerzo diario del pastor que encuentra en la práctica del ministerio sacerdotal una utilización concreta del texto sagrado. Gregorio proclamaba su propia experiencia en la búsqueda del télos de la vida cristiana, o sea, el final del exilio interior del monje que lo asimila con una dimensión angélica.

El carácter insólito ${ }^{34}$ que le asigna Brown al ejercicio y reflexión sobre el poder que efectuó Gregorio, tanto en su correspondencia como en la Regula, se debe al hecho de elaborar una especie de metodología para liberar a los hombres de las inquietudes surgidas de la acción política y religiosa; se trata del ars artium, regimen animarum ${ }^{35}$, una "cura" de las almas atribuladas,

30 La inspiración agustiniana que Brown en idem (12), p. 127 le atribuye a la Regula se ve ampliada por la afirmación del obispo Liciniano de Cartago, quien en una carta registrada con el número 41a del L. I de Regestum, de fecha incierta, señalaba que en las enseñanzas morales del papa Gregorio se atestiguaban "los antiguos santos padres, doctores y defensores de la iglesia, Hilario, Ambrosio, Agustín, Gregorio" (refiriéndose al Nazianceno): Adtestantur huic eximiae doctrinae tuae sancti antiqui patres, doctores defensoresque ecclesiae, Hilarius, Ambrosius, Augustinus, Gregorius. ("Registrum Epistolarum Gregorii I Papae". Monumenta Germaniae Historica. Epistolarum Tomi I, Pars I, Gregorii I, Registri LI-IV. Berlín, 1887).

$3^{1}$ En dos oportunidades Gregorio abandonó su vida de "hombre político" para dedicarse a la vida monástica.

32 Idem (12), p. 909.

33 Zurutuza señala en idem (31) que la correspondencia de Gregorio incluía un número de veinte mil cartas, de las que se conservaron ochocientas sesenta y seis. Brown señala en idem (12), p. 130 que el 63\% de esas cartas, es decir, rescriptos, es decir, respuestas a una solicitud de normativa en materia administrativa o eclesiástica. Esto supone el manejo político establecido por Gregorio para la comunicación con las delegaciones que llegaran a Roma.

34 Idem (29).

$35 \mathrm{Al}$ comienzo de la Regula pastoralis Gregorio afirma: Ab imperitis ergo pastorale magisterium qua temeritate suscipitur, quando ars est artium regimen animarum? (“¿Por lo tanto, de 
surgida de un conocimiento extraordinario de las mismas que sólo puede estar inspirado en la experiencia del maestro o del monje. Asimismo el rector espiritual debía contar con las dotes de un "médico" que percibía a través de los signa, las causas de su enfermedad ${ }^{36}$, al igual que debía contar con un conocimiento profundo de la palabra divina. Este saber se alcanzaba en la meditación de una vida santa, para así anunciarlo a los fieles casi con un carácter profético ${ }^{37}$.

A la simbología médica que observa Brown en la Regula y la anunciada "revelación" que le cabe al "rector" como función propia de su oficio, se le suma el valor exegético, al que recurre Gregorio para llevar adelante la "metodología de la salvación del alma”. Se requiere, en consecuencia, que el mensaje salvífico conducido por el obispo, el abad, el clérigo en general, goce de características parenéticas y alegóricas ${ }^{38}$ por medio de las cuales se ejerza un control de las conductas, ciñéndose a los ejemplos virtuosos extraídos de las Escrituras. En definitiva, el "arte de gobernar las almas" no se comportaba de manera diferente a la filosofía, tal como era entendida por los estoicos, con la diferencia de que esta última ponía límites a las pasiones que hicieran peligrar el equilibrio social ${ }^{39}$, frente a la necesidad que observaba Gregorio, de contener individualmente las necesidades de cada cristiano para llegar a la contemplación de la divinidad.

La preocupación ética, como se destacó anteriormente, instala el eje motivador de su discurso y su pensamiento y lo vincula especialmente con los hombres del período en cuestión, el Tardoantiguo, en la medida que no puede solucionar, sino a través de la denominada condescensio, la tensión dicotómica que divide su deseo de santidad entre el poder seglar y la austeridad monástica. A partir de la contextualización personal, Gregorio desarrolla un paradigma de poder eclesiástico que se sostiene en el ejercicio de la contención pastoral y en la compasiva capacidad de la cura animae, este ars artium que posibilita orientar los espíritus, sorteando la distancia que media entre los dos polos de la antinomia que impedía el progreso espiritual de la humanidad.

Desde los primeros siglos del cristianismo existía la necesidad de contar con un guía espiritual que instara a las prácticas virtuosas y que asistiera a los fieles en su peregrinación de "exiliado" en un espacio que lo alejaba de lo

lo no experimentado con qué temeridad el magisterio pastoral se sostiene, cuándo el arte de las artes es la conducción de las almas?”). El texto transcripto pertenece a la versión de N. Turchi, utilizada por G. Cremascoli en Idem (28).

${ }^{36}$ Idem (12), p. 127.

37 Idem (28), pp. 48-49.

38 Idem (28), pp. 52 y ss.

39 Véase en Habinek, Thomas N.: The Politics of Latin Literature. Writing, Identity, and Empire in Ancient Rome. Princeton, 1998. Chapter 7, pp. 136 y ss, cuando afirma que, en particular Séneca "inventa", combinando tradición e innovación, una aristocracia de la virtud. 
ultraterreno ${ }^{40}$. Por lo tanto, la ruptura que practica el monje en soledad tiende a conciliarse con la experiencia de Gregorio, que estimaba que el supremo acto de Dios había residido en su "descenso" al mundo para transformarse en la encarnación misma del exilio ${ }^{41}$. La condescensio debe entenderse como un estado que tiende a equilibrar "con afabilidad", dos instancias en las que se impone el poder de lo divino: el espacio celestial y el humano, pero al mismo tiempo se tiende a conciliarlos a través del ejemplo evangélico. El "mediador" que la usa como instrumento, ejerce particularmente un poder de control y contención casi monopólico del alma a gobernar.

Este tipo de práctica de control sobre "los otros", ejecutada de manera continua y permanente, es lo que M. Foucault denomina como pastorado o poder individualizador ${ }^{42}$. Surgido en las sociedades orientales y desarrollado particularmente por los hebreos, el pastorado se funda en el hecho de que es la divinidad quien le encomienda al gobernante la tarea de reunir un rebaño al que le da o promete una tierra ${ }^{43}$. En su función de conductor o rector, el pastor, a diferencia del jefe político que hace prevalecer la unidad de la ciudad, hace uso de una bondad constante, individualizada y finalizada. ${ }^{44}$ Esta alegoría de la conducción señalada por la divinidad, pretende explicar el camino propio del "exiliado" que sigue el pueblo elegido hasta alcanzar el Paraíso redimido; los cristianos se valieron de las imágenes de los conductores de Israel para prefigurar la venida de Cristo, quien dirige el alma de los fieles hacia la redención final en un espacio supraterrenal ${ }^{45}$.

La "tecnología del poder" sustentada por Gregorio se basa en una relación de intercambio con sus alocutarios, con los que se comporta responsablemente, es decir dando respuestas asistenciales a los problemas planteados en lo político, lo económico, lo monacal o, simplemente, aquellos surgidos de las tensiones anímicas. La relación que se establece a través de la correspondencia, se funda en la fuerza de los lazos morales que asocian al pastor a cada miembro de su tribu ${ }^{46} \mathrm{y}$, en consecuencia, entre los miembros se establece una dependencia individual, que tiende al control de la voluntad. Foucault recuerda que, según la regla benedictina, los monjes no seguían su libre albedrío, sino que estaban sometidos sumisamente a la autoridad del abad, cuyo conocimiento individualizado surgía del examen y dirección de la conciencia ${ }^{47}$.

40 Véase Brown, Peter: El cuerpo y la sociedad. Los hombres, las mujeres y la renuncia sexual en el cristianismo primitivo. Barcelona, 1993. 5, pp. 152 y ss.

41 Idem (18), pp. 129-131.

42 Foucault, Michel: Tecnologías del yo y otros textos afines. Barcelona, 1995. 2. "Omnes et singulatim: Hacia una crítica de la "razón política", I, p. 98.

43 Idem (42), p. 100.

44 Idem (42), p. 101.

45 Idem (41).

46 Idem (42), p. 112.

47 Idem (42), pp. 113-114. 
Pero la habilidad pastoral de Gregorio que cultivó estas estrategias, consistió en la inclusión de su propia experiencia dicotómica, mostrándose como un hombre "mortificado" que renuncia al mundo y a sus propios intereses para hallar la salvación; pero llegado el caso asume sus compromisos de "ciudadano de Dios" 48 para sumarse al juego político. Gregorio, en definitiva, se adelanta al surgimiento del Estado moderno al aunar su condición de civis y de rector en un ejercicio complejo que suponía la racionalidad del político y la aspiración mística del monje ${ }^{49}$.

3. La elección del género epistolográfico por parte de Gregorio, inserta su correspondencia en la tradición ya desarrollada en la Antigüedad y en particular por San Pablo, en un claro ejemplo de utilizar el discurso epistolar como un mecanismo de cohesión dogmática y de control político. Si bien, desde la perspectiva de la tradición retórica, no son muchas las características ni los preceptos que se tienen acerca de este tipo discursivo, las cartas de Gregorio parecen obedecer a un criterio de síntesis entre "lo público y lo privado", si se recuerda la clasificación ciceroniana que estimaba la comunicación con un destinatario único o bien, multitudinario 50 .

El hecho de que las cartas contenidas en el Regestum fueran sometidas a criterios de corrección y selección por parte del remitente, es un indicador de que la finalidad era la publicación, por lo tanto más que "cartas personales" en las que se contenían las inquietudes espirituales de la acción pastoral, deberían considerarse como epístolas ${ }^{51}$; es decir que la comunicación establecida con sus interlocutores contenía temas concernientes a la política eclesiástica y monacal, doctrinarios, filosóficos y teológicos, a la vez que mostraban un estilo severo y grave.

48 P. Brown recuerda en idem (12), p. 130 el epitafio de Gregorio Magno, a quien se lo califica como consul Dei.

49 Obsérvese cómo en la Vita Gregorii, Cap. I, Paulo Diácono reconocía en la etimología del nombre Gregorio, la condición de vigilator de la conciencia de los fieles a través del uso de la doctrina y los preceptos surgidos de ella: Non sine magno praesagio tale sortitus est nomen. Gregorius namque ex Graeco eloquio in nostra lingua Vigilator seu Vigilans sonat. ("No sin un gran prodigio fue fijado por el destino tal nombre. Pues Gregorio, proveniente del griego, suena en nuestra lengua como el vigilador o el que vigila.").

50 Ingeborg Braren en "Como definir essência das cartas e das epístolas? en Actas de las VII Jornadas de Estudios Clásicos. UCA, Buenos Aires, 1995, p. 48, recuerda la afirmación de Cicerón en Fam. 15, 21, 4: aliter enim scribimus quod eos solos quibus mittimus, aliter quod multos lecturos putamus ("escribimos pues de una forma cuando pensamos en esos solos con los que nos comunicamos, de otro modo cuando pensamos que son muchos los que lo leerán”).

$5^{1}$ Idem (50), pp. 48-49: Se recurre a las categorías y métodos para distinguir variaciones entre "cartas" y "epístolas" aportados por K. Thraede en Grundzüge griechisch-römischer Brieftopik. München, 1970, pp. 2-3. 
Si se sigue esta tipología epistolográfica establecida por Cicerón ${ }^{52}$, se encasilla la correspondencia de Gregorio al modelo de la epístola tal como la entendían los antiguos retores y en consecuencia se contrapondría al concepto pragmático de la condescensio y al poder del pastor, que pretende asistir a los fieles en su individualidad. Si bien estas cartas eran destinadas a la lectura, no dejan de mostrar tampoco un aspecto personal y confesional; quizás adaptado a las necesidades hagiográficas de Gregorio de ejemplificar en sí mismo un conflicto de espacios sin resolver ${ }^{53}$. Por otra parte, las cartas de Pablo, argumentativas y retóricas, donde se puede oir su voz autorizada y demarcatoria de su status apostólico ${ }^{54}$, debieron ser estimadas por Gregorio en la medida que funcionaron como instrumentos de poder, en medio del proceso de construcción de la iglesia como institución unificadora.

En definitiva, tal como lo entiende H. Gamble ${ }^{55}$, ya desde los comienzos del cristianismo, existía una gran variedad epistolar que se utilizaba conforme a los fines y al nivel de escolarización de los interlocutores; estas distintas formas de correspondencia combinaban la familiaridad de la carta personal, la autoridad de la misiva oficial y el carácter didáctico y expositivo de la carta filosófica; en consecuencia, en materia de géneros literarios, los cristianos no hicieron más que adaptar una forma ya establecida por el mundo grecorromano que se conservó a pesar del paso de los siglos, a través de la formación retórica.

Gregorio fusionó los estilos e hizo uso de las posibilidades epistolares conforme a los temas a tratar y a los receptores a quienes se dirigía. Mostró conocer a la perfección las situaciones comunicativas diversas ${ }^{56}$ que exigían diferentes tipos de correspondencia. Si se toma el Libro I del Regestum ${ }^{57}$ para ejemplificar esta competencia lingüística dirigida a la conducción de las voluntades, se podrá reconstruir el sistema de poder establecido por Gregorio

\footnotetext{
52 Braren recurre nuevamente a Thraede en Idem (51) para referir los géneros de cartas aludidos por Cicerón en Fam. 2, 4, 5: genus I: la carta como una misiva para comunicar noticias nuevas, genus II: la carta como instrumento de consuelo o de comunicación de asuntos gratos y genus III: la carta en la que se tratan temas filosóficos y políticos

53 Considerar las cartas de Gregorio Magno desde una perspectiva hagiográfica, supone que se entiende la hagiografía como un género que presenta diversificaciones tipológicas que responden a nuevas exigencias religiosas, eclesiásticas e inclusive, pastorales, donde el elemento autobiográfico constituye una novedad, tal como ocurre con la obra de Gregorio. Al respecto, véase Boesch Gajano, Sofia: "L'agiografia" en idem (17), pp. 804 y ss.

54 Gamble, Harry Y.: Books and readers in the early church. A history of early christian texts. Michigan, 1995. III, p. 95.

55 Idem (53), I, pp. 36-37.

56 En idem (25), p. 102, n. 239 se hace referencia a una clasificación de las cartas de Gregorio llevada a cabo por Turchi Nicolau; se las divide en familiares o aquellas enviadas a los amigos, económicas las que se ocupan de la administración del patrimonio de la iglesia, canónicas, litúrgicas, políticas, pastorales, dogmáticas y espirituales.

57 Cabe aclarar que sólo se contemplará este libro del epistolario de Gregorio, para la realización de este trabajo.
} 
al comienzo de su papado, ya que en este libro están comprendidas las cartas enviadas y recibidas entre septiembre del año 590 y agosto del 591.

De los ochenta y dos textos epistolares del mencionado volumen se destacan, en primer lugar por su número ${ }^{58}$, aquellos que relacionan a Gregorio con la diócesis siciliana, una parte importante de la vasta red de patrocinio $y$ administración ${ }^{59}$ que incluía la cuenca mediterránea desde Marsella hasta Cartago; además de ser un territorio con el que estaba unido económica y afectivamente por línea materna.

Entre las preocupaciones del pontífice aparecen aquellas surgidas de la aceptación de su autoridad o la de su enviado $(I, 1)^{60}$, las exhortativas a la concordiam, iustitiam, honestitatem que hace a Justino, el pretor de Sicilia $(\mathrm{I}, 2)$, además de la presentación que hace a su receptor, del nuevo conductor económico de la diócesis, el subdiácono Pedro $(\mathrm{I}, 3)^{61}$. A través de estas cartas, emitidas en septiembre del 590, Gregorio da inicio a su administración manipulando diversas estrategias para el control de Estado, inclusive la "sutileza" del "buen padre" que conduce a la reflexión sobre la brevedad de la vida en la que debe prepararse para el juicio de Dios ${ }^{62}$. Sin embargo, más allá de las habilidades pastorales del pontífice, se destaca su férrea decisión de cuidar "los bienes de San Pedro"63, tal como se ve ejemplificado en estas cartas y muchas otras, por ejemplo la I, 71, enviada en agosto del año 591, al ya mencionado subdiácono Pedro para que tramitara la restitución de las posesiones de una iglesia siciliana que habían sido expropiadas injustamente ${ }^{64}$.

$5^{8}$ Se pueden contar dieciocho cartas enviadas a receptores sicilianos en el mencionado volumen I, que representa el $21,9 \%$ del total.

59 Idem (32).

60 I, 1, 11-13: Valde necessarium esse perspeximus, ut, sicut decessorum nostrorum fuit iudicium, ita uni eidemque personae omnia committamus, et, ubi nos praesentes esse non possumus, nostra per eum, cui praecipimus repraesentetur auctoritas. ("Percibimos que es muy necesario, que, así como fue el juicio de nuestros predecesores, de esta manera unimos todas las cosas en una misma persona, y, cuando nosotros no podamos estar presentes, nuestra autoridad estará representada a través de él, a quien recomendamos").

${ }^{61}$ I, 3, 14-15: Petrum vero, subdiaconum nostrum, quem pro regendo ecclesiae patrimonio, Deo auctore, transmisimus, vestrae gloriae per omnia commendamus. ("En verdad a Pedro, nuestro subdiácono, a quien remitimos para regir el patrimonio de la iglesia, siendo Dios el garante, encomendamos para todo a vuestra gloria.").

62 I, 2, 9-10: Quam sit vita brevis aspicite, ad quem quandoque ituri estis iudicem, qui iudiciariam potestatem geritis, cogitate. (" Examinad cuán breve es la vida, pensad hacia qué juez y cuándo iréis, que lleváis sobre vosotros la potestad judicial”).

63 Idem (25), pp. 62-63: En el cargo de obispo de Roma, debió administrar los bienes eclesiásticos de Sicilia, Campania, Córcega, Cerdeña, Provenza, Dalmacia y África que constituyeron la base de los Estados Pontificios. Estas adquisiciones territoriales fueron obtenidas por los pontífices a partir de una ley de Constantino, del año 324, que le permitía a la iglesia recibir o heredar toda clase de bienes.

64 I, 71, 15: Et quia domus vel fines atque possessiones Tauromenitanae iuri ecclesiae pertinentes dicuntur $a b$ actionariis nostrae ecclesiae contra rationis ordinem occupatae, "Y porque 
Su capacidad de observación de los conflictos que afectaban su jurisdicción, hizo que desplegara una gama muy amplia de recursos para mantener la pax en las distintas áreas de su competencia; esto se advierte en el control de la ortodoxia y el cuidado puesto sobre cuestiones heréticas que aún en su tiempo, seguían hostigando la unidad eclesial. Obsérvese en la carta I, 1665 el carácter imperativo de Gregorio para que se presentaran en Roma, Severo, obispo de Aquilea66, y sus compañeros acusados de poner en duda el dogma católico, defendiendo la posición cismática de "los tres capítulos".

Esta disputa teológica, que se extendió entre los años 543 y 554, fue la culminación de un intento del emperador Justiniano de reducir la influencia monofisita en Oriente, declarando como sospechosos de "nestorianismo"67, los escritos de tres padres de la iglesia siria: Teodoro de Mopsuestia, Teodoreto de Ciro e Ibas de Edesa, quienes fueron finalmente condenados en el concilio de Constantinopla del año 55368. La solución del emperador no tuvo éxito en Occidente ya que los tres condenados se habían reconciliado con la Iglesia; en consecuencia el conflicto no concluyó; contrariamente a lo esperado se sumaron al llamado cisma de "los tres capítulos", algunos obispos de la Italia septentrional ${ }^{69}$, como este Severo, al que Gregorio amonestaría con severidad pontificia.

Con carácter ejemplar, conforme a la intención hagiográfica gregoriana ${ }^{70}, y$ no exenta de recursos literarios ${ }^{71}$, la carta I, 16 está encabezada por comparaciones que ponen como ejemplo al cristiano que inquiere sobre la verdad del amor divino, urgiéndolo a tomar el camino más inaccesible, aquel que lleva a la santidad: Sicut gradientem per avia, carpentem denuo rectum tramitem, tota Dominus aviditate complectitur, demum de deserente cognitam veritatis viam

la casa o bien los límites y las posesiones son considerados por los agentes de nuestra iglesia, pertenecientes por derecho a la iglesia de Taormina ocupados contra el orden de la razón,”).

65 Las epístolas I, 16a y I, 16b están relacionadas con el conflicto originado por Severo de Aquileia; la primera de estas tiene como remitentes a los obispos de las provincias de Istria quienes afirman no estar involucrados con las posiciones nestorianas y la segunda es un pedido del emperador Mauricio a Gregorio para que los involucrados en estas cuestiones heréticas no sean obligados a ir a Roma para ser juzgados.

66 Aquilea es una ciudad perteneciente a la zona de Istria.

67 El nestorianismo, contrario a la posición monofisita, nació en Antioquía inspirado por Nestorio (380-451), quien consideraba la existencia de dos personas en Cristo y negaba a María como "madre de Dios". Véase idem (25), p. 19.

68 Idem (6), p. 195.

69 Idem (25), p. 36.

70 Leonardi, Claudio: “Agiografia” en Lo Spazio Letterario del Medioevo. 1. Il Medioevo Latino. Volume I, p. 439.

${ }^{71}$ Donnini, Mauro: "Struttura letteraria dell'agiografia umbra altomedievale” en idem (13), pp. 540 y ss: El autor señala que se pueden observar en los textos hagiográficos umbros, el uso de recursos retóricos que permiten entrever las intencionalidades literarias propias de una èlite intelectual. 
maiori merore, quam gaudio quo de convertente laetatus fuerat, contristaur; 72 Con una estructura basada en formulaciones paralelas, Gregorio insiste en las antinomias semánticas estableciendo una dualidad de conductas que lleva al interlocutor a elegir sólo una que implicará la salvación del que se somete a la unidad de la iglesia 73 , o bien la perdición del errabundo que insiste en el error de negarse a conocer la verdad por convicción ${ }^{74}$.

Los recursos antinómicos del pontífice se encaminan a mostrar una dicotomía sémica que representa la situación del interlocutor, vertebrada entre dos topografías contrarias: la de la inclusión en el espacio conceptual del dogma, o la exclusión del sistema de protección que brinda la iglesia como institución aglutinadora de los fieles bajo su red de control, aún a los que vacilan, atrayéndolos a través del "mediador" que aplica un sistema correctivo, en primer lugar, a través de la persuasión lingüística, y si es necesario a través de la fuerza militar para obligar a los "dubitativos" a presentarse ante la autoridad del papa, como es el caso del obispo Severo ${ }^{75}$.

A través de analogías que provienen del campo semántico del cultivo del campo $^{76}$, previene, en la carta I, 75 de agosto del 591, a los obispos númidas de no mezclarse con posiciones heréticas, particularmente donatistas ${ }^{77}$, llamándolos a guardar su lugar como "pastores" y guardianes de la fe católica78.

\footnotetext{
72 I, 16, 20-22: "Así como al que avanza por lugares inaccesibles, al que aprovecha por segunda vez el camino recto, el Señor lo abraza con toda su avidez, así precisamente se entristece por el que abandona la vía de la verdad con una aflicción mayor, que el gozo con el que se había alegrado por el que se convierte".

73 Idem (70), 25-26: Et nos siquidem quantum reincorporatum te iam pridem fuisse in unitatem ecclesiae gavisi fueramus, ("Y si en verdad nosotros nos habíamos alegrado de cómo te habías reincorporado ya hacía un tiempo a la unidad de la iglesia,").

74 Idem (70), 24-25: Aliudque est quod ab errante committitur, aliud quod per scientiam perpetratur. ("Una cosa es lo que se opone por equivocación, otra lo que se perpetra a causa del saber"). 75 La carta I, 16 fue llevada a Severo por los emisarios del papa Gregorio, es decir, soldados acompañados de un tribuno y un guardia de los que se hace referencia en la epístola I, 16b, 1112: In quibus omnes dixerunt, tuam beatitudinem milites ad illos transmisisse cum uno tribuno et excubitore, ("En las cuales todos dijeron, que unos soldados transmitieron a ellos tu beatitud con un tribuno y un guardia,").

${ }^{6}$ I, 75,6-9: Si quando, karissimi in Christo fratres, inter virentes segetes zizaniorum quaedam se infert inportuna commixtio, hanc radicitus necesse est cultoris manus adimat, ne futurus secundae segetis fructus possit intercipi. ("Queridísimos hermanos en Cristo, si en un momento entre los verdes sembradíos se produce alguna inoportuna mezcla de cizañas, es necesario que la mano del cultivador la suprima desde la raíz, para que el fruto futuro de la siguiente siembra pueda ser aprovrechado.").

77 Las cartas I, 72; 73; 74 y 82 tienen diferentes destinatarios pero todos ellos están llamados por el pontífice para resguardar la pureza del dogma ante la persistencia de ciertos principios donatistas en los territorios africanos.

78 I, 75, 28-29: ..., quoniam pastores constituti estis et Dominus gregum ab his quibus commisit pastoribus, fructum multiplicati gregis expectat. (“..., porque habéis sido constituidos pastores y el Señor a partir de estos rebaños con los que une a los pastores, espera el fruto de una grey multiplicada.").
} 
La imperativa prescripción del cuidado que debe darse al alma, alimenta la esperanza en la vida futura alejada de transitorios privilegios terrenales para mostrarse al fin, despojada ante la mirada del juez supremo ${ }^{79}$. Esta carta es ejemplificadora del modelo gregoriano que pretende llamar al orden con mesura pero haciendo gala de firmeza apodíctica y dogmática; el carácter de amonestación sugerido por el uso de numerosos imperativos, está "silenciado" por el hecho de recordar a los destinatarios su condición de iguales ante el pontífice, es decir que como custodios de la grey, deben ser ejemplos de caridad y de sosiego.

$\mathrm{Al}$ igual que Gregorio se preocupó por la unidad dogmática de la iglesia, también dirigió su mirada hacia las prácticas monacales, que conoció desde su conversión al monasticismo y a las que angustiosamente pretendió volver, una vez que fue destinado al ejercicio de la política eclesial. Un ejemplo de su rigurosa concepción ascética puede observarse en la carta I, 40 enviada al subdiácono Antemio, rector del patrimonio campanio, en abril del año 591; en ésta el pontífice le comunica un hecho de indisciplina por parte de unos monjes de la diócesis de Sorrento, que, con un comportamiento seglar, "transmigran" de uno a otro monasterio apartándose de la regla abacial 80 .

Las órdenes que emanan de Gregorio para su delegado tienden a prescribir conductas ante el relajamiento de la vida monacal, como la permanencia en el espacio monástico al que perteneciera el monje, la amonestación coercitiva para aquellos que se apartaran de la regla, la prohibición de volver a la iglesia en la que militaran aquellos clérigos convertidos a la vida monacal y finalmente, lo que es estimado por el pontífice como un hecho aberrante, la observación cuidadosa de que los monjes no hagan vida marital públicamente $^{81}$; ante esto último, espera que los que faltaran a la regla sean devueltos a sus monasterios de origen para su castigo. Sin embargo, como Gregorio es un hábil manipulador de las preocupaciones diversas que atañen a un pastor,

79 I, 75, 21-25:Vos ergo, fratres karissimi, admonitiones nostras zelo caritatis Dominicae praevenite, scientes, quod districtus iudex ad examinandum deducturus est cuncta quae gerimus et unumquemque nostrum non ex praerogativa sublimioris gradus, sed ex operum meritis approbabit. ("Por lo tanto, vosotros, hermanos queridísimos, tened en cuenta nuestras advertencias con el celo de la caridad del Señor, sabedores de que el juez riguroso ha sido conducido para examinar todo lo que llevamos y a cada uno de nosotros aprobará no por la prerrogativa de un grado más elevado, sino por los méritos de nuestras obras.”).

80 I, 40, 8-11: Iohannes frater et coepiscopus noster,..., inter alia plura hoc noscitur intimasse, aliquos monachos monasteriorum in Surrentina diocesi positorum de monasterio in monasterium,..., transmigrare et a propii abbatis regula desiderio rei saecularis abscedere. ("El hermano Juan también nuestro co-obispo,..., entre otras muchas cosas nos hace saber esto, que algunos monjes de los monasterios ubicados en la diócesis de Sorrento,..., transmigran de monasterio a monasterio y se alejan de la regla del propio abad con deseos de ser seglares.").

${ }^{81}$ I, 40, 22-23: Et quia aliquos monachorum usque ad tantum nefas prosilisse cognovimus, ut uxores publice sortiantur, ("Y porque hemos sabido que algunos de los monjes se precipitaron una y otra vez a tanto hecho sacrílego, que elegían públicamente sus mujeres,”). 
recomienda que todos aquellos que quieran pasar a la vida monacal, lo hagan pues conformes con su deseo, lo que evitará contiendas a la iglesia y con ello se agradará a la divinidad, único afán para un cristiano atormentado 82.

Los ejes temáticos de estas cartas representan las diversas facetas del Gregorio administrador, teólogo, pastor, monje a las cuales se le pueden sumar la del evangelizador y el político: la contienda de Italia contra la invasión longobarda requirió del pontífice un criterioso sentido del equilibrio en el ejercicio de la diplomacia, observable en la evolución de los calificativos con los que estimaba a los invasores. Gregorio no dejó de ser un civis romanus en lo que respecta a su concepción del Estado, ya que no cejó en su afán de incorporar a los longobardos en una especie de societas fundada en la concordia ordinum y sustentada en la conversión al catolicismo ${ }^{83}$. Por otra parte su misión pastoral ocupó gran parte de su preocupación apostólica en la medida que la salvación del alma residía también en la expansión de las fronteras hacia donde la palabra divina fuera extendida; al respecto ha de recordarse, particularmente, su participación en la conversión de los reyes británicos en el 597 y la difusión de la muerte de Hermenegildo, príncipe de la casa real visigótica, que habría de influir en Recaredo, para que renunciara al arrianismo en el año $589^{84}$.

Pero del conjunto de epístolas que componen este Libro I, se destacan las que contienen un inapreciable valor autobiográfico ya que muestran al Gregorio opuesto a su elección como pontífice, al que se siente obligado a abandonar su espacio de meditación e imperturbabilidad ascética para lanzarse al gobierno de la "nave del Estado" 85 donde sólo hallará el desasosiego de un mundo en transición. De este material epistolar, se considerarán las I, 5 y I, 6 porque el tiempo de enunciación de las mismas coincide con la asunción de Gregorio al papado y, en consecuencia, dejan entrever la tensión del emisor entre dos espacios de poder disímiles.

82 I, 40, 25-26: Sed et de clericis ad monachatum venientibus, sicut supra diximus, peragere omittas. Ita enim Dei placabis oculos, ("Pero también acerca de los clérigos que vienen al monacato, como dijimos arriba, no omitas que se haga. Así pues agradarás los ojos de Dios,”).

83 Véase el análisis de la relación de Gregorio con los lombardos en idem (25), pp. 54-60.

84 En la carta I, 41 de abril del año 591 Gregorio responde a Leandro, obispo de España, mostrándose satisfecho por la conversión de Recaredo, ocurrida en el 587 y oficialmente comunicada durante el Concilio de Toledo. Véase en idem (25), pp. 66-67.

85 Obsérvese como en la epístola I, 41, 12-16 y ss., señala a Leandro los avatares mundanos a los que se enfrenta en la labor pastoral y política: Tantis quippe in hoc loco huius mundi fluctibus quatior, ut vetustam ac putrescentem navem, quam regendam occulta Dei dispensatione suscepi, ad portum dirigere nullatenus possim. Nunc ex adverso fluctus inruunt, nunc ex latere cumuli spumosi maris intumescunt, nunc a tergo tempestas insequitur. ("Ciertamente soy sacudido en este lugar de este mundo por tantos oleajes, que a la vetusta y pútrida nave, que recibí para ser regida por un secreto designio de Dios, no podría de ninguna manera dirigirla a puerto. Ahora por el lado contrario se precipitan las olas, ahora desde el costado los cúmulos espumosos del mar se elevan, ahora desde atrás sigue la tormenta."). 
La primera de las cartas mencionadas arriba tiene como destinatario a Teoctista, la hermana del emperador Mauricio, con la que había entablado amistad durante su permanencia en Bizancio86; a ella se queja por haber sido reducido a una condición mundanal ${ }^{87}$ que lo exilia de la continencia del monasterio, poniéndolo al servicio de las preocupaciones terrenales ${ }^{88}$. La epístola está estructurada por Gregorio sobre la base de antinomias topográficas que representan la dualidad "del adentro y del afuera" por una parte y "del arriba y el abajo" por otra; es decir que se siente excluido del elevado goce de la quietud ascética para ascender en la exterioridad del mundo, al tiempo que siente desplomarse interiormente ${ }^{89}$. A través de esta "geometrización" del espacio mental, el pontífice simboliza filosóficamente el "afuera" como el territorio del "no ser" y el "adentro" como el "ser", estableciendo una serie de imágenes representativas de este desgarramiento con las que funda su estado de hostilidad con respecto al "mundo" 90.

Excluirse del "afuera” permitía a Gregorio experimentar la vía contemplativa que lo llevaría hacia la divinidad, pues lo que deja entrever en la carta es precisamente, su anhelo de Dios y para ello se obligaba en un explícito repliegue del espíritu, a abandonar mundum, carnem, fantasmata corporis ${ }^{91}$. El exilio de lo mundanal lo aventuraba a "elevarse" en una verticalidad ascendente que lo alejaba de los temores cotidianos 92 ; es por ello que siguiendo la áscesis monacal haría suya las palabras de Isaías $(58,14)$ que incluye en la carta: Sustollam te super altitudines terrae ("Me elevaré por encima de las alturas de la tierra")93. Sin embargo es la polaridad "arriba-abajo" la que

\footnotetext{
86 Idem (25), p. 49.

87 I, 5, 21: ...ad saeculum sum reductus, (“...fui reducido a lo secular”). En idem (25), pp. 48-49 se evoca de qué manera abrumadora sorprendió a Gregorio la noticia de su elección como pontífice y su rechazo que no fue aceptado ya que, casi a la fuerza, fue consagrado en septiembre del año 590. Esta carta está fechada en octubre del mismo año

88 Idem (36): ...tantis terrae curis inservio. (“...me pongo al servicio de tantas preocupaciones terrenales").

89 I, 5, 22-23: Alta enim quietis meae gaudia perdidi et intus corruens ascendisse exterius videor. ("Pues perdí los elevados goces de mi quietud y me parece que he ascendido más exteriormente mientras me desplomo en mi interior").

90 Bachelard, Gastón: La poética del espacio. Buenos Aires, 2000. IX, pp. 185-186.

91 I, 5, 24-26: Conabar namque cotidie extra mundum, extra carnem fieri, cuncta fantasmata corporis ab oculis mentis abigere et superna gaudia incorporaliter videre, et non solis vocibus, sed medullis cordis ad Dei speciem anhelans, dicebam: ("Pues me obligaba cotidianamente a tornarme fuera del mundo, fuera de la carne, a alejar de los ojos de la mente todas las representaciones del cuerpo y ver de manera inmaterial los goces de lo alto, y decía no con la voz solamente, sino con las entrañas del corazón anhelando la mirada de Dios:").

92 Idem (90), I, pp. 43-44.

93 Gregorio hace uso de las citas bíblicas en aquellas cartas donde el contenido de las mismas está en consonancia con necesidades exegéticas y pastorales; en este caso la intimidad de su palabra y el deseo personal de aquietar su espíritu requieren de los textos escriturales interpretándolos en un sentido alegórico. Véase idem (28), pp. 50 y ss.
} 
domina la ubicación de Gregorio en su espacio como hombre deseoso de Dios, ya que el descenso hacia lo mundanal, que es entendido como una turbación repentina, lo instala concientemente en un nuevo "exilio"94.

Gregorio manifiesta su temor ante la imposibilidad de retornar a la "casa" de Dios 95 , presionado por los demonios a los que creyó vencer, aunque de un modo pasajero; ante las dudas que asaltan su espíritu no dispuesto a comprometerse con las saeculi curae, compara su estado con la futilidad del humo que rápidamente se disipa 96 . Con la imagen sálmica de la "rueda"97, no ausente de la concepción estoica que consideraba la vida humana sujeta al azar de la fortuna, Gregorio interpreta su espacialidad cambiante entre el vaivén del "arriba-abajo", con el que representa la vanalidad de la gloria terrenal 98 .

Siguiendo los conceptos de una antropología de la imaginación, según los principios de G. Bachelard99, el "adentro" y el "afuera" plantean conflictos que no siempre son simétricos en lo que respecta a su definición; por lo tanto podrían ser representados por diversos calificativos como es el caso de la carta hasta aquí tratada, en la que Gregorio simboliza en dos polaridades antitéticas, la pesadumbre de su espíritu ya comprometido con la contemplación ascética.

Con similitudes alegóricas, escribe a su amigo Narsés de Constantinopla en octubre del 590 ${ }^{100}$, oponiendo la vida del primero dedicada a la contemplación de Dios, frente a su propia existencia, hundida en gemidos ruinosos: Dum con-

94 I, 5, 7-9: Sed repente a rerum vertice temptationis huius turbine impulsus ad timores pavoresque corrui, quia etsi mihi nil timeo, eis tamen, qui mihi commissi sunt, multum formido. ("Pero de repente desde el remolino de las cosas, impulsado por el torbellino de esta tentación me derrumbé hacia los temores y pavores, porque aunque para mí nada temo, sin embargo a esos, que han sido hostigados por mí, mucho temo.”).

95 A partir de la cita bíblica que corresponde a Marc. 5, 19: Revertere in domum tuam et adnuntia ("Vuelve a tu casa y anuncia"), Gregorio se interroga acerca de la posibilidad de volver a la predicación: Sed quis inter tot terrenas curas valeat Dei miracula praedicare, cum iam mihi difficile sit saltim recolere? (I, 5, 23-24: "¿Pero quién entre tantas preocupaciones terrenas tendría fuerzas de predicar los milagros de Dios, cuando ya para mí es difícil ejercitar de nuevo el espíritu?”).

96 La imagen del humo, extraída de Psal. 36, 20: Deficientes ut fumus deficient ("Los que caen en falta, cesan como el humo"), le permite efectuar a Gregorio el siguiente comentario: Fumus quippe ascendendo deficit et sese dilatando evanescit. (I, 5, 29-30: "Ciertamente el humo se deshace al ascender y al extenderse se desvanece a sí mismo.").

97 El pasaje de Psal. 82. 14: Deus meus pone illos ut rotam ("Dios mío, ponlos como a la rueda") es expandido por el pontífice en la siguiente metáfora: Rota quippe ex posteriori parte attollitur, in anterioribus cadit. (I, 5, 32-33: "Por cierto la rueda es levantada desde la parte posterior, en las anteriores cae.").

98 I, 5, 36-38: Peccator ergo cum in praesenti vita profecerit, ut rota ponitur, quia in anterioribus corruens ex posterioribus elevatur. Nam cum in hac vita gloriam percipit, quam relinquit, ab illa cadit, quae post hanc venit. ("En consecuencia el pecador aunque haya crecido en la vida presente, cuando es puesto en la rueda, porque derrumbándose en anteriores circunstancias, es elevado en las posteriores. Pues cuando percibe la gloria en esta vida, que abandona, cae de aquella, la que viene después de esta.”).

99 Idem (90), pp. 188 y ss.

100 Se trata de la carta I, 6. 
templationis alta describitis, ruinae mihi gemitum renovastis ${ }^{101}$. Gregorio insiste en la pérdida de su interioridad concreta, fundada en la inclusión monacal que lo alejaba de los cataclismos externos; frente a la vastedad del afuera, que, si bien supone una ascensión en el dominio de las esferas políticas y administrativas, implica para el novel pontífice, una inclusión no deseada en el saeculum por el desconocimiento de sus verdaderas fronteras ${ }^{102}$.

Se acumulan como en la epístola anterior las imágenes de la caída y la expulsión ${ }^{103}$ que, a pesar de la angustia real que se advierte en el texto, le permite a Gregorio construirse a sí mismo como modelo hagiográfico; es decir, aquel que, como Abraham, lucha desde su posición de "exiliado de Dios" para vencer las tentaciones mundanales ${ }^{104}$. Sin embargo, este tópico se fusiona con el que representaron Ambrosio o Paulino de Nola, quienes, al igual que Agustín, se valieron de la fuerza de la palabra exaltada para dar nacimiento a una figura monástica casi contradictoria: en ella oscilan la quietud contemplativa y la acción puesta al servicio de la conversión del mundo ${ }^{105}$.

Según Leonardi, esta tensión dialéctica es la que caracterizó al Occidente cristiano precisamente desde Gregorio en adelante, distinguiéndose de la posición oriental e imponiendo una visión misional de la historia que se concentró en el concepto de la "predicación”106. En función de esta, el pontífice mostró esa misma contradicción en la epístola I, $5^{107}$, retomando el episodio evangélico de Marta y María del que Casiano se valió para representar la vida activa que cumple con el ministerio sacerdotal, frente a la vida contemplativa que sigue la doctrina espiritual de Cristo ${ }^{108}$. La situación dual en la que el pontífice se ve sumergido lo llena de amargura ${ }^{109}$, aunque no sea más que una figura retórica por medio de la cual representa esta nueva forma de martirologio.

${ }^{101}$ I, 6, 11: "Mientras describís lo altura de tu contemplación, renováis para mí el gemido de mi ruina,". 102 Idem (101), 12: qui audivi, quid intus perdidi, dum foras ad culmen regiminis immeritus ascendi. ("yo que escuché, qué cosa perdí interiormente, mientras ascendí inmerecidamente afuera, hacia lo más alto del gobierno.”).

103 Idem (101), 3-4: Penso enim ab alto quietis meae culmine corruens, ad quam deiectum exterioris provectus culmen ascendi. ("Pues me juzgo precipitándome desde el punto más alto de mi quietud, a la cual ascendí mientras era arrastrado hacia el vértice abatido del mundo exterior.”). 104 Idem (18), p. 129: El autor señala que los temas comunes de la literatura monástica son: la vocación de Abraham, la vida angélica, la vida profética, la vida apostólica y la vida del martirio. 105 Idem (70), p. 459.

106 Idem (70), pp. 459-460.

107 I, 5, 18-20: Sedere ad pedes Domini cum Maria festinavi, verba oris eius percipere, et ecce cum Martha compellor in exterioribus ministrare, erga multa satagere. ("Me apresuré a sentarme junto a María ante los pies del Señor, a percibir las palabras de su boca, y he aquí que soy obligado a servir con Marta en las cosas exteriores, por lo tanto estoy destinado a llevar a delante muchas cosas.").

108 Casiano toma de Luc. X, 40-42 para oponer en Conlationes I, 8 y en otros pasajes, la vida activa a la teorética. Véase Pastorino, idem (18), pp. 139-140.

109 IEn I, 6, 11, Gregorio reproduce el pasaje de Ruth I, 20 en la que Noemí cambia su nombre por estar presa de amargura. 
4. La figura de Gregorio Magno funciona como punto de inflexión y de transición de las conductas del Tardoantiguo hacia nuevos espacios medievales de poder; desde la perspectiva de los géneros discursivos, aquellos que los autores cristianos adaptaron y crearon, las producciones del pontífice gozan de la novedad pragmática de su funcionalidad como instrumentos de conversión y de labor pastoral. La epistolografía gregoriana es un eje transversal de la ideología de su autor, pues permite efectuar una observación de las estrategias directivas puestas en práctica en la administración del papado.

De esta mirada resulta concluyente la elección de Gregorio de recursos dialécticos para ejercer sobre el interlocutor sus dotes de conductor, atendiendo desde la observancia fiel del dogma, la multiplicidad de conflictos que afectaron su gobierno; inclusive la "autopsia" de sus turbaciones anímicas resultaron ejemplificatorias al momento de ofrecer un modelo a seguir. En el diálogo, la confesión y la introspección se funda la tecnología política de Gregorio quien controló desde lo epistolar, el surgimiento de una nueva topografía de poder. 


\section{Bibliografia}

Bachelard G., La poética del espacio, Buenos Aires, 2000

Brown P., El primer milenio de la cristiandad occidental, Barcelona, 1997

Cremascoli G., "La Bibbia nella Regola Pastorale di San Gregorio Magno".

Vetera Christianorum, Anno 6, 1969. Fasc. 1-2

Donnini M., "Struttura letteraria dell'agiografia umbra altomedievale" en $L o$

Spazio Letterario del Medioevo. 1. Il Medioevo Latino, Volume I

Foucault M., Tecnologías del yo y otros textos afines, Barcelona, 1995

Gamble H.Y., Books and readers in the early church. A history of early christian texts, Michigan, 1995

Ingeborg B., "Como definir essência das cartas e das epístolas?”, en Actas de las VII Jornadas de Estudios Clásicos, UCA, Buenos Aires, 1995

Leonardi C., "Agiografia" en Lo Spazio Letterario del Medioevo. 1. Il Medioevo Latino, Volume I

Maier F., Las transformaciones del mundo mediterráneo. Siglos III-VIII, México, 1989

Pastorino A., "I temi spirituali della vita monastica in Giovanni Cassiano", Civiltà Classica e Cristiana. Anno I, No 1 , Aprile 1980

Pricoco S., "Le trasformazioni del monachesimo occidentale fra Tarda Antichità e Alto Medioevo" en Morfologie sociale e culturali in Europa fra Tarda Antichità e Alto Medioevo, Spoleto, 1998

Thraede K., Grundzüge griechisch-römischer Breiftopik, München, 1970

Brown P., El cuerpo y la sociedad. Los hombres, las mujeres y la renuncia sexual en el cristianismo primitivo. Barcelona, 1993

Habinek T.N., The Politics of Latin Literature. Writing, Identity, and Empire in Ancient Rome, Princeton, 1998

Zurutuza H., "Los "hombres de Iglesia" en la Umbria Tardoantigua. La discretio como criterio de ordenamiento de la comunidad monástica", en Umbria cristiana. Dalla diffusione del culto al culto del santi (secc. $I V-X$ ), Spoleto, 2001, pp. 905-914 



\title{
La Regula benedictina como principio de mutación individualy de resocialización colectiva
}

\author{
Hugo Andrés Zurutuza - Horacio Botalla
}

\section{En torno al impacto sociocultural de la regula benedictina}

La Regula benedictina, desde su enunciación a mediados del siglo VI, desempeñó un papel significativo en los procesos de establecimiento de nuevas redes sociales en las décadas posteriores a la crisis del Imperio Romano en Occidente, en la medida que esa crisis se manifestó, entre otros fenómenos, a través de marcados signos de "desocialización" o fractura de los tejidos sociales existentes. La difusión de la Regula permitió crear nuevos circuitos socioculturales y es así como las normas que fijaba habilitaron nuevos tipos de vínculos. El interés por el resguardo de una comunidad de intereses demandó un disciplinamiento y una uniformidad de las conductas que, más allá de otros instrumentos normativos, dejaron su impronta en cada una de las instancias de la vida cotidiana. Los principios prescriptivos de la Regula funcionaron como instrumento de resocialización, llegando a converger con el accionar que, en el mismo sentido ordenador, llevaban a cabo otros dispositivos normativos como los códigos surgidos en el contexto de los reinos romano-bárbaros. Como paradigma o modelo normativo, la regula, a diferencia de las leges que, en principio, se restringen a las situaciones conflictivas, afecta al individuo en su totalidad y en cada uno de los registros de sus prácticas cotidianas, interviniendo en la diversidad de sus comportamientos y haciendo posible la reformulación de las formas habituales de las relaciones sociales. Al ordenar la vida interna del monasterio en los aspectos más esenciales: la celebración litúrgica, los oficios diurno y nocturno, la fijación de horarios, etc., señala un programa de vida y reglamenta las relaciones con el exterior. El mismo término, regula, adquirió a lo largo del siglo VI, el significado técnico con el cual viene referido a la realidad monástica, es decir, de un código legislativo escrito. La regula emerge como un contrapeso a la realidad de desorden y al imaginario que dicha realidad instituye, así como a la búsqueda de amparo frente a estos condicionantes procurando el retiro del mundo. 
No se debe escindir este proceso de resocialización de la atención privilegiada otorgada al ejercicio de prácticas letradas desarrolladas en los monasterios. Hasta fines del siglo VIII y principios del IX, en que el accionar de los carolingios se propone hacer de la Regula de san Benito un medio para disciplinar al clero secular, las comunidades monásticas vieron surgir en su interior ámbitos de circulación textual que suponían necesidades particulares y perfiles específicos en los individuos que las integraban.

Hasta el siglo VIII, la Regula va incorporando dimensiones que manifiestan su versatilidad, v.g. como medio de conocimiento de las Escrituras por cuanto estimula la exégesis de los fundamentos bíblicos del texto de Benito. La Regula lejos de constituir una entidad estática, estimula y alimenta dos procesos: el disciplinamiento del fenómeno monástico y la articulación de un proyecto de desarrollo letrado sistematizado, que es llevado adelante por los mismos monjes. En ese plano transformador de actitudes y comportamientos se reconocen nuevas concreciones de lo oral y lo escrito. En las prescripciones sobre la lectura se percibe la nueva significación a que dará lugar el período carolingio.

\section{El contexto benedictino original}

En el siglo VI Benito de Nursia dió inicio a un derrotero geográfico-espiritual (Roma, Affide, Subiaco) que dió finalmente como resultado definitivo la fundación monástica de Montecassino donde compuso la Regula y murió? .

El fenómeno monástico conocía ya dos siglos de intensa y variada experiencia. Salido de Egipto y del corredor sirio-palestinense, tuvo modos de expandirse también en Occidente. El ideal monástico consistía en el abandono del mundo, en el empeño constante de una vida de penitencia y de plegaria, ya en forma eremitica o cenobitica, según el género de vida iniciado en el siglo IV por Antonio, Paconio y Basilio. La larga distancia cronológica y cultural no debe hacernos olvidar también las diferencias que existían en el seno de tal experiencia ascética: interés por el individuo o por la comunidad, tendencia al aislamiento o al espíritu eclesial, desprecio por el mundo o apego a un inicial, aunque modesto, desarrollo de los valores culturales. Existía ya toda una copiosa literatura, consistente en vidas, reglas, sermones, cartas,

\footnotetext{
${ }^{1}$ Benito de Nursia vivió en el medio de la guerra greco-gótica (535-553), generada por los bizantinos por la recuperación de Italia ocupada por los ostrogodos, si bien este conflicto no ha dejado en principio huellas en la Regula. El santo ha trascurrido toda la vida en la restringida franja de Italia Central (Umbria y Lacio) por lo que, aún admitiendo que su Regula pudiera también ser adoptada en otros monasterios, no podía ser prevista la futura expansión a partir del período carolingio.
} 
diálogos, incluyendo la experiencia monástica occidental e itálica, de la que San Benito, no podía absolutamente prescindir². Todo este material textual va constituyendo un fondo de prescripciones del que se sirvieron las diferentes iniciativas monásticas que sin demandar una forzosa sistematización,

2 El monacato arribó a Occidente de Oriente a través de numerosos canales y ofreciendo modelos múltiples. Egipto era en la literatura y en el imaginario social, la tierra de los monjes, de sus hazañas ascéticas y taumatúrgicas. La vida de Antonio de Atanasio con su gran difusión por el mundo mediterráneo tardoantiguo cumplió un rol didáctico. En este contexto ubicamos las diversas fuentes e influencias que afectaron de diferentes formas la composición de la Regula benedictina:

La Regula de San Pacomio está considerada la primera regula monástica escrita. Fue traducida al latín por San Jerónimo convirtiéndose en el referente básico de todos los autores posteriores. San Benito (RB, LXXIII, 5) habla de la Regula sancti patris nostri Basilii. Basilio escribió dos colecciones de reglas: Reglas largas (Regulae fusius tractatae) y Reglas breves (Regulae brevius tractatae), traducidas después al latín por Rufino. Interesado por la ascesis monástica San Agustín elaboró una breve Regula ad servos Dei, donde la discretio encuentra en él y en San Basilio, a los precursores de San Benito ( $C f$. Zurutuza, H, "Los 'hombres de Iglesia' en la Umbria cristiana. La discretio como criterio de ordenamiento de la comunidad monástica”. En: Umbria cristiana dalla diffusione del culto al culto dei santi - secc. IV-X, II, Spoleto, 2001). Juan Casiano es un útil instrumento para la comprensión de la vida monástica de los padres del Desierto a través de sus obras, De Institutis cenobiarum y Collationes. San Benito (R.B., XLII, 3-5; LXXIII, 5) recomienda su lectura, porque si bien los términos institutiones y collationes (conferencias) pueden indicar ciertamente la obra de Juan Casiano, por otro lado, como nombres comunes también podrían no referirse necesariamente a ella. Este autor introdujo en Galia, en Lérins, una forma de ascetismo inspirado en la tradición egipcia pero moderado por una prudencia que parece anunciar la discretio benedictina.

Las Vitae Patrum, obra recomendada también a los monjes por el santo de Nursia, contiene una colección de documentos biográficos antiguos que llega a nosotros por una transcripción del siglo XVII, reunida en 10 libros que contiene diversos argumentos: Vidas de los Padres (Antonio, Pacomio, etc.), Apotegmas o Dichos de los Padres del Desierto, Historia de los monjes de Egipto, Historia Lausiaca de Palladio, Collationes, conferencias seleccionadas de Juan Casiano, etc.).

La Regulae Patrum constituye un conjunto de reglas que forman un corpus: Regula Quattuor Patrum, Secunda Regula Patrum, Regula Macarii, Regula orientalis,Tertia Regula Patrum. La más antigua de las reglas latinas escritas en Occidente, la Regula quattuor Patrum, está constituída por fragmentos atribuídos a cuatro famosos ascetas orientales, seudónimos que estarían ocultando a algunos integrantes del primer monacato galo: Regula Sanctorum Patrum Serapionis, Macharii, Pafnutii et alterius Macharii.

La Regula Magistri, es la que se proyectó con mayor intensidad en la Regula de Benito. No pocos capítulos están simplemente yuxtapuestos pero una lectura atenta permite reconocer que luego de esta dependencia literal en los primeros capítulos, va tomando distancia hasta que en los capítulos finales aparece una elaboración personal, incluso para algunos autores, del todo desvinculada del modelo. Esto ha suscitado un gran discusión sobre la originalidad de la Regula benedictina.Vide: La regola di san Benedetto e le regole dei Padri (a cura di S. Pricoco), Fondazione Lorenzo Valla, Italia, 1998; A. de Vogüé, Las Règles monastiques anciennes. 400-700. Turnhout, 1985; del mismo autor, La regola di S. Benedetto. Commento dottrinale e spirituale. Abbazia di Praglia, 1984, entre las principales obras de los autores mencionados.

También podemos mencionar otras regulae que no constituyem estrictamente fuentes de la Regula benedictina pero que pueden posibles relaciones como las Regulae provenzales del siglo VI: Regula Aureliani, Regula Tarnantensis, Regula Ferreoli; como así también personajes contemporáneos al contexto histórico cultural del santo de Nursia como San Cesáreo de Arles y Casiodoro. 
establecieron el orden de las regulae mixtae. Benito de Nursia opera una síntesis de esta experiencia y de esta literatura sirviéndose en el plano compositivo de una anónima regula latina del siglo VI, la llamada Regula Magistri.

San Benito no escribe para todos los monasterios de Italia. Por dos siglos su regula circuló en ámbitos restringidos y sólo en el VIII, cuando Montecassino fue restaurado después de la destrucción lombarda y devino un gran centro de vida monástica, comenzó a tener circulación en el Occidente medieval imponiéndose sobre las otras a partir de la época carolingia, por el impulso de la nueva condición socio-política y con el concurso de un patricio visigodo, Benito, abad de Aniano, que cumplió y ejecutó las directivas políticas de Carlomagno y Ludovico Pío para reducir a una unidad legislativa los monasterios del imperio.Benito de Nursia tenía una idea propia del monasterio y de la vida que en el mismo deseaba ordenar; instituyó nuevos oficios, estableció nuevos contactos no sólo de los monjes con el superior, el abad, sino también de los monjes entre sí mediante un estímulo del sentido de fraternidad, confiriéndole a la vida de la comunidad una estructura más flexible a la vez que más articulada. Destacaba en particular la celebración del oficio divino (Opus Dei), pero mientras al trabajo le asignaba numerosas horas del día también puede dar razón de una experiencia compleja en la que tiene gran importancia la práctica de la lectio divina, lectura sapiencial de los textos bíblicos. Esta centralidad asignada a la celebración de la liturgia y a la práctica de la lectio divina, plantea la premisa, de disponer de textos adecuados a ese objetivo y de preparar individuos aptos para su compresión y transmisión.

La comunidad monástica es, según la Regula, única, independiente, autosuficiente, separada del mundo sobre el que no está previsto ningún tipo influencia. El sustento proviene de trabajos de carácter artesanal desarrollados al interior del monasterio, mientras sólo excepcionalmente está previsto el trabajo del campo. La Regula supone evidentemente una particular interpretación del Evangelio tomada de la tradición monástica, consistente en la imitación de Cristo y de la primera comunidad apostólica, sin, por otro lado, presentar una reflexión sistemática de todos estos aspectos.

Frente a un conjunto heterogéneo de actores sociales que debían estar disciplinados e integrados - ya que varias categorías de personas podían formar parte de las comunidades monásticas - observamos que la mayoría eran de condición laica, mientras que los sacerdotes constituían un exigua minoría. Si algún abad solicitaba que fuese ordenado un presbítero o diácono, debía seleccionar entre los monjes quien fuese digno del ejercicio del sacerdocio. Pero el ordenado no debía actuar luego con soberbia y no podía hacer nada que no le ordenase el abad y, sobre todo, no debía olvidar con ocasión del sacerdocio la obligación ineludible de obedecer la Regula, respetar el lugar que ocupaba en el orden de la comunidad - o sea el de entrada en el monas- 
terio, exceptuando el oficio del altar - y observar lo prescripto por los decanos (decani) y el prepósito (praepositus) ${ }^{3}$. Si bien la Regula benedictina impone que la organización del monasterio dependa del arbitrio del abad contempla la presencia de decani ${ }^{4}$ para satisfacer todas las necesidades de la comunidad, según las haya determinado él mismo. En cuanto al prepósito ${ }^{5}$, puede ser elegido por el consejo de sacerdotes (consilium fratrum) y se advierte en la decisión benedictina una preocupación o temor porque el seleccionado no cumpla con lo que el abad le mandare, exigiendo que no haga nada contra la disposición del mismo y atienda con solicitud la observancia de los preceptos de la Regula. La construcción de la autoridad hegemónica del abad en el disciplinamiento del monasterio debe sancionar con disposiciones estrictas las manifestaciónes de competencia en el espacio de poder, la de aquellos que ne forte invidiae aut zeli flamma urat anima ${ }^{6}$.

San Benito al escribir su Regula, parece tener en cuenta no sólo su propio monasterio de Montecassino, sino también a los demás, En el cap, I, 13 manifiesta que intentaba reglamentar la vida de los cenobitas (genus cenobitarum), de los que vivían en un monasterio bajo la regula de un abad. Sin embargo este primer monasticismo benedictino tenía una acotación espacial y la Sancta Regula debería esperar hasta los siglos VIII y IX para la difusión de los manuscritos que la reproducían, analizaban y comentaban e incluso permitirían su aplicación en todo el Occidente medieval.

El autógrafo de la Sancta Regula conservado en Montecassino, fue salvado por los monjes durante la destrucción del monasterio por lo lombardos (577), y llevado a Roma. Allí debió pasar a la biblioteca papal, pues cuando en el siglo VIII, Petronax de Brescia restauró la vida monástica en el cenobio

\footnotetext{
3 R.B. LXII, 11. De sacerdotibus monasterii.

4 R.B. XXI, 1-7. De decanis monasterii.

1. Si maior fuerit congregatio, elegantur de ipsis fratres boni testimoni et sanctae conversationis, et constituantur decani. 2. qui sollicitudinem gerant super decanias suas in omnibus, secundum mandata Dei et precepta abbatis sui. 3. Qui decani tales elegantur, in quibus securus abbas partia onera sua; 4 . et non elegatur per ordinem, secundum vitae meritum et sapientiae doctrinam. 5. Quique decani, si ex eis aliqua forte quis inflatus superbia repertus fuerit repraehensibilis, correptus semel et iterum atque tertio, si emendare noluerit deiciatur; 6. el alter, in loco eius, qui dignus est subrogetur. 7. Et de praeposito eadem constituimus.

Esta modalidad organizativa es retomada por san Benito ya que tenía antecedentes en San Jerónimo (Epis.22, 35), en San Agustín (De moribus Ecc. cath., 1, 31) y en Juan Casiano (Inst.IV, $7,19,17)$. Podemos por lo tanto considerar que la tarea del abad podía complicarse tanto en los aspectos cuantitativos (incremento del número de monjes) como cualitativos (omisiones en el cumplimiento de los preceptos regulares, conflictos internos, etc.) y se reproduce la necesidad de contar en los monasterios con un grupos de monjes que cooperen con el abad pero que no se constituirían en fiscalizadores de su gestión ni defensores de los miembros de la comunidad en un enfrentamiento con él mismo ( $R B$ LXIX, 1-4. Ut in monasterio non praesumat alter alterum defendere).

5 R.B. LXV, 1-22. De praeposito monasterii.

${ }^{6}$ R.B. LXV, 22.
} 
cassinense, el papa Zacarías (741-752) envió a este monasterio, al mismo tiempo que un ejemplar de la Biblia y de la Regulae quam beatus pater Benedictus suis sanctis manibus conscripsit. Así lo afirma Pablo Diácono7 . A pesar de ciertas reservas eruditas, se ha admitido generalmente que el historiador de los longobardos se refiere aquí al códice y no simplemente a un códice de la Regula, es decir, el papa Zacarías devolvió a Montecassino el manuscrito considerado como el autógrafo. Restituído al lugar donde fue escrito, el códice considerado original de San Benito, permaneció en Montecassino hasta la segunda devastación del cenobio por los sarracenos en 883. Pero esta vez también fue salvado por los monjes fugitivos que lo llevaron a Teano. Será destruído por un incendio ocasional en ese monasterio en el año 896.

En 717 había sido restaurada la antigua fundación de san Benito, Montecassino, abandonada después de la invasión longobarda. Este emprendimiento fue obra de un bresciano de origen longobardo o romano 8 de nombre Petronax, que de paso por Roma durante un viaje a Tierra Santa, aceptó el pedido del papa Gregorio II para concretar la mencionada restauración. Este último, siguiendo el ejemplo de su ilustre homónimo Gregorio I, papa-monje, había convertido su casa en monasterio, rodeándose de monjes para ejercer la Ia administración de Letrán. Sin embargo Montecassino no podía improvisar una actividad intelectual. La biblioteca era modesta y tanto que el papa Zacarías debió dotarla, como señalamos, de un fondo bibliográfico básico.

7 Paulo Diacono, Historia langobardorum. VI, 40. Circa haec tempora Petronax, civis Brexianae urbis, divino amore conpunctus, Romam venit hortatuque tunc Gregorii apostolicae sedis papae huc Cassinum castrum petiit, atque ad sacrum corpus beati Benedicti patris perveniens, ibi cum aliquibus simplicibus viris iam ante residentibus habitare coepit. Qui eundem venerabilem virum Petronacem sibi seniorem statuerunt. Hic non post multum tempus, cooperante divina misericordia et suffragantibus meritis beati Benedicti patris, iamque evolutis fere centum et decem annis, ex quo locus ille habitatione hominum destitutus erat, multorum ibi monachorum, nobilium et mediocrium, ad se concurrentium pater effectus, sub sanctae regulae iugum et beati Benedicti institutione, reparatis habitaculis, vivere coepit atque hoc sanctum coenobium in statum quo nunc cernitur erexit. Huic venerabili viro Petronaci insequenti tempore sacerdotum praecipuus et Deo dilectus pontifex Zacharias plura adiutoria contulit, libros scilicet sanctae scripturae et alia quaeque quae ad utilitatem monasterii pertinent; insuper et regulam, quam beatus pater Benedictus suis sanctis manibus conscripsit, paterna pietate concessit. Monasterium vero beati Vincentii martyris, quod iuxta Vulturni fluminis fontem situm est, et nunc magna congregatione refulget, a tribus nobilibus fratribus, hoc est [Tato Taso et Paldo], iam tunc aedificatum, sicut viri eruditissimi Autperti eiusdem monasterii abbatis in volumine, quod de hac re conposuit, scripta significant. Superstite sane adhuc beato papa Gregorio Romanae sedis, Cumanum castrum a Langobardis Beneventanis pervasum est; sed a duce Neapolitano noctu superveniente quidam ex Langobardis capti, quidam perempti sunt. Castrum quoque ipsum a Romanis est receptum. Pro cuius castri redemptionem pontifex septuaginta libras auri, sicut primitus promiserat, dedit.

8 Cf. Cracco, G. Dai longobardi ai carolingi. I percorsi di una religione condizionata. En: Storia dell'italia religiosa. Roma-Bari, 1993. 1. L'antichità e il Medioevo. p. 136. 
Existía ya en Montecassino una escuela, pero es necesario esperar a Pablo Diácono y el comentario de la Regula que se le atribuye, para tener una valiosa reseña sobre la educación de los monjes; un cuadro costumbrista de mediados del siglo VIII que evoca a los jovenes monjes ocupados en la lectura.

El desarrollo de Montecassino en esta época, no es precisamente de orden intelectual. Como Letrán era una escuela de liturgia, en cambio este monasterio era una escuela de la vida monástica. Allí se llega para aprender la observancia de la Regula benedictina, es así como Sturm, discípulo de Bonifacio, pasa un año en Montecassino, y hacia la mitad del siglo VIII, príncipes que abandonan el mundo, como el lombardo Ratchis y el franco Carlomagno, adoptan este monasterio como lugar de retiro. Es en torno al siglo VIII que Montecassino comienza a organizar su scriptorium. En 750 el futuro abad de Nonantola viene a pasar algún tiempo en la abadía y lleva muchos manuscritos que constituyen el primer fondo de la biblioteca de su nuevo monasterio 9 Pero falta aún esperar una veintena de años para constatar que los estudios hechos en Montecassino no sean solamente religiosos. El primer monje letrado de relevancia de la abadía es Pablo Diácono que arriba en 774. La historia de Montecassino como centro de estudios entra en el marco de la gran reforma carolingia en la que la Regula benedictina ocuparía un lugar singular ${ }^{10}$.

\section{El texto de la Regula y la política carolingia}

Carlomagno, alrededor de 787, deseoso de que todos los monasterios de su imperio poseyeran el texto exacto de la Regula, requiere y obtiene del abad Teodomaro de Montecassino (muerto en 797), una copia del ejemplar de la Regula considerado autógrafo de Benito. La petición imperial fue atendida y esta copia, que debió servir de ejemplar a todos los manuscritos que se escribieran en el imperio, fue conservada algún tiempo en Aquisgrán aunque finalmente acabó por perderse ${ }^{11}$.

Tal vez uno de los principales fenómenos relacionados con el incremento de la política regulatoria de los carolingios sea la literatura de los commenta-

9 Riché, P. Éducation et culture dans l'Occident barbare. VI'-VIII ${ }^{\circ}$ siècle. Paris, 1995 (1962). pp. 328-329.

10 Ibidem. p. 329.

${ }^{11}$ Pero antes de este accidente ya se habían hecho otras copias. Una de ellas ha llegado hasta nosotros: Sangallensis 914. Dos monjes de Reichenau, Tatón y Grimaldo, enviados poco después del 817 al monasterio de Inden, junto a Aquisgrán, fundado por Benito de Aniano, habían realizado la copia por encargo del bibliotecario de Reichenau, Regimberto. Existe otro tipo de texto benedictino, reproducido ya en el siglo VIII por Pablo Diácono y en el IX por HIldemaro en sus respectivos comentarios a la Regula, representando el resultado de las tentativas de los amanuenses por nomalizar el latín del siglo VI según las normativas de la gramática clásica que habían aprendido en las escuelas carolingias. 
ria que se registra entre las últimas dos décadas del siglo VIII y la primera mitad del IX. Precisamente, no conocemos comentarios a la Regula benedictina hasta estas fechas, esto es dos siglos y medio después de su redacción. Una serie de textos que respondían a unos géneros específicos, muestran cómo en el período carolingio se llevó adelante una especial labor sobre la Regula. La elaboración de expositiones, commentaria o concordiae no solamente ponen en evidencia el interés por esa Regula sino que, al compararla con otras normativas monásticas o desplegar sus respectivos capítulos, permiten afirmar la voluntad política de los monarcas francos de erigirla como parámetro de uniformidad para las comunidades monásticas del Imperio. Este proceso culminaría con la obra de Benito de Aniano y Esmaragdo en el marco del accionar de Ludovico Pío.

Benito de Aniano produjo dos textos claves para fundamerntar su acción niveladora en el monasticismo de la época: una recopilación de todas las reglas que se encontraban en lengua latina, el Codex Regularum ${ }^{12}$ y un comentario de la Regla benedictina en que incluyó pasajes de otros textos normativos monásticos, la Concordia Regularum ${ }^{13}$.

El más antiguo de los conocidos es debido a Pablo Diácono, identificado por algunos como Pablo Warnefrido. Las opiniones se dividen sobre el lugar de su composición, mientras ciertos autores piensan que fue escrito en Italia del norte, en el monasterio de Civate, otros fijan su redacción en Montecassino. De todos modos el valor de la obra es grande porque ofrece la primera interpretación de la Regula llegada a nosotros y nos da un cuadro completo de la vida de un cenobio benedictino antes de la reforma de Benito de Aniano. En el siglo IX diversos autores se basaron en él para hacer sus propios comentarios como en el caso particular de Hildemaro, monje franco del monasterio de Civate. Entre el 817 y el 820, Esmaragdo, abad de Saint Mihiel y gran adminador de Benito de Aniano, compuso una Expositio in Regulam Sancti Benedicti14, destinada a una enorme difusión. Formado en gran parte de extractos de reglas monásticas y de obras patrísticas, este comentario se aplica sobre todo a esclarecer los pasajes más difíciles de la Regula y ofrece noticias acerca de los usos monásticos en el área franca, a principios del siglo IX. Una serie de disposiciones capitulares de la época de Ludovico Pío ${ }^{15}$, junto a otras provenientes del reinado de Carlomagno y su

\footnotetext{
12 Sancti Benedicti Abbatis Anianensis, Concordia Regularum. En: Migne, P.L., CIII, c. 7011380 .

13 Sancti Benedicti Abbatis Anianensis, Codex regularum monasticarum et canonicarum. Ibidem. c. 393-702.

14 Smaragdis Abbatis, Commentaria in Regulam S. Benedicti. En: Migne, PL, Tomvs CII.(Saeculum IX) Annus 820. c.689-936.

15 170. Capitulare monasticum, 817.Iul.1O. M.G.H. Legum Sectio II. Tomus. I.
} 
padre Pipino ${ }^{16}$, permiten reconocer una tipología documental, particularmente representativa de la influencia de la Regula como disciplina dominante, que refleja la existencia del estrecho contacto forjado entre el mona-

Anno incarnationis domini nostri Iesu Christi DCCCXVII, imperii vero gloriosissimi principis Hludowici quarto, VI. Idus Iulias, cum in domo Aquisgrani palatii, quae Lateranis dicitur, abbates cum quam pluribus una sui residerent monachis, haec quae subsequuntur capitula communi consili ac pari voluntate inviolabiliter a regularis conservari decreverunt.

1.Ut abbates, mox ut ad monasteria sua remeaverint, regulam per singula verba discutientes pleniter legant et intelligentes, Domino opilutante, efficater cum monachis suis implere studeant.

2.Ut monachi omnes qui possunt memoriter regulam discant.

3. Ut officium iuxta quod in regula sancti Benedicti continetur celebrent.(...)

19. Ut in quadragesima libris de bibliotheca secundum prioris dispositionem acceptis, alios nisi prior devreverit expidere, non accipiant. (...)

2o.Ut quando frates pos sextam dormiunt, si quis eorum voluerit legere, in ecclesia aut in lecto suo legat.

Cf.16o. Capitula de inscipendis monasteriis. (Capitularia italica).Ibid.

1.Abbates, qui ab episcopis electi sunt ad conspiciendum regulae observationem in monasteriis, iustum deben tenere modum en his quae eis iniuncta sunt.

2.Deinde, si intellexerint abbatem neglegentem suum ministeriium agere aut de semetipso aut de fratibus suis, secundum regulam auctoritatem commoneant illum. Similiter etiam faciant, si ex fratribus fuerint neglentes inventi: cum abbate suo secundum regulae auctoritatem eos commoneant.Si ignorantia est, per eandem regulam docendo corrigant eos...

16 10. Karlamanni Principis Capitularia. M.G.H., op.cit.

742.April.21

7 ...Et ut monachi et ancillae Dei monasteriales iuxta regulam sancti Benedicti ordinare et vivere, vita propiam gubernare studeant.

11. Karlamanni Principis Capitulare Liptinense. Ibid.

Kal.Mart. anni 743 vel paullo posterioris

2. Abbates et monachi receperunt sancti patris Benedicti [regulam] ad restaurandam norman regularis vitae...

12. Pippini Principis Capitulare Suessionense. Ibid.

744. Mart.2

3. ...Ut ordo monachorum vel ancillarum Dei secundum regula sancta stabiles permaneant...

20. Capitulare Haristallense. Ibid.

779 mense Martio

3. ...De monasteriis qui regulares fuerunt, ut secundum regulam vivant; necnon et monasteria puellarum ordinem sanctum custodiant, et unaquaeque abbatissa in suo monasterio sine intermissione resedeat...

23. Duplex Legationis Edictum. Ibid.

789.m. Martio 23

19. De monasteriis minutis ubi nonnanes sine regula sedent, volumus in unum locum congregatio fiat regularis...

33. Capitulare Missorum Generale. Ibid.

802 initio

12. Ut abbate, ubi monaci sunt, pleniter cum monachis secundum regula vibant adque conones diligenter discant et observen; similiter abbatissae faciant.(...)

17. Monachi autem, ut firmiter ac fortiter secundum regula vivant ...

34. Capitulare Missorum Specialia. Ibid.

802 initio

3. De abbatibus, utrum secundum regulam an canonice vivant, et si regulam aut canones bene 
cato benedictino y el reino franco, manifestando así la profunda relación entablada con la misma sociedad de la época, fuertemente condicionada por la presencia de una red integrada por un gran número de monasterios ${ }^{17}$. Éstos no sólo favorecían un encuentro entre miembros de culturas diversas, alguna vez en lucha entre ellos mismos, sino también la articulación de los espacios socioculturales entre sí, fomentado dispositivos de ordenamiento e integración frente a diversos procesos de fractura de las relaciones de sociabilidad: invasiones, itinerancia, marginalidad, heterodoxias, etc.

\section{La diversidad del fenómeno letrado: escritura, libros y bibliothecae}

Hay que remarcar la escasa densidad letrada en un lapso muy extenso, como es el que abarca los fines del siglo V a la segunda mitad del VIII. En ese tiempo, las comunidades monásticas debieron echar mano al exiguo conjunto de textos disponibles.

En Lérins, como más tarde en Montecassino, había libros, pero únicamente libros cristianos. Justamente, tenemos testimonios, que desde el siglo IV en las comunidades monásticas se practicaba la copia de libros. Esta actividad es reconocida desde los tiempos de Jerónimo y Rufino que se dedicaron en su juventud a esa actividad en Tierra Santa. La producción de libros deviene poco a poco monopolio de las fundaciones monásticas. La lectio divina toma en el monacato su fisonomía definitiva y los monjes son considera-

intellegant.

4. De monasteriis virorum ubi monachi sunt, si secundum regulam vivant ubi promissa est.

5. De monasteria puellarum, utrum secundum regulam an canonice vivant, et de claustra earum.

71. Capitularia tractanda cum comitibus episcopis et abbatibus. Ibid.

811

12. De conversatione monachorum, et utrum aliqui monachi esse possint praetereos qui regulam sancti Benedicti observant. Inquirendum etiam, si in Gallia monachi fuissent priusquam traditio regulae sancti Benedicti in has parrochias pervenisset.

17 Durante los siglos VIII y IX la institución monástica conoció tanto en el contexto lombardo como en el franco después, una continuidad que se visibiliza en particular en las capitulares carolingias. La fuerte red de monasterios de herencia lombarda sobre la que legislan los monarcas carolingios constituye el testimonio de una perduración del fenómeno monástico que ha llevado a un debate historiográfico con los autores que propugnaban la extinción del mismo en el territorio de la península itálica como consecuencia de la invasión lombarda. Para un estado de la cuestión. Cf. Picasso, G. Il monachesimo in Umbria. En: AAVV, Umbria cristiana dalla difusione del culto al culto dei santi (sec. $I V$-X). Centro Italiano di Studi sull'Alto Medioevo, Spoleto, 2001 (Atti del XV Congresso internazionale di studi sull'alto medioevo, Spoleto 23-28 ottobre 2000), II, p. 553 y ss.; Susi, E. Monachesimo e agiografia in Umbria. En: AAVV, Umbria cristiana dalla difusione del culto al culto dei santi (sec. IV-X), p. 569 y ss.; Azzara, C., Moro, P. I capitulari italici. Storia e diritto della dominazione carolingia in Italia, Roma, 1998 (Altomedioevo, 1). 
dos por los simples fieles como los profesionales de la lectura sagrada. Así asistimos progresivamente a la reducción del sentido de la palabra bibliothe$c a$. Desde el siglo VI, o incluso antes, bibliotheca, en lugar de designar alguna colección de libros y el sitio donde son colocados, tiende a significar el conjunto de libros que constituye el canon bíblico. Esta acepción restringida corresponde a la realidad del período precarolingio, que sin sustituir enteramente a la otra, se convierte en la acepción principal.

Las regulae monásticas tratan todas de la lectura colectiva pero la Regula Benedicti va más lejos, haciendo de la lectura personal una obligación de la vida religiosa. Cada monje recibirá un libro sacado de la biblioteca que deberá leer en seguida e integralmente ${ }^{18}$. Debemos interrogarnos mucho sobre el sentido exacto de los términos singulos codices de bibliotheca empleados por el autor de la Regula en este pasaje. Es seguro que la palabra bibliotheca debe ser entendida aquí en sentido restringido. La biblia estaba en la Alta Edad Media contenida en nueve codices, como lo vemos en Casiodoro ${ }^{19}$, los monjes debían en nueve años leer todas las Sagradas Escrituras, Antiguo y Nuevo Testamento. Es verdad también que el termino codex puede designar a cualquier libro, por ejemplo un comentario o un tratado cristiano y la frase de la regula de Benito es poco explícita. Según las época podrá ser diversamente interpretada y en un sentido más o menos amplio. Esmaragdo, que ha leido a Isidoro 20 interpreta bibliotheca en sentido antiguo como "el local donde son guardados los libros"21.

De la mitad del siglo VI a mediados del siglo VIII se han dejado de copiar los autores antiguos. Las bibliotecas son muy exiguas, algunas decenas de libros o un poco más. La fabricación está en manos de clérigos y en especial de monjes. Tenemos bibliotecas no de conservación sino dirigidas a la utilidad cotidiana. En general el contenido de las bibliotecas de la Alta Edad Media es inestable porque los libros viajan, lo que asegura la difusión y el mantenimiento de la cultura escrita pero no compensa la "rareza" de los libros $^{22}$. Hay continuidad en lo que concierne a la técnica del libro, que se afirma y diversifica mientras hay destrucciones masivas y se da una muy fuerte baja de la producción.

18 R.B.,XLVIII, 15 y ss.

19 Cf. Institutiones I, I, primera linea de los capítulos I a IX.

20 Etym. VI, 3, I.

21 Smaragdis Abbatis, Commentaria in Regulam S. Benedicti. En: Migne, P.L., Tomvs CII.(Saeculum IX) Annus 820. c.836.

'In quibus diebus Quadragesimae accipiant omnes singulos codices de bibliotheca, quos per ordinem ex integro legant. Qui codices in capite Quadrage imae aandi sunt'.De bibliotheca dicit, id. est, de cellula ubi libri recondutur. Nam quod Graece bibliotheca, Latine repositio librorum dicitur

22 Holtz, L., "Vers la création des bibliothêques médiévales en Occident". En: AAVV Morfologie sociale e... I.II. 1998, p.110. 
El libro antiguo, un bien cultural identificado como un producto artesanal, que siglos de experiencia productiva habían elaborado en función de las necesidades de una sociedad letrada, todavía reconocible en los sectores de la jerarquía eclesiástica itálica del siglo VI, cambia su posición y significación. A partir de los nuevos ambientes monásticos no podemos poner el libro y la escritura en el centro de una sociedad de transición y detectamos también nuevas gradaciones de valores, en las que la cultura era sustituida por la piedad, el diálogo por el aislamento laborioso, es así que la escritura es reducida al rango de trabajo manual. Por lo tanto el libro disminuye de importancia y también de prestigio 23 . Sin embargo el libro entendido como instrumento para la comprensión de la cultura cristiana es incluído en la Regula de Benito.

El primer monacato benedictino no fue un monacato de scriptoria y de libros; es así como tradicionalmente la imagen del Montecassino de Desiderio se ha sobrepuesto a aquella que ofrecen los rudos cenobios de Benito, en los cuales se ha querido ver los lugares donde la tarea de copia de los monjes habría salvado para los posteriores los trabajos de la cultura clásica. Esta visión de los hechos es del todo falsa, en realidad en los primeros monasterios benedictinos la lectio era limitada a la Regula, a los libros litúrgicos, a la Biblia y a algunos pocos textos religiosos como confirma una atenta lectura de la Regula ${ }^{24}$. Además entre muchos de los monjes que habitaban un cenobio, había analfabetos y también otros que no sabían leer. El hecho que san Benito afirme explicitamente que los monjes no deben poseer personalmente neque codicem, neque tabulas, neque graphium ${ }^{25}$, hace pensar más bien una voluntad de impedir, por parte de los pocos que hubiesen podido, una actividad cultural independiente, que no al contrario, ya que dentro del equipo entregado a cada miembro de la comunidad por el abad era prevista la presencia del graphium y de tabulae para fomentar la alfabetización y la lectura.

Podemos constatar que el único monasterio que en la primera mitad del siglo VIII, funciona como un ámbito intelectual es la fundación irlandesa de Bobbio. Al fin del siglo VII el scriptorium de Bobbio que no había producido más que obras eclesiásticas, comienza a interesarse por obras profanas. Durante la primera mitad del siglo VIII, las gramáticas, los tratados de métrica, los glosarios, de los extractos de historiadores profanos y los filólogos son copiados por los monjes ${ }^{26}$. Según algunos autores son los monjes de Bobbio,

23 Petrucci, A. "La concezione cristiana del libro fra VI e VII secolo" ("Studi medievali", XIV, 1973). En: Cavallo, G. (a cura di) Libri e lettori nel medioevo. Guida storica e critica. Roma-Bari, 1989 (1977). pp.17-18

24 R.B. XLII, 3-4; LXVI, 8.

25 Petrucci, A. "La concezione cristiana del libro fra VI e VII secolo", op.cit. p.18.

26 Riché, P. Éducation et culture dans l'Occident barbare. VI $I^{\circ}-V I I I^{\circ}$ siècle. Paris, 1995 (1962), p. 329 . 
y no los de Montecassino, los que pueden en esta época reivindicar el título de "humanistas benedictinos"27.

En contraste todo nos induce a pensar que en los cenobios benedictinos del siglo VI los libros serían pocos, de argumentos exclusivamente religioso y de nivel elemental, y además debido a una demanda escasa y a una producción limitada, entendemos que poco monjes, y sólo intermitentemente, se dedicarían al trabajo de copiar y que la cultura gramatical y retórica tradicional, podría estar del todo ausente 28 .

En el lapso que abarca de la fundación de Montecassino (529) a su primera destrucción (577), en el cenobio está atestiguada una práctica escrituraria, a la que hace alusión la Regula de san Benito29, pero se debe considerar limitada a aquellos pocos libros religiosos necesarios para la vida de la comunidad. En esta época, en Montecassino, la instrumentación no era otra que la alfabetización y la enseñanza de las esenciales normas gramaticales indispensables para la recta comprensión de la lectio, impuesta por la misma Regula. La economía rural, todavía poco desarrollada, del monasterio daba preeminencia a las labores manuales a fin de obtener el sustento más que a iniciativas de cultura y de transcripción libraria.Por lo tanto el monasterio deseado por Benito era una comunidad de hombres dedicados al trabajo, sobre todo manual, y a la plegaria, como él mismo lo define una officina ${ }^{30}$, y sus miembros los operarii ${ }^{31}$; en oposición al monasterio organizado como una escuela en la cual se enseñaba tanto la ciencia sagrada como la profana. Una escuela basada sobre una concepción del todo libraria y filológica de la cultura como se manifiesta en Casiodoro. Sin embargo la obra de Casiodoro se dispersó, el cenobio de Vivarium cae en la nada y las Institutiones no sus-

27 Ibidem. pp.329-330.

Comment expliquer la place particulière de Bobbio dans la culture monastique italienne? Par les liens qui continuent d'exister entre le monastere, les Iles Britanniques et la Gaule, c'est certain. Mais il y a plus. Au début du VlIle siecle un éveque irlandais, Cumméan, vient finir ses jours à Bobbio. Pour son tombeau, un moine poète compose une épitaphe en vers rythmiques, et un sculpteur, maître Jean, décore la pierre tombale. Or, poème et sculpture rappellent le travail que I'on fait a Pavie a la meme époque; entre I'abbaye et la capitale lombarde, existent toujours des relations étroites. C'est au moment où les études littéraires et I'art réapparaissent a Pavie, que Bobbio s'ouvre a la culture profane et artistique. C'est donc surtout du cóté des écoles lombardes qu'il nous faut chercher I'explication du développement culturel de Bobbio.

28 Petrucci, A. La concezione cristiana del libro fra VI e VII secolo...op.cit. pp. 18-19.

29 R.B. XXXIIII, 3: neque aliquid habere proprium, nullam omnino rem, neque codicem, neque tabulas, neque graphium, sed nihil omnino.

R.B. LV, 18-19:Et ut hoc vitium peculiaris radicitus amputetur, dentur ab abbate omnia quae sunt necessaria, id est cuculla, tunica, pedules, caligas, bracile, cultellum, graphium, acum, mappula, tabulas, ut omnis auferatur necessitatis excusatio.

$3^{0}$ R.B. IV, 78: Officina vero ubi haec omnia diligenter operemur, claustra sunt monasterii et stabilitas in congregatione.

${ }^{1}$ R.B. VII, 49: Sextus humilitatis gradus est, si omni vilitate vel extremitate contentus sit monachus; et ad omnia quae sibi iniunguntur, velut operarium se malum iudicet et indignum... 
citaron ecos en la espiritualidad altomedieval. La Regula de Benito, superó la prueba de los hechos y marcó todo el monasticismo occidental por la acción de distintos promotores políticos y culturales durante siglos.

Luego del 577 hay un silencio que dura prácticamente durante todo el siglo VII y los primeros decenios del VIII. Existe una discutida tradición de una "continuidad cassinense" en el Laterano, atestiguada por Leone Marsicano ${ }^{32}$, cuyo fundamento pudo ser tomado por el mismo autor de la información dada por Paolo Diácono sobre los monjes fugitivos de Montecassino a Roma ${ }^{33}$.

\section{La lectura entre la oralidad y la escritura}

Petrucci sostiene que la antigüedad tardía dejó como legado al Medioevo diversas modalidades de lectura. Casiodoro distingue claramente la sedula lectio a la que se dedica él mismo ${ }^{34}$ de la simplicissima lectio, que es la de los monjes menos cultivados ${ }^{35}$. La primera morfología de lectura constituye una

32 Chron. Mon. Casin., M.G.H. SS VII, p. 581. Leone Marsicano (s. XI), monje y cronista, tuvo una larga residencia en Montecassino donde escribió un Chronicon Monasteri Casinensis. que abarcaba desde los orígenes hasta el 1075.

33 Hist. Langob., IV, 17. M.G.H. Script. rer. Langob.

34 Inst. I, praef. 8. Sed quamvis omnis Scriptura divina superna luce esplendeat, et in ea Spiritus sancti virtus evidenter irradiet, in Psalterio tamen et Prophetis et Epistulis Apostolorum maximum studium laboris impendi, quoniam mihi visi sunt profundiores abyssus commovere, et quasi arcem totius Scripturae divinae atque altitudinem gloriosissimam continere. quos ego cunctos novem codices auctoritatis divinae, ut senex potui, sub collatione priscorum codicum amicis ante me legentibus sedula lectione transivi; ubi multum me laborasse Domino iuvante profiteor, quatenus nec eloquentiae modificatae deessem nec libros sacros temeraria praesumptione Iacerarem.

35 Ibidem. 9.Illud quoque credidimus commonendum, sanctum Hieronymum simplicium fratrum consideratione pellectum in Prophetarum praefatione dixisse, propter eos qui distinctiones non didicerant apud magistros saecularium litterarum colis et commatibus translationem suam, sicut hodie legitur, distinxisse. quod nos quoque tanti viri auctoritate commoniti sequendum esse iudicavimus, ut cetera distinctionibus ornentur. ista vero sufficiant simplicissimae lectioni, quae supradictus vir, sicut dictum est, ad vicem distinctionum colis et commatibus ordinavit, ne supra iudiciumtant viri vituperabili praesumptio ne venisse videamur. Reliquos vero codices, qui non sunt tali distinctione signati, notariis diligenti tamen cura sollicitis relegendos atque emendandos reliqui; qui etsi non potuerint in totum orthographiae minutias custodire, emendationem tamen codicum antiquorum, ut opinor, adimplere modis omnibus festinabunt. habent enim scientiam notarum suarum, quae ex maxima parte hanc peritiam tangere atque ammonere noscuntur. sed ut error inolitus aliquatenus de medio tolleretur, factum est ut in sequenti libro de orthographiae regulis perstrictim pro captu ingenii nonnulla poneremus, ne praecipitanter emendantium impolita praesumptio posteris carpenda traderetur. paravi quoque quantos potui priscos orthographos inverire, per quos etsi non omnino correcti tamen ex magna parte meliorati esse videantur. orthographia siquidem apud Graecos plerumque sine ambiguitate probatur expressa; inter Latinos vero sub ardua difficultate relicta monstratur, unde etiam modo studium magnum lectoris inquirit. 
operación cultural propia del letrado que, por su intermedio, se apropia del texto para instruirse, comentarlo o compararlo, sólo o con algunos colaboradores de su elección; la segunda práctica de lectura es una operación esencialmente litúrgica, pública para la ocasión, y, por tanto, pronunciada en voz alta, contrariamente a la primera, que es silenciosa y solitaria. A través del análisis del autor es posible distinguir tres técnicas de lectura ampliamente difundidas y utilizadas desde situaciones diferentes: la lectura silenciosa; la lectura en voz baja, llamada susurro o ruminatio, que servía de apoyo a la meditación y de instrumento nemotécnico; y por último, la lectura pronunciada en voz alta que exigía, como en la antigüedad, una técnica particular y se aproximaba bastante a la práctica de la recitación litúrgica y del canto36.

Cada una de estas modalidades se articulaba con una función precisa y se practicaba en circunstancias y ambientes específicos: la primera y probablemente la segunda se desarrollaban en la intimidad de la celda, en cambio, la tercera en público, frente a la comunidad.

Si bien la palabra sagrada escrita se legitimaba a través de una suprema autoridad y gravitaba en la formación de los ideales de conducta de los cristianos, estos conocían la doctrina más por escucharla, cantarla y contemplar imágenes que por la lectura y el estudio. Los textos sagrados podían estimular en algunos la inquietud de leer más, pero no necesariamente convertían a los cristianos en lectores habituales.

La palabra escrita cobró nueva fuerza sobre todo entre aquellos que se retiraban de la vida activa en busca de perfección. El texto temprano más explícito sobre este particular es la regula para las comunidades monásticas de los discípulos de San Pacomio, quizá esta regula no haya sido formulada por el mismo Pacomio, pero respondía a las aspiraciones de sus sucesores. El candidato a ingresar en un monasterio debía conocer y aceptar la regula. Se le entregaban unos veinte salmos o dos de las epístolas de los Apóstoles o alguna otra parte de las Escrituras y si el candidato era analfabeto, en las horas primera, tercera y sexta debía presentarse ante áquel que pudiera enseñarle y además que hubiera sido especialmente designado para asistirlo. El candidato debía estar con el maestro y aprender con mucha dedicación y extrema gratitud. Se seleccionaban para él los elementos fundamentales del silabario, los verbos y los sustantivos y, aún cuando él no estuviese dispuesto a hacerlo, debía ser obligado a leer. Por lo tanto era fundamental aprender a leer y memorizar fragmentos de las escrituras, por lo menos de los Evangelios y el Salterio. Como consecuencia de la experiencia pacomiana, entendemos que una parte de las Escrituras se conocía y se memorizaba, que se pautaba la

36 Petrucci, A. Alfabetismo, escritura, sociedad (con prólogo de Roger Chartier y Jean Hébrard), Barcelona, 1999 (colección Lea): III. Leer lo escrito. 1. Leer en la Edad Media, p. 184. 
entrega de los textos y su devolución como también sabemos que ciertas horas del día se destinaban a la recitación de textos y a la meditatio monástica.

\section{La memoria y la oralidad}

Las regulae sobre meditación, memorización y copia de textos, propias de los primeros establecimientos de Pacomio, pasaron a las regulae de otras comunidades. Algunos autores han señalado el poder que para los cristianos comunes tenían los textos sagrados contra demonios e invasores, han indicado el poder simbólico que tenían para conversos y miembros legos del cristianismo, el poder que proyectaban en una cultura principalmente oral y visual $^{37}$. Al meditar sobre las escrituras, esos cristianos se acercaban más a la presencia y a la voluntad divinas.

Ciertamente, sea en Oriente u Occidente, escribir libros de las Sagradas Escrituras deviene meritoria a los ojos de Dios. Los santos mismos escriben o hacen escribir biblias para darlas y difundir la palabra y voluntad divinas. Pero el salto de calidad más fuerte determina en el Occidente latino un cambio importante en el estatuto del arte de escribir y del escriba. Escribir, transcribir los libros permanecía como trabajo manual y de sustento puesto en el mismo plano del tejer redes para pescar, pero se compensa con la lectio, por la lectura de los textos sagrados que nutren el alma.

En la Regula de Benito la lectura revierte en la comunidad por un lector, más o menos experto, lector ebdomandarius, resultando netamente distinta de las lectiones suae, la lectura propia.. La institución monástica se encontraba en la necesidad de deber suplir una fuerte carencia de instrucción, la alfabetización ${ }^{38}$.

37 Lane Fox, R. Cultura escrita y poder en el cristianismo de los primeros tiempos. En: Bowman, A., Woolf, G. (Comps.), Cultura escrita y poder en el Mundo Antiguo, Barcelona, 20oo, p. 229. $3^{8}$ R.B. XXXVIII. De ebdomadario lectore.

1. Mensis fratrum lectio deesse non debet, nec fortuito casu qui arripuerit codicem legere ibi, sed lecturus tota hebdomada dominica ingrediatur. 2. Qui ingrediens, post Missas et Communionem petat ab omnibus pro se orari, ut avertat ab ipso Deus spiritum elationis. 3. Et dicatur hic versus in oratorio tertio ab omnibus, ipso tamen incipiente: 'Domine, labia mea aperies, et os meum adnuntiabit laudem tuam'; 4. et sic accepta benedictione ingrediatur ad legendum.

5.Et summum fiat silentium, ut nullius mussitatio vel vox nisi solius legentis ibi audiatur. 6. Quae vero necessaria sunt comedentibus et bibentibus sic sibi vicissim ministrent fratres ut nullus indigeat petere aliquid. 7. Si quid tamen opus fuerit, sonitu cuiuscumque signi potius petatur quam voce. 8. Nec praesumat ibi aliquis de ipsa lectione aut aliunde quicquam requirere, ne detur occasio: 9. nisi forte prior pro aedificatione voluerit aliquid breviter dicere.

10. Frater autem lector hebdomadarius accipiat mixtum priusquam incipiat legere, propter communionem sanctam, et ne forte grave sit ei ieiunium sustinere; 11. postea autem cum coquinae hebdomadariis et servitoribus reficiat.

12. Fratres autem non per ordinem legant aut cantent, sed qui aedificant audientes. 
A fines del siglo VIII Carlomagno en la Epistola de Litteris Colendis afirmaba que después de haber deliberado con los fieles, habían juzgado conveniente que los obispados y monasterios que, por la gracia de Cristo, habían sido colocados bajo su gobierno, además del orden de una vida regular y de la práctica de la santa religión, debian aplicar también su celo al estudio de las letras y enseñarlas a quienes pudieran aprenderlas. de acuerdo con su capacidad individual y destacaba que mientras la observancia de la Regula sustentaba la honestidad de las costumbres, el deseo de aprender y de enseñar pondría orden en el lenguaje ${ }^{39}$.

En este período es cada vez más clara la correspondencia entre lenguaje y sentido. En la mencionada epístola hay una explícita queja sobre las cartas remitidas desde los monasterios que se caracterizan por un sentido correcto y un lenguaje inculto - sensus rectos et sermones incultos -. La epístola enuncia también que se había comenzado a temer que, si faltaba sabiduria para escribir, habría también menos capacidad para interpretar las Sagradas Escrituras. Si bien los errores de expresión son peligrosos, se advertía que los errores de sentido lo son mucho más ${ }^{40}$.

La diferencia entre el acto de lectura y su comprensión se continúa constatando a fines del VIII o comienzos del IX, cuando el arzobispo de Lyon, Leidradus, le escribía a Carlomagno para comunicarle que poseía escuelas de lectura, en las cuales no sólo se practicaba la lectura de las "lecciones" para los funcionarios, sino que se aplican al estudio de las Sagradas Escrituras, para alcanzar a comprender mejor su significado espiritual ${ }^{41}$.

\section{Conclusión: la cultura de la Regula}

Mientras el perfil de la disciplina individual había caracterizado las tendencias primitivas y era consecuente con el movimiento eremítico, la Regula benedictina respondió a las necesidades de un contexto que involucraba la

39 29. Karoli Epistola de Litteris Colendis - 780-800, M.G.H. Legum II. I.

sicut regularis norma honestatem morum, ita quoque docendi et discendi instantia ordinet et ornet seriem verborum, ut, qui deo placere appetunt recte vivendo, ei etiam placere non neglegant recte loquendo...

40 Ibidem. ...Et bene novimus omnes, quia, quamvius periculosi sint errores verborum, multo periculosiores sunt errores sensuum.

${ }^{41}$ Leidradus, Epistolae I. En: Migne, P.L., t. XCIX, c. 87l-872.

(...) Nam habeo scholas cantorum, ex quibus plerique ita sunt eruditi, ut alios etiam erudire possint.Praeter haec vero habeo scholas lectorum, non solum qui officiorum lectionibus exercentur, sed etiam in divinorum librorum meditatione spiritalis intelligentiae fructus consenquatur; ex quibus nonnuli de libro Evangeliorum sesum spiritalem etiam ex parte adipisci possunt. Plerique vero librum prophetarum secundum spiritalem intelligentiam adepti sunt. Similiter libros Salomonis, vel libros Psalmorum, atque etiam Job. In libris quoque conscribendis, in eadem Ecclesia, in quantum potui, elaborarvi (...). 
desocialización, provocada por el debilitamiento de las diferentes relaciones de la trama social del Occidente europeo.

La Regula partió de un contexto que reformuló los vínculos sociales y, si bien, permitió una amplia incorporación de individuos de las más diversas extracciones, devino en un espacio de aglutinamiento que enfatizó ciertas actividades. La letrada adquirió mayor visibilidad y permitió incorporar en el ámbito monástico su tendencia ordenadora. Las prácticas de la escritura se proyectan en el propio grupo que hace uso de ellas y los disciplina pero también permite irradiar esas formas de organización fuera de ese mismo grupo hacia otros miembros de la orden y hacia el espacio social exterior al monasterio.

El ámbito monástico constituye un espacio en el que se pueden desarrollar determinadas actividades sin sensibles perturbaciones. No se debe separar el proceso de resocialización de la atención privilegiada en el ejercicio de prácticas letradas en los monasterios. Hasta fines del siglo VIII y principios del IX, en que el accionar de los carolingios se propone hacer de la Regula de san Benito un medio para disciplinar al clero regular, las comunidades monásticas vieron surgir en su seno ámbitos de circulación textual que suponían necesidades particulares y perfiles específicos en los individuos que los integraban.

En el plano de las posibilidades de inclusión, hay que enfatizar el carácter protector que detenta también el monasterio y que puede constatarse desde la segunda mitad del siglo III cuando las comunidades monacales servían de refugio contra una fiscalidad opresiva o cualquier otra modalidad coercitiva del Estado imperial romano ${ }^{42}$.

No se debe escindir el proceso de resocialización de la preocupación por el ejercicio de prácticas letradas monásticas, en particular a partir de fines del siglo VIII y principios del IX, cuando la política carolingia instala o recupera - según los casos - el uso de la Regula de san Benito como dispositivo de control de la extensa red monástica que cubre el imperio. Son numerosos los capitulares carolingios que denotan esta permanente necesidad de organizar el espacio social, tanto eclesial como monástico, a partir de imponer y preservar la vigencia del orden canónico, en el primer caso, y de la Sancta Regula en el que especialmente analizamos. En lo concerniente a los monasterios, habitados por los monjes, se impone que se viva allí según la Regula y se establece también que los monasterios de mujeres observen la Sancta Regula. Regula que se debe no sólo practicar sino también enseñar. Además denota un claro objetivo de reproducir la necesidad benedictina de ponderar

42 Vide v.g., el edicto del año 370 o 373 dado por los emperadores Valentiniano y Valente, dirigido a Modesto, prefecto de pretorio de Oriente, en que se refiere a algunos adeptos de la facilidad abandonando las cargas de las ciudades, ganan los desiertos y los lugares apartados y, bajo el pretexto de la religión, se integran a las comunidades monásticas. 
la jerarquía y la autoridad del abad, como principio de ordenamiento que coincide a su vez con el diseño del proyecto carolingio. Ordenamientos como el representado por la Capitular de Epistolis Colendis y la Sancta Regula convergen en el objetivo prescriptivo de la política oficial. Leges y regulae desarrollan así unas posibilidades que, tomadas cada una de ellas en forma aislada, se proyectaban en un espacio social más acotado. El entramado que ambos tipos de instrumentos normativos configuran a partir del mencionado horizonte político, cierra un proceso de resocialización como no se conocía desde hacia casi tres siglos y que, al profundizarse la feudalización, no habría de alcanzar la plena madurez.

En consecuencia, podemos hablar de una "cultura de la Regula" en la medida que dicha cultura permitió desarrollar a los sujetos que involucraba, particulares posibilidades, tanto de recuperación y superación de las fragmentadas redes sociales como de interacción y aceptación de modelos culturales diversos que estaban en vías de acomodación, permitiéndoles consumar un conjunto de materializaciones y representaciones simbólicas. Es decir que quienes se sometieron a su influjo pudieron alcanzar unas condiciones especiales de sociabilidad en las que fueron posibles la recuperación, producción y circulación de bienes culturales, a través de la acción estabilizadora de los monasterios. Desde un fondo modesto de material escrito instrumental, que fue seleccionado para acompañar el trabajo cotidiano, fijado en lo funcional y pautado en lo temporal, accedemos a los scriptoria de los siglos VIII y IX, entendidos como dinámicos centros de producción cultural. 


\section{Bibliografia}

Azzara C., Moro P., I capitulari italici. Storia e diritto della dominazione carolingia in Italia, Roma, 1998 (Altomedievale, I)

Cracco G., Dai longobardi ai carolingi. I percorsi di una religione condizionata. En: Storia dell'italia religiosa, Roma-Bari, 1993, pp. 111-154

de Vogüé A., La regola di S. Benedetto. Commento dottrinale e spirituale, Abbazia di Praglia, 1984

de Vogüé A., Las Règles monastiques anciennes. 40o-70o, Turnhout, 1985

Holtz L., "Vers la création des bibliothêques médiévales en Occident". En: AAVV Morfologie sociale e... I.II. 1998, pp. 1059-1106

Lane Fox R., Cultura escrita y poder en el cristianismo de los primeros tiempos. En: Woolf G. (comps.), Cultura esuita y poder en el Mundo Antiguo, Barcelona, 2000, pp. 199-234

Petrucci A., Alfabetismo, escritura, sociedad. (Con prólogo de Roger Chartier y Jean Hébrard), Barcelona, 1999

Petrucci A., "La concezione cristiana del libro fra VI e VII secolo" ("Studi medievali”, XIV, 1973). En: Cavallo G., (a cura di), Libri e lettori nel medioevo. Guida storica e critica, Roma-Bari, 1989 (1977), pp. 5-26

Picasso G., Il monachesimo in Umbria. En: AAVV, Umbria cristiana dalla difusione del culto al culto dei santi (sec. $I V$-X), Centro Italiano di Studi sull'Alto Medioevo, Spoleto, 2001 (Atti del XV Congresso internazionale di studi sull'alto medioevo, Spoleto 23-28 ottobre 2000), pp. 553-568

Pricoco S., (a cura di), La regola di san Benedetto e le regole dei Padri, Fondazione Lorenzo Valla, Italia, 1998

Riché P., Éducation et culture dans l'Occident barbare. $V I^{\circ}-V I I I^{\circ}$ siècle, Paris, 1995 (1962)

Susi E., Monachesimo e agiografia in Umbria. En: AAVV, Umbria cristiana dalla difusione del culto al culto dei santi (sec. IV-X), pp. 569-605

Zurutuza H., "Los 'hombres de Iglesia' en la Umbria cristiana. La discretio como criterio de ordenamiento de la comunidad monástica”. En: Umbria cristiana dalla diffusione del culto al culto dei santi-secc. IV-X, II, Spoleto, 2001, pp. 905-914 


\title{
Venanzio Fortunato e la società del VI secolo*
}

\author{
Cristina La Rocca
}

\section{Il VI secolo e il recente dibattito storiografico}

L'esperienza di Venanzio Fortunato, non solo di poeta e agiografo, ma soprattutto di individuo, si svolse in un contesto cronologico e geografico di eccezionale interesse. La seconda metà del secolo VI costituisce infatti un momento di cruciale importanza per il passaggio dalla società tardoantica a quella altomedievale, e il regno dei Franchi rappresenta indubbiamente l'osservatorio privilegiato per esaminare lo sviluppo delle nuove forme di autorità regia, di supremazia politica e di pratiche aristocratiche che portarono, nel corso del secolo VIII, all'emergere non soltanto della dinastia dei Pipinidi e della creazione dell'unità carolingia, ma anche alla nascita di una ideologia politica stabilmente basata sul coerente rapporto tra istituzioni pubbliche e istituzioni ecclesiastichel. Proprio la sua posizione di ponte tra un epoca e un'altra non ha però giovato agli studi su questo periodo. A cavallo com'è tra due discipline accademiche - la storia romana e la storia medievale - la società del secolo VI è stata osservata secondo due prospettive divergenti, ma entrambe sminuenti: mentre per i tardoantichisti essa costituisce il momento finale di destrutturazione dei fenomeni del passato, gli altomedievisti tendono invece a interpretarla come fenomeno di embrionale novità. Enfatizzando rispettivamente ciò che del passato vi è ancora, con lo sguardo malinconicamente rivolto all'indietro, oppure ciò che del futuro vi è già, con la mente proiettata in avanti, le caratteristiche intrinseche del VI secolo finiscono col diventare solo una rozza e informe somma di elementi 'finali' oppure di aspetti 'preparatori'2.

\footnotetext{
* Questo saggio è già apparso in AA.VV., Venanzio Fortunato e il suo tempo, Treviso 2002, pp. 15-36.

${ }^{1}$ Cfr. G. Tabacco, Il volto ecclesiastico del potere in età carolingia, in La Chiesa e il potere politico, Torino 1986 (Storia d'Italia Einaudi. Annali, 9), pp. 7-41 (ora in G. Tabacco, Sperimentazioni del potere nell'alto medioevo, Torino 1993, pp. 165-208).

$2 \mathrm{Si}$ tratta insomma dello stesso atteggiamento già verificato, a proposito del tema delle istituzioni cittadine tra altomedioevo ed età comunale, da G. Sergi, Le città come luoghi di continuità di nozioni pubbliche del potere. Le aree delle marche di Ivrea e di Torino, in Piemonte medievale. Studi per Giovanni Tabacco, Torino 1985, pp. 5-7.
} 
Nel caso di Venanzio, poi, questa tendenza è stata ulteriormente accentuata dalle stesse vicende biografiche del poeta. Nato in Italia durante il lungo conflitto che oppose l'esercito dei Goti a quello imperiale, ma operante nel regno dei Franchi, Venanzio è stato a lungo studiato come italiano in terra straniera e la sua produzione è stata valutata tracciando una linea di confine tra le caratteristiche culturali 'romane' del decadente e opportunista Venanzio, a confronto con quelle 'germaniche', rozze e incolte dei suoi sponsor franchi, non senza una venatura di disprezzo nel constatare il prostrarsi dei raffinati strumenti retorici e poetici della tradizione classica nell'omaggiare un pubblico 'barbaro', incapace di apprezzarli compiutamente 3 . Ma questa rigida separazione etnica e culturale sembra più il frutto di ricostruzioni storiografiche che non della realtà: se è pur vero che una volta Venanzio si definisce italus, questo termine è utilizzato soltanto per indicare la distanza geografica del suo luogo di origine ${ }^{4}$; i lavori di Walter Goffart, poi, hanno dimostrato che il termine barbarus era utilizzato nel VI secolo come etichetta neutra, priva di qualsiasi significato dispregiativo, che gli stessi Franchi o i Burgundi non disdegnarono di applicare a sé stessi ${ }^{5}$, senza contare che lo stesso Venanzio lo applicò a persone che intendeva lodareb.

Come si è potuto accertare nella più recente storiografia, a partire dal III secolo barbari e romani facevano parte di uno stesso sistema, di cui il mondo romano costituiva il centro e i barbari, stanziati ai suoi confini, la periferia. Il mondo romano stimolava i barbari a diventare parte attiva del centro attraverso una complessa dinamica di integrazione, stimolandone i bisogni, accrescendone la stabilità sociale, fornendo i simboli e gli oggetti materiali di

$3 \mathrm{Si}$ vedano, a questo proposito, le belle pagine di L.Pietri, Venance Fortunat et ses commanditaires: un poète italien dans la société gallo-franque, in Committenti e produzione artistico-letteraria nell'alto medioevo occidentale, Spoleto 1992 (Settimane di studio del Centro italiano di studi sull'alto medioevo, 39), pp. 729-754.

4 I riferimenti all'opera di Fortunato si riferiscono all'edizione di F. Leo (M.G.H., Auctores Antiquissimi, IV/1, Hannoverae 1881, d'ora in avanti Carmina) e di B. Krusch (M.G.H., Auctores Antiquissimi, IV/2, Hannoverae 1885, d'ora in avanti Opera pedestria) Venantius Fortunatus, Carmina, V, 18, v.5. Più frequentemente Venanzio si dice semplicemente provenire dall'Italia: Carmina, IV 20, v. 5; VII 9, v. 7; VIII 1, v. 12; X 13, v. 10, 16, v. 1

5 W. Goffart, Foreigners in the Histories of Gregory of Tours, «Florilegium», 4 (1982), pp. 8099; W. Goffart, The Narrators of Barbarian History. Jordanes, Gregory of Tours, Bede and Paul the Deacon, Princeton 1988, pp. 162-164, 212- 213.

${ }^{6}$ Barbarus: Venantius Fortunatus, Carmina, IV 26, v. 14, VI 5, v. 52; VII 8 v. 63, 18, v. 19; IX 1, v. 27; app. I v. 31, II, v. 83; Vita Martini, I, v. 480, III, v. 497; si veda a questo proposito, L. van Acker, Barbarus und seine Abletungen im Mittellatein, in "Archiv für Kulturgeschichte», 47 (1965), pp. 125-140; quanto all'identità dei Romani in Gallia, cfr. J.D.Harries, Sidonius Apollinaris and the frontiers of Romanitas, in Shifting Frontiers in Late Antiquity, a cura di R.W. Mathisen, H.S. Sivan, Oxford 1996, pp. 31-44, che ridiscute le conclusioni tradizionali di G.B. Ladner, On Roman attitudes toward Barbarians in Late Antiquity, «Viator», 7 (1976), pp. $1-25$. 
ostentazione del prestigio 7 . In particolare nelle aree di frontiera, i modelli di affermazione sociale furono ispirati all'attività militare e furono interpretati e utilizzati su un identico piano sia dai barbari sia dai romani, come prova, tra l'altro, la nascita di uno specifico corredo funerario maschile, dotato di armi e cinture ${ }^{8}$. La coscienza di una separazione etnica oltre che istituzionale tra le due componenti della società venne quindi soppiantata, a partire dal V secolo, dallo svilupparsi di identità etniche totalmente fittizie dal punto di vista biologico, ma invece molto attive e proficue sul piano politico e culturale. I Franchi di Childerico alla metà del secolo V e i Franchi del tempo di Sigeberto e Chilperico alla metà del secolo successivo non hanno in comune che il nome, poiché le loro caratteristiche biologiche, sociali e culturali si erano totalmente trasformate, non da ultimo perché il nome Francus andò a qualificare tutti coloro che, indipendentemente dalle loro origini etniche, riconoscevano la supremazia politica dei re merovingi ${ }^{9}$. Allo stesso modo in cui la confederazione di popoli che, in nome della fedeltà al clan degli Amali, si stanziò in Italia sotto il nome di Goti nel 493, non aveva niente da spartire con coloro che si denominavano Goti cinquant'anni più tardi ${ }^{10}$ : se ha ragione Patrick Amory questo nome venne infatti a indicare tutti coloro che ricoprivano le cariche militari, indipendentemente dalle loro radici biologiche ${ }^{1}$.

Se la fine del mondo romano si manifestò in modi e tempi assai diversi nelle varie regioni dell'Impero, essa si avviò soprattutto quando i funzionari imperiali cessarono di agire in quanto delegati del potere centrale e utilizzarono invece, per dominare, la loro leadership, fondata sul prestigio militare, le alleanze e le clientele che essi avevano costruito localmente. In questo processo venne dunque meno il ruolo dello stato nell'organizzare e disciplinare le gerarchie sociali attraverso titoli pubblici: perciò la competizione tra le élites divenne uno dei fattori principali di azione della vita politica e sociale ${ }^{12}$. In questa

\footnotetext{
7 Si vedano, a questo proposito, le conclusioni e gli spunti di ricerca offerti da S. Gasparri, Prima delle Nazioni. Popoli, etnie e regni fra Antichità e Medioevo, Roma 1997; e da W. Pohl, Le origini etniche dell'Europa. Barbari e Romani tra antichità e medioevo, Roma 2000, con la relativa bibliografia.

8 Cfr. G. Halsall, The origins of the Reihengräberzivilisation: forty years on, in Fifth century Gaul. A crisis of identity?, a cura di J. Drinkwater, H. Elton, Cambridge 1992, pp. 196-207.

9 Sulla formazione dell'identità etnica dei Franchi, cfr. W. Pohl, Alemannen und Franken. Schluâbetrachtung aus historischer Sicht, in Die Franken und die Alemannen bis zur "Schlacht bei Zülpich"(496-497), a cura di D. Geuenich, Berlin New York 1998, pp. 636-651 (ora in Pohl, Le origini etniche, pp. 59-76). Per i Burgundi: P. Amory, The meaning and purpose of etnic terminolgy in the Burgundian laws, «Early Medieval Europe», 2 (1993), pp. 1-28.

10 Cfr. W. Pohl, I Goti d'Italia e le tradizioni delle steppe, in Teoderico il Grande e i Goti d'Italia, Spoleto 1993 (Atti del XIII Congresso internazionale di studi sull'alto medioevo), pp. 227-251 (ora in Pohl, Le origini etniche, pp. 101-125) con la relativa bibliografia.

${ }^{11} \mathrm{P}$. Amory, People and Identity in Ostrogothic Italy, 489-554, Cambridge 1997.

12 La principale discussione su questo tema è $\mathrm{C}$. Wickham, The other transition: from ancient world to feudalism, «Past \& Present», 103 (1984), pp. 3-36.
} 
prospettiva, tra il regno dei Franchi ove Venanzio andò a risiedere e quello dei Goti, presso i quali il poeta aveva trascorso la giovinezza, vi erano molte più similitudini di quanto le etichette etniche abbiano portato a credere.

\section{Venanzio e i suoi patroni}

Inoltre il supporre una netta contrapposizione culturale tra il poeta e i suoi committenti ha fatto sì che abbia prevalso, nel valutare le informazioni offerte da Venanzio, il suo punto di vista come semplice osservatore passivo, o tutt'al più come mistificatore dei fatti, e non quello di Venanzio come personaggio attivo, apprezzato e richiesto interprete delle ambizioni e delle tensioni della società in cui egli agiva, considerando cioè il rapporto che venne instaurandosi tra il poeta e i suoi committenti e le dinamiche della loro relazione. Se osservata da questa prospettiva, la produzione encomiastica di Venanzio non è infatti di semplice valore constatativo, di documentazione della realtà - ancorché rivestita di una patina antica e nobilitante -, ma acquista un forte valore propositivo, generatore di modelli e di comportamenti, specchio della cultura letteraria, dei pregiudizi, dei progetti delle élites del VI secolo, e soprattutto delle loro difficoltà. La stessa carriera di Venanzio da poeta, a presbyter sodale della regina Radegonda e infine a vescovo di Poitiers ${ }^{13}$ è la prova di quanto l'abilità letteraria fosse tenuta in considerazione presso la società franca del VI secolo ${ }^{14}$.

Come è stato osservato da più parti, la principale fonte su Venanzio Fortunato, sulla sua vita e sulle sue opere, è quanto egli stesso ci ha tramandato di sé. Questo costituisce una particolarità del nostro autore che forse non è stata sufficientemente sottolineata, poiché, a dispetto della varietà di individui e di ruoli sociali con cui Venanzio ebbe a che fare nel corso della sua vita, questi rapporti sono singolarmente caratterizzati dalla mancanza di reciprocità, per lo meno di reciprocità scritta. Lo stesso Gregorio di Tours, il cui rapporto con Venanzio appare improntato dall'amicizia e dalla solidarietà, non gli dedica che una scarna riga nelle sue Historiae, e solo in quanto presbyter autore della Vita Beati Germani, dimostrando di non volersi affatto dilungare né sulle sue qualità poetiche, né sulla sua personalità ${ }^{15}$. A fron-

13 La carriera di Venanzio è efficacemente riassunta da B. Brennan, The career of Venantius Fortunatus, in «Traditio», 46 (1985), pp. 49-78.

14 Sono aspetti evidenziati da I. Wood, Merovingian Kingdoms 450-751, London New York 1994, pp. 26-27.

15 Gregorii episcopi Turonensis, Historiarum libri X, a cura di B. Krusch, Hannoverae 1951 (M.G.H., Scriptores rerum Merovingicarum, I), V, 8. Le menzioni da parte di Gregorio di Tours a proposito di Venanzio, in tutta la sua opera, si contano sulle dita di una mano: sono raccolte da Goffart, The Narrators, p. 146 n. 149. 
te delle centinaia di epistolae redatte da Venanzio, non ci è stata tramandata nessuna epistola a lui scritta, sebbene in qualche caso egli stesso testimoni di essere in regolare consuetudine con alcune figure laiche ed ecclesiastiche ${ }^{16}$. Questa unidirezionalità di rapporti deve farci riflettere su uno degli aspetti preminenti della società del VI secolo, pienamente testimoniata dagli scritti di Venanzio e dalla struttura stessa della sua opera, organizzata per gruppi sociali di destinatari: per Venanzio come per i suoi illustri interlocutori, l'altissimo grado di instabilità delle élites rendeva necessario ostentare e ribadire costantemente gli aspetti visibili e condivisibili della preminenza. Il ruolo che Venanzio si ritagliò in seno alla società merovingia - o perlomeno quello che lui stesso volle sottolineare di sé - è infatti quello di maestro della parola e della poesia: parole sapientemente ordinate a dare luce e anima alle caratteristiche altrui sono il peculiarissimo oggetto del rapporto che Venanzio instaura con coloro a cui dedica i suoi versi. Si tratta di relazioni presentate come diseguali, intrecciate da una posizione di subalternità, veri e propri doni ai potenti. Ma si tratta di falso understatement. Le qualità oratorie e poetiche che costantemente Venanzio esalta nei suoi patroni sono infatti quelle in cui egli stesso sa di primeggiare: magnificandole nei suoi interlocutori egli le propone come categorie di distinzione sociale e di eccellenza che servono a qualificare prima di tutto lui stesso di fronte al suo uditorio ${ }^{17}$.

Della realtà delle relazioni sociali di Venanzio sono spia ben più efficace le lettere di raccomandazione che egli stesso rivolge ai vescovi locali a favore di suoi propri protegés - come nel caso in cui egli si fa da tramite con il vescovo Siagrio di Autumn per il pagamento di un riscatto per un servo, oppure quando, in numerose occasioni, sollecita Gregorio di Tours a liberare ragazze accusate di furto e ingiustamente imprigionate ${ }^{18}$-: esse testimoniano che Venanzio, a un certo punto della sua carriera, era perfettamente in grado di attivare un certo numero di rapporti di subordinazione. Anche i piccoli componimenti occasionali svelano la capacità di Venanzio di instaurare rapporti paritari di familiarità: ne siano un esempio per tutti le conchiglie portate in dono a Placidina, che, in quanto dono gratuito e fuggevole, testimoniano la qualità della relazione di intimità personale che il poeta aveva instaurato con la illustre moglie del vescovo Leonzio di Bordeaux ${ }^{19}$.

\footnotetext{
16 Per esempio, Venantius Fortunatus, Carmina, V 17; VII 9, 10, 21, 25; IX 6, app. I, IV.

17 Cfr. la brillante analisi di P.Godman, Poets and Emperors. Frankish Politics and Carolingian Poetry, Oxford 1987, pp. 15-21

18 Venantius Fortunatus, Carmina, V 6, 10, 14, 15, 18; X 12, 13, .

19 Venantius Fortunatus, Carmina, I, 17. Su questo carme, cfr. l'interpretazione di M. Reydellet, Venance Fortunat. Poèmes, I, livres I-IV, Paris 1994, p. XXX.
} 


\section{Il problema della nobilitas}

Sarebbe perciò un errore pensare che l'immagine di instabilità che Venanzio stesso enfatizza di sé, cioè quella del topolino alla ricerca di cibo alla tavola dei potenti ${ }^{20}$, fosse un elemento a lui peculiare: tutta la società con cui Venanzio ha rapporti vive, con la stessa intensità, seppur su piani e modi diversi, nella necessità di vedere confermate e apprezzate le proprie specificità per dimostrare di appartenere alle élites nel presente, e per trasmettere una tale eredità immateriale alla generazione successiva.

La produzione di Venanzio è perciò osservabile come elemento attivamente ricercato per confermare o proporre la supremazia di coloro a cui i carmina sono dedicati: uno dei fili rossi dei carmi di Venanzio è infatti quello della stabilità sociale, o meglio quello delle prove attraverso le quali la stabilità dei ruoli sociali può essere confermata e ribadita. Come Venanzio aveva certo sperimentato durante la sua giovinezza, vissuta durante il breve e contrastato momento della restaurazione imperiale in Italia, la stabilità sociale era l'oggetto controverso di due modelli in antitesi tra di loro: da un lato, un modello di tipo pubblico, ove era lo stato ad assegnare e garantire, attraverso propri titoli onorifici, la posizione del singolo e del suo gruppo famigliare all'interno della società. Dall'altro un modello più incerto e labile, ma certo diffusissimo, perché lasciava ampio spazio alle possibilità individuali, all'interno del quale la rilevanza sociale si estrinsecava attraverso la stabilità dei propri legami personali, la disponibilità di terra, la capacità di enucleare attorno a sé gruppi di fedeli armati, oppure di sottoposti: insomma vincoli privati di natura militare e familiare, di subordinazione o di pari livello sociale, che prevedevano un grande investimento di energie, materiali e politiche, nel ribadire costantemente di fronte al proprio pubblico la continuità di tali prerogative. Tale supremazia, o leadership, però, non poteva contare su una titolatura ufficiale che la fissasse stabilmente all'interno delle gerarchie sociali, ma solo sugli epiteti onorifici derivati dalla coscienza dinastica del gruppo familiare nelle generazioni, dalle imprese militari, dai legami di protezione instaurati verso l'alto e dalle relazioni di reciprocità attivate attraverso il sistematico scambio dei doni21.

20 Venantius Fortunatus, Carmina, praefatio, 6.

${ }^{21}$ Sullo scambio di doni come parte fondante dell'economia e delle relazioni sociali nell'alto medioevo, cfr. il classico M. Mauss, Saggio sul dono. Forma e motivo dello scambio nelle società arcaiche, in M.Mauss, Teoria generale della magia, Torino 1965 (trad. italiana dell'ediz. originale Sociologie et antropologie, Paris 1950). La dinamica della reciprocità nelle relazioni altomedievali, impostate sull'organico scambio di doni e di contro-doni, in un sistema di scambio che tendeva a definire e a precisare le gerarchie e gli obblighi sociali tra beneficante e beneficato, era perfettamente nota a Venanzio: nel cantare le virtù del ricco mercante Giuliano e del ricco e nobile Avolo, Venanzio sottolinea che entrambi distribuirono doni in segreto, cioè senza testimoni. Il legame di reciprocità e di subordinazione che il dono implicava veniva così a collocarsi 
È bene chiarire che la compresenza di questi due modelli di affermazione sociale - il primo che tendeva a basarsi sulla tradizione, il secondo sulle possibilità del presente - si riverberava in pieno anche sulla componente ecclesiastica, che da quegli stessi gruppi aristocratici era tratta. La nomina vescovile, ad esempio, si trovava in continua oscillazione nel conflitto tra gruppi familiari che ne avevano dinastizzato la carica, i gruppi aristocratici loro rivali all'interno della stessa comunità, e infine le fazioni nate all'interno del clero locale. Le Historiae di Gregorio di Tours mostrano infatti numerosi esempi delle ambizioni nate in seno al gruppo degli arcidiaconi che tendevano a presentarsi quali naturali successori del proprio vescovo, e della loro capacità di mobilitare le proprie fazioni di sostenitori locali 22 .

A questa continua negoziazione con la società locale, si aggiunga, per i laici come per gli ecclesiastici, la diretta ingerenza del re nella nomina vescovile come in quella degli ufficiali pubblici: il processo di rafforzamento e di separazione della famiglia merovingia dalle altre famiglie aristocratiche del regno era infatti consistito nel porsi al centro dei destini individuali dei funzionari, che spesso venivano designati senza avere nessun legame locale - né familiare né patrimoniale - con la loro sede, riservandosi il diritto di rimuoverli dalla loro carica non appena il loro rapporto di coesione con il re fosse venuto meno. Secondo Venanzio, lo stesso Gregorio doveva la sua nomina di vescovo di Tours all'intervento diretto di re Sigiberto e della moglie Brunilde $^{23}$, mentre i suoi beni e le sue relazioni familiari erano incentrati in Burgundia e in Alvernia ${ }^{24}$. Il potere pubblico e il potere episcopale operavano dunque in una stretta contiguità e reciprocità di rapporti con il potere regio: se al re era necessario il supporto dei propri fedeli armati, ugualmente necessario gli era l'appoggio dei vescovi nelle principali città. Inoltre, così come il mantenimento dello status aristocratico era garantito dalla continuità di sintonia con il re, così i chierici necessitavano del supporto regio per effettuare la propria ascesa vescovile. In questa prospettiva, la separazione,

in una dimensione strettamente privata, nota solo alle due parti, che non recava alcun potenziamento della fama pubblica del donatore. Venantius Fortunatus, Carmina IV 21, v.5-10: (Avolus) templa dei coluit, latitans satiauit egentem:/ plenius illa metit quae sine teste dedit./ nobilitate potens, animo probus, ore serenus,/ plebis amore placens, fundere promptus opes,/ non usurae auidus, licet esset munere largus,/ plus nihil expetiit quam numerando dedit. Venantius Fortunatus, Carmina IV 23, v. 11-14: (Iulianus mercator) nec solum refouens, sed dona latendo ministrans / amplius inde placet quod sine teste dedit./ felicem censum qui fratris migrat in aluo!/ et uiuos lapides aedificare potest. Sui doni gratuiti, cfr. J. Parry, The gift, the Indian gift and the 'Indian gift', «Man», n.s. 21, pp. 453-473.

22 Cfr. Wood, Merovingian Kingdoms, pp. 77-79

23 Venantius Fortunatus, Carmina, V 3, v. 15-16

24 Gregori episcopi Turonensis, Historiarum Libri X, V, 49. Su questi aspetti, cfr. N. Wood, The ecclesiastical politics of Merovingian Clermont, in Ideal and Reality in Frankish and Anglo-Saxon society, a cura di P.Wormald, Oxford 1983, pp. 34-57; Wood, Merovingian kingdoms, pp. 79-84. 
anche di recente proposta, tra i carmina di Venanzio dedicati ai vescovi da quelli dedicati all'aristocrazia laica, tende a nascondere le origini comuni di questi due gruppi e dunque la problematica sociale che entrambi pienamente condividevano ${ }^{25}$.

Un caso significativo è quello del gruppo familiare del vescovo Avito di Clermont, imparentato con Sidonio Apollinare, la cui dinastia cessò di avere ogni rilevanza nella sede originaria della famiglia, potenziandosi successivamente a Bordeaux, con la coppia vescovile formata da Leonzio e dalla moglie Placidina ${ }^{26}$, a cui Venanzio dedicò numerosi suoi componimenti. Il carme I 15, in lode di Leonzio, si apre anzitutto precisando le basi della sua eccellenza sociale: il primo elemento che identifica lo status di Leonzio è il suo legame diretto con il re Childeberto I e l'attività militare che egli ha svolto al seguito del re, presentando il background di fedeltà e di valore in guerra come il fattore che ha permesso a Leonzio di ascendere alla carica vescovile 27 . Il secondo elemento è quello dell'antichità della sua stirpe, la quale però non ha di per sé una funzione nobilitante, ma risulta prestigiosa solo in quanto avvalorata dalle azioni compiute da Leonzio. La stirpe è paragonata, in modo assai efficace, a una antica villa che non è andata in rovina nel corso del tempo, ma è stata restaurata e rinnovata dallo stesso Leonzio ${ }^{28}$. Il rapporto di legittimità è quindi rovesciato: è l'agire di Leonzio che nobilita l'antico prestigio dei suoi antenati e non vice versa. Per Venanzio e per Leonzio, dunque, la coscienza dinastica, l'illustre e nobile progenie del passato, non sono un elemento sufficiente per essere definiti nobili, poiché le origini devono trovare una loro conferma nel presente. La nobiltà non è allora presentata come elemento dal movimento discendente, che si trasmette geneticamente nelle generazioni, bensì all'inverso: la stirpe è solo la radice di una pianta, di cui Leonzio è il frutto fronzuto che la riveste e la abbellisce 29 .

25 Questa separazione è proposta, ad esempio, da J. W. George, Venantius Fortunatus. A latin poet in Merovingian Gaul, Oxford 1992; J.W. George, Portraits of two Merovingian bishops in the poetry of Venantius Fortunatus, «Journal of Medieval History», 13 (1987), pp. 189-207; B.Brennan, The image of the Merovingian bishop in the poetry of Venantius Fortunatus, «Journal of Medieval History», 18 (1992), pp. 115-139.

26 Venantius Fortunatus, Carmina, I, 14-16, 18-20; III 24; IV 10 . Le vicende del gruppo parentale sono state esaminate da Wood, Merovingian Kingdoms, pp. 83-84.

27 Venantius Fortunatus, Carmina, I 15 vv. 7-10: qui, cum se primo uestiuit flore iuuentus,/paruus eras annis et grauitate senes;/uersus ad Hispanas acies cum rege sereno,/militiae creuit palma secunda tuae.

28 Venantius Fortunatus, Carmina, I 15, vv. 19-22: tempora diffugiunt et stat tamen aula parentum/nec patitur lapsum te reparante domus./nobilitas longos non inclinauit in annos, cui magis ascensum proles opima dedit.

29 Venantius Fortunatus, Carmina, 1,15 vv. 29-30: emicat altus apex generosa stemmata pandens,/cuius apud reges unica palma patet. Sul tema della stabilità sociale, cfr. B. Brennan, Senators and social mobility in sixth-century Gaul, «Journal of Medieval history», 11 (1985), pp. 89-136. 
Ł̀ interessante che per esemplificare la trasmissione della nobilitas Venanzio ricorra a immagini edilizie di tipo archeologico, quali gli scavi ci riportano con grande intensità proprio nel territorio di Bordeaux: si tratta infatti di un paesaggio fittamente occupato da residenze rurali aristocratiche costruite in età classica che subiscono, nel corso del V e del VI secolo, una notevole fase di rioccupazione e di risistemazione edilizia, che comprende in alcuni casi l'ampliamento degli spazi abitativi, in altri il mutamento di destinazione di alcune parti residenziali in edifici di culto ${ }^{30}$. In altri tre carmi lo stesso Leonzio è celebrato da Venanzio proprio per i restauri da lui fatti eseguire su antichi edifici abbandonati, che sono riportati a nuovo splendore, come la villa porticata di cui Leonzio ha restaurato l'impianto termale ${ }^{31}$. Né i paragoni edilizi sono peculiarità dell'agire vescovile: anche il duca Launebode è illustre per le sue attività che nobilitano i suoi avi, e la prova edilizia del loro valore è utilizzata da Venanzio come elemento visibile e noto a tutti 32 .

Nel sottolineare la necessità dell'agire nel presente per rendere vivo il passato, definendo lo status aristocratico come organico bilancio tra tradizione dinastica e attualità, Venanzio fa dunque riferimento a immagini concrete che erano percepite e comprese con chiarezza dal suo uditorio proprio in quanto facevano parte integrante del paesaggio visivo locale, oltre che essere, naturalmente, il prodotto stesso delle attività edilizie dei suoi interlocutori. Nel fare ciò Venanzio dichiarava del tutto sorpassata l'idea antica che riservava ai soli costruttori di edifici nuovi il plauso e il pubblico riconoscimento, che aveva permesso ad Ammiano Marcellino di biasimare un praefectus urbis perché si faceva passare per fondatore di edifici che aveva in realtà solo riadattato 33 .

30 In Aquitania il V secolo è contraddistinto dalla persistenza della tipologia della villa suburbana come residenza aristocratica, come dimostrano gli esempi di Chiragan, Plassac, St.Emilion, presso Bordeaux, tutte contraddistinte dalla presenza di terme e di ricchi mosaici. Se in alcuni casi si trattò di rioccupazione di edifici preesistenti, in altri, come quello di Palat, si tratta di costruzioni impiantate ex-novo. Cfr. H. Sivan, Town and country in Late Antique Gaul: the example of Bordeaux, in Fifth century Gaul, pp. 132-143.

${ }^{31} \mathrm{Si}$ tratta rispettivamente di Venantius Fortunatus, Carmina, I 18, 19, 20.

32 Venantius Fortunatus, Carmina, II 8, vv. 21-24: Launebodis enim post saecula longa, ducatum/ dum gerit, instruxit culmina sancta loci./ quod nullus ueniens Romana gente fabriuit,/ hoc uir barbarica prole peregit opus/; ibid., vv. 39-40 sed quamvis altum teneat de stirpe cacumen/ moribus ipse suos amplificavit avos.

33 Ammianus Marcellinus, Rerum Gestarum Libri qui supersunt, II, a cura di C.U.Clark, Berolini 1910, XXVII, 3, 7, p.423: "Per omnia enim civitatis membra, quae diversorum principum exornarunt impensae, nomen proprium inscribebat, non ut veterum instaurator, sed conditor". Su questo tema, si veda in generale B. Ward-Perkins, From Classical Antiquity to the Early Middle Ages. Urban public building in Northen and Central Italy. A.D. 300-850, Oxford 1984, pp. 37-49, con gli esempi ivi indicati. La lode della renovatio è anche uno degli assi portanti dell'ideologia edilizia del regno di Teoderico: cfr. C. La Rocca, Una prudente maschera "antiqua". La politica edilizia di Teoderico, in Teoderico il Grande e i Goti d'Italia, pp. 451-515. 
Il tema della nobilitas viene poi saldamente agganciato alla figura regia e al rapporto di fedeltà instaurato con il re. Nell'epitaffio redatto per lo stesso Leonzio si ribadisce infatti che la sua preminenza deriva sì dalle sue origini "quale genus Romae forte senatus habet", ma precisando, subito dopo, che questa caratteristica è resa attuale dai legami instaurati dal presule, primo tra tutti quello con il re ("regum summus amor"), la società locale ("patriae caput"), il proprio gruppo familiare ("arma parentum"), i propri sodali ("tutor amicorum"), infine la collettività urbana di Bordeaux ("plebis et urbis honor"): ed è proprio la molteplicità di queste sfere di rapporti personali e familiari che ha permesso a Leonzio di agire in modo giusto ed efficace, in qualità di mediatore tra il re e la cittadinanza ("placabat reges, recreans moderamine cives") ${ }^{34}$. Il legame con il re come fonte indiscutibile della preminenza è presente anche in altri epitaffi di laici e di ecclesiastici: per il prete Servilione, la sua nobiltà deriva non solo dall'eredità di lignaggio, ma soprattutto dalla carica pubblica di domesticus all'interno del palazzo regio e dalle virtù di saggio amministratore del fisco regio ${ }^{35}$; Aracario è illustre perché egli "palatina refulsit clarus in aula" 36 ; Orienzio perché per lui ‘il palazzo regio era sempre aperto" 37.

In altri casi, come quello di Gogo, fedele del re Sigeberto, si afferma invece esplicitamente che la nobilitas raggiunta nel presente è esclusivamente il frutto del benvolere regio: Gogo è stato scelto dal re "come un'ape che sceglie i suoi fiori": intendendo implicitamente che la posizione di Gogo e la stima di cui gode sono esclusivamente il frutto della contingenza e quindi suscettibili di mutare nel corso del tempo ${ }^{38}$. Come risulta ormai chiaro, i doni di terra effettuati dai re merovingi per ricompensare i loro funzionari non erano affatto donazioni permanenti in piena proprietà ed è probabile, come si è discusso a lungo negli ultimi anni, che esse consistessero esclusivamente nel diritto di raccoglierne le imposte invece del re, oppure di riscuoterne i censi39. Dunque, il venir meno della carica significava per i funzionari anche il venir meno della terra, cioè della principale risorsa aristocratica. Venanzio sembra perfettamente al corrente della complessa rete di legami e di raccordi che era

34 Venantius Fortunatus, Carmina, IV 10, rispettivamente ai vv. 8, 11-12, 21.

35 Sui panegirici ai funzionari regi, dal punto di vista stilistico e di contenuto, cfr. George, Venantius Fortunatus, pp. 132-151. Venantius Fortunatus, Carmina, IV 13, vv. 3-5: hoc igitur tumulo Seruilio clausus habetur,/ nobilis et merito nobiliore potens/.Ipse palatinam rexit moderatius aulam./

$3^{6}$ Venantius Fortunatus, Carmina, IV 19, vv. 5-6: ipse palatina refulsit clarus in aula /et placido meruit regis amore coli.

37 Venantius Fortunatus, Carmina, IV 24, vv. 6-7: palatina prius mansit aperta domus/consiliis habilis regalique intimus aulae.

$3^{8}$ Venantius Fortunatus, Carmina, VII 1, v. 38

39 Cfr. W. Goffart, Barbarians and Romans. A.D. 418-584. The Techniques of Accomodation, Princeton 1980, pp. 162-174. 
necessaria per conservare il favore regio: non da ultimo per il fatto che la politica matrimoniale dei re e la mancanza di un diritto successorio provocavano una situazione di costante conflitto all'interno della stessa famiglia merovingia. In altre parole, la fedeltà a un re poteva tramutarsi all'improvviso in un elemento negativo presso il suo successore. Perciò nel lodare il domesticus Condane, Venanzio descrive il dipanarsi della sua carriera di ufficiale pubblico come una successione di cariche agganciate alla personalità di cinque diversi re - Teoderico I (511-533), Teodeberto(533-548), Teodebaldo(548555), e il loro rivale Clotario I (511-561) e infine Sigeberto I (561-575) - che si succedettero sul trono di Reims tra 511 e 565 , vantando anzitutto l'abilità dello stesso Condane a dimostrarsi, nei fatti, un uomo indispensabile: "I re sono cambiati - dice Venanzio - ma tu non hai mutato i tuoi honores. Tu sei il degno successore di te stesso" 40 . Nell'illustrare il curriculum di Condane da tribunus a comes a domesticus e infine a commensale del re Sigeberto, Venanzio spiega che tale progressione è stata effettuata da un uomo privo di qualsiasi background di passato ${ }^{41}$, presentando esplicitamente l'aristocrazia come gruppo mobile, e di origini variegate, ove i valenti parvenus, come Condane e lo stesso Venanzio, hanno la possibilità di emergere grazie alle loro intrinseche qualità.

\section{Il ruolo femminile nell'aristocrazia}

Un altro aspetto che laici ed ecclesiastici condividono nell'opera di Venanzio è quello della celebrazione congiunta del nucleo coniugale come fonte di legittimazione della discendenza. Uno degli aspetti che differenziava Franchi e Romani era anzitutto la struttura della famiglia e dunque la modalità stessa della trasmissione dei beni. Se la famiglia romana era organizzata come struttura patrilineare di lignaggio, quella franca aveva invece una struttura prevalentemente cognatica, e cioè aperta alle eredità derivanti sia dal ramo materno che da quello paterno. Nel VI secolo, una delle possibilità di individuazione e di trasmissione della nobilitas derivava dall'uso di prelevare i nomi della propria discendenza indifferentemente dall'uno o dall'altro bacino di parentela, a seconda di quale dei due gruppi godesse di maggiore prestigio. Proprio perché nell'alto medioevo l'aristocrazia praticava di norma l'omogamia, vale a dire l'unione di individui provenienti da gruppi parentali di status analogo, la linea di tendenza prevalente era quella di trasmettere

40 Venantius Fortunatus, Carmina, VII 16, vv. 35-36: mutati reges, vos non mutatis honores/ successorque tuus tu tibi dignus eras.

41 Venantius Fortunatus, Carmina, VII 16, vv. 15-16: a parvo incipiens existi semper in altum/ perque gradus omnes culmina celsa tenes. 
nomi derivanti dalla famiglia paterna. La presenza di nomi derivanti dal ramo materno è dunque indice preciso della volontà di utilizzarli per rivendicare la trasmissione di specifici diritti ${ }^{42}$. L'elogio di Placidina, la moglie di Leonzio di Bordeaux, è infatti indissolubilmente unito da Venanzio a quello del marito, poiché la sua stirpe può contare tra gli avi l'imperatore Eparchio Avito e Sidonio Apollinare ${ }^{43}$. In contrapposizione con Leonzio, la cui stirpe, nonostante le diverse congetture formulate a proposito, non è affatto certa, se non come gruppo che fornì alla città di Bordeaux due vescovi prima di lui ${ }^{44}$, il background familiare di Placidina è l'elemento che contribuisce per via matrilineare a innalzare e a sostanziare quello del marito. Sembrerebbe dimostrarlo il fatto che l'unico loro figlio che noi conosciamo, Arcadio, celebrato da Venanzio nel suo epitaffio funebre, fu denominato per ripetizione con il nome del nonno materno, così precisando e accrescendo, appunto nella direzione materna, il rango della discendenza della coppia episcopale ${ }^{45}$.

L'elogio della coppia e delle sue caratteristiche congiunte di eminenza e di concordia è presente, come ho già sottolineato, sia nei carmina dedicati ai laici sia a quelli per gli ecclesiastici: nell'epitaffio del sacerdote Ilario, 'egregia de nobilitate refulgens', Venanzio precisa che anche la sua defunta moglie era dello stesso grado sociale ('conubio iunctus simili') 46 . Così come Placidina e Leonzio sono ritratti da Venanzio agire in perfetta sintonia nella loro opera di edificatori di chiese e delle proprie residenze, ripartendosi i compiti di abbellimento e di decorazione, come nel caso della chiesa di S.Martino presso Parigi ${ }^{47}$, anche Basilio e Baudegonde ampliano la chiesa di S.Martino presso Poitiers 'cum Baudegonde quo mente Basilius una'48, e Launebode e Beretrude insieme fondano la chiesa di S.Saturnino presso Toulouse, ripartendosi equamente le opere di abbellimento della chiesa e quelle di pietà nei confronti dei poveri ${ }^{49}$.

Sullo stesso piano di reciproco rafforzamento va visto il ruolo delle mogli, che Venanzio costantemente enfatizza, come custodi della memoria familiare qualora esse diventino vedove: così come è Placidina a richiedere a Venanzio

42 Cfr. R.Le Jan, Dénomination, parenté et pouvoir dans la société du haut Moyen Âge, in R. Le Jan, Femmes, pouvoir et société dans le haut Moyen Âge, Paris 2001, pp.224-238.

43 Venantius Fortunatus, Carmina, 1 15, vv. 93-100: Cogor amore etiam Placidinae pauca referre,/quae tibi tunc coniunx, est modo cara soror./lumen ab Arcadio ueniens genitore refulget,/quo manet augustum germen, Auite, tuum;/imperii fastus toto qui rexit in orbe,/cuius adhuc pollens iura senatus habet./humani generis si culmina prima requiras,/semine Caesareo nil superesse potest.

44 Cfr. Wood, Merovingian kingdoms, p. 84

45 Venantius Fortunatus, Carmina, IV 17

46 Venantius Fortunatus, Carmina, IV, 9, vv. 9 e 11

47 Venantius Fortunatus, Carmina, I 6, v. 21

48 Venantius Fortunatus, Carmina, I 7, v. 7

49 Venantius Fortunatus, II, 8; Di Berterude, Gregorio di Tours precisa che aveva fondato un monastero femminile e che lo aveva dotato attraverso i suoi beni fondiari: Gregori Episcopi Turonensis, Historiarum Libri X, IX, 35 . 
di redigere l'epitaffio di Leonzio 50 , l'epitaffio di Basilio, più volte inviato regio presso i Visigoti, sottolinea che la moglie Baudegonde fu sposata con lui per vent'anni ${ }^{51}$. Nel caso poi di Brumachius, anch'egli inviato regio, defunto in Italia, si sottolinea che fu la moglie Frigia a riportare le spoglie del marito presso la sua residenza e a occuparsi delle sue esequie funebri e del suo sepolcro 52 .

Come ha sottolineato Janet Nelson, la società altomedievale è fitta di giovani vedove, anzitutto per il diverso momento della vita in cui le unioni matrimoniali avevano luogo: appena adolescenti le femmine, già uomini maturi i maschi. Ma la posizione sociale delle vedove era di grande precarietà: non più vergini e non più sposate, esse si collocavano in un ambito liminale soggetto sia alle pressioni della loro famiglia di origine a contrarre una nuova unione, sia a quelle della famiglia d'acquisto a rimanere 'non sposate'. Specie per quanto riguarda la gestione dei loro beni fondiari, una parte dei quali derivava loro dai doni nuziali offerti dal marito, le vedove si trovavano al centro di pressioni divergenti: quelle della loro famiglia di origine a contrarre un nuovo matrimonio, quelle della famiglia del marito a rimanere 'non sposate'53. Queste considerazioni generali valgono in modo speciale per le mogli dei vescovi, le quali, venendo meno la funzione civile ed ecclesiastica del loro sposo, e dunque il loro status di 'moglie del vescovo', tendono normalmente a presentarsi come custodi ed eredi della sua memoria, acquisendo uno status di 'vedova episcopale' che esse cercano di trasformare in quello di 'madre episcopale' - come per esempio Armentaria, madre di Gregorio di Tours ${ }^{54}$ - attraverso la trasmissione della carica paterna ai propri figli. $\mathrm{Nel}$ caso del vescovo di Nantes, Eumerio, la fama del padre, dice Venanzio, sopravvive grazie a quella del figlio Felice, suo erede biologico e anche della sede episcopale ${ }^{55}$. Per Nicasia, vedova dell'ufficiale pubblico Orienzio, e custode del sepolcro e della memoria coniugale, e per Eufrasia, moglie di Namazio, poi vescovo di Vienne ${ }^{56}$, la vedovanza significò invece porsi sotto la

50 Venantius Fortunatus,, Carmina,IV 10

51 Venantius Fortunatus,, Carmina, IV 18

52 Venantius Fortunatus, Carmina, IV 20, vv.5-6): finibus Italiae raptus, sed Frigia coniunx/ detulit huc cari funus amando uiri.

53 J. Nelson, The wary widow, in Property and Power in the Early Middle Ages, a cura di W. Davies, P. Fouracre, Cambridge 1995, pp. 82-113 e anche il classico lavoro di K. Leyser, Rule and Conflict in an Early Medieval society. Ottonian Saxony, London 1979, pp. 15-27. Sulle strategie matrimoniali nel modo franco si veda, naturalmente, R. Le Jan, Famille et pouvoir dans le mond franc, Paris 1995, pp. 287-332.

54 Venantius Fortunatus, Carmina, X 15 (5-10): tu quoque prole potens, recte Armentaria felix,/nec minor ex partu quam prior illa suo./illa uetus numero maior, tu maxima solo:/quod poterant plures, unicus ecce tuus. fetu clara tuo, geniti circumdata fructu,/est tibi Gregorius palma corona decus.

55 Venantius Fortunatus, Carmina, IV 1

56 Venantius Fortunatus, Carmina, IV 24, 27 
protezione ecclesiastica, acquisendo il ruolo di vedova velata, cioè di donna che, a patto di non più risposarsi, poteva continuare a risiedere all'interno della propria casa senza contrarre l'obbligo di entrare in un monastero, e alla quale la protezione ecclesiastica garantiva il pieno possesso dei suoi beni, tutelandola dalle pressioni dei propri parenti ${ }^{57}$.

Per il gruppo familiare in genere, e in particolare per le donne, gli epitaffi di Venanzio Fortunato e i dati archeologici mettono bene in luce la rilevanza fondamentale del rituale funerario nel ribadire e rivendicare le stesse prerogative sociali del defunto per il suo gruppo familiare. Proprio nel momento in cui Venanzio componeva le sue 'epigrafi letterarie' - come le ha chiamate Robert Favreau 58 - si assiste soprattutto nell'area di Metz al rafforzamento dell'investimento funerario delle élites attraverso l'impianto di grandi necropoli: tra la seconda metà del VI e l'inizio del VII secolo si moltiplicano infatti le sepolture con ricchi corredi di armi oppure di gioielli59. Lungi dall'enfatizzare l'appartenenza etnica a gruppi di germani, queste sepolture riccamente ornate testimoniano l'investimento operato dalle élites locali che utilizzarono il rituale funerario quale occasione pubblica per ridefinire o confermare la posizione del gruppo famigliare all'interno della comunità: come dimostrano le ricerche di recente effettuate nell'ambito dell'archeologia merovingia, le sepolture con corredo sono il preciso segnale della precarietà e dell'incertezza sociale e non dell'orgoglio guerriero 'tipicamente germanico' come un tempo si era supposto. Per dare un'idea dell'entità di questo fenomeno, il numero delle necropoli nella sola valle della Seille passò da tre nel V secolo a nove in quello successivo: esse sono poste di preferenza nei pressi delle rovine di antiche ville romane, che diventano perciò il punto di attrazione della comunità che frequenta il cimitero, fornendo anche materiale da costruzione per le sepolture. Gli studi archeologici hanno dimostrato come il criterio per l'attribuzione di un corredo più o meno ricco, più o meno sessualmente caratterizzato, fosse basato anzitutto sull'età di morte. Per i defunti di sesso femminile, tale età è quella compresa tra i 13 e i 20 anni, mentre le sepolture delle donne più anziane o delle bambine ne sono del tutto prive o contengono oggetti non caratterizzati sessualmente: i parenti sottolineavano perciò la gravità della perdita subita anzitutto nella loro qualità di wife -givers, cioè di detentori

57 Cfr. C.La Rocca, Les femmes et la loi dans le royaume des Lombards, in Femmes et pouvoirs des femmes en Occident et à Bysance, a cura di S. Lebecq, A. Dierkens, R. Le Jan, J.M. Sansterre, Lille 2000, pp. 37-50.

58 R. Favreau, Fortunat et l'epigraphie, in Venanzio Fortunato tra Italia e Francia, Treviso 1993, pp. 161-175.

59 Le necropoli altomedievali dell'area di Metz sono analizzate in modo particolareggiato da G. Halsall, Settlement and social organization. The Merovingian Region of Metz, Cambridge 1995, pp. 220-245. 
del principale strumento di alleanza con altri gruppi parentali e di continuità dei gruppi familiari stessi 60 .

Anche gran parte dei carmina funerari di Venanzio si indirizzano al planctus familiare nei confronti di individui giovani, - si pensi al celebre epitaffio di Vilituta ${ }^{61}$ - e a giovanette morte di parto. Particolarmente significativo è, a questo proposito il carme per Eusebia, morta a dieci anni, il cui epitaffio è incentrato non tanto sulla morte di una bimba, ma sulla morte di una sposa mancata, il cui padre si dispera per non poter diventare suocero e per non poter avere più un genero ${ }^{62}$. È dunque possibile che gli epitaffi di Venanzio fossero intesi come strumento di commemorazione orale, anziché scritta, da declamare al momento delle esequie, esprimendo in una forma nobilitante gli intenti che erano visivamente espressi dal corredo funerario ${ }^{63}$. Proprio nel carme per Vilituta Venanzio sottolinea che essa aveva donato alle chiese e ai poveri tutto ciò che poteva esser destinato all'ornato femminile, cioè il corredo con cui il suo gruppo familiare l'avrebbe onorata nel sepolcro, e che, proprio per questo, essa avrebbe potuto nuovamente indossarlo nel al di là 64 : Venanzio si fa dunque interprete dell'idea, poi pienamente sviluppata in età carolingia, che la trasmissione dei beni ai pauperes, anziché la loro tesaurizzazione nel sepolcro, garantisse la conservazione perenne dello status sociale 65 .

La rilevanza del rituale funerario per stabilire un legame di continuità con i defunti e le loro prerogative, sta anche alla base del rinnovato rapporto instaurato dai vescovi con le reliquie dei santi locali, normalmente santi

60 Cfr. Halsall, Settlement, pp. 235-238; G. Halsall, Female status ans power in early Merovingian central Austrasia: the burial evidence, «Early Medieval Europe», 5 (1996), pp. 124.

61 Venantius Fortunatus, Carmina, IV 26, per il quale si veda la fine analisi Epitaphium Vilithutae (IV 26), a cura di P. Santorelli, Napoli 1994.

62 Venantius Fortunatus, Carmina, IV 28: vv. 15-18: conteriturque socer cui nata generque recedit:/ haec letalis obit, ille superstes abit./sit tamen auxilium, quia non es mortua Christo:/uiues post tumulum uirgo recepta deo.

63 La declamazione di carmi celebrativi in occasione delle esequie è stata di recente supposta anche per il regno longobardo. Cfr. F. De Rubeis, La tradizione epigrafica in Paolo Diacono, in Paolo Diacono. Uno scrittore fra tradizione longobarda e rinnovamento carolingio, a cura di P.Chiesa, Udine 2000, pp. 139-162.

64 Venantius Fortunatus, Carmina, IV 26, vv. 71-74: "nam quod ad ornatum potuit muliebre uideri,/ecclesiis prompte pauperibusque dedit./hic nulla ex illis rebus peritura reliquit,/ut modo praemissas diues haberet opes.

65 B. K. Young, Exemple aristocratique et mode funéraire dans la Gaule mérovingienne, «Annales E.S.C.», 41 (1986), pp. 379-407; B. Effros; Symbolic expressions of sanctity: Gertrude of Nivelles in the context of Merovingian mortuary custom, «Viator», 27 (1996), pp. 1-10. Sul concetto di tesoro sempiterno, composto proprio dagli oggetti di ornamento personale, che, donati alla Chiesa e non più tesaurizzati nel sepolcro, costituiscono nel paradiso la prova dello status di colui al quale originariamente appartenevano, cfr. C. La Rocca, Donare, distribuire, spezzare. Pratiche di conservazione della memoria e dello status in Italia tra VIII e IX secolo, in Sepolture tra IV e VIII secolo, a cura di G. P. Brogiolo, G.Cantino Wataghin, Mantova 1998, pp. 77-88; C. Treffort, L'Église carolingienne et la mort, Lyon 1996, pp. 165-184. 
vescovi che li avevano preceduti nella stessa sede ${ }^{66}$. Accanto all'attività di restauratore di edifici residenziali, Venanzio loda Leonzio e Placidina sia per aver fatto erigere edifici ecclesiastici del tutto nuovi, sia per aver ampliato o restaurato edifici di culto già esistenti 67 , descrivendo, talora con grande minuziosità, la portata di questi interventi: a Saintes, nella basilica di S. Viviano, Placidina si è occupata di onorare il sepolcro con le reliquie del santo, dotandolo di una teca d'argento, Leonzio ha offerto le nuove decorazioni musive per le pareti della chiesa ${ }^{68}$; ancora a Saintes, Leonzio e Placidina hanno fatto rivivere il culto del vescovo Eutropio, restaurandone la chiesa cimiteriale, e fornendo l'edificio di un nuovo soffitto di legno scolpito e di nuovi affreschi69. L'attività di cura e di tutela degli edifici ecclesiastici e dei sacri resti da loro ospitati si presenta poi come uno degli elementi che caratterizzano la continuità dell'azione vescovile sotto il profilo dinastico: per la chiesa di St.Denis a Bordeaux si sottolinea che le reliquie del santo furono portate in città da Amelio, predecessore e padre dello stesso Leonzio, trasportandole da un luogo lontano, e che fu Amelio a costruire la piccola chiesa che ora Leonzio ha ampliato ${ }^{70}$. L'insediamento del gruppo parentale di Leonzio a Bordeaux e il suo successivo rafforzamento come famiglia vescovile pare dunque realizzarsi attraverso la progressiva concentrazione dei culti praticati nella propria diocesi all'interno della città sede episcopale, e quindi attraverso il fermo controllo delle reliquie e delle devozioni, connotando visivamente la paternità del proprio operato ${ }^{71}$. Allo stesso modo, le immagini edilizie sono utilizzate da Venanzio per esprimere un giudizio negativo: un vescovo inefficiente come Emerio, designato e poi deposto vescovo di Saintes, manifesta la sua indegnità a ricoprire il suo ruolo attraverso la sua incapacità a continuare la chiesa iniziata dal suo predecessore ${ }^{72}$. Restaurando le antiche chiese che ospitavano le sepolture dei santi vescovi del passato, ritrovan-

66 Venantius Fortunatus, Carmina, I 18, 19, 20

67 Edifici nuovi: Venantius Fortunatus, Carmina, II 11, 12; edifici preesistenti rinnovati: I 7, 10, $11,12,13,15$.

68 Venantius Fortunatus, Carmina, I, 12.

69 Venantius Fortunatus, Carmina, I 13.

70 Venantius Fortunatus, Carmina, I 11, vv. 5-10: exiguam dederat hic praesul Amelius arcem,/ Christicolam populum nec capiente loco:/ quo uitae claudente diem dehinc prole graduque/ uenit ad heredem hoc opus atque locus,/ fundauitque piam hanc papa Leontius aulam,/ obtulit et domino splendida dona suo.

${ }^{71}$ Sull'importanza della topografia delle reliquie, cfr. il lavoro di S. Boesh Gaiano, L'agiografia di Venanzio Fortunato, in Venanzio Fortunato e il suo tempo, Treviso 2002, pp. 103-116. In generale, i saggi contenuti nel volume miscellaneo Les reliques. Objets, cultes, symboles, a cura di E. Bozoki, A. M. Helvetius, Turnhout 1999.

72 Venantius Fortunatus, Carmina, I 12, vv. 1-6: Digna sacerdotis Bibiani templa coruscant./ quo si iusta petis, dat pia uota fides./ quae praesul fundauit ouans Eusebius olim./ ne tamen expleret raptus ab orbe fuit./ cui mox Emerius successit in arce sacerdos,/ sed coeptum ut strueret, ferre recusat onus. 
do e onorando le loro reliquie, i nuovi vescovi, specie se provenienti da contesti territoriali estranei da quello in cui si trovavano a dover operare, si proclamavano custodi della loro memoria ed eredi del loro culto, proponendosi alla collettività come figli spirituali dei loro illustri predecessori. Per i laici, così come per gli ecclesiastici, il rituale della morte e la memoria dei defunti era dunque uno strumento attivo per comprovare i loro legami con il passato, definendo la propria identità nel presente ${ }^{73}$.

\section{La corte regia: il ruolo del re e della regina}

$\mathrm{Al}$ di là delle strategie elaborate dalle élites per sancire di fronte alla comunità la preminenza, il tema che attraversa tutte le composizioni celebrative di Venanzio è quello della rilevanza e della pregnanza della figura regia. La caratterizzazione della famiglia merovingia conteneva alcuni aspetti che certo a Venanzio dovevano essere ben presenti, altri che dovevano risultargli del tutto nuovi. Anzitutto quello della continuità dinastica.

Proprio l'esperienza elaborata all'interno del regno dei Goti, da cui Venanzio proveniva, aveva eloquentemente dimostrato che, nonostante la profonda liason con l'impero d'Oriente intrattenuta da Teoderico, e l'organizzazione di forme ideologiche tese a recuperare forme di legittimazione del potere derivate dall'autorità imperiale, il problema delle modalità della trasmissione del potere regio aveva costituito, alla morte di Teoderico, una fortissima fonte di conflitto tra le aristocrazie. Nonostante la genealogia costruita da Cassiodoro per Teoderico, con la quale si legittimava la supremazia dinastica degli Amali sugli altri gruppi aristocratici in quanto detentori di una regalità sacrale attraverso le generazioni, le lotte per la successione di Teoderico avevano dimostrato quanto forte fosse ancora la tendenza tra $\mathrm{i}$ gruppi aristocratici a sostenere l'idea che il re dovesse essere eletto tra tutti i membri dell'aristocrazia per il suo valore e non per diritto dinastico ${ }^{74}$. Nel regno dei Franchi, invece, la competizione tra le famiglie aristocratiche per il titolo regio era stata del tutto risolta: Clodoveo e i suoi figli riuscirono infatti a eliminare tutti i possibili rivali regi o nobili, come testimonia Gregorio di Tours ${ }^{75}$, e a creare attorno al proprio gruppo famigliare una barriera di invalicabile distinzione da tutti gli altri gruppi aristocratici. Tale barriera si

$73 \mathrm{Si}$ veda anche Venantius Fortunatus, Carmina, I, 8 ove Leonzio è lodato per aver rinverdito il culto di S.Vincenzo, santo locale di Vernemetum e Pompeiacum presso Poitiers, dotando le reliquie di una nuova teca.

74 P.Heather, Theoderic, king of the Goths, «Early Medieval Europe», 4 (1995), pp. 145-173.

75 Gregorii Episcopi Turonensis, Historiarum Libri X, II, 40-42. Cfr. Wood, Merovingian Kingdoms, pp. 58-59. 
sostanziava anzitutto nelle pratiche da essi adottate sotto il profilo matrimoniale, che si strutturarono in modo del tutto antitetico a quelle dell'aristocrazia. Se per l'aristocrazia, come abbiamo già detto, la pratica dell'omogamia garantiva l'unione e il rafforzamento di gruppi parentali che potevano mutualmente fornirsi clientele, oltre che supporto politico e territoriale, i re merovingi praticarono quella che gli antropologi chiamano 'monogamia seriale', vale a dire una sequenza di unioni legittime successive. Essi si unirono di preferenza con donne serve o, all'opposto della scala sociale, figlie o sorelle di re di regni contermini. Prive com'erano di supporto locale e di sostegno familiare, sia la serva sia la principessa straniera dovevano integralmente al loro legame sessuale con il re la loro posizione sociale di 'regina'. Specialmente le serve potevano essere ripudiate con relativa facilità. Per questo il nucleo famigliare di un re merovingio era spesso composto da numerosi figli di madri diverse, molte delle quali ancora in vita. La regina di umili origini si trovava però in una condizione che, se era indubbiamente fonte di incertezza e di debolezza, le consentiva nondimeno di agire con una "paradossale libertà" nella scelta dei legami più opportuni al proprio sostegno. Essa non risultava infatti condizionata dalle clientele della propria famiglia di origine, oppure dalla dislocazione del suo patrimonio fondiario in una precisa area geografica, ma poteva utilizzare le risorse del tesoro regio per legarsi $\mathrm{a}$ chi le pareva più opportuno ${ }^{76}$. Proprio i casi di Brunilde, la principessa straniera, e di Fredegonda, la serva, con cui Venanzio ebbe personalmente a che fare, dimostrano quanto grandi fossero le opportunità di stringere alleanze e di mantenere lo status di regina, anche dopo la morte del proprio marito ${ }^{77}$.

Oltre alle pratiche matrimoniali, la strategia di differenziazione attuata dalla famiglia merovingia consistette nel creare attorno a sé un gruppo di aristocratici, funzionari pubblici, la cui stabilità e preminenza derivava esclusivamente dai legami stessi di fedeltà intrattenuti con il re, per i quali la ricompensa di terra donata dal re costituiva la prova materiale e lo strumento di tale collegamento. Gli unici aristocratici che sono dotati di un titolo nel Pactus della Legge Salica, sono infatti gli ufficiali regi, i suoi fedeli, i suoi compagni d'arme ${ }^{78}$. Il re controllava le aristocrazie attraverso l'assegnazione, il ritiro e la ridistribuzione delle cariche pubbliche, donando e poi reclamando i propri diritti sul fisco regio. A questo si aggiunga, naturalmente, la carat-

76 Questi aspetti sono esaminati nel fondamentale lavoro di J.L.Nelson, Queens as Jezabels: Brunhild and Bathild in Merovingian history, in J.L.Nelson, Politics and Rituals in Early Medieval Europe, London 1986, pp. 1-48.

77 Cfr. Wood, Merovingian Kingdoms, pp.121- 136.

78 Pactus Legis Salicae; a cura di K. A. Eckhardt, Hannover Leipzig 1892 (M.G.H. Leges Nationum Germanicarum, IV/1)cfr Le Jan, Famille et pouvoir, pp. 32- 35. 
terizzazione sacrale dei merovingi come reges criniti, re dai lunghi capelli79. La preminenza del re e la sua diversità dalle altre famiglie aristocratiche annullava di fatto le differenze di status di coloro che si trovavano al disotto del re: perciò sotto lo strato regio la struttura sociale era permanentemente fluida, stimolando il desiderio e l'ambizione a entrare in rapporto con il re, presentato come unica fonte di stabilità 80 .

Detto questo non si deve pensare che la società merovingia fosse, grazie alla stabilità dinastica della famiglia regia, una società priva di competizione. Anzi, proprio la strategia matrimoniale adottata da quei re per distinguersi dal resto dell'aristocrazia, era uno dei veicoli che permettevano alla competizione sociale di aggregarsi e di ricomporsi. Infatti l'abitudine a trasmettere il potere del re al primogenito non era affatto diffusa, poiché la regalità era concepita come patrimonio famigliare, da spartirsi di diritto tra tutti i figli maschi ${ }^{81}$; né, quando si cercò di la competizione tra fratelli terminava, il vincitore risultava accettato senza contrasti e opposizioni. Poiché incerte e sempre fonte di conflitti erano le consuetudini che regolavano la successione al trono, il destino della regina e il mantenimento del suo status erano costantemente in pericolo, specie se, come spesso accadeva essa restava vedova. La compresenza di numerose mogli precedenti del re e dei loro figli, faceva sì che non vi fosse alcuna certezza per l'ultima regina che uno dei propri figli sarebbe riuscito a succedere al padre, né tanto meno che, tra di loro, sarebbe stato scelto quello a lei più legato. Si può facilmente capire perché i diritti del primogenito furono, in tale frangente, ostacolati anzitutto dalle varie mogli del re in nome del loro vantaggio personale: il conflitto per la successione permetteva a ognuna delle mogli del re di provare a far eleggere il proprio candidato, attraverso le alleanze da esse nel frattempo instaurate ${ }^{82}$. Il conflitto per la successione regia che negli altri regni barbarici divampava all'interno dell'aristocrazia, nel regno dei Franchi era quindi trasposto all'interno della famiglia merovingia e delle molteplici e contraddittorie alleanze che i suoi numerosi membri avevano stretto con le fazioni aristocratiche, con i vescovi delle città, con i funzionari pubblici.

La società all'interno della quale Venanzio operò era dunque una società pervasa dall'instabilità. Anche se articolata gerarchicamente al suo interno, a partire dal re, i destini individuali erano costantemente in pericolo: l'aggre-

\footnotetext{
$79 \mathrm{Si}$ veda, sul tema, il fondamentale lavoro di J.M. Wallace-Hadrill, The Long-Haired kings, London 1962.

80 Questo è perfettamente chiaro a Venanzio, il quale fa uso a più riprese del concetto di amor regis come strumento della stabilità: Venantius Fortunatus, Carmina, II 10, v. 17; 11, v. 22; 16, v. 161; IV 10, v. 11; 18 v. 11; 19, v. 6; VI 6, v. 9; VII 16, vv. 6, 34, 39, 49; X 18, v. 7.

81 Wood, Merovingian Kingdoms.

$82 \mathrm{Si}$ veda, su questo punto, la discussione di P. Stafford, The king's wife in Wessex 80o-1066, «Past \& Present», 91 (1981), pp. 7-13.
} 
garsi e il disaggregarsi del consenso faceva sì che l'opera poetica di Venanzio, alla stessa stregua dei banchetti, delle chiese e delle ville ricostruite, delle reliquie di santi ritrovati e onorati, dei sepolcri corredati di armi, gioielli ed epitaffi, delle politiche matrimoniali, contribuisse a plasmare l'identità delle aristocrazie, fornendo ulteriori elementi da esibire e ostentare nella ricerca del consenso. E certo fu questa incertezza ad offrire a Venanzio Fortunato la chance di trasformarsi da nuovo Orfeo a vescovo di Poitiers. 


\section{Bibliografia}

Amory P., People and Identity in Ostrogothic Italy, 489-554, Cambridge 1997

Amory P., The meaning and purpose of etnic terminolgy in the Burgundian laws, «Early Medieval Europe», 2 (1993)

Bozoki E., Helvetius A.M. (a cura di ), Les reliques. Objets, cultes, symboles, Turnhout 1999

Brennan B., Senators and social mobility in sixth-century Gaul, «Journal of Medieval history», 11 (1985)

Brennan B., The image of the Merovingian bishop in the poetry of Venantius Fortunatus, «Journal of Medieval History», 18 (1992)

Brennan B., The career of Venantius Fortunatus, in «Traditio», 46 (1985)

Clark C.U. (a cura di ), Ammianus Marcellinus, Rerum Gestarum Libri qui supersunt, II, Berolini 1910

De Rubeis F., La tradizione epigrafica in Paolo Diacono, in Paolo Diacono. Uno scrittore fra tradizione longobarda e rinnovamento carolingio, a cura di Chiesa P., Udine 2000

Eckhardt K.A. (a cura di ), Pactus Legis Salicae, Hannover Leipzig 1892

Effros B., Symbolic expressions of sanctity: Gertrude of Nivelles in the context of Merovingian mortuary custom, «Viator», 27 (1996)

Favreau R., Fortunat et l'epigraphie, in Venanzio Fortunato tra Italia e Francia, Treviso 1993

Gasparri S., Prima delle Nazioni. Popoli, etnie e regni fra Antichità e Medioevo, Roma 1997

George J. W., Portraits of two Merovingian bishops in the poetry of Venantius Fortunatus, «Journal of Medieval History», 13 (1987)

George J. W., Venantius Fortunatus. A latin poet in Merovingian Gaul, Oxford 1992

Godman P., Poets and Emperors. Frankish Politics and Carolingian Poetry, Oxford 1987

Goffart W., Barbarians and Romans.A.D. 418-584. The Techniques of Accomodation, Princeton 1980

Goffart W., Foreigners in the Histories of Gregory of Tours, «Florilegium», 4 (1982)

Goffart W., The Narrators of Barbarian History. Jordanes, Gregory of Tours, Bede and Paul the Deacon, Princeton 1988

Halsall G., Female status ans power in early Merovingian central Austrasia: the burial evidence, «Early Medieval Europe», 5 (1996) 
Halsall G., Settlement and social organization. The Merovingian Region of Metz, Cambridge 1995

Halsall G., The origins of the Reihengräberzivilisation: forty years on, in Fifth century Gaul. A crisis of identity?, a cura di Drinkwater J., Elton H., Cambridge 1992

Harries J.D., Sidonius Apollinaris and the frontiers of Romanitas, in Shifting Frontiers in Late Antiquity, a cura di Mathisen R.W., Sivan H.S., Oxford 1996

Heather P., Theoderic, king of the Goths, «Early Medieval Europe», 4 (1995)

Ladner G.B., On Roman attitudes toward Barbarians in Late Antiquity, «Viator», 7 (1976)

La Rocca C., Donare, distribuire, spezzare. Pratiche di conservazione della memoria e dello status in Italia tra VIII e IX secolo, in Sepolture tra IV e VIII secolo, a cura di Brogiolo G. P., Cantino Wataghin G., Mantova 1998

La Rocca C., Les femmes et la loi dans le royaume des Lombards, in Femmes et pouvoirs des femmes en Occident et à Bysance, a cura di Lebecq S., Dierkens A., Le Jan R., Sansterre J.M., Lille 2000

La Rocca C., Una prudente maschera "antiqua". La politica edilizia di Teoderico, in Teoderico il Grande e i Goti d'Italia

Le Jan R., Dénomination, parenté et pouvoir dans la société du haut Moyen Âge, in Le Jan R., Femmes, pouvoir et société dans le haut Moyen Âge, Paris 2001

Le Jan R., Famille et pouvoir dans le mond franc, Paris 1995

Leyser K., Rule and Conflict in an Early Medieval society. Ottonian Saxony, London 1979

Mauss M., Saggio sul dono. Forma e motivo dello scambio nelle società arcaiche, in M.Mauss, Teoria generale della magia, Torino 1965

Nelson J.L., Queens as Jezabels: Brunhild and Bathild in Merovingian history, in Nelson J.L., Politics and Rituals in Early Medieval Europe, London 1986

Nelson J.L., The wary widow, in Property and Power in the Early Middle Ages, a cura di Davies W., Fouracre P., Cambridge 1995

Pietri L., Venance Fortunat et ses commanditaires: un poète italien dans la société gallo-franque, in Committenti e produzione artistico-letteraria nell'alto medioevo occidentale, Spoleto 1992

Pohl W., Alemannen und Franken. Schluâbetrachtung aus historischer Sicht, in Die Franken und die Alemannen bis zur "Schlacht bei Zülpich"(496-497), a cura di Geuenich D., Berlin New York 1998

Pohl W., I Goti d'Italia e le tradizioni delle steppe, in Teoderico il Grande e $i$ Goti d'Italia, Spoleto 1993

Pohl W., Le origini etniche dell'Europa. Barbari e Romani tra antichità e medioevo, Roma 2000 
Reydellet M., Venance Fortunat. Poèmes, I, livres I-IV, Paris 1994

Sergi G., Le città come luoghi di continuità di nozioni pubbliche del potere. Le aree delle marche di Ivrea e di Torino, in Piemonte medievale. Studi per Giovanni Tabacco, Torino 1985

Stafford P., The king's wife in Wessex 80o-1066, «Past \& Present», 91 (1981)

Tabacco G., Il volto ecclesiastico del potere in età carolingia, in La Chiesa e il potere politico, Torino 1986

Treffort C., L'Église carolingienne et la mort, Lyon 1996

van Acker L., Barbarus und seine Abletungen im Mittellatein, in «Archiv für Kulturgeschichte», 47 (1965)

Wallace-Hadrill J.M., The Long-Haired kings, London 1962

Ward-Perkins B., From Classical Antiquity to the Early Middle Ages. Urban public building in Northen and Central Italy. A.D. 300-850, Oxford 1984

Wickham C., The other transition: from ancient world to feudalism, «Past \& Present», 103 (1984)

Wood I., Merovingian Kingdoms 450-751, London New York 1994

Wood N., The ecclesiastical politics of Merovingian Clermont, in Ideal and Reality in Frankish and Anglo-Saxon society, a cura di Wormald P., Oxford 1983

Young B. K., Exemple aristocratique et mode funéraire dans la Gaule mérovingienne, «Annales E.S.C.», 41 (1986) 



\title{
Archeologia longobarda e archeologia dell'alto medioevo italiano: un bilancio critico*
}

\author{
Sauro Gelichi
}

\section{Premessa}

In questo contributo vorrei tracciare un breve bilancio critico sui metodi, gli obbiettivi e i risultati che l'archeologia longobarda ha conseguito in Italia, tenendo conto dei limiti contenuti nella definizione stessa, che sono quelli di essere circoscritti alle sole fonti di un popolo, o ad esso riconducibili. Con archeologia longobarda, infatti, si è inteso nel passato riferirsi ai resti materiali del periodo in cui i Longobardi governarono su parte della penisola italica (569-774). Tale definizione, peraltro, ha ingenerato una sorta di ambiguità che si scontra di fatto con l'evidenza materiale, la quale non può oggettivamente caratterizzarsi sempre in senso etnico-culturale o comunque identificarsi con la complessità dei modelli di organizzazione sociale ed economica anche di quei territori che furono sotto il controllo dei Longobardi. A partire dagli anni '70 del secolo scorso, peraltro, l'affermarsi di un'archeologia del medioevo anche in Italia ha consentito il superamento di un approccio di questa natura, facendo confluire l'età longobarda e le espressioni culturali di questo periodo nel più ampio contesto di un'archeologia dell'alto medioevo italiano.

Per una serie di motivi intrinseci al dato materiale, tuttavia, l'archeologia del nostro paese è andata ad occuparsi di reperti longobardi (essenzialmente provenienti da sepolture) molto precocemente; e un'attenzione nei confronti di questi specifici marker ha anticipato di molto una seria e consapevole pratica archeologica rivolta alle età post-classiche. Se un'archeologia longobarda, in senso stretto, o del periodo longobardo, non ha mai avuto di fatto nessun tipo di riconoscimento sul versante accademico, essa è stata però più o meno esplicitamente professata e praticata da molti archeologi a partire soprattutto dall'8oo.

\footnotetext{
* Questo contributo costituisce la parziale rielaborazione del capitolo (Un articolo poco noto di Paolo Orsi e le origini dell'archeologia longobarda in Italia), tratto dal mio volume Introduzione all'archeologia medievale. Storia e ricerca in Italia, Roma 1997, pp. 33-51, e di un mio articolo (L'archeologia longobarda in Italia) pubblicato nel volume I Longobardi e la guerra. Da Alboino alla battaglia sulla Livenza (secc. VI-VIII), Roma 2004, pp. 41-49.
} 


\section{L'ombra di Gisulfo: l'archeologia longobarda tra positivismo e nazionalismi}

Un interesse per le sepolture longobarde fa la sua comparsa in Italia già nel corso del XIX secolo, e qualche sparuto episodio si segnala anche in precedenza, ad esempio a Cividale del Friuli (Forum Iulii). Sempre a Cividale, nel 1874, era stata ritrovata la cosiddetta tomba di Gisulfo: un sarcofago con ricco corredo recante un'iscrizione che lo associava al primo duca della città friulana, cioè Gisulfo, nipote di Alboino. Il corredo venne successivamente riconosciuto come non congruente con il periodo in cui Gisulfo fu duca di Forum Iulii e la stessa iscrizione è definitivamente risultata, al vaglio di un'attenta critica, un falso clamoroso, prodotto nello stesso ambiente cividalese ${ }^{1}$. Il ritrovamento di un grande contesto archeologico di età longobarda aveva dunque aperto la finestra sul passato illustre della cittadina friulana e la falsificazione era servita a rafforzare il collegamento con l'aureo periodo del ducato. Ma i Longobardi non avrebbero sempre goduto di questa attenzione, né la riscoperta delle loro antichità avrebbe rappresentato, come in altre regioni europee in relazione al loro passato "barbarico", un modo per recuperare una perduta identità nazionale².

Sempre nella seconda metà del XIX secolo era stata indagata l'importante necropoli di Civizzano in Trentino ${ }^{3}$ e, per mano dei fratelli Calandra, venne scavata e pubblicata la necropoli di Testona, nei pressi di Torino ${ }^{4}$. Quale sia stato l'approccio di questi ricercatori è esplicitato dai metodi d'indagine impiegati e dai modi in cui vennero conservati i materiali. Anche nei casi in cui non si assiste ad un impoverimento o depauperamento del contesto archeologico (per cessione o vendita dei reperti), la sua unitarietà non venne riconosciuta: i nuclei tombali furono dunque smembrati e gli oggetti, come nel caso di Testona ${ }^{5}$, accorpati secondo categorie tipologiche.

Tali ricerche talora si mescolano con un interesse più generale nei confronti della fonte materiale, secondo il principio positivista della necessità di analizzare e comprendere tutto quanto apparteneva al passato ${ }^{6}$. In Emilia, ad

\footnotetext{
${ }^{1}$ I. Barbiera, "E ai di" remoti grande pur egli il Forogiulio appare". Longobardi, storiografia e miti delle origini a Cividale del Friuli, "Archeologia Medievale", XXV, 1998, pp. 345-357.

${ }^{2}$ Jones S., The Archaeology of Ethnicity. Constructing identities in the past and present, London, 1997. 3 L. Campi Dei, Le tombe barbariche di Civezzano e alcuni rinvenimenti medioevali nel Trentino, Trento, 1886; F. Wieser, Das langobardischen Fürstengrab und Reihengräberfelder von Civizzano bei Trient beschrieben, Innsbruck, 1887.

4 C. Calandra, E. Calandra, Di una necropoli barbarica scoperta a Testona, "Atti della Società d'Archeologia e Belle Arti per la Provincia di Torino", IV, 1880, pp. 5-39.

5 O. Von Hessen, Die langobardischen Funde aus dem Gräberfeld von Testona (Moncalieri/Piedmont), Torino, 1971.

6 R. Peroni, Preistoria e Protostoria. La vicenda degli studi in Italia, in Le vie della Preistoria, Roma, 1992, pp. 9-70.
} 
esempio, materiali del periodo longobardo vennero raccolti per confluire nelle organizzate sistemazioni dei nascenti musei civici. Un episodio illuminante è rappresentato dalle collezioni del Museo di Reggio Emilia, allestite per la parte archeologica da Gaetano Chierici e nelle quali confluirono una quantità non irrilevante di reperti tombali del periodo longobardo, alcuni raccolti dal Chierici stesso, altri giunti al museo per donazioni o acquisti ${ }^{7}$.

Sempre in questo clima vede la luce, nel 1887, un articolo di Paolo Orsi su alcune crocette auree del Museo di Bologna ${ }^{8}$. Nonostante la giovane età dell'autore il contributo si pone, anche per rigore di metodo, come la prima seria e cosciente trattazione di un problema archeologico legato al cosiddetto periodo delle migrazioni barbariche. Oggetto specifico della trattazione sono due crocette auree (che oggi sappiamo essere appliques cucite su velari funebri) conservate nel Museo Civico di Bologna (peraltro neppure di provenienza locale, ma arrivate al museo bolognese attraverso il collezionismo). Orsi trae spunto da questi due oggetti per comporne un primo corpus; tenta di comprenderne la funzione e di attribuire loro uno specifica origine etnicoculturale (anche se rimane incerto tra Goti e Longobardi); le analizza infine nel quadro dell'artigianato artistico. Ma le pagine di questo lavoro si fanno apprezzare anche per alcune riflessioni più generali, che superano lo specifico di quei materiali, per riandare al senso e al significato di un'archeologia del medioevo in Italia. È questo il primo caso in cui si esplicita la necessità che l'approccio archeologico, cioè lo studio delle fonti materiali, si applichi anche all'età post-antica ("si può affermare, non esistere per anco un ramo delle discipline storiche, che rigorosamente possa chiamarsi l'archeologia del medioevo") 9 .

L'articolo di Paolo Orsi resta una parentesi pressoché isolata nella biografia dell'autore, ma prelude ad un trentennio di proficuo lavoro per l'archeologia longobarda. Si colloca in questo periodo l'attività di Carlo Cipolla, figura emblematica sia per il suo non occasionale interesse verso l'archeologia "barbarica", sia per gli orientamenti metodologici che lo portarono, agli inizi del secolo, ad abbandonare questo settore della ricerca, con conseguenze significative nell'atteggiamento culturale complessivo nei confronti di queste tematiche, anche sul piano accademico ${ }^{10}$. Nello stesso tempo, come era successo per l'Emilia, molti altri curatori di musei di recente istituzione manife-

\footnotetext{
7 M. Desittere, Dal Gabinetto di Antichità Patrie al Museo di Storia Patria di Reggio Emilia (1862-1886), Reggio Emilia, 1985.

8 P. Orsi, Di due crocette auree del Museo di Bologna e di altre simili trovate nell'Italia superiore e centrale, "Atti e Memorie della Reale Deputazione di Storia Patria per le Province di Romagna”, V, 1887, pp. 333-414.

9 Ivi, p. 333.

10 C. La Rocca, Uno specialismo mancato. Esordi e fallimento dell'archeologia medievale italiana alla fine dell'Ottocento, "Archeologia Medievale", XX, 1993, p. 18.
} 
starono un'attenzione specifica verso la raccolta e la catalogazione di reperti dell'età delle migrazioni; e datano inoltre a questi stessi anni gli scavi di due tra le più importanti necropoli fino ad oggi indagate in Italia: quella di Nocera Umbra e quella di Castel Trosino.

Lo scavo di Castel Trosino venne pubblicato dal Mengarelli nel $1902^{11}$, mentre l'edizione di Nocera Umbra, a causa della morte dello scavatore, cioè il Pasqui, vide la luce solo nel 1918, a cura dello stesso Pasqui e di Paribeni, che nel frattempo gli si era affiancato ${ }^{12}$.

Nell'area del sito di Castel Trosino, un insediamento lungo la via Salaria in provincia di Ascoli Piceno, furono individuate numerose aree funerarie, ma la necropoli più vasta ed interessante risulta quella scavata in Contrada Santo Stefano, ubicata su uno sperone roccioso ad est dell'abitato. In questa zona vennero indagate regolarmente 190 tombe, mentre di altre fu possibile recuperare e ricomporre il corredo.

A Nocera Umbra (TR), invece, venne scavato un vasto cimitero in loc. Portone, a nord dell'abitato (ubicato questa volta lungo la via Flaminia). In totale furono indagate 168 tombe e l'edizione di scavo è, se vogliamo, ancora più accurata rispetto a quella, già eccellente, del Mengarelli per Castel Trosino. Ad esempio, di ben 27 tombe vengono pubblicate piante dettagliate con il disegno della posizione del defunto e dei materiali di corredo o abbigliamento personale ad esso associati.

Le grandi necropoli di Castel Trosino e Nocera Umbra, spesso con ricchi oggetti d'oro e d'argento (selle, cinture multiple per la sospensione della spada, collane, fibule etc.), vennero associate ai Longobardi, nonostante che, ancora in quel periodo, la raffinatezza dell'indagine archeologica non avesse consentito una certificazione sicura nell'attribuzione dei corredi del periodo delle migrazioni.

Le altre due scoperte più significative per l'archeologia longobarda negli anni intorno alla prima guerra mondiale si segnalano in Toscana. Nel 190910 furono esplorate 27 tombe in occasione degli scavi ad ovest del teatro romano di Fiesole (nei pressi di Firenze), in via Riorbico, pubblicate quasi immediatamente ${ }^{13}$. Le sepolture, di cui per fortuna si sono conservati i corredi divisi secondo i contesti originari, si disponevano seguendo degli allineamenti regolari, rispettando gli orientamenti forniti dai perimetrali di un tempio (probabilmente riutilizzato quale cappella funeraria).

\footnotetext{
11 R. Mengarelli, La necropoli barbarica di Castel Trosino presso Ascoli Piceno, "Monumenti Antichi dei Lincei”, XII, coll. 145-380, 1902.

12 A. Pasqui, R. Paribeni, Necropoli barbarica di Nocera Umbra, "Monumenti Antichi dei Lincei”, XXV, coll. 137-352, 1918.

13 E. Galli, Fiesole. Gli scavi - il museo, "Il piccolo cicerone moderno", 11, 1914; O. Von Hessen, Die langobardenzeitlichen Grabfunde aus Fiesole bei Florenz, München, 1966.
} 
Tra il 1913 e il 1914, invece, sempre il Galli, scavò un piccolo cimitero di 13 tombe ai piedi del colle Arcisa, nella campagna del "Portonaccio" presso Chiusi, con sepolture maschili con armi e femminili abbigliate ${ }^{14}$.

L'archeologia nazionale, dunque, si era interessata ai Longobardi solo sotto il profilo funerario; e, con l'eccezione di Orsi, quasi mai era andata al di là dell'edizione, più o meno accurata, dei contesti. Contrariamente a quanto era avvenuto (o stava avvenendo) in Francia, e a quanto avverrà in Germania, dove l'archeologia del periodo merovingico si connota di aspetti sempre più accentuatamente nazionalistici, in Italia l'interesse si risolse in un quadro teorico e ideologico debole, se non assente. L'impressione che si ricava (e non è forse un caso che anche gli scavi delle necropoli longobarde tendano a diminuire a partire dal secondo decennio del '90o), è che essa costituisca una sorta di precipitato terminale di atteggiamenti ancora di stampo positivista; rappresenti cioè un pendant di quelle esperienze rivolte allo studio complessivo dei territori e dei contesti archeologici, che avevano talora trovato, nel metodo filologico-stratigrafico, lo strumento più idoneo di conoscenza storica, e che avevano caratterizzato una parte, non irrilevante, dell'archeologia nazionale fino ai primi anni del ' $900^{15}$. In queste ricerche (meglio sarebbe dire scoperte), e soprattutto in chi le realizza, mancano i presupposti di una competenza specialistica, ma soprattutto sono assenti le motivazioni per far superare all'indagine sul campo il mero livello documentario. Bisogna dunque rivolgersi a specialisti di altri paesi perché l'archeologia del periodo delle migrazioni (e con essa anche i resti appartenenti all'età longobarda in Italia) registri un salto di qualità, se non altro sul piano della tassonomia, cioè della costruzione di precise serie crono-tipologiche di manufatti. Dobbiamo ad Åberg, infatti, che oltretutto schedò molti materiali di musei italiani, un contributo fondamentale nel quale si chiariscono definitivamente i caratteri della "cultura materiale" attribuibile al periodo goto e all'età longobarda 16 . E mentre l'archeologia italiana dimenticava il medioevo e con esso le culture barbariche, alcuni ricercatori tedeschi si muovevano verso il mare del nord nel tentativo di scoprire le tracce più lontane delle stirpi germaniche ${ }^{17}$ ed un altro studioso tedesco, il Fuchs, cominciava, con teutonica sistematicità, la schedatura dei reperti longobardi conservati nei musei italiani. La guerra gli consentirà di pubblicare solo un volume (curiosamente quello dedicato alle crocette auree, che già erano

14 E. Galli, Nuovi materiali barbarici dell'Italia centrale, "Atti della Pontificia Accademia Romana di Archeologia - Memorie”, III, VI, 1942, pp. 1-37; O. Von Hessen, Primo contributo all'archeologia longobarda in Toscana. Le necropoli, Firenze, 1971.

15 D. Manacorda, Cento anni di ricerche archeologiche italiane: il dibattito sul metodo, "Quaderni di Storia", 16, 1982, pp. 85-119.

16 N. Åberg, Die Goten und Langobarden in Italien, Uppsala, 1923.

17 S. Jones, The Archaeology, cit., fig. 1.1. 
state argomento di quell'articolo di Orsi che abbiamo ricordato) ${ }^{18}$; e, nel dopoguerra, un secondo volume vide la luce con la collaborazione del giovane Joachim Werner, questa volta dedicato alle fibule ${ }^{19}$. Forse il progetto originario era quello di costruire serie catalogiche per tipi funzionali; ma se la serie, da questo punto di vista, non ebbe seguito (se non nel volume, di molti anni più tardo, che Otto von Hessen dedicherà alla ceramica longobarda) ${ }^{20}$, i lavori di Fuchs e poi di Werner sancirono, nel secondo dopoguerra, un rinnovato interesse per il periodo longobardo e l'impostazione teorico-metodologica ne marcò per buona parte anche gli orientamenti.

3. Una nuova archeologia longobarda: le esperienze italiane nel secondo dopoguerra

Nell'approccio che ha caratterizzato la ricerca nell'immediato secondo dopoguerra si possono distinguere nella sostanza due filoni.

Un primo filone costituisce una sorta di prosecuzione della ricerca anteguerra e riguarda essenzialmente lo studio e l'analisi dei cimiteri. Praticato, almeno in origine, quasi esclusivamente da archeologi non italiani, si caratterizza per un'attenzione rivolta essenzialmente verso i corredi tombali. Naturalmente si esportano in Italia gli stessi procedimenti critico-analitici tipici di gran parte della cultura archeologica europea di quegli anni, interessata allo studio delle società merovingiche: ad un grande rigore filologico nell'analisi dei reperti (provenienza, distribuzione, cronologia) si associa un modo più tradizionale di interpretare i dati del contesto funerario, letto come espressione, in trasparenza, di un'appartenenza etnico-culturale o di status sociale. I limiti di questo approccio sono stati messi in discussione, almeno in una parte della cultura archeologica europea, soprattutto a partire dagli anni ' $70^{21}$, quando si è incominciato a studiare questi fenomeni applicando ad essi alcune categorie teoriche utilizzate nello studio delle culture dell'Europa protostorica22.

Un secondo filone si pone come obbiettivo la ricostruzione della storia dell'insediamento, sia urbano che rurale. Dobbiamo, tuttavia, distinguere tra le ricerche condotte da gruppi di studiosi stranieri (una equipe polacca a

18 S. Fuchs, Die langobardischen Goldblattkreuze aus der Zone südwärts der Alpen, Berlin, 1938.

19 S. Fuchs, J. Werner, Die langobardischen Fibeln aus Italien, Berlin, 1950.

20 O. Von Hessen, Die langobardische Keramik aus Italien, Wiesbaden, 1968.

${ }^{21}$ C. La Rocca, Le sepolture altomedievali del territorio di Verona, in D. Modonesi - C. La Rocca (a cura di), Materiali di epoca longobarda nel veronese, Verona, 1989, pp. 149-186.

22 S. Gelichi, Funeraria archeologia. Medioevo, in R. Francovich- D. Manacorda (a cura di), Dizionario di Archeologia, Roma-Bari, 2000, pp. 150-154. 
Castelseprio, l'Università di Monaco ad Ibligo Invillino) ${ }^{23}$ e l'attività di un archeologo italiano, Cagiano de Azevedo, sulle città, sull'urbanistica e sull'edilizia abitativa altomedievale (dunque anche del periodo longobardo) ${ }^{24}$.

Le ricerche del gruppo di archeologi polacchi guidati da Witold Hensel erano state indirizzate ad indagare un castello (Castelseprio) probabilmente fondato intorno al $\mathrm{V}$ secolo, ma che sicuramente aveva conosciuto una significativa fase d'occupazione durante l'epoca longobarda. Le indagini di scavo avevano interessato due aree dell'abitato: una in prossimità degli imponenti complessi ecclesiastici e l'altra in vicinanza delle mura, dove furono riconosciuti una serie di edifici abitativi databili, almeno per alcune fasi, al periodo longobardo. È interessante innanzitutto notare come, forse per la prima volta in Italia, un'indagine archeologica fosse andata ad occuparsi di abitazioni, segnando un vero e proprio salto di qualità rispetto al passato. Ad una novità di approccio metodologico (lo scavo stratigrafico sulle case) non fa però riscontro un altrettanto innovativo approccio teorico; gli archeologi polacchi, ad esempio, sono interessati essenzialmente a rimarcare le componenti alloctone, o comunque non classiche, delle tecniche costruttive delle abitazioni e della "cultura materiale" presente sul sito. Un confronto, questo, tra culture differenti, che rimanda peraltro alla base del progetto di Bognetti, di cui i polacchi furono i portavoce archeologici. Un progetto che già traspariva nella scelta delle aree campione da indagare, che erano, come è noto, Torcello, nella laguna veneziana (emporio bizantino e centro di nuova fondazione) e Castelseprio, appunto, nell'entroterra, in quei territori che avevano costituito fin dagli inizi il cuore del regno longobardo.

Gli scavi realizzati dal gruppo di archeologi dell'Università di Monaco a Ibligo Invillino vanno segnalati, in primo luogo, perché anch'essi certificano, alle soglie degli anni '6o, un'attenzione verso un'archeologia degli insediamenti altomedievali del tutto nuova per il nostro paese. Certo, i Longobardi sono ancora i protagonisti, in quanto la scelta del luogo da indagare discende dall'analisi di un passo di Paolo Diacono ${ }^{25}$; ma non sono più le sepolture l'oggetto principale dell'indagine, bensì un sito fortificato. Tra i risultati più significativi conseguiti va peraltro segnalata non tanto l'assenza di segni tangibili della presenza dei Longobardi negli aspetti della "cultura materiale" del sito (un fatto questo che destò agli inizi grande scalpore e che meriterebbe

23 M. Dabrowska, L. Leciejewicz, E. Tabaczynska, S. Tabaczynski, Castelseprio. Scavi diagnostici 1962-63, "Sibrium", XIV, 1978-79, pp. 1-137; V. Bierbrauer, Invilino-Ibligo in Friaül I. Die römische siedlung und das spätantik-frümittelarterliche castrum, München, 1987.

24 Alcuni contributi sono riuniti in M. Cagiano De Azevedo, Casa, città e campagna nel Tardo Antico e nell'Alto Medioevo, a cura di C. Damiano Fonseca, D. Adamesteanu, F. D’Andria, Galatina, 1986.

25 Historia Langobardorum IV, 37. 
comunque una qualche riflessione), quanto la scarsa relazione causale tra lo sviluppo dell'insediamento e la presenza longobarda. Se i Longobardi erano stati a Ibligo (e di questo non possiamo dubitare, a meno che non sia in errore la fonte, Paolo, oppure si sia sbagliato sito), la loro presenza sembra abbastanza irrilevante nella definizione dei caratteri dell'insediamento. In poche parole un insediamento accentrato esisteva ben prima dell'arrivo dei Longobardi e forse venne fortificato nel corso del V secolo (probabilmente nel quadro di quel sistema di difesa che prende nome di Tractus Italiae circa Alpes). I Longobardi si saranno pure rifugiati nel castrum di Ibligine, "cuius positio omnino inexpugnabilis existit" ("che ha una posizione davvero inespugnabile”), per scampare alle incursioni degli Avari del 610, ma certamente non sembrano aver lasciato molte tracce.

Una menzione a parte merita invece Michelangelo Cagiano de Azevedo, figura di studioso abbastanza anomala nel quadro accademico nazionale (basti pensare che nel 1966 lasciò l'insegnamento di Archeologia Cristiana per assumere, primo in Italia, quello di Archeologia e Topografia del Medioevo, alla Cattolica di Milano). Contrariamente ai filoni tradizionali, Cagiano sembra poco o niente coinvolto nei temi dell'archeologia funeraria, ma forte della sua formazione di archeologo classico (o della tarda antichità), sono invece le componenti dell'urbanesimo tardo antico e altomedievale ad interessarlo; e, in subordine, dell'edilizia abitativa, in prima battuta dei palazzi o delle grandi residenze. In queste sue ricerche Cagiano si troverà ad intercettare i Longobardi; ma, ancora una volta, il problema che si pone è quello del riconoscimento di un'identità longobarda, sia nell'edilizia abitativa, sia nell'urbanistica ${ }^{26}$ (sintomatico è il titolo di un suo famoso articolo del 1974: Esistono una architettura e una urbanistica longobarde?). Decisamente più innovativi, anche per le tematiche che venivano affrontate $\mathrm{e}$ per i risultati che vengono conseguiti, sono invece i suoi lavori sull'edilizia abitativa, anche se basati essenzialmente sull'analisi delle fonti scritte altomedievali.

Per riassumere, i tratti salienti della ricerca archeologica che si richiama, espressamente o indirettamente, ai Longobardi, si caratterizza, nel secondo dopoguerra, per un interesse marcato ad evidenziare e distinguere i caratteri salienti di un popolo, soprattutto attraverso le fonti materiali provenienti da contesti funerari. Quando l'attenzione si sposta dai contesti tombali a quelli insediativi, sono ancora le peculiarità e le diversità della cultura di questo popolo ad essere ricercate e, casomai, ad essere comparate e messe a confronto con quella degli autoctoni, da una parte, e degli altri popoli barbarici, dall'altra (gli Avari, i Burgundi etc.).

26 Sintomatico è il titolo di un suo famoso articolo del 1974: Esistono una architettura e una urbanistica longobarde? 
Negli ultimi anni la situazione appare sensibilmente cambiata. Innanzitutto dobbiamo segnalare un indubbio incremento degli scavi e delle iniziative volte ad indagare contesti genericamente altomedievali, sia di natura funeraria che di carattere insediativo. Per quanto riguarda i primi, ad un salto di qualità che coincide con un aumento esponenziale delle necropoli integralmente o quasi integralmente scavate, non hanno fatto seguito, secondo un malcostume endemico della nostra archeologia, adeguate edizioni di scavo. Ad esempio, e per restare alle sepolture del periodo longobardo, sono state scavate alcune ricche tombe della necropoli di Trezzo sull'Adda ${ }^{27}$ e le necropoli di Sacca di Goito in Lombardia ${ }^{28}$, di Sovizzo nel veronese ${ }^{29}$ (ed altre nel trevigiano), di Romans d'Isonzo ${ }^{30}$ e Santo Stefano "in Pertica" a Cividale in Friuli ${ }^{31}$, di Collecchio nel parmense ${ }^{32}$. Nessuna di queste è stata pubblicata integralmente e dunque non disponiamo ancora di un'edizione critica di altri cimiteri Longobardi dopo quelli di Nocera Umbra e Castel Trosino (e per edizione critica intendo un'analisi completa non solo dei reperti, ma anche della topografia del cimitero, della tipologia delle sepolture e, non ultimo, delle componenti antropologiche). Anche l'archeologia funeraria, dunque, che si poteva supporre godere di maggiori attenzioni e di conseguenti investimenti, segna per certi versi il passo. Ciò non meraviglia, qualora si consideri la natura dell'approccio a queste tematiche, incentrato ancora sullo studio e sulla classificazione degli oggetti e, molto raramente, sui contesti; un cambiamento di prospettiva, che sul piano teorico si rende necessario, deve quindi coincidere con strategie di scavo che portino ad indagini il più possibile complete dei cimiteri di questo periodo (frazioni di necropoli sono di scarsa utilità), accompagnate anche da un rinnovamento nei metodi diagnostici sul campo (cioè dello scavo stesso) e da investimenti cospicui su quello che si definisce il post-scavo (vale a dire l'edizione critica del contesto).

Lo scarso interesse manifestato nel passato da quanti hanno dichiarato di occuparsi di archeologia longobarda nei confronti dei contesti insediativi ha giocato invece favorevolmente; nel senso che, quando sono emerse, tali tema-

27 E. Roffia (a cura di), La necropoli longobarda di Trezzo sull'Adda, Firenze, 1986.

28 E. M. Menotti, La necropoli longobarda di Sacca di Goito. I primi materiali restaurati, Mantova, 1994.

29 M. Rigoni - E. Possenti (a cura di), Il tempo dei Longobardi. Materiali di epoca longobarda dal trevigiano, Padova, 1999, PP. 82-89 passim.

$3^{\circ} \mathrm{F}$. Maselli Scotti (a cura di), Longobardi a Romans d'Isonzo. Itinerario attraverso le tombe altomedievali, Trieste, 1989.

${ }^{1}$ I. Ahumada Silva, P. Lopreato, A. Tagliaferri, La necropoli di Santo Stefano in "Pertica". Campagne di scavo 1987-1988, Città di Castello, 1990.

32 M. Marini Calvani, Collecchio ( $\mathrm{Pr}$ ). Necropoli altomedievale, "Notiziario di Archeologia Medievale”, 28, 1980, pp. 38-39; E. E. Catarsi (a cura di), I Longobardi in Emilia Occidentale, Parma, 1993. 
tiche sono state analizzate nella loro complessità, e non soltanto nelle relazioni, più o meno evidenti, con i Longobardi. Oggi possiamo dire di conoscere meglio la città del periodo longobardo, soprattutto nel nord Italia, perché è il fenomeno dell'urbanesimo tardo antico ed alto medioevale, nel suo insieme, ad essere meglio conosciuto.

E veniamo all'ultimo aspetto che dobbiamo trattare, quello dell'evoluzione del territorio. Qui può essere interessante notare come la ricerca si sia sviluppata, essenzialmente, in tre direzioni: alcuni studi hanno posto l'accento essenzialmente sugli insediamenti di carattere militare (castra oppure stazioni, non meglio precisate, di controllo del territorio); altri studi hanno affrontato il tema dei caratteri del popolamento rurale vero e proprio, partendo però dalle strutture di organizzazione territoriale del mondo antico, cioè le ville e le fattorie; il terzo punto di vista analizza invece i processi di cristianizzazione delle campagne, studia cioè le strutture di organizzazione religiosa del territorio (ma sotto questo profilo, il problema di una caratterizzazione della presenza longobarda è stato fino ad oggi ritenuto marginale o comunque poco sviluppato).

Per quanto concerne il problema dei castelli d'epoca longobarda il tema ha goduto di una certa attenzione fino agli anni '70; poi ha registrato un rapido declino, soprattutto a seguito delle critiche rivolte da storici come Tabacco (1966) e Settia (1984); poi ancora è stato ripreso verso la fine degli anni '8o in forma leggermente differenziata rispetto al passato. Alcuni aspetti sembrano oramai sufficientemente chiari; altri meno. Innanzitutto, i castelli compaiono con una certa evidenza, anche nelle fonti archeologiche, non prima della fine del IV secolo e in gran parte sembrano ricollegabili ai processi di militarizzazione delle aree di confine (prima l'arco alpino, poi probabilmente il Po) ${ }^{33}$; quasi tutti questi siti dovevano svolgere funzioni di controllo territoriale, ma anche di carattere insediativo (vedi ad esempio la comparsa di chiese e battisteri al loro interno, come ad esempio a Castelseprio o all'Isola Comacina) ${ }^{34}$; nel contempo pochi casi paiono riferibili all'azione diretta dei Longobardi e questi vanno per il momento collocati nell'area appenninica e nella Tuscia, mentre per i siti fortificati del nord Italia sembra più chiaro che i Longobardi dovettero appoggiarsi a strutture pre-esistenti. Infine, non esiste assolutamente nessun collegamento tra siti fortificati tardo-antichi/altomedievali e la successiva ondata di castelli fondati a partire dal X secolo, se non puramente casuale; la fortuna di questi nuovi centri del potere, dunque, va analizzata caso

33 G. P. Brogiolo, S. Gelichi, Nuove ricerche sui castelli altomedievali dell'Italia settentrionale, Firenze, 1996.

34 V. Fiocchi Nicolai, Sauro Gelichi, Battisteri e chiese rurali (IV-VII secolo), in L'edificio battesimale in Italia. Aspetti e problemi, Genova-Sarzana-Albenga-Ventimiglia, Finale 1998, Bordighera, 2001, pp. 303-380. 
per caso e comunque non è questo fenomeno che produce un generalizzato processo di accentramento dell'habitat nei primi secoli dell'alto medioevo.

Per quanto concerne l'analisi del popolamento nelle campagne tra l'età tardo-antica e l'alto medioevo, nel nord Italia, fino ad oggi, è stato affrontato o su dati quantitativi molto generali (derivati essenzialmente da ricognizioni di territori estesi, ma con la specifica finalità di indagare i processi insediativi antichi), oppure su dati puntiformi, quasi sempre riferibili a scavi di ville/fattorie romane ${ }^{35}$. I risultati sono stati, nell'un caso come nell'altro, sufficientemente coincidenti, nel senso che hanno marcato una netta flessione delle occupazioni dopo il VI secolo e la quasi totale desertificazione dei siti abitati, interpretabili come ville/fattorie, più o meno nello stesso periodo. L'impressione è che questi dati, che pure mantengono un loro valore generale, scontino molto il punto di vista (antichistico) dal quale sono stati analizzati. Tra l'altro questi elementi sono in contrasto con il quadro territoriale descritto dalle fonti contemporanee.

$\grave{E}$ evidente che il periodo longobardo sancisce in maniera definitiva la fine di un modo di vivere in ambito rurale, rappresentato appunto dal sistema delle ville/fattorie: i dati degli scavi sembrano, da questo punto di vista, abbastanza coincidenti. Tuttavia vi è anche da dire che la stragrande maggioranza di questi insediamenti non attesta rifacimenti della pars urbana (quella cioè residenziale) già a partire dal IV secolo e documenta invece, nelle fasi successive, forme di occupazione estremamente diversificate quanto a caratteristiche e collocazione topografica. In poche parole il fenomeno sembra già attivo a partire del IV-V secolo, con qualche rara eccezione. Tuttavia ciò non significa neppure il totale inurbamento delle nuove classi di possessori terrieri, in quanto abbiamo un'indiretta documentazione archeologica della loro presenza attraverso impianti cimiteriali talvolta con ricchi corredi e, successivamente, connessi con edifici di culto databili ancora nel corso del VII secolo.

Per quanto riguarda la Toscana, invece, dove i risultati delle ricognizioni di superficie descrivono scenari sostanzialmente simili, indagini mirate e pluriennali su castelli dei secoli centrali del medioevo hanno restituito quadri insediativi sufficientemente omogenei e riferibili a forme di occupazione accentrata precedenti alle fasi di incastellamento. Il modello che se ne è desunto diverge notevolmente da quello elaborato, sulle fonti scritte e per altre aree dell'Italia centrale, da Pierre Toubert nei primi anni '7036. I modelli di occupazione delle campagne tipici dell'età romana (per quanto già profondamente trasformati a partire dal III-IV sec. d. C.) sarebbero stati sosti-

35 G. P. Brogiolo (a cura di), La fine delle ville romane: trasformazioni nelle campagne tra Tarda Antichità e Alto Medioevo, Gardone Riviera 1995, Mantova, 1996.

36 P. Toubert, Les structures du Latium médiéval. Le Latium méridional et la Sabine du IXe a la fin du XIIe siècle, Roma, 1973. 
tuiti da un popolamento i cui caratteri avrebbero previsto forme generalizzate di insediamento accentrato (in particolare d'altura) ${ }^{37}$. Gruppi di contadini avrebbero dunque dato vita abbastanza precocemente alle prime comunità di villaggio, caratterizzate da una sostanziale assenza di gerarchizzazione sociale al loro interno. Soltanto a partire dall'VIII-IX secolo si assisterebbe al ritorno di un nuovo forte controllo da parte delle aristocrazie nella gestione e nell'organizzazione dei villaggi, dunque degli insediamenti e della conduzione fondiaria. Il caso dello scavo di Poggibonsi, in Toscana, sicuramente tra i migliori e i più significativi degli ultimi anni in Italia, ha in effetti rivelato questi passaggi attraverso una specifica caratterizzazione dei marcatori materiali (tipologie delle case, tipologie dei consumi e dei manufatti, indicatori antropologici).

In questo contesto l'archeologia longobarda rischia di trovarsi sempre più emarginata e sullo sfondo, anche se non bisogna disconoscere o sottovalutare la possibilità di un utilizzo, quando presenti, degli indicatori funerari. In questo caso non tanto per identificare etnie e culture, quanto per seguire la dislocazione e i cambiamenti che si rilevano all'interno di nuove classi di proprietari terrieri, come è avvenuto in un eccellente scavo a Collegno, in Piemonte ${ }^{38}$, dove è stato possibile indagare le trasformazioni di una piccola comunità dal periodo delle migrazioni fino al secolo VIII, attraverso le ricerche su una porzione dell'abitato e del cimitero.

L'archeologia, dunque, almeno nelle aree coincidenti con quello che fu il cuore del Regno longobardo, ci ha restituito ancora scarse e frammentarie indicazioni sui modelli di questi nuovi insediamenti e sui caratteri del popolamento. Tra la fine delle ville e l'inizio del sistema curtense, non conosciamo quasi nulla sul versante della "cultura materiale" delle comunità che vivevano nelle campagne.

Più che pensare che l'invisibilità del dato archeologico sia sempre da ricollegare alla continuità di occupazione di un sito (cioè alla sua fortuna nel tempo), dobbiamo riconsiderare la mimeticità del dato archeologico per questo periodo e il suo possibile trasferimento in quello che viene chiamato nelle ricerche di archeologia di superficie "off-site". Ė dunque un problema di strategia che segna il passo. Si è già dimostrato, anche se per altre aree, come per l'alto medioevo possa risultare maggiormente pagante un approccio più selezionato e mirato nei confronti dei campioni territoriali o dei siti da sottopor-

37 R. Francovich - R. Hodges, Villa to village. The transformation of the Roman Countryside in Italy c. 400-100o, London, 2003; M. Valenti, L'insediamento altomedievale nelle campagne toscane. Paesaggi, popolamento e villaggi tra VI e X secolo, Firenze, 2004.

38 L. Pejrani Baricco (a cura di), Presenze longobarde. Collegno nell'alto medioevo, Torino, 2004. 
re ad indagine. È anche chiaro, peraltro, che tali problemi (ad esempio l'identificazione di marker specifici per questo periodo), possano essere risolti solo attraverso la comparazione dei risultati dell'indagine di superficie con quelli derivanti da opportuni accertamenti stratigrafici di limitate dimensioni $\mathrm{o}$ anche scavi estensivi. Ma più in generale sarà da grandi progetti di ricerca territoriale, dove sia possibile alternare l'indagine di superficie per campioni a scavi mirati, a doverci dare le risposte che ci aspettiamo: e mi sembra che i risultati, dove queste ricerche sono avanzate, siano incoraggianti.

I Longobardi saranno forse un po' scomparsi da questi progetti ma, di converso, sarà la storia della società (urbana e rurale) dell'alto medioevo, in questo caso, ad avvantaggiarsene. 


\section{Bibliografia}

Åberg N. 1923, Die Goten und Langobarden in Italien, Uppsala

Ahumada Silva I., Lopreato P., Tagliaferri A. 1990, La necropoli di Santo

Stefano in "Pertica". Campagne di scavo 1987-1988, Città di Castello

Barbiera I. 1998, "E ai di" remoti grande pur egli il Forogiulio appare". Longobardi, storiografia e miti delle origini a Cividale del Friuli, "Archeologia Medievale", XXV, pp. 345-357

Bierbrauer V. 1987, Invilino-Ibligo in Friaül I. Die römische siedlung und das spätantik-frümittelarterliche castrum, München

Brogiolo G. P. (a cura di) 1996, La fine delle ville romane: trasformazioni nelle campagne tra Tarda Antichità e Alto Medioevo, Gardone Riviera 1995, Mantova

Brogiolo G. P., Gelichi S. 1996, Nuove ricerche sui castelli altomedievali dell'Italia settentrionale, Firenze

Cagiano De Azevedo M. 1986, Casa, città e campagna nel Tardo Antico e nell'Alto Medioevo, a cura di C. Damiano Fonseca, D. Adamesteanu, F. D'Andria, Galatina

Calandra C., Calandra E. 1880, Di una necropoli barbarica scoperta a Testona, "Atti della Società d'Archeologia e Belle Arti per la Provincia di Torino", IV, pp. 5-39

Campi Dei L. 1886, Le tombe barbariche di Civezzano e alcuni rinvenimenti medioevali nel Trentino, Trento

Catarsi E. E. (a cura di) 1993, I Longobardi in Emilia Occidentale, Parma

Dabrowska M., Leciejewicz L., Tabaczyska E., Tabaczyski S. 1978-79, Castelseprio. Scavi diagnostici 1962-63, "Sibrium”, XIV, pp. 1-137

Desittere M. 1985, Dal Gabinetto di Antichità Patrie al Museo di Storia Patria di Reggio Emilia (1862-1886), Reggio Emilia

Fiocchi Nicolai V., Gelichi Sauro 2001, Battisteri e chiese rurali (IV-VII secolo), in L'edificio battesimale in Italia. Aspetti e problemi, GenovaSarzana-Albenga-Ventimiglia, Finale 1998, Bordighera, pp. 303-380

R. Francovich - R. Hodges 2003, Villa to village. The transformation of the Roman Countryside in Italy c. 400-100o, London

Fuchs S. 1938, Die langobardischen Goldblattkreuze aus der Zone südwärts der Alpen, Berlin

Fuchs S., Werner J.1950, Die langobardischen Fibeln aus Italien, Berlin Galli E. 1914, Fiesole. Gli scavi - il museo, "Il piccolo cicerone moderno", 11

Galli E. 1942, Nuovi materiali barbarici dell'Italia centrale, "Atti della Pontificia Accademia Romana di Archeologia - Memorie”, III, VI, pp. 1-37 
Gelichi S. 2000, Funeraria archeologia. Medioevo, in R. Francovich- D. Manacorda (a cura di), Dizionario di Archeologia, Roma-Bari, pp. 150154

Von Hessen 1966, Die langobardenzeitlichen Grabfunde aus Fiesole bei Florenz, München

Von Hessen 1968, Die langobardische Keramik aus Italien, Wiesbaden

Von Hessen O. 1971a, Die langobardischen Funde aus dem Gräberfeld von Testona (Moncalieri/Piedmont), Torino

Von Hessen 1971b, Primo contributo all'archeologia longobarda in Toscana. Le necropoli, Firenze

Jones S. 1997, The Archaeology of Ethnicity. Constructing identities in the past and present, London

La Rocca C. 1989, Le sepolture altomedievali del territorio di Verona, in D. Modonesi - C. La Rocca (a cura di), Materiali di epoca longobarda nel veronese, Verona, pp. 149-186

La Rocca C. 1993, Uno specialismo mancato. Esordi e fallimento dell'archeologia medievale italiana alla fine dell'Ottocento, "Archeologia Medievale", XX, pp. 13-43

Manacorda D. 1982, Cento anni di ricerche archeologiche italiane: il dibattito sul metodo, "Quaderni di Storia", 16, pp. 85-119

Marini Calvani M. 1980, Collecchio (Pr). Necropoli altomedievale, "Notiziario di Archeologia Medievale", 28, pp. 38-39

Maselli Scotti F. (a cura di) 1989, Longobardi a Romans d'Isonzo. Itinerario attraverso le tombe altomedievali, Trieste

Mengarelli R. 1902, La necropoli barbarica di Castel Trosino presso Ascoli Piceno, "Monumenti Antichi dei Lincei", XII, coll. 145-380

Menotti E. M. 1994, La necropoli longobarda di Sacca di Goito. I primi materiali restaurati, Mantova 1994

Orsi P. 1887, Di due crocette auree del Museo di Bologna e di altre simili trovate nell'Italia superiore e centrale, "Atti e Memorie della Reale Deputazione di Storia Patria per le Province di Romagna”, V, pp. 333-414

Pasqui A., Paribeni R. 1918, Necropoli barbarica di Nocera Umbra, "Monumenti Antichi dei Lincei", XXV, coll. 137-352

L. Pejrani Baricco (a cura di) 2004, Presenze longobarde. Collegno nell'alto medioevo, Torino

Peroni R. 1992, Preistoria e Protostoria. La vicenda degli studi in Italia, in Le vie della Preistoria, Roma, pp. 9-70

Rigoni M. - Possenti E. (a cura di) 1999, Il tempo dei Longobardi. Materiali di epoca longobarda dal trevigiano, Padova

Roffia E. (a cura di) 1986, La necropoli longobarda di Trezzo sull'Adda, Firenze

Settia A.A. 1984, Castelli e villaggi nell'Italia padana. Popolamento, potere 
e sicurezza tra IX e XIII secolo, Napoli

Tabacco G. 1966, I liberi del re nell'Italia carolingia e postcarolingia, Spoleto

P. Toubert 1973, Les structures du Latium médiéval. Le Latium méridional et la Sabine du IXe a la fin du XIIe siècle, Roma

M. Valenti 2004, L'insediamento altomedievale nelle campagne toscane. Paesaggi, popolamento e villaggi tra VI e X secolo, Firenze

Wieser F. 1887, Das langobardischen Fürstengrab und Reihengräberfelder von Civizzano bei Trient beschrieben, Innsbruck 


\section{Le unità dell'esercito bizantino nel VI secolo tra continuità e innovazione ${ }^{*}$}

Giorgio Ravegnani

L'esercito nazionale bizantino nel $\mathrm{V}$ secolo era suddiviso in truppe da campagna e di frontiera. Alla prima categoria appartenevano comitatenses, palatini e pseudocomitatenses, mentre della seconda facevano parte i limitanei. I comitatenses erano almeno in linea di principio gli effettivi delle armate regionali, i palatini i soldati direttamente a disposizione dell'imperatore e come pseudocomitatenses venivano definiti i reparti confinari promossi nell'esercito mobile. I limitanei, dislocati in permanenza a difesa dei confini, erano così chiamati dalla loro presenza in un limes e venivano detti anche ripenses, riparienses o castriciani, castellani e castresiani se acquartierati rispettivamente lungo una ripa fluviale o nei castelli. A questi si aggiungevano infine i reparti della guardia imperiale, costituiti dalle scholae palatinae, dai protectores e, a partire dalla seconda metà del V secolo, dal nuovo corpo degli excubitores. Le unità venivano inoltre designate con termini differenti a seconda del tipo o dell'epoca in cui erano state costituite. La Notitia Dignitatum, che riporta per l'Oriente romano la situazione esistente all'inizio del V secolo, classifica i reparti dell'esercito mobile in auxilia, legiones, e vexillationes e le truppe di frontiera in alae, auxilia, cohortes, cunei equitum, equites, legiones e milites ${ }^{1}$. Auxilia, cohortes e legiones erano truppe di fanteria, alae e vexillationes forze di cavalleria, mentre milites è una denominazione generica di reparti costituiti in epoca tarda. Queste distinzioni andarono però perdendosi nel corso del tempo e, nel VI secolo, il quadro si è notevolmente semplificato: permane la divisione fra comitatenses e limitanei, ma pare caduta quella fra comitatenses e palatini, e la definizione tecnica prevalente di tutti i reparti è numerus (in greco arithmos) accanto alla quale si incontrano le varianti per lo più letterarie di katalogos, tagma, taxis o anche $t_{e l o s}^{2}$. L'antica terminologia non doveva tuttavia essere andata del tutto per-

\footnotetext{
* In corso di stampa nella Miscellania in memoria di Ottone D’Assia.

${ }^{1}$ Not. Dign., Or., V-IX, XXVIII-XXIX, XXXI-XLII (Notitia Dignitatum, a c. di O. Seek, Berlin 1876).

2 Il termine numerus, da punto di vista tecnico, indicava in origine le formazioni barbariche irregolari ma già nel V secolo si era venuto affermando per definire tutte le unità: cfr. Sozomeni
} 
duta e, oltre che nelle leggi del Codex Iustinianus, ricompare in altre fonti con una significativa alternanza fra vecchie e nuove denominazioni per le unità di antica formazione ${ }^{3}$. Nello Strategicon di Maurizio, il manuale di arte militare composto fra VI e VII secolo, si ha infine un'ulteriore distinzione, apparentemente di carattere tecnico, fra tagma o bandon per la cavalleria e arithmos per indicare i reparti di fanteria ${ }^{4}$.

Non sappiamo con esattezza quale sia stata la forza delle diverse unità dell'esercito tardo romano, ma si ritiene in genere che si aggirasse intorno ai cinquecento uomini, eccezion fatta per le legioni che paiono averne compresi normalmente un migliaio e forse, in alcuni casi, anche più ${ }^{5}$. La stessa incertezza vale per i numeri del VI secolo, per i quali si può forse supporre un'analoga consistenza media di circa cinquecento unità. L'unico riferimento preciso ci viene in proposito dai Numidae Iustiniani di Ermopoli in Egitto, di cui un papiro ricorda con precisione l'organico di 508 soldatí. Non è da escludere

Historia ecclesiastica, a cura di J. Bidez - G.C. Hansen, Berlin 1960, I, 8: «i reparti romani che ora chiamano arithmoi».

3 R. Grosse, Römische Militärgeschichte von Gallienus bis zum Beginn der byzantinischen Themenverfassung, Berlin 1920, p. 273. Numerus come termine tecnico compare ad esempio in Cod. Iust., I, 27, 2, 8, a. 534 e arithmos nello stesso senso si trova in Ed. Iust., IV, 2, s. d. (a. 535 o 536). Le varianti taxis e telos fanno parte della terminologia letteraria, mentre katalogos $e$ tagma si trovano anche nel linguaggio ufficiale, ad es. in Nov. Iust., 102, 2, a. 536 o 148, 2, a. 566. In un documento ufficiale del 505 (Catalogue of the Greek and Latin Papyri in the John Rylands Library Manchester, IV, a c. di C. H. Roberts - E. G. Turner, Manchester 1952, nr. 609) gli equites Mauri Scutarii di Ermopoli (un reparto già noto dal IV secolo) sono definiti sia vexillatio che numerus e in Greek Papyri in the British Museum, V, a c. di H. I Bell, Oxford 1917, nr. 1724, a. 578-582 la stessa unità di stanza a Siene viene indicata contemporaneamente come legion e arithmos (così anche in Byzantinische Papyri der Bayerischen Staatsbibliothek München, a c. di A. Heisenberg - L. Wenger, Stuttgart 1986², nr. 15, fine VI secolo: un campiductor della legione di Siene e un augustalios del numero di Siene). In questo caso non si conosce il nome dell'unità ma è probabile che si tratti di una legione qui stanziata già nel V secolo, cfr. A. H. M. Jones, Il tardo impero romano 284-602 d. C., trad. it., II, Milano 1974, p. 902. La terminologia usata dagli storici eruditi è un elemento di confusione piuttosto che di chiarezza, dato il ricorso a uno stile elegante: così in Procopio è d'uso pressoché costante katalogos, diversamente da Agazia che preferisce taxis o tagma (A. Müller, Das Heer Justinians nach Procop und Agathias, in «Philologus» 71 (1912), pp. 101-102); lo stesso Procopio inoltre si serve di lochos che almeno in un caso pare l'equivalente di legio: così in de aed. III, 4, 16 (Procopii Caesariensis Opera omnia, IV, a c. di J. Haury - G. Wirth, Lipsiae 1964), dove parla del reparto anticamente stanziato a Melitene di Armenia: «il lochos era chiamato legione» (si tratta della legio duodecima fulminata ricordata in Not. Dign., Or., XXXVIII, 14 e dallo stesso autore in de aed. I, 7, 3). Il termine "legio» viene inoltre usato anche per il reparto di stanza a Tessalonica fra fine VI e inizio VII in Les plus anciens recueils des miracles de saint Démétrius, a cura di P. Lemerle, I, Paris 1979, p. 84.

4 F. Aussaresses, L'armée byzantine à la fin du VI e siècle d'après le «Strategicon» de l'empereur Maurice, Bordeaux 1909, p. 20.

5 Jones, Il tardo impero... cit., II,p. 924.

6 P. Cairo, III, nr. 67321, a. 548 o 563 (Catalogue général des antiquités égyptiennes du Musée du Caire, III, Papyrus grecs d'époque byzantine, a c. di J. Maspero, Le Caire 1916). 
però che esistessero numeri di diversa consistenza, sia di maggiore ampiezza sia al contrario con una forza inferiore. Una conferma significativa può forse venire da quanto Procopio scrive a proposito del reparto di fanteria attivo nel 539 in Italia agli ordini di un ufficiale di nome Demetrio, che doveva essere sicuramente ben al di sopra delle cinquecento unità e, forse, corrispondeva a un'antica legione dell'esercito campale ${ }^{7}$. All'estremo opposto, oltre alle testimonianze non sempre chiare delle fonti letterarie, è significativo quanto si legge nello Strategicon di Maurizio, che propone numeri variabili da un minimo di duecento a un massimo di quattrocento uomini e normalmente oscillante fra trecento e quattrocento ${ }^{8}$. La contraddizione è comunque soltanto apparente, se si tiene conto che l'autore pensa all'unità come forza combattente e che, in condizioni normali, un certo numero dei soldati in forza ai reparti non doveva essere impiegato in servizio attivo, sia perché destinati a compiti amministrativi sia perché inadatti al combattimento. Era inoltre una buona regola tattica costituire unità di diversa consistenza, per ingannare il nemico sulla dimensione dell'esercito calcolata dal numero degli stendardi e ciò spiega facilmente la varietà della forza numerica prevista per l'impiego\% Incerta è anche l'esatta composizione dell'organico delle unità, dato che le fonti del VI secolo ci pongono di fronte a una serie di gradi diversi, che a fatica possono essere combinati in un quadro unitario. Il motivo è ancora una volta di ordine storico, tenendo conto che nella prima età bizantina i reparti di epoca antica coesistono con quelli di più recente costituzione. Si ha così una stratificazione, che ci consente di rilevare la sopravvivenza di gradi appartenenti alle formazioni del principato in parallelo a quelli delle unità costituite nel III e IV secolo, di cui conosciamo la struttura essenziale da un passo di S. Gerolamo $^{10}$. Al di là di queste notizie frammentarie abbiamo infine lo

7 Proc. Bell. Goth. II, 23, 2 (Procopii Caesariensis Opera omnia, II, a c. di J. Haury - G. Wirth, Lipsiae 1963): Belisario invia a Fiesole cinquecento fanti del reparto «al comando di Demetrio». Un'altra indicazione numerica relativamente precisa ci viene dalle scholae palatinae il cui organico era composto da 500 uomini. Abbiamo inoltre numerose testimonianze su formazioni che variano fra le cinquecento e le cento unità, ma non siamo in grado di precisare se si trattava di numeri completi o di parti di questi: cfr. G. Ravegnani, Soldati di Bisanzio in età giustinianea, Roma 1988, p. 31 n. 12.

8 Mauricii Strategicon, a c. di G. T. Dennis - E. Gamillscheg, Wien 1981, I, 4, pp. 88, 90 («Corpus Fontium Historiae Byzantinae, XVII»).

9 Ibid. I, 4, p. 90.

10 Hieron. In Ioh. Hierosol., 19 (PL XXXIII, c. 386): «...finge aliquem tribunitiae potestatis suo vitio regradatum, per singula militiae equestris officia, ad tironis vocabulum devolutum: numquid ex tribuno statim fit tiro? Non, sed ante primicerius, deinde senator, ducenarius, centenarius, biarchus, circitor, eques dein tiro». Questa stessa gerarchia, che s. Gerolamo indica nella struttura essenziale riferendola alla cavalleria, è attestata dalle fonti in scholae, vexillationes e auxilia: cfr. Jones, Il tardo impero..., cit., II, pp. 1125-26 e ibid, p. 916 per i vecchi gradi riscontrabili in unità egiziane del VI secolo. Una ricostruzione delle diverse articolazioni cronologiche dei quadri è proposta da W. Treadgold, Byzantium and Its Army 284-1081, Standford 1995, pp. 87-95. 
Strategicon di Maurizio, a cui si deve un quadro coerente delle unità intese come forza combattente, con la relativa gerarchia operativa, che dobbiamo ritenere in uso nella prassi del tempo, tenendo conto del carattere eminentemente pratico di questo manuale di arte militare ${ }^{11}$.

La storia militare del V secolo dispone di un documento di eccezionale valore, la Notitia Dignitatum, in cui sono indicati i nomi della maggior parte dei reggimenti imperiali. Per il secolo successivo manca una lista di questo genere, ma non di meno attraverso fonti di provenienza diversa si conserva la denominazione di un buon numero di unità esistenti a quel tempo. Il confronto con la Notitia, inoltre, consente in alcuni casi di verificare la sopravvivenza di formazioni precedenti, cosa che sembra suggerire un'ipotesi di continuità almeno parziale dell'esercito romano in Oriente al di là delle vicende che condussero alla disintegrazione di quello occidentale. Come già nella Notitia, risultano avere una propria denominazione ufficiale soltanto i reparti dell'esercito nazionale, mentre ne paiono privi i nuovi reggimenti di foederati barbari che nel VI secolo avevano assunto un carattere di formazioni regolari, come pure di bucellarii, i soldati privati dei singoli generali, ugualmente divenuti nel VI secolo una milizia riconosciuta legalmente.

A Costantinopoli sono ricordate soltanto due fra le numerose unità dell'esercito mobile (gli exercitus praesentales) che vi erano acquartierate secondo le liste della Notitia Dignitatum, ma spesso, come si vedrà più avanti, questi stessi reparti risultano impiegati in zone operative nel quadro dei grandi movimenti militari del tempo. La prima di cui si ha notizia, i Lanciarii, era un'unità di fanteria presente nel 518 allorché prese parte alla solenne proclamazione del nuovo imperatore Giustino I, eletto il 10 luglio dopo la morte di Anastasio I. Com'era nella consuetudine, un campidoctor dei Lanciarii di nome Godilas incoronò il neo eletto sollevato su uno scudo con il torques o maniakis, la collana che alcuni soldati portavano come decorazione. Poco più tardi, poi, gli stessi Lanciarii formarono con gli scudi la «testuggine» per consentire a Giustino I di indossare gli abiti imperiali al riparo dalla vista dei presenti ${ }^{22}$. Si tratta con

${ }^{11} \mathrm{Il}$ numerus di Maurizio, suddiviso in ecatontarchie, decarchie e tetrarchie, è al comando di un comes o tribunus con al seguito un piccolo stato maggiore composto da portaordini (mandator), vessillifero (bandophoros nella cavalleria e draconarius in fanteria), trombettieri (bucinator e tubator), ordinanza (o ten kappan bastazon) e araldo (cantator). Al di sotto del tribuno i quadri degli ufficiali sono composti dal vice comandante dell'unità (ilarca nella cavalleria, vicarius o campiductor in fanteria) e dall'ecatontarca; vengono quindi i sottufficiali e graduati con decarca, pentarca e tetrarca, comandanti delle rispettive formazioni, e il serrafila (phylax). Alcuni soldati scelti hanno infine incarichi speciali: addetto alla sanità (deputatus), all'accampamento (mensor), avanguardia (antecessor), osservatore (sculcator) e infine responsabile delle salmerie (tuldophylax): cfr. Aussaresses, L'armée..., cit., p. 33.

12 Constantini Porphyrogeniti de cerimoniis aulae byzantinae, a c. di I. I. Reiske, I, Bonnae 1829, I, 93, p. 429. Il campidoctor (o campiductor) era un ufficiale istruttore ed è attestato solo nella fanteria: Grosse, Römische Militärgeschichte..., cit., p. 127. 
ogni probabilità di reparti già attivi nel V secolo, i Lanciarii seniores oppure i Lanciarii iuniores, che erano legiones palatinae alle dipendenze dei magistri militum di stanza a Costantinopoli ${ }^{13}$. In seguito se ne perdono le tracce, ma è possibile che lo stesso reggimento o parte di questo abbia poi seguito Godilas dieci anni più tardi quando, divenuto ufficiale superiore, fu uno dei due comandanti che condussero un esercito a Bosporo di Crimea per sedarvi la rivolta degli Unni. ${ }^{14}$. La seconda unità di Costantinopoli è invece attestata nel 541 quando venne redatto un atto privato sottoscritto da un soldato «dell'arithmos dei valorosissimi sesto Dalmati», di nome Massimo, che fece da testimone per un prestito fatto a due egiziani momentaneamente domiciliati nella capitale dell'impero. Anche in questo caso è plausibile l'identificazione con gli equites sesto Dalmatae, una vexillatio comitatensis attiva nel secolo precedente agli ordini di uno dei due magistri militum praesentales ${ }^{15}$.

A Bosporo di Crimea si ha al contrario notizia di un reparto che non trova corrispondenza nelle liste più antiche. Si legge infatti nella Chronographia di Malala che, nel 528, Giustiniano vi stanziò un «reparto di soldati romani, ovvero italici, chiamato Hispani» ponendo al comando di questo un tribuno, di cui una fonte più tarda tramanda il nome di Dalmazio $^{16}$. Dovevano essere sicuramente comitatenses, dato che vengono definiti come stratiotai, il termine tecnico in uso nel VI secolo per indicare i soldati dell'armata campale in contrapposizione ai limitanei ${ }^{17}$. Non sappiamo da cosa sia derivato il nome del reparto, ma si deve ritenere che sia stato costituito ex novo in assenza di precedenti indicazioni sulla sua esistenza. L'occasione per inviarlo fu data dal trattato di alleanza concluso con Grod, re degli Unni di Crimea, che nel 528 si recò a Costantinopoli convertendosi solennemente al cristianesimo. A seguito di ciò il sovrano di Bisanzio rafforzò il controllo già acquisito dal predecessore sulla libera città di Bosporo inviando il presidio militare ma, di lì a poco, il fratello del re unno guidò una sollevazione dei sudditi rimasti pagani, si impadronì della città e fece massacrare il reggimento imperiale. Giustiniano reagì prontamente con una spedizione terrestre e navale, che ebbe successo e condusse

13 Not. Dign., Or., V, 42 (Lanciarii seniores), VI, 47 (Lanciarii iuniores).

14 J. R. Martindale, The Prosopography of the Later Roman Empire, III A-B, A. D. 527-641, Cambridge 1992, pp. 539-540.

15 P. Cairo, II, nr. 67126, 7 gennaio 541 (Catalogue général des antiquités égyptiennes du Musée du Caire, II, Papyrus grecs d'époque byzantine, a c. di J. Maspero, Le Caire 1913); Not. Dign., Or. VI, 37. La restituzione toxotodalmaton fatta dall'editore, e la conseguente identificazione con un non meglio attestato reparto di arcieri dalmati, va verosimilmente corretta in [S] extodalmaton, cfr. D. Hoffmann, Das spätrömische Bewegungsheer und die Notitia Dignitatum, I, Dusseldorf 1969, p. 262.

16 Ioannis Malalae Chronographia, a c. di I. Thurn, Berlin-New York 2000, XVIII, 14, p. 361; Theophanis Chronographia, a c. di C. De Boor, I, Lipsiae 1883, p. 176.

17 Jones, Il tardo impero..., cit., p. 899. 
in breve al ristabilimento della sovranità bizantina, ma si ignora se il reggimento degli Hispani venne ricostruito ${ }^{18}$.

In alcune città dell'Oriente minacciate dai Persiani, scrive Procopio, furono acquartierati nel 534 quattro reparti di Vandali Iustiniani costituiti con prigionieri catturati in Africa dopo la fine della guerra vandalica. L'usanza di formare unità di truppe regolari con prigionieri di guerra non è nuova nel mondo tardo antico e si trova poi attestata anche in Italia; per prudenza, a quanto pare, venivano però dislocate a distanza notevole dai luoghi di origine. I Vandali prigionieri costituirono inizialmente cinque katalogoi di cavalleria che seguirono Belisario quando tornò a Costantinopoli, ma durante il successivo trasferimento alla zona operativa uno di questi, composto da circa 400 uomini, si ammutinò subito dopo la partenza da Lesbo costringendo i marinai imperiali a fare vela verso l'Africa dove si unirono ai ribelli al dominio di Bisanzio. I Vandali che raggiunsero l'Oriente furono tuttavia acquartierati senza incidenti ed erano ancora in servizio alcuni anni più tardi. A quanto si deduce dallo stesso autore, inoltre, non costituirono unità a sé stanti, ma vennero suddivisi in diversi nuclei che andarono a rafforzare le preesistenti guarnigioni imperiali ${ }^{19}$. In Frigia nel 529 dovevano infine essere di stanza i Lykokranitai, un'unità di fanteria utilizzata per una spedizione in territorio persiano 20 il cui nome, come spiega Procopio, doveva provenire da un monte della Pisidia ${ }^{21}$.

Altre notizie sulla presenza di numeri nelle regioni orientali vengono dalla Siria, dalla Fenicia Libanese e dalla Palestina. A Beroia di Siria era di stanza il katalogos dei Quartoparthi, un'antica legione limitanea che nel secolo precedente risulta dislocata nel castello di Circesio in Osroene. In contrasto con la decadenza dei reparti confinari, che vennero anche parzialmente smilitarizzati da Giustiniano, i Quartoparthi furono inseriti nell'armata del magister militum per Orientem Filippico e nel 586 si distinsero in combattimento contro i Persiani a Solachon ${ }^{22}$. Un editto di Giustiniano del 535 o 536 ricorda quindi fra le truppe della Fenicia Libanese un altro reparto dell'esercito

18 E. Stein, Histoire du Bas-Empire, II, De la disparition de l'Empire d'Occident à la mort de Justinien (476-565), Paris-Bruxelles-Amsterdam 1949, p. 304.

19 Proc. Bell. Vand. II, 14, 17-20 (Procopii Caesariensis Opera omnia, II, a c. di J. Haury - G. Wirth, Lipsiae 1962). L'ipotesi che siano stati utilizzati per rafforzare guarnigioni esistenti pare risultare da quanto scrive Procopio (ib. 18). Vandali che militano al seguito di Belisario nelle guerre successive sono ricordati in Proc. Bell. Pers. II, 21, 4 (Procopii Caesariensis Opera ommia, II, a c. di J. Haury - G. Wirth, Lipsiae 1962).

20 Ioannis Malalae Chronographia..., cit., XVIII, 34, p. 373.

21 Proc. Bell. Goth. III, 27, 20.

22 Theophylacti Simocattae Historiae, a c. di C. De Boor - P. Wirth, Lipsiae 1972, II, 6, g, Not. Dign., Or., XXXV, 24: praefectus legionis quartae Parthicae, Circesio (sub dispositione viri spectabilis ducis Osrhoenae). Per la smilitarizzazione dei limitanei in epoca giustinianea si ha la testimonianza di Proc. Hist. Arc. 24, 13-14 (Procopii Caesariensis Opera omnia, III, a c. di J. Haury - G. Wirth, Lipsiae 1963). 
campale, la vexillatio dei Tertio Dalmatae, che faceva parte delle truppe del magister militum dell'Oriente e che, per ordine di Giustiniano, fu messo a disposizione del governatore civile della regione ${ }^{23}$. Si tratta, in questo caso, di uno dei numerosi esempi di regionalizzazione delle forze dell'armata mobile, che è un fenomeno tipico del VI secolo ${ }^{24}$. In Palestina, oltre alla verosimile esistenza degli Arcadiani presenti a Cesarea nel 484-485 ${ }^{25}$, si ha notizia di un arithmos di Theodosiaci dislocato nel castrum di Nessana. Sono ricordati da un dossier costituito da diciassette papiri che coprono il periodo dal 504 al 596 , tutti di carattere privato e relativi a diverse operazioni economiche che coinvolgono i soldati della guarnigione ${ }^{26}$. La presenza di numerosi reparti teodosiani nella Notitia ne rende difficile l'identificazione certa con un'unità preesistente e si è pensato sia ai balistarii Theodosiaci dell'esercito campale di Oriente che a un reparto di limitanei non altrimenti noto, il cui nome potrebbe derivare dall'imperatore Teodosio II 27 .

Assai ricco è il panorama dell'Egitto a motivo, soprattutto, della conservazione di un buon numero di fonti papirologiche relative sia ad atti di natura privata che pubblica. Nella seconda metà del V secolo vi compaiono gli Armigeri, a Ossirinco nel 488, e gli Isauri, in cui militò il padre di S. Saba, attivi ad Alessandria dal 444/45 fino al 491; in un caso e nell'altro si tratta verosimilmente di reparti dell'esercito campale dell'Oriente, di cui il primo potrebbe essere in transito a differenza degli Isauri che, al contrario, paiono stanziati stabilmente ad Alessandria ${ }^{28}$. Ad Arsinoe sono presenti i Leones Clibanarii o Leontoclibanarii, una formazione di cavalleria corazzata posteriore alla Notitia, attestati dal 487 al 54629; i Transtigritani attivi nel 498, 508 e 531, una legio pseudocomitatensis del magister militum dell'Oriente ${ }^{30}$,

23 Ed. Iust. IV, 2, s. d. (535 o 536), cfr. Not. Dign., Or., VII, 27: equites tertio Dalmatae (sub dispositione viri illustris magistri militum per Orientem),

24 Jones, Il tardo impero..., cit., p. 900.

25 Hoffmann, Das spätrömische Bewegungsheer..., cit., p. 242.

${ }^{26}$ Excavations at Nessana, III, Non-literary papyri, a c. di C. J. Kraemer, Princeton 1958, nr. 14-30. Il nome del reparto è fornito dal pap. 15 .

27 Hoffmann, Das spätrömische Bewegungsheer..., cit., II, Düsseldorf 1970, p. 97 n. 335.

28 The Oxyrhynchus papyri, XVI, a. c. di B. P. Grenfell - A. S. Hunt - H. I. Bell, London 1924, nr. 1888: si tratta di un ordine del comes Phoebammon per il rifornimento dell'unità in transito, cfr. Not. Dign., Or., VII, 26: equites Armigeri seniores orientales, una vexillatio comitatensis del magister militum per Orientem; Cyrilli Vita S. Sabae, a c. di E. Schwartz, Kyrillos von Skythopolis, Leipzig 1939, I p. 87, IX p. 92, XXV p. 109, cfr. Not. Dign., Or., VII, 56: Prima Isaura sagittaria, una legio pseudocomitatensis ugualmente in forza all'esercito del magister militum per Orientem.

29 J. M. Diethart - P. Dintsis, Die Leontoklibanarier. Versuch einer archäologisch-papyrologischen Zusammenschau, in BYZANTIOS. Festschrift für Herbert Hunger zum 7o. Geburtstag, Wien 1984, p. 80 (pp. 67-84).

30 Jones, Il tardo impero..., cit., p. 901; Studien zur Palaeographie und Papyruskunde, a c. di G. Wessely, XX, nr. 131, a. 508; XX, nr. 139, a. 531 (prestito di denaro fra soldati dei Daci e dei Leones Clibanarii, di cui è testimone un soldato dei Transtigritani), cfr. Not. Dign., Or., VII, 58: Transtigritani. 
e un'altra legione palatina, i Daci, ricordata in precedenza ad Apamea e quindi con ogni probabilità trasferita in Italia ${ }^{31}$. Ad Ossirinco un frammento di papiro, che conserva una quietanza, ricorda la presenza di non meglio noti Salonitae ${ }^{32}$, mentre diverse testimonianze fanno riferimento agli equites Mauri Scutarii di Ermopoli in Tebaide, un reparto limitaneo ivi attestato dal 340 fino al $53^{33}$. Interessante in proposito è un documento latino del 505 che conserva la lettera inviata da dux di Tebaide al tribuno, comandante della vexillatio di Ermopoli, con l'ordine di includervi come recluta un tale Eracleona originario della stessa città: si tratta infatti, assieme a un altro papiro del 578, di una testimonianza sul sistema di arruolamento nel VI secolo $^{34}$. Questo reparto, a quanto pare, si dissolse tra la fine del 538 l'inizio dell'anno successivo, forse per confluire nei Numidae Iustiniani, la cui istituzione, chiaramente databile all'età giustinianea, potrebbe essere legata alla riorganizzazione amministrativa compiuta in Egitto nel 53935. Ad Antaiopoli sono attivi inoltre i Macedones, un'unità di limitanei apparentemente da identificare con una più antica stanziata altrove nel $\mathrm{V}$ secolo ${ }^{36}$, i Bis-Electi forse costituiti in Africa e in seguito spostati in Egitto ${ }^{37}$ e gli Schytae attesta-

${ }^{31}$ Studien zur Palaeographie..., cit., XX, nr. 139, cfr. Not. Dign., Or., VI, 43: Daci, legio palatina a disposizione del magister militum praesentalis. Per il trasferimento in Italia si veda più avanti n. 91.

32 Papiri greci e latini, III, a c. di G. Vitelli - M. Norsa e altri, Firenze 1914, nr. 247 («Pubblicazioni della Società Italiana per la ricerca dei papiri greci e latini in Egitto»).

33 J. Maspero, Organisation militaire de l'Égypte byzantine, Paris 1912, pp. 142-143 («Bibliothèque de l'École des Hautes Études», fasc. 201), cfr. Not. Dign., Or., XXXI, 23: cuneus equitum Maurorum scutariorum, Lico e 24: cuneus equitum scutariorum, Hermupoli (sub dispositione viri spectabilis ducis Thebaidos).

34 Catalogue of the Greek and Latin Papyri..., cit., nr. 609, cfr. per il 578 Byzantinische Papyri der Bayerischen Staatsbibliothek..., cit, nr. 2.

35 R. Rémondon, Soldats de Byzance d'après un papyrus trouvé à Edfou, in «Recherches de Papyrologie», I (1961), p. 82 (41-93). I Numidae Iustiniani, uno dei numerosi reparti che presero nome da Giustiniano, potrebbe essere stato costituito in Africa e quindi trasferito in Egitto verso il 539: cfr. D. Pringle, The defence of Bizantine Africa from Justinian to the Arab Conquest. An account of the military history and archaeology of the African provinces in the sixth and seventh centuries, Oxford 1981, p. 73. In Egitto i Numidae Iustiniani sono ricordati da P. Cairo, III, nr. 67321, a. 548 o 563 (ordine del praeses di Tebaide relativo all'annona dei Numidae Iustiniani di Ermopoli), cfr. i documenti analoghi in Greek Papyri in the British Museum..., cit., V, nr.1663 e Sammelbuch griechischen Urkunden aus Aegypten, V, a c. di F. Bilabel, Heidelberg 1934, nr. 8028.

36 P. Cairo, I, nr. 67002 (Catalogue général des antiquités égyptiennes du Musée du Caire, I, Papyrus grecs d'époque byzantine, a c. di J. Maspero, Le Caire 1911): richiesta del villaggio di Aphrodito al duca di Tebaide contro un pagarca, nr. 67005 (richiesta di una vedova al duca di Tebaide), cfr. Not. Dign., Or., XXVIII, 14: legio quinta Macedonica, Memfi (sub disposizione viri spectabilis comitis rei militaris per Aegyptum). La stessa unità potrebbe essere identificata nei Kyntanoi (Quintani) di un papiro del IV-V secolo: Papyri russischer und georgischer Sammlungen, III, a c. di G. Zereteli - P. Jernstedt, Tiflis 1930, nr. 10.

37 P. Cairo, I, nr. 67057 (bisilektoi), 67058, di guarnigione ad Antaiopoli qualche tempo dopo il 540. Il reggimento potrebbe essere stato costituito sotto Giustiniano in Africa, dove un nume- 
ti sia ad Antaiopoli che ad Apollonopolis Magna, ridenominati Schytae Iustiniani a seguito verosimilmente di una riorganizzazione nel quadro della riforma giustinianea della diocesi egiziana ${ }^{38}$. Anonimi sono infine i numeri di Siene, File ed Elefantina che a più riprese compaiono in un dossier papiraceo, ma potrebbe trattarsi delle antiche legio I Maximiana, dei milites Miliarenses e della cohors I Felix Theodosiana, reparti limitanei che la Notitia Dignitatum ci dice acquartierati nelle tre località nilotiche ${ }^{39}$.

La serie delle unità conosciute nel VI secolo prosegue in Libia con i Paratonitae Iustiniani, così detti dalla città di Paratonio, e i Libyes Iustiniani. La denominazione ne rende evidente l'istituzione, o quanto meno il rimaneggiamento, da parte di Giustiniano e in entrambi i casi dovrebbe trattarsi di nuovi reparti di comitatenses messi a disposizione del dux di Libia, quando il sovrano riorganizzò la provincia collocando a la sede del $d u x$ a Paratonio e subordinando l'autorità civile a questo governatore militare 40 . In Africa, dove dopo la vittoria sui Vandali venne ricostruito un esercito romano ${ }^{41}$, si hanno numerose fonti sui soldati di Bisanzio, ma sono tramandate soltanto le denominazioni dei Bis Electi di Hippo Regius in Proconsolare e dei Primi Felices Iustiniani a Rusguniae in Mauretania Caesariensis. Il primo reparto era probabilmente un'unità mobile di fanteria ed è ricordato dall'epigrafe funeraria di Maxentius, senator del numerus, che potrebbe risalire al 537 se si accetta la tesi secondo cui la stessa formazione si trasferì poco

rus di Electi esiste prima della conquista vandala, e in seguito trasferito in Egitto. In tal caso sarebbe un ulteriore esempio di mobilità delle unità comitatensi nel VI secolo: cfr. Pringle, The defence..., cit., p. 73 e Jones, Il tardo impero..., cit., p. 900.

38 The Oxyrhynchus papyri..., cit., XVI, nr. 1920, tardo VI secolo (distribuzione di razioni agli Schytae), 2046 (Schytae); P. Cairo, I, nr. 67002, 67009 (richieste al duca di Tebaide: Schytae), 67057 (conto finanziario dall'ufficio di Antaiopoli, probabilmente fra 554 e 559: Schytae Iustiniani); New Classical Fragments and other Greek and Latin Papyri, a c. di B. P. Grenfell A. S. Hunt, II, Oxford 1897, nr. 95 (Apollonopolis Magna: Schytae Iustiniani acquartierati nel monastero di Bayllos, VI-VII secolo), cfr. Not. Dign., Or., VI, 44: Schytae, legio palatina di un magister militum praesentalis.

39 Il dossier, costituito dalle carte di famiglia di Flavio Patermuthis figlio di Menas, soldato del castello di Elefantina, è pubblicato in Byzantinische Papyri der Bayerischen Staatsbibliothek..., cit, nr. 1-18. e in Greek Papyri in the British Museum..., cit., V, nr. 1719-1737 e comprende una serie di transazioni di cui sono parti o testimoni i soldati di Siene, File ed Elefantina: cfr. Jones, Il tardo impero..., cit., p. 902. Un solo documento ha carattere militare ed è la probatoria, o certificato di arruolamento, di Flavio Patermuthis, figlio di Dios, incorporato nel numerus di Elefantina nel 578. La legio I Maximiana di File compare in Not. Dign., Or., XXXI, 37, i milites Miliarenses di Siene in XXXI, 35 e la cohors prima felix Theodosiana di Elefantina in XXXI, 64. 40 Ed. Iust. XIII, 18, s.d. (a. 539). La qualifica di comitatenses pare evidente dal fatto che nell'editto si fa riferimento a tagmata di stratiotai messi a disposizione del governatore della provincia. Apparentemente si tratta di due soli numeri, ma potrebbe forse anche essere una denominazione collettiva per indicare reggimenti diversi: cfr. Maspero, Organisation militare..., cit., p. 148. L'istituzione di presidi a Paratonio ad opera di Giustiniano è ricordata anche in Proc. de aed., VI, 2, 2.

${ }^{41}$ Cod. Iust. I, 27, 2, 8, a. 534. 
più tardi in Egitto ${ }^{42}$. I Primi felices Iustiniani, un altro reggimento istituito sotto Giustiniano, sono ugualmente noti attraverso un'epigrafe funeraria non datata, questa volta del tribuno comandante dell'unità morto in servizio dopo dodici anni che esercitava il comando ${ }^{43}$. Ancora all'Africa, in rapporto all'amministrazione del tempo, va infine ricondotto un probabile numerus dromonariorum di stanza a Cagliari, un'unità della marina imperiale nota attraverso un epitaffio di lettura incerta 44 .

L'Italia offre come l'Egitto un buon numero di testimonianze tramandate da fonti di diversa natura e relative a unità acquartierate nelle regioni del nord e del centro fino a Roma. Si tratta sia di reparti provenienti dall'Oriente, a volte identificabili nelle liste della Notitia, sia di altri di evidente formazione locale, le cui denominazioni derivano per lo più dalle città in cui erano di presidio. L'epoca della guerra gotica ci fa conoscere con i sicurezza tre diversi reggimenti: i Regii, i Primi Theodosiani e i Perso-Iustiniani. I Regii erano in azione durante l'assedio goto di Roma, nel 537 e qui al comando di Ursicino difesero la porta Flaminia. Si tratta di un reparto di fanteria e non paiono esservi dubbi sull'identificazione con i Regii della Notitia Dignitatum, un auxilium palatinum incorporato nell'armata di Belisario quando questi nel 535 intraprese la campagna in Italia ${ }^{45}$. I Primi Theodosiani compaiono nel 547 Firenze dove fu sepolto Macrobis primicerius primi Theodosianorum numeri e anche in questo caso è plausibile l'identificazione con l'auxilium palatinum dei Primi Theodosiani o anche con gli equites primi Theodosiani attestati nella Notitia ${ }^{46}$. Non è possibile però stabilire l'esatta cronologia dell'arrivo in Italia, dato che l'armata bizantina fu rinforzata a varie riprese prima del $547^{47}$, ma è probabile che come i Regii abbiano fatto parte del primo corpo di spedizione inviato da Costantinopoli. Più chiare sono le infor-

42 Pringle, The defence..., cit., pp. 332-333 nr. 43 (con una datazione che oscilla dal VI al VII secolo e l'indicazione delle altre edizioni dell'epigrafe). Per la presenza in Egitto si veda qui n. 37. Il senator era un sottufficiale anziano presente nelle scholae, negli operai militarizzati delle fabbriche di armi ( i fabricenses) e nella fanteria: cfr. Grosse, Römische Militärgeschichte..., cit, pp. 119-120 e qui n. 10.

43 Pringle, The defence..., cit., p. 333 nr. 45.

44 S. Cosentino, Gaudiosus «draconarius». La Sardegna bizantina attraverso un epitafio del secolo VI, Bologna 1994, p. 29.

45 Proc. Bell. Goth. I, 23, 3 (un pezikon telos), cfr. Not. Dign., Or., VI, 49: Regii fra le truppe di uno dei magistri militum praesentales. Ursicino, probabilmente un tribuno, sbarcò in Sicilia con Belisario nel 535 al comando di reparti di fanteria (Proc. Bell. Goth. I, 5, 3).

46 Corpus Inscr. Lat. XI, 1, 1693; Inscriptiones latinae christianae veteres, I, a c. di E. Diehl, Berolini 1925, nr. 486; Inscr. Lat. sel., I, nr. 2806, cfr. Not. Dign. V, 64 (un auxilium palatinum di un magister militum praesentalis), VIII, 27 (una vexillatio comitatensis del magister militum per Thracias). Il primicerius era il grado più elevato dei sottufficiali, cfr. Grosse, Römische Militärgeschichte..., cit., p. 122 e qui n. 10.

47 A. Pertusi, Ordinamenti militari, guerre in Occidente e teorie di guerra dei Bizantini (secc. VI$X$ ), in Ordinamenti militari in Occidente nell'alto Medioevo, II, Spoleto 1968, p. 636 (631-700). 
mazioni sui Persoiustiniani, un'unità di cavalleria formata con prigionieri persiani catturati da Belisario nel 541 e trasferita in Italia dove operò subito dopo a Verona al comando dell'armeno Artabaze ${ }^{48}$. In seguito se ne perdono le tracce, ma è verosimile che abbia seguito il suo comandante fino a Faenza dove questi morì in combattimento; la ritroviamo però alcuni anni più tardi acquartierata a Grado ${ }^{49}$. Si tratta almeno inizialmente di un reggimento composto da ottocento uomini, forse un altro esempio di numerus con una forza eccedente i limiti normali50.

Altre unità sono attestate per l'età successiva alla guerra gotica o, comunque, non risultano di datazione sicura come le tre precedenti. A Trieste potrebbe essere esistito già dal VI secolo un numerus Tergestinus, che si conosce soltanto in epoca molto più tarda ${ }^{51}$, mentre in prossimità di Aquileia doveva essere stanziato un numerus Saliorum riconducibile probabilmente a un'unità più antica ${ }^{52}$. Per la vicina Grado, al contrario, si hanno notizie certe sulla presenza di almeno tre reparti imperiali, il numerus equitum Persoiustiniani, il numerus Cadisianus e il numerus Tarvisianus. Del primo si è già osservata l'origine e la successiva presenza nel castrum di Grado, in cui si rifugiarono i profughi di Aquileia al momento dell'invasione longobarda53. Al tempo della costruzione della basilica di S. Eufemia, che venne dedicata nel 579, un soldato dei Persoiustiniani di nome Giovanni contribuì alla realizzazione del pavimento musivo ${ }^{54}$. A parecchi anni di distanza dal trasfe-

48 Proc. Bell. Pers. II, 19, 25; Bell. Goth. III, 3, 11.

49 S. Cosentino, Prosopografia dell'Italia bizantina (493-804), I, Bologna 1996, pp. 180181(Artabaze). Per la successiva presenza a Grado si veda più avanti n. 54 .

$5^{0}$ La forza di ottocento uomini è data da Proc. Hist. Arc. 2, 28 ed è relativa al momento della cattura in Persia.

${ }^{1}$ Il numerus Tergestinus è attestato soltanto dal placito di Risano dell'804 ed è difficile dire se si tratta del nome di un'antica unità bizantina o, piuttosto, l'indicazione generica del complesso degli abitanti di Trieste secondo il significato assunto dal termine numerus in tarda epoca esarcale: Documenti relativi alla storia di Venezia anteriori al Mille, I, a c. di R. Cessi, Padova 1991, p. 63 e, per l'evoluzione del significato di numerus, V. von Falkenhausen, L'esarcato d'Italia (VIVIII secolo), in I Bizantini in Italia, Milano 1982, p. 32.

52 Corp. Inscr. Lat. VI, 2, 8280; Inscriptiones latinae christianae..., cit., I, nr. 560 (iscrizione ritenuta di Aquileia e in seguito scomparsa, cfr. ibid., IV, Supplementum, a c. di J. Moreau - A. I Marrou, Berlin 1967, p. 508): «Paulus v(ir) r(eligiosus?) serbus et milex de num(ero) Zal(iorum)» da leggersi probabilmente Saliorum, cfr. Cosentino, Prosopografia..., cit., p. 65 n. 290. L'identificazione possibile è con i Salii di Not. Dign., Or., V, 51, un auxilium palatinum di un magister militum praesentalis di Costantinopoli, ma non si hanno elementi per stabilire la datazione dell'epigrafe, che è comunque anteriore al 568/569 quando la città fu presa dai Longobardi.

53 Paolo Diacono, Storia dei Longobardi, a c. di L. Capo, Milano 1992, II, 10, p. 88.

54 Corp. Inscr. Lat. V, 1, 1591; Inscriptiones latinae christianae..., cit., I, nr. 558; Inscr. Lat. sel., I, nr. 2810; Rugo, Le iscrizioni..., cit., II, nr. 56a: «[Io]hannis [mil]es de nu[me]ro equit(um) [pe]rsoiustiniani votum solvit»; J.P. Caillet, L'évergétisme monumental chrétien en Italie et à ses marges d'après l'épigraphie des pavements de mosä̈que (IV -VII $^{e}$ s.), Roma 1993 (Collection de l'École française de Rome, 175), p. 239, cfr. D. Hoffmann, Der "numerus equitum Persoiustinianorum" auf einer Mosaikinschrift von Sant'Eufemia in Grado, in "Aquileia 
rimento in Italia la componente etnica originaria doveva essere esaurita, come d'altronde prova anche il nome dell'offerente, ed è verosimile inoltre che questi soldati, forse allo stesso modo dei Cadisiani, abbiano ripiegato su Grado dalla terraferma quando arrivarono i Longobardi. Il numerus Cadisianus è ugualmente attestato da un'epigrafe di offerenti nella basilica di S. Eufemia, in cui il miles Giovanni e la moglie Severina fecero eseguire venticinque piedi di pavimento ${ }^{55}$. Null'altro si conosce in questo caso, ma la denominazione del reparto fa chiaramente pensare a un'unità costituita con prigionieri di guerra, tenendo conto che i Cadiseni erano una popolazione soggetta ai Persiani. La sanguinosa sconfitta da questi subita ad opera dei Bizantini alla battaglia di Dara, nel 530, spinge inoltre a ritenere che siano stati catturati in tale occasione e, in seguito, impiegati in Italia ${ }^{56}$. In un caso e nell'altro si tratta di reparti trasferiti dall'Oriente, a differenza del numerus Tarvisianus, un'unità di cavalleria di cui è evidente l'origine locale connessa alla città di Treviso. Ci è nota attraverso tre iscrizioni musive, di cui le prime due conservate nella chiesa di S. Maria e la terza in quella di S. Eufemia. Nella prima è ricordato l'offerta votiva di una imprecisata porzione di pavimento da parte di Zimarcus primicerius nomini (= numeri) Tarbisiani, mentre la seconda fa riferimento a un'analoga oblazione da parte di Stefano, milis numeri Tarbisiani appartenente alla turma di Giustino ${ }^{57}$. Più dettagliata, da questo punto di vista, è infine l'iscrizione nella navata settentrionale di $\mathrm{S}$. Eufemia con il ricordo di Laurentius figlio di Domno, soldato dello stesso reparto, offerente di venticinque piedi di pavimento ${ }^{58}$. I Goti di Treviso fecero atto di sottomissione a Belisario nel 540, ma se anche i Bizantini ne presero possesso, la città tornò presto nelle loro mani per restarvi probabilmente fino almeno al 556 quando Narsete conquistò il nord Italia ${ }^{59}$. La costituzione

Nostra» XXXII-XXXIII (1961-1962), cc. 81-96.

55 Corp. Inscr. Lat. V, 1, 1590; Inscriptiones latinae christianae..., cit., I, nr. 546; Inscr. Lat. sel., I, nr. 2808; Rugo, Le iscrizioni..., cit. II, nr. 56c; Caillet, L'évergétisme monumental..., cit., pp. 240241. Sui Cadiseni cfr: G. Greatrex, Rome and Persia at war, 502-532, Leeds 1998, p. 181.

56 Proc. Bell. Pers. I, 14, 38-41.

57 Corp. Inscr. Lat. V, I, 1614 (solo l'epigrafe di Zimarco); Inscriptiones latinae christianae..., cit., I, nr. 488; Rugo, Le iscrizioni..., cit., II, nr. 64; Caillet, L'évergétisme monumental..., cit., pp. 210-211. Il termine turma, in epoca tardo antica, è una denominazione generica dei reparti di cavalleria (Grosse, Römische Militärgeschichte..., cit., p. 48) e, in questo caso, Giustino potrebbe essere il tribuno comandante dell'unità.

58 Corp. Inscr. Lat. V, 1, 1593; Inscriptiones latinae christianae..., cit., I, nr. 559; Inscr. Lat. sel., I, nr. 2809; Caillet, L'évergétisme monumental..., cit., p.244; Rugo, Le iscrizioni..., cit., II, nr. 50-51: «Laurent(ius mi)lis de n(umero) Tarvis(iano et) filius (Dom)ni fec(it pedes XXV)».

59 Proc. Bell. Goth. II, 29, 40 (resa di Treviso); III, 1, 35 (sconfitta bizantina nei pressi della città); III, 2, 7-9, 11 (Totila al comando del presidio goto di Treviso). Negli anni che seguirono le regioni del nord restarono spartite fra Bizantini, Franchi e Goti e i primi possedevano soltanto le località costiere del Veneto (ibid., IV, 24, 6-9). La data del 556 per la riconquista bizantina è indicata da Marii episcopi Aventicensis Chronica a. CCCCLV-DLXXXI, a c. di Th. Mommsen, in 
dei Tarvisiani, di conseguenza, è circoscrivibile in questi anni e va collocata nel quadro della riorganizzazione politico-militare della provincia operata da Narsete. Anche in questo caso lo spostamento a Grado dovrebbe essere legato all'invasione longobarda, cioè al 568 o 569, e se ne ha verosimilmente una prova indiretta sulla base di quanto scrive Paolo Diacono, secondo il quale il vescovo di Treviso offrì la resa della città al re Alboino ottenendo garanzie per la sua chiesa ${ }^{60}$. Al di là del racconto, necessariamente generico, si può intravedere una resa della città concordata come in altre occasioni con il presidio imperiale e che implicava per questo la facoltà di ripiegare indenne fino a Grado, dove i Tarvisiani fissarono i loro nuovi quartieri ${ }^{6}$. Ancora all'antica provincia di Venetia et Histria riporta infine una testimonianza controversa fornita da un'epigrafe greca conservata in una chiesetta di Lison di Portogruaro edificata nel 1565 . Si tratta di un'iscrizione votiva con il nome di Stefano sinator scholes armatouron, datata normalmente al VI o VII secolo, che pare attestare la presenza nel territorio di Concordia di una schola palatina $^{62}$. La testimonianza va tuttavia accolta con cautela sia per motivi storico-artistici, non essendo nota la provenienza dell'arcata marmorea su cui si legge l'iscrizione, sia per il riferimento implicito all'impiego delle scholae come truppe combattenti, in contrasto con la prassi attestata da alcune fonti per il VI secolo. Le scholae palatinae nel tardo impero esistevano sia in Occidente che in Oriente; i reparti occidentali vennero formalmente mantenuti da Teodorico, che concesse ai soldati di trasmettere in eredità sia lo stipendio che il titolo ${ }^{63}$, mentre quelli di Costantinopoli continuarono a essere regolarmente reclutati. Al tempo in cui fu redatta la Notitia Dignitatum le scholae orientali comprendevano sette reggimenti, il primo e secondo Scutarii, gli Scutarii Sagittarii e Clibanarii, i Seniores e gli Iuniores Gentiles e gli Iuniores Armaturae ${ }^{64}$, che restarono tali fino all'inizio del regno di

Mon. Germ. Hist., Auct. Antiq., XI, 2 (Chronica minora saec. IV.V.VI.VII), Berolini 1894, p. 237, a. 556: «Eo anno exercitus rei publicae resumptis viribus partem Italiae, quam Theudebertus rex adquisierat, occupavit».

60 Paolo Diacono, Storia dei Longobardi..., cit., II, 12, p. 90.

61 Altri esempi di resa con i soldati di presidio: ibid. III, 27, p. 158 (insula Comacina), IV, 23, p. 200 (Padova); IV, 28, p. 204 (Mantova).

62 Inscr. Lat. Sel., II, nr. 8883; B. Forlati Tamaro, Iscrizioni di orientali nella zona di Concordia, in Aquileia e l'Oriente mediterraneo, I, Udine 1977, p. 391 ("Antichità altoadriatiche», XII); ead., in AA. VV., Iulia Concordia dall'età romana all'età moderna, Treviso $1978^{2}$, pp. 180-181; ead., Un cimelio di Lison di Portogruaro, in «Aquileia Nostra», XLIX (1978), cc.161-180; ead., in Da Aquileia a Venezia, Milano 1980, pp. 87-88; M. Guarducci, Epigrafia greca, IV, Roma 1978, pp. 510-512; M. Bonfioli, Tre arcate marmoree protobizantine a Lison di Portogruaro, Ricuperi bizantini in Italia, I, Roma 1979, pp. 25, 31-42; A. Carile, Materiali di storia bizantina, Bologna 1994, p. 271.

63 Proc. Hist. Arc., 26, 27-28.

64 Not. Dign., Or., XI, 3-10. 
Giustino I quando vennero arruolati altri quattro reggimenti soprannumerari, sciolti però qualche anno dopo da Giustiniano ${ }^{65}$. Secondo Procopio e Agazia gli scholares avevano perso le loro qualità marziali già dal V secolo e venivano usati soltanto come truppe da parata, tant'è che Giustiniano sarebbe riuscito a farli rinunciare allo stipendio con la minaccia di inviarli al fronte 6 . Le loro testimonianze sono tuttavia contraddette da altre fonti, che implicano chiaramente un impiego operativo degli scholares ancora nel VI secolo rendendone quindi plausibile la presenza in Italia. Nel caso di Concordia, l'iscrizione greca e il nome orientale del soldato suggeriscono l'invio di una schola da Costantinopoli e si può forse pensare al tempo di Tiberio II che, a corto di truppe, nel 579 rispose alla richiesta di aiuto del senato romano trasferendo in Italia alcuni reparti «che aveva a disposizione» 67 , un'indicazione generica forse relativa a reggimenti della guardia imperiale.

Nel territorio ravennate è presente un buon numero di reparti imperiali. A Classe, nel 591, Giovanni adorator del numerus felicum Ravennatum comprò terre in territorio riminese dalla dama italica Rusticiana e dal marito di questa Tzittane, o Zittane, soldato del numerus felicum Persoarminorum 68 . $\mathrm{Si}$ tratta quindi, a giudicare dalle denominazioni, di un reggimento costituito localmente e di un secondo formato in Persarmenia, verosimilmente dopo la caduta definitiva della regione in mano bizantina nel $571^{69}$. Il primo di questi, forse, corrisponde ai Ravennenses attestati in Egitto nel 568 insieme a reparti di Goti, probabilmente bucellarii, agli ordini del patrizio Atanasio duca di Tebaide ${ }^{70}$. Verso l'anno 600 risultano acquartierati a Ravenna il numerus victricium Mediolanensium, di cui un optio di nome Adquisitus fece da testimone per un atto di donazione di terre ${ }^{71}$, e il numerus

65 Proc. Hist. Arc., 24, 18-20.

66 Ibid., 24, 15-21; Agathiae Myrinaei Historiarum libri quinque, a c. di R. Keydell, Berolini 1967, V, 15, 4. Per l'impiego delle scholae come truppe combattenti cfr. Ravegnani, Soldati di Bisanzio..., cit., p. 97 e la testimonianza di Ioannis Malalae Chronographia..., cit, XVIII, 129, 132, pp. 421, 423 relativa a scholai trasferite in Tracia dall'Asia Minore.

67 Menandri Protectoris Fragmenta, a c. di L. Dindorf, in Historici Graeci Minores, II, Lipsiae 1871, p. 121.

68 Pap. Ital. II, nr. 37, 10 marzo 591 (J. O. Tjäder, Die nichtliterarischen lateinischen Papyri Italiens aus der Zeit 445-70o, II, Papyri 29-59, Stokholm 1982). I Ravennates sono poi attestati da un primicerius num(eri) Rav(ennatis) dal Pap. Ital. I, nr. 23, forse databile all'anno 700 ca. (J. O. Tjäder, Die nichtliterarischen lateinischen Papyri Italiens aus der Zeit 445-70o, I, Papyri 1-28, Lund 1955). Il rango di adorator, frequente nel VI secolo, indica i soldati che avevano ricevuto il grado onorifico di protector (Jones, Il tardo impero..., cit., p. 897) e il nome del soldato Tzittane, variamente scritto nel papiro, è di origine armena (ibid., p. 899) piuttosto che gotica come in Martindale, The prosopography, cit., p. 1348.

69 Hoffmann, Der "numerus equitum Persoiustinianorum"..., cit., c. 90.

70 Papiri greci e latini..., cit., VIII, Firenze 1927, nr. 953, 35, cfr. Rémondon, Soldats de Byzance..., cit., pp. 87-88.

${ }^{71}$ P. Ital. I, nr. 20, a. 600 ca. (590-602?), 76: «Adquisitus, opt(io) num(eri) vict(ricium) 
Theodosiacus, rappresentato dal primicerius Giovanni che donò parte dei suoi beni alla chiesa ravennate e dall'adorator Teodato testimone in una donazione ${ }^{72}$. Per il primo è facilmente da ipotizzare un'originaria formazione a Milano, nel quadro della ricostruzione operata da Narsete, e un successivo trasferimento a Ravenna al momento della caduta della città (3 sett. 569), mentre per i Theodosiaci è possibile l'identificazione con i Theodosiaci attestati a Roma nel 592 e, forse, con un'unità della Notitia ${ }^{73}$. Nel 639 compare un numerus Armeniorum con un soldato di nome Paulacis che fece dono di terre alla chiesa di Ravenna, ma dovrebbe trattarsi di un'unità già da tempo in Italia, forse acquartierata a Padova, e comunque già presente nelle liste della Notitia Dignitatum ${ }^{74}$. Seguono quindi i Veronenses, verosimilmente istituiti da Narsete e ripiegati nel 569 da Verona ${ }^{75}$, i felices Laeti stanziati nel

Mediol(anensium)» e 122: «Adquisitus v(ir) c(larissimus), optio numeri Mediol(anensium). L'optio era un sottufficiale addetto all'approvvigionamento delle truppe: Ravegnani, Soldati di Bisanzio..., cit, p. 35.

72 Pap. Ital. I, nr. 16, forse dell'anno 600 ca.: Giovanni primicerio del numerus felicum Theodosiacus, già spatharius del magister militum Giorgio; I, nr. 17, prob. di inizio VII secolo: Theodatus adorator del numerus Theodosiacus.

73 Not. Dign., Or., VI, 33: la vexillatio palatina degli equites Theodosiaci seniores (un reparto di un magister militum praesentalis). Altre ipotesi suggeriscono una derivazione del nome dagli imperatori Teodosio I, Teodosio II o anche da Teodosio, figlio di Maurizio e da lui associato al trono (P. Goubert, Byzance avant l'Islam, I, Byzance et l'Orient sous les successeurs de Justinien. L'empereur Maurice, Paris 1951, p. 68 n. 311). Assai improbabile è però il legame con la città di Theodosia del Chersoneso Tracico, a est della penisola di Crimea, suggerita da A. Guillou, Régionalisme et indépendance dans l'Empire byzantin au VII siècle, Roma 1969, pp. 153-154. Per i Theodosiaci a Roma cfr. più avanti n. 85 .

74 P. Ital. I, nr. 22, novembre 639: Paulacis miles numeri Arminiorum figlio del quondam Stefano primicerio dei Veronenses (cfr. n. seguente) e, nello stesso documento, Theodoracis ex scriba della stessa unità. Un numerus Armeniacus compare in un falso documento redatto a Padova nell'XI secolo, secondo cui nel 673 un domesticus di nome Barbato avrebbe fatto da testimone per una donazione al monastero di S. Giustina (Codice diplomatico padovano dal secolo sesto a tutto l'undecimo, a. c. di A. Gloria, Venezia 1877, p. 3 «Monumenti storici pubblicati dalla Deputazione di storia patria, s. I, Documenti II», e, per l'inattendibilità del testo, Guillou, Régionalisme..., cit., pp. 283-290. La redazione a Padova del documento potrebbe tuttavia ricordare la presenza del numerus Armeniorum, tenendo conto anche del fatto che nel 601 i soldati di presidio ripiegarono a Ravenna: «Milites tamen qui in ea fuerunt Ravennam remeare permissi sunt» (Paolo Diacono, Storia dei Longobardi..., cit., IV, 23, p. 200). Il numerus Armeniorum di Ravenna ricompare in Pap. Ital. I, 23, prob. a. 700 ca. ed è possibile l'identificazione con i comites sagittarii Armeni di Not. Dign., Or., VI, 31, una vexillatio palatina di Costantinopoli, cfr. Jones, Il tardo impero..., cit., II, p. 1135 n. 111 e Hoffmann, Das spätrömische Bewegungsheer..., cit., II, p. 100 n. 404.

75 P. Ital. I, nr. 22, nov. 639, 3-4: donazione «facta a Pau[la]cine v(iro) d(evoto), milite numer(i) Arminiorum, filium [q(uon)d(am)] [St]efani primicer[ii numer(i)] Veronensiu[m]»: Verona fu conquistata da Narsete nel 561-562 (Ioannis Malalae Chronographia..., cit., XVIII, 140, p. 425; Theophanis Chronographia..., cit., p. 237; Agnelli Liber Pontificalis ecclesiae Ravennatis, a. c. di O. Holder Egger, in Mon. Germ. Hist., SS. Lang. et Ital., Hannoverae 1878, c. 79) e divenne longobarda nel 568-569 Paolo Diacono, Storia dei Longobardi..., cit., II, 14, p. 94). Secondo T. S. Brown, Gentlemen and Officers. Imperial Administration and Aristocratic Power in 
591 a Genova e altri reparti di successiva costituzione ricordati da fonti più $\operatorname{tarde}^{76}$. I Laeti sono l'unità meglio attestata dalle fonti esarcali e il loro nome veniva verosimilmente dai discendenti dei laeti stanziati in Italia fra cui erano stati reclutati. Venivano così denominate le colonie militari barbariche insediate nel territorio dell'impero romano e, nel caso specifico, potrebbe trattarsi di Alamanni e dei Taifali stanziati in Emilia nel IV secolo ${ }^{77}$. Dovevano essere un reparto di fanteria e li troviamo per la prima volta a Genova nel 591 attraverso l'epigrafe funeraria del soldato Magnus ${ }^{78}$ e nel VII secolo a Ravenna, dove vennero verosimilmente trasferiti intorno al 640 a seguito della caduta della Liguria bizantina in mano longobarda ${ }^{79}$. Fra VI e VII secolo sono inoltre presenti a Ravenna due scholae, la schola armaturae rappresentata da Costanzo vir devotus testimone per una donazione alla chiesa ravennate e la schola Gentilium, di cui un anonimo componente fu ugualmente testimone in una donazione ${ }^{80}$. Difficile dire però se si tratti di reparti della guardia provenienti dall'Oriente, di cui il primo potrebbe anche essere lo stesso di Concordia, o più semplicemente di discendenti di scholares occidentali che si fregiavano per concessione ereditaria del titolo di appartenenti agli antichi reparti della guardia81. Il quadro delle unità dell'a-

Byzantine Italy A. D. 554-80o, Roma 1984, p. 86 Mediolanenses, Tarvisiani e Veronenses sarebbero reggimenti reclutati fra i profughi dalle città prese dai Longobardi.

76 Agnello Ravennate ricorda l'esistenza di undici reggimenti (banda) in cui fu divisa nel 710 la popolazione di Ravenna per far fronte a Giustiniano II: «Unusquisque miles secundum suam militiam et numerum incedat, id est: Ravenna, Bandus Primus, Bandus Secundus, Bandus Novus, Invictus, Constantinopolitanus, Firmens, Laetus, Mediolanensi, Veronense, Classensis...Et haec ordinatio permanet usque in praesentem diem». (Agnelli Liber Pontificalis..., cit, 140). Sui nuovi reparti ravennati cfr. anche J. O. Tjäder, Il nuovo papiro ravennate dell'VIII secolo a Belluno e il papiro Marini CXI (Introduzione e Parte I), in «Bullettino dell'Archivio Paleografico Italiano», n. s. II-III (1956-1957), pp. 343-356.

77 Guillou, Régionalisme..., cit., p. 154.

78 Corp. Inscr. Lat. V, 2, 7771: mil. nome. elicileto (= miles numeri felicium Letorum, ma con la lettura erronea Illyricianorum); Inscriptiones latinae christianae..., cit., I, nr. 550. La costituzione del numerus a Genova si deve forse all'iniziativa degli esuli milanesi: cfr. S. Origone, Bisanzio e Genova, Genova $1997^{2}$, p. 24.

79 P. Ital. II, nr. 37, a. 591 Giovanni adorator dei Ravennates «qui nunc milex numeri felicum Lectum» (sembra attestare che l'adorator Giovanni è in via di trasferimento nei Laeti piuttosto che la presenza di questi ultimi a Classe dove è redatto il documento); ibid. I, nr. 24, Ravenna metà VII secolo, 1: «dom(esticus) num(eri) fel(icum) let(orum)», 21: «dom(esticus) num(eri) fel(icum) leton(um) », cfr. anche ll. 46 e 47; I papiri diplomatici raccolti ed illustrati dall'abate Gaetano Marini, Roma 1805 nr. 109, fine VII secolo, cfr. J.-O. Tjäder, Papiri ravennati, o probabilmente o possibilmente ravennati, dei secoli V-VII scomparsi, in Studi in memoria di Giuseppe Bovini, II, Ravenna 1989, pp. 669-670 (659-681), con la probabile lettura: «dom(esticus) num(eri) ped(itum) l(etorum)»; Cosentino, Prosopografia..., cit., I, p. 315, 3 marzo 767: un tribuno dei Laeti testimone di un atto di donazione.

80 Pap. Ital. I, 27, forse della metà del VI secolo (scola armaturae) e I, 24, metà VII secolo (scola Gentilium).

${ }^{81}$ Le scholae occidentali nel V secolo comprendevano cinque reggimenti: il primo, secondo e 
rea esarcale, infine, può essere completato con la menzione degli Argentenses, la cui creazione dovrebbe risalire ai primi anni del VII secolo e di cui un primicerius di nome Giovanni nel 639 fece da testimone per una donazione alla chiesa ravennate ${ }^{82}$.

A Rimini era probabilmente attiva fin dal VI secolo un'unità di Ariminenses $^{83}$, sebbene se ne abbia notizia molto più tardi, e lo stesso valeva forse per Civitavecchia con l'esistenza già dal VI secolo di un numerus Centumcellensis, conosciuto come tale soltanto nell'VIII secolo ${ }^{84}$. Le ultime unità dell'Italia esarcale sono infine attestate a Roma. Qui, nel 592, l'unico reparto presente pare essere stato il già ricordato numerus Theodosiacus, di cui parla S. Gregorio Magno in una lettera a Giovanni arcivescovo di Ravenna, lamentando che a fatica si adattavano a far la guardia alle mura, a causa del lungo ritardo dello stipendio che ne aveva minato il morale 85 . Lo stesso reggimento è poi ricordato da un'epigrafe funeraria non datata di Vitaliano primicerius et autenta fatta eseguire dalla moglie Pascasia ${ }^{86}$ e non molto più tardi, come si è visto, sembra essersi trasferito a Ravenna. L'esistenza dei soli Theodosiaci a Roma deve essere stato un fatto occasionale, perché altre fonti ci mostrano a cavallo fra VI e VII secolo la presenza di un numerus Sermisianus, un numerus devotus e un numerus Dacorum. Verso l'inizio del VII secolo, infatti, un optio dei Sermisiani, di nome Giorgio, fece da testimone per una donazione e, intorno alla stesso periodo, un altro optio, di nome Domnicis, fu ugualmente testimone per la cessione alla chiesa ravennate di terre nel territorio di

terzo Scutarii, i Seniores Gentiles e i Seniores Armaturae: cfr. Not. Dign., Occ., IX, 3-8.

82 P. Ital. nr. 22, nov. 639. Il nome dell'unità viene dal castrum di Argenta, la cui fondazione è comunemente attribuita agli inizi del VII secolo: G. P. Brogiolo - S. Gelichi, Nuove ricerche sui castelli altomedievali in Italia settentrionale, Firenze 1996, p. 57. Assai improbabile al contrario è il legame con l'antica Argentina (nella regione di Srebrnica nell'est della Bosnia) in Guillou, Régionalisme..., cit., p. 156, cfr. anche Brown, Gentlemen..., cit, p. 90 n. 18.

83 Il numerus Ariminensium è attestato per la prima volta fra fine VII e inizio VIII secolo: Breviarium Ecclesiae Ravennatis (Codice Bavaro), a c. di G. Rabotti e altri, Roma 1985, nr. 64 («Fonti per la storia d'Italia», 110), ma in una lettera di S. Gregorio Magno del luglio 591 si fa riferimento alla presenza di un dux imperiale a Rimini, per cui si può pensare che il reparto già esistesse a quella data (Gregorii I Papae Registrum epistolarum, a c. di P. Ewald - L. M. Hartmann, in Mon. Germ. Hist., Epp., I, Berolini 1887, I, 56).

84 La prima menzione del numerus Centumcellensis è del 767 (I. Giorgi - I. Balzani, Il regesto di Farfa di Gregorio di Catino, II, Roma 1879, nr. 41), ma l'esistenza di un tribunus et comes già nel 590 può farlo supporre attivo già nel VI secolo (Gregorii I Papae Registrum epistolarum..., cit., I, 13, dicembre 590).

85 Ibid. II, 45, luglio 592: «Theodosiaci vero, qui hic remanserunt, rogam non accipientes vix ad muorum quidem custodiam se accommodant».

86 Corp. Inscr. lat. VI, 32970; Inscriptiones latinae christianae..., cit., I, nr. 131. L'aut(h)enta (da authentes) era un ufficiale subalterno che svolgeva le funzioni di comandante del reparto: E. Ch. Babut, Recherces sur la garde impériale et sur le corps d'officiers de l'armée romaine aux $I V^{e}$ et $V^{e}$ siècles, in «Revue historique» 114 (1913), p. 260 n. 3. 
Gubbio ${ }^{87}$. Incerta è la provenienza di questo numerus e si è variamente pensato a Sirmium sul Danubio, a Zarmisia o Sarmisia che sarebbero stati altri nomi di Sarmizegethusa (Ulpia Traiana) o anche Sermitium in Liguria ${ }^{88}$. L'ipotesi più probabile è tuttavia che si connetta a Sirmium, da dove probabilmente l'unità raggiunse l'Italia quando nel 580 la città cadde in mano agli Avari89. Il numerus devotus è ricordato da un'epigrafe funeraria di Totila milix de numero devoto, mutila e non databile ma che dovrebbe risalire alla seconda metà del VI secolo 90 . Di questo reparto non si hanno particolari elementi di identificazione, se non che il miles Totila sembra essere stato un germano e che il nome dell'unità si connette al titolo di vir devotus, abitualmente attribuito ai soldati. I Daci devono la loro notorietà a un papiro forse di inizio VII secolo con la menzione di Giovanni domesticus numeri Dacorum testimone di un atto di donazione fatto a Roma dal greco Stefano ${ }^{91}$. Se, come è probabile, si tratta dello stesso reggimento presente in Egitto nel VI secolo, è una testimonianza in più sulla mobilità delle truppe comitatensi, da ricollegare alle grandi guerre del tempo, che richiedevano un continuo afflusso di truppe.

87 P. Ital. I, 17, Roma, prob. di inizio VII, 27: «Georgius, opt(io) num(eri) mil(itum) Sermisiani»; 18-19, prob. inizio VII, 53, 66: «optio numer(i) Sermi[si(ani)]».

88 Ibid., p. 455.

89 Brown, Gentlemen..., cit, p. 90; Theophylacti Simocattae Historiae..., cit., I, 3, 3 (caduta di Sirmio).

90 Corp. Inscr. Lat. VI, 2, 32967; Inscriptiones latinae christianae..., cit., I, nr. 529. L'iscrizione sembra datare al 561 ca., cfr. ibid., IV, Supplementum..., cit., p. 508: XX [...p.c. Basili].

91 P. Ital. I, 18-19, Roma prob. inizio VII, 29: Iohannes, dom(esticus) num(eri) Dac(orum). Il domesticus era il più alto subalterno di un ufficiale: cfr. Grosse, Römische Militärgeschichte..., cit., pp. 120-121. 


\section{Bibliografia}

AA. VV., Iulia Concordia dall'età romana all'età moderna, II, Treviso 1978

Aussaresses F., L'armée byzantine à la fin $d u V^{e}$ siècle d'après le «Strategicon» de l'empereur Maurice, Bordeaux 1909

Babut Ch., Recherces sur la garde impériale et sur le corps d'officiers de l'armée romaine aux IV et $V^{e}$ siècles, in «Revue historique» 114 (1913)

Bell H.I. (a cura di), Greek Papyri in the British Museum, V, Oxford 1917

Bidez J. - Hansen G.C. (a cura di), Historia ecclesiastica, Berlin 1960

Bilabel F. (a cura di), Sammelbuch griechischen Urkunden aus Aegypten, V, Heidelberg 1934

Bonfioli M., Tre arcate marmoree protobizantine a Lison di Portogruaro, Ricuperi bizantini in Italia, I, Roma 1979

Brogiolo G. P. - Gelichi S., Nuove ricerche sui castelli altomedievali in Italia settentrionale, Firenze 1996

Caillet J.P., L'évergétisme monumental chrétien en Italie et à ses marges d'après l'épigraphie des pavements de mosaïque (IV ${ }^{e}-V I I^{e}$ s.), Roma 1993 (Collection de l'École française de Rome, 175)

Carile A., Materiali di storia bizantina, Bologna 1994

Cessi R. (a cura di), Documenti relativi alla storia di Venezia anteriori al Mille, I, Padova 1991

Chapot V., La frontière de l'Euphrate de Pompée à la conquête arabe, Paris 1907

Cosentino S., Gaudiosus «draconarius». La Sardegna bizantina attraverso un epitafio del secolo VI, Bologna 1994

Cosentino S., Prosopografia dell'Italia bizantina (493-804), I, Bologna 1996

De Boor C. (a cura di), Theophanis Chronographia, I, Lipsiae 1883

De Boor C. - Wirth P. (a cura di), Theophylacti Simocattae Historiae, Lipsiae 1972

Dennis G. T. - Gamillscheg E. (a cura di), Mauricii Strategicon, Wien 1981

Diacono P., Storia dei Longobardi, a c. di L. Capo, Milano 1992

Diethart J. M. - Dintsis P., Die Leontoklibanarier. Versuch einer archäologisch-papyrologischen Zusammenschau, in BYZANTIOS. Festschrift für Herbert Hunger zum 7o. Geburtstag, Wien 1984

Dindorf L. (a cura di), Menandri Protectoris Historia, in Historici Graeci Minores, II, Lipsiae 1871

Ewald P. - Hartmann L. M. (a cura di), Gregorii I Papae Registrum epistolarum, in Mon. Germ. Hist., Epp., I, Berolini 1887

Forlati Tamaro B., Iscrizioni di orientali nella zona di Concordia, in Aquileia 
e l'Oriente mediterraneo, I, Udine 1977

Greatrex G., Rome and Persia at war, 502-532, Leeds 1998

Giorgi I. - Balzani I., Il regesto di Farfa di Gregorio di Catino, II, Roma 1879

Grenfell B. P. - Hunt A. S. (a cura di), New Classical Fragments and other Grek and Latin Papyri, II, Oxford 1897

Grenfell B. P. - Hunt A. S. - Bell H. I. (a cura di), The Oxyrhynchus papyri, XVI, London 1924

Grosse R., Römische Militärgeschichte von Gallienus bis zum Beginn der byzantinischen Themenverfassung, Berlin 1920

Guarducci M., Epigrafia greca, IV, Roma 1978

Haury J. - Wirth G. (a cura di), Procopii Caesariensis Opera omnia, IV, Lipsiae 1964

Hoffmann D., Das spätrömische Bewegungsheer und die Notitia Dignitatum, I, Dusseldorf 1969

Hoffmann D., Der "numerus equitum Persoiustinianorum" auf einer Mosaikinschrift von Sant'Eufemia in Grado, in "Aquileia Nostra» XXXII-XXXIII (1961-1962)

Lemerle P. (a cura di), Les plus anciens recueils des miracles de saint Démétrius, I, Paris 1979

Jones A. H. M., Il tardo impero romano 284-602 d. C., trad.it., II, Milano 1974

Keydell R. (a cura di), Agathiae Myrinaei Historiarum libri quinque, Berolini 1967

Kraemer C. J. (a cura di), Excavations at Nessana, III, Non-literary papyri, Princeton 1958

Martindale J. R., The Prosopography of the Later Roman Empire, III A-B, A. D. 527-641, Cambridge 1992

Maspero J. (a cura di ), Catalogue général des antiquités égyptiennes du Musée du Caire, III, Papyrus grecs d'époque byzantine, Le Caire 1916

Maspero J., Organisation militaire de l'Égypte byzantine, Paris 1912

Müller A., Das Heer Justinians nach Procop und Agathias, in «Philologus» 71 (1912)

Pertusi A., Ordinamenti militari, guerre in Occidente e teorie di guerra dei Bizantini (secc. VI-X), in Ordinamenti militari in Occidente nell'alto Medioevo, II, Spoleto 1968

Pringle D., The Defence of Bizantine Africa from Justinian to the Arab Conquest. An account of the military history and archaeology of the African provinces in the sixth and seventh centuries, Oxford 1981

Rabotti G. e altri (a cura di), Breviarium Ecclesiae Ravennatis (Codice Bavaro), Roma 1985

Ravegnani G., Soldati di Bisanzio in età giustinianea, Roma 1989

Rémondon R., Soldats de Byzance d'après un papyrus trouvé à Edfou, in «Recherches de Papyrologie», I (1961) 
Roberts C. H. - Turner E. G. (a cura di), Catalogue of the Greek and Latin Papyri in the John Rylands Library Manchester, IV, Manchester 1952

Stein E., Histoire du Bas-Empire, II, De la disparition de l'Empire d'Occident à la mort de Justinien (476-565), Paris-Bruxelles-Amsterdam 1949

Thurn I. (a cura di), Ioannis Malalae Chronographia, Berlin-New York 2000

Tjäder J. O., Die nichtliterarischen lateinischen Papyri Italiens aus der Zeit 445-70o, I, Papyri 1-28, Lund 1955

Tjäder J. O., Die nichtliterarischen lateinischen Papyri Italiens aus der Zeit 445-70o, II, Papyri 29-59, Stokholm 1982

Treagold W., Byzantium and Its Army 284-1081, Standford 1995

Vitelli G. - Norsa M. e altri (a cura di), Papiri greci e latini, III, Firenze 1914 von Falkenhausen V., L'esarcato d'Italia (VI-VIII secolo), in I Bizantini in Italia, Milano 1982

Wessely G. (a cura di), Studien zur Palaeographie und Papyruskunde, XX, Leiprig 1921

Zereteli G. - Jernstedt P. (a cura di), Papyri russischer und georgischer Sammlungen, III, Tiflis 1930 



\title{
La regalità longobarda. Dall'età delle migrazioni alla conquista carolingia*
}

\author{
Stefano Gasparri
}

1. "Rex gentis": il re tribale

I più antichi re longobardi sono personaggi dalla fisionomia mitica. Le asciutte righe del catalogo dei re premesso all'Editto di Rotari del 643, il periodare talvolta un po' oscuro del breve testo anonimo conosciuto come Origo gentis Langobardorum (fine del VII secolo), le prime pagine dell'Historia Langobardorum di Paolo Diacono (fine dell'VIII secolo) ci parlano di sovrani che agiscono in un tempo che non è quello proprio della storia, ma che appartiene piuttosto ad un passato eroico e mitologico. Gli stessi re sono parte dei, parte eroi. Stirpe di dei sono i fratelli Ibor e Aione, condottieri dei Winnili (i futuri Longobardi) al momento della loro partenza dalla Scandinavia e poi durante le loro prime difficili prove; essi appartengono a quella nutrita schiera di "gemelli divini”, figli della divinità celeste, dei quali è ricca la letteratura mitologica di tanti popoli ${ }^{1}$. Ugualmente discendente dagli dei è, ovviamente, il figlio di Aione, Agilmundo, il primo re, almeno secondo la tradizione dei Longobardi d'Italia; alcuni re, infatti, sono nominati solo dalle fonti nordiche ed ignorati invece da quelle italiane, come Sceaf, altro personaggio di caratura superumana. Agilmundo, affermano in modo concorde le fonti longobarde italiche, era della stirpe dei Gugingi, un nome che sembra alludere in modo inequivocabile alla tremenda lancia di Odino, gungnir nelle fonti norrene ${ }^{2}$. Il suo figlio adottivo Lamissione, ci racconta,

\footnotetext{
* Questo saggio rappresenta una versione riveduta ed ampliata (con l'aggiunta del paragrafo 5) di quello apparso con il titolo La regalità longobarda nel volume Visigoti e Longobardi, a cura di J. Arce e P. Delogu, Firenze 2001, pp. 305-327.

${ }^{1}$ Paolo Diacono, Historia Langobardorum, in MGH, Scriptores rerum Langobardicarum et Italicarum saec. VI-IX, ed. L. Bethmann - G. Waitz - O. Holder-Egger, Hannoverae 1878, I, 3, 7, 14. Sui fratelli divini: Ward 1968 (alle pp. 50-52 su Ibor e Aione).

2 Paolo Diacono, Historia Langobardorum cit., I, 14, e Leges Langobardorum 643-866, Germanenrechte Neue Folge, Westgermanisches Recht, bearb. von F. Beyerle, Witzenhausen 1962 (rist. anast. di Weimar 1947), Roth. prol. Su Sceaf e gli altri re ignoti alle fonti italiane, Gasparri 1983, pp. 23 e 34-35.
} 
stavolta da solo, Paolo Diacono, fu trovato semivivo da Agilmundo in una pozza d'acqua, abbandonato insieme a sei fratelli (tutti morti) dalla madre nei suoi primi giorni di vita; un racconto che, nella sua apparente bizzarria, tradisce una struttura mitica molto arcaica, che unisce l'acqua - ossia la fertilità - all'immagine della regalità 3 .

$\mathrm{Al}$ centro della saga longobarda si colloca quindi saldamente la figura dei re, a cominciare dai più antichi, autentici condottieri-eroi semidivini, per giungere fino ad Alboino, il re che condusse il suo popolo in Italia. Con Alboino cessa definitivamente il tempo del mito ed inizia quello della storia, che è storia del regno e della sua lenta e faticosa affermazione nella peniso$\mathrm{la}^{4}$. Colpisce, a paragone di ciò che sappiamo di altri popoli barbarici, la ricchezza del materiale mitico longobardo che è stato tramandato. Certo, è impossibile pensare di trovarsi di fronte a contenuti storico-religiosi rimasti inalterati nel corso della loro lunga e travagliata trasmissione, che ci rimandino cioè senza alterazioni significative il quadro di una più o meno mitica civiltà longobarda originaria. Del resto, la saga longobarda trascritta da Paolo Diacono, così come le narrazioni omologhe riportate dagli altri cronisti del primo medio evo - Giordane, Beda, Gregorio di Tours -, alcuni anni fa è stata fortemente svalutata, nei suoi contenuti di storicità, negli studi di Walter Goffart, che riteneva queste cronache frutto della cultura erudita - ecclesiastica e di matrice tardoantica - dei loro autori e testimonianze più dell'epoca in cui costoro vissero che del periodo che essi vollero narrare ${ }^{5}$. Osservazioni certo valide, se intese a rifiutare una ricezione acritica di ciò che è stato messo per iscritto nel VI, VII o VIII secolo, ma che non possono essere estese indiscriminatamente a tutti i testi e a tutte le situazioni. Nel caso longobardo, infatti, la complessità della saga, la sua ricchezza e al tempo stesso la sua solo relativa coerenza interna - sintomo di scarsa rielaborazione - risultano pressoché uniche nel panorama dei "narratori della storia barbarica", come li definisce Goffart. Inoltre, un testo colto come quello di Paolo Diacono è affiancato e sostenuto da altri testi di natura diversa: il prologo dell'editto, cioè un atto di natura giuridica e documentaria, espressione della cultura dei circoli di corte pavesi del secolo precedente a quello di Paolo, e la stessa Origo, abbozzo di narrazione concepita però come "prologo lungo" dell'editto da ambienti, sempre pavesi, di una generazione successiva rispetto all'età

3 Paolo Diacono, Historia Langobardorum cit, I, 15. Sull'episodio, Gasparri 1983, pp. 13-16 e 22-27.

4 Gasparri 1983, pp. 41-44.

5 Goffart 1988, pp. 329-431 per Paolo Diacono ("When Paul's narrative is subjected to literary analysis, it turns to be not a haphazard assemblage of historical extracts and barbarian legends, but an instructive and eminently Christian interpretation of the Lombard past”, p. 333) e pp. 432-437 per le conclusioni, dove egli definisce in modo illuminante i quattro autori "deliberate creators" (p. 436). 
di Rotari ${ }^{6}$ Senza contare poi la presenza di numerosi indizi, che affiorano qua e là nelle fonti (non solo in Paolo Diacono) e che testimoniano l'esistenza di una cultura tradizionale longobarda il cui radicamento nel mito appare indubbio7.

Qui tuttavia si inserisce un secondo problema metodologico, che si pone a monte della stessa patente di autenticità, sia pure relativa, da attribuire ai cronisti altomedievali. I più recenti indirizzi di ricerca hanno infatti risolutamente sottoposto ad analisi critica il concetto stesso di "etnicità" nel mondo barbarico in generale. Si tratta della spallata forse decisiva portata a idee vecchie e tuttavia ancora non del tutto estirpate, che mettevano al centro l'equazione tra etnia e razza; un'equazione affermatasi già più di cento anni fa, a partire almeno dagli anni '70 dell'Ottocento, che aveva conosciuto il suo tragico zenith con il nazismo ma che anche dopo non era stata completamente smantellata nei suoi presupposti culturali e ideologici ${ }^{8}$. Oggi si ritene al contrario l'etnicità un fatto eminentemente culturale, risultato di un impasto di modi di vita, lingua, norme giuridiche, religione; un'impostazione, questa, che è assolutamente da condividere ${ }^{9}$. Ma, respingendo in tal modo l'idea delle gentes barbariche come unità biologiche chiuse, come etnie razzialmente compatte - e del resto, l'idea stessa di razza viene ormai rifiutata anche in campo scientifico -, si è finito non solo per accentuarne l'aspetto polietnico, ma anche per sottolineare l'estrema lentezza con la quale si compirono i processi di etnogenesi e la pluralità degli attori che influirono su di essa. È per questa via, ad esempio, che Patrick Geary è potuto arrivare a proporre una definizione dei Germani come "la più grande e duratura creazione del genio politico e militare di Roma"; espressione intrigante nella sua apparente paradossalità e per ciò stesso risultata di grande successo ${ }^{10}$. Concetto molto giusto, peraltro, questo proposto da Geary, a patto di non portarlo fino alle sue estreme conseguenze. Dire che sui Germani hanno influito i Romani e poi i popoli nomadi; aggiungere che tutto il processo genetico delle gentes è plurisecolare e che è avvenuto per contatti culturali e per sovrapposizioni di gruppi umani di origine diversa; sostenere, infine, che i popoli invasori dell'impe-

6 Origo gentis Langobardorum in MGH, Scriptores rerum Langobardicarum cit., pp. 1-16, e Gasparri 1992, pp. X-XI.

7 Il riferimento in generale è al mio libro sulla cultura tradizionale dei Longobardi (Gasparri 1983), dove sono raccolte tutte le testimonianze presenti nelle fonti, non ultima quella, per certi versi straordinaria, rappresentata dalla Vita Barbati (del secolo IX), che ci tramanda il ricordo del rito equestre dell'albero sacro (pp. 69-91).

8 La ricostruzione del dibattito nella cultura europea è in Orsucci 1998; per la discussione in ambito inglese e tedesco, Härke 1998, pp. 19-45.

9 In prima fila in questa interpretazione sono gli studiosi della scuola di Vienna; per tutti cfr. Pohl 1991, pp. 39-49.

10 Geary 1988, p. 6. 
ro erano popoli "nuovi", formatisi compiutamente solo al momento delle invasioni e in molti casi anche dopo, su suolo romano (l'esempio classico è quello dei Franchi), non deve però portare a posizioni come quelle espresse da Patrick Amory, che annacqua la fisionomia etnica - di un'etnia intesa nel senso di un popolo con una sua cultura riconoscibile ed autonoma - degli Ostrogoti al punto tale da dire che, di fatto, essi non sarebberto mai esistiti come popolo: sarebbero semplicemente stati un esercito di guerrieri federati, con al seguito donne, figli, preti, schiavi, un gruppo cioè portatore non di una cultura germanica, ma solo di una versione particolare della cultura militare mediterranea tardoromana ${ }^{11}$.

Posizioni estreme e ancora una volta paradossali. La profondità dell'influenza romana e di altre culture, come quella dei popoli nomadi - ma non andrebbe trascurato nemmeno il rapporto di scambio con gli Slavi12 ${ }^{2}$, è indubbia, ma non si può negare del tutto l'esistenza, all'interno di alcune almeno delle gentes parlanti lingue germaniche, di un nucleo antico di tradizioni di stirpe ${ }^{13}$. È evidente, del resto, la differenza fra un popolo del tutto o quasi recente come i Franchi, la cui cultura tradizionale è pressoché inesistente, e i Goti o ancor più i Longobardi, il cui patrimonio mitico non può essere frutto solo un'invenzione erudita ${ }^{14}$. Questa riflessione è di primaria importanza per il tema da trattare qui, in quanto non solo la fisionomia antica della regalità longobarda, ma anche i suoi rituali si rispecchiano nel grande serbatoio rappresentato dalla saga.

La saga longobarda ci offre dunque il racconto della nascita della regalità, della sua fondazione, che appare strettamente intrecciata con le più antiche vicende della stirpe. Il modello di questa regalità antica unisce tratti sacrali e caratteristiche militari: i re infatti comandano l'esercito, che - per ciò che concerne gli uomini - si confonde con il popolo nella sua interezza. Non è possibile dunque, come faceva invece la letteratura tradizionale di lingua tedesca, porre in sequenza Sacralkönigtum e Heerkönigtum, interpretandoli come due stadi l'uno successivo all'altro, il primo precedente alle migrazioni, il secondo tipico di quest'ultimo periodo, caratterizzato da guerre continue ${ }^{15}$. Si tratta al

\footnotetext{
${ }^{11}$ Amory 1997, p. es. pp. 18-25 e 40-42. Secondo l'autore, gli Ostrogoti sarebbero stati in sostanza "the army of Italy" (p. 320), un'etichetta puramente professionale trasformata in etichetta etnica dall'ideologia politica di governo di Teodorico e di Giustiniano, che impiegava i criteri interpretativi propri dell'etnografia antica.

12 Modzelewski 1997, pp. 377-409.

13 Il lavoro di base su questo tema è Wenskus 1961, cui si possono aggiungere diversi interventi di Herwig Wolfram e di altri studiosi della scuola di Vienna (v. ad es. sopra, nota 9, e Amory 1997, p. 35 in nota).

14 Sui Franchi, Gasparri 1997, pp. 75-77 e 84-85; sui Goti, Gasparri 1992² ${ }^{2}$, pp. 201-226 e POHL 1992, pp. 227-251.

15 Cfr. ad esempio Höfler 1952 e 1956, pp. 75-104 (quest'ultimo saggio prende in considerazione il dibattito storiografico sul tema), e Sschlesinger 1956, pp. 105-142. Più di recente, la
} 
contrario di due dimensioni che convivono nella preistoria longobarda: Ibor, Aione, Agilmundo, Lamissione sono comandanti militari oltre che dei o semidei. Né il caso longobardo è unico: ad esempio, nonostante i suoi lunghi capelli che rinviavano, forse, alla sfera della fertilità, sarebbe ben difficile interpretare il re franco-merovingio Clodoveo altrimenti che come un sovrano guerriero $^{16}$. Gli schemi interpretativi di tipo evoluzionistico vanno dunque respinti.

La caratterizzazione militare del comando aumenta, presso i Longobardi, a partire dal loro ingresso nell'area danubiana, dal regno di Tatone in poi (489), da quando cioè inizia il loro coinvolgimento nella turbolenta area balcanica e le figure dei sovrani acquistano spessore storico uscendo progressivamente dalle nebbie del mito ${ }^{17}$. Ma anche allora i caratteri sacrali della regalità non si perdono del tutto, o quantomeno sono trasfigurati in una dimensione eroica. È il caso di Alboino, guerriero vittorioso e fortunato fino alla sua tragica morte per mano di una donna (572): le sue gesta giovanili e della maturità e la sua fine forniscono materiale abbondante per la costruzione di una saga, che vivrà a lungo nei carmi non solo dei Longobardi ma anche di Sassoni e Bavari ${ }^{18}$.

La fantasia collettiva si focalizzerà allora sulle armi di Alboino. Di lui si ricorderanno la spada e, accanto ad essa, anche altre armi "di foggia particolare" (così le definisce Paolo Diacono), fatte costruire durante il suo regno; senza dimenticare che, in gioventù, una delle azioni più eroiche del re era stata proprio quella di andare a rivendicare alla corte dei Gepidi le armi del principe gepido da lui stesso ucciso in battaglia ${ }^{19}$. Il duca veronese Giselperto, un secolo e mezzo dopo la morte di Alboino, ne aprì la tomba alla ricerca della spada, probabilmente la stessa che, secondo la leggenda - a rappresentare lo stato di impotenza in cui era piombato l'eroe -, sarebbe stata fraudolentemente legata al momento dell'attacco da parte del suo assassino: "per questo, con la solita vanità degli ignoranti, si gloriava di aver veduto Alboino", commenta sprezzante Paolo, contemporaneo agli avvenimenti20. E tuttavia, c'era qualcosa di logico nell'azione del duca (che peraltro si impadronì anche del resto del corredo), giacché ogni eroe germanico aveva la sua arma, che era quasi il suo doppio. In un certo senso, la spada "era" il re defunto, la sua essenza eroica. Come vedremo, però, nonostante tutta l'insistenza della leggenda sulla spada di Alboino, non era questa l'arma tipica dei re longobardi.

discussione è stasta ripresa - sfumando l'approccio evoluzionistico al rapporto fra i due "tipi" monarchici - da Wormald 1986, pp. 151-183.

16 Sulla pluralità delle tradizioni franche, alcune delle quali legate all'acqua e dunque alla fertili-

tà, si veda Wood 1995 .

17 Delogu 1980, pp. 10-11.

18 Paolo Diacono, Historia Langobardorum cit, I, 23, 24, 27, II, 6-9, 14, 25-28.

19 Paolo Diacono, Historia Langobardorum cit, I, 24.

20 Paolo Diacono, Historia Langobardorum cit, II, 28. 
La stabilizzazione in Italia chiude la fase mitico-eroica della regalità. Alboino è l'ultimo rex gentis della Völkerwanderungszeit, il discorso, dopo di lui (e dopo l'insignificante parentesi del regno di Clefi), potrà essere ripreso - trascorsi i dieci anni della cosiddetta "anarchia ducale" (574--584) - solo su basi nuove che, in rapporto all'ambiente nel quale i Longobardi erano ormai inseriti, non potevano essere che basi romane ${ }^{21}$. La fase antica comunque lasciò tracce cospicue di sé in età successiva, cosicché le nuove basi romane andarono a mescolarsi con la trasmissione di caratteri simbolici fortemente arcaici. Questi ultimi si riscontrano innanzitutto nel rituale di elezione, il cui modello mitico è presentato nel racconto della storia di Agilmundo e Lamissione.

Narra Paolo Diacono che il re, quando trovò il fanciullo mezzo morto nello stagno, lo toccò con la lancia; allora questi l'afferrò, segnalando così non solo di essere vivo, ma di meritare il regno. In tal modo Lamissione divenne anche lui, per adozione da parte del re, che lo fece raccogliere ed educare come un figlio, un membro della stirpe dei Gugingi, dei re il cui nome derivava dalla lancia di Odino ${ }^{22}$. Che i membri di questa stirpe si trasmettessero il potere passandosi l'un l'altro la lancia sacra è più che un'ipotesi, che è peraltro confermata dall'unica fonte che ci descrive, sia pure sommariamente, un rituale di elezione, e che è del pieno VIII secolo, dunque molto tarda (ne parleremo subito appresso). Sfruttando inoltre gli scarsi accenni contenuti nell'epilogo dell'editto di Rotari, nel quale si fa intravedere lo svolgimento di un'assemblea militare, e combinandoli appunto con i dati che abbiamo per il secolo VIII, possiamo pensare - con un buon grado di plausibilità - che al re venisse consegnata la lancia, simbolo della regalità derivante dall'evidente influenza dei Reitervölker, i popoli nomadi cavalieri, mentre i guerrieri battevano sugli scudi in segno d'approvazione. Sarebbe questa l'assemblea detta, nell'antica lingua longobarda conservataci dall'Editto di Rotari, gairethinx, una parola forse traducibile con "assemblea delle lance". Si trattava di una riunione che vedeva schierato il popoloesercito dei Longobardi (nella realtà, una sua qualificata rappresentanza) per fatti decisivi quali l'approvazione di leggi, la partenza per una spedizione militare, l'elezione di un $\mathrm{re}^{23}$. Questo rituale elettivo fu praticato almeno fino alla metà circa del secolo VIII, quando Paolo Diacono ci racconta che Ildeprando, nipote del re Liutprando, mentre questi era malato e dato ormai per spacciato, fu eletto fuori delle mura di Pavia - dunque in un luogo aperto e adatto ad un'assemblea militare - proprio mediante la consegna di un

${ }^{21}$ Sugli eventi di questo periodo, e sulle modalità del primo insediamento, Delogu 1980, pp. 12-23.

22 Paolo Diacono, Historia Langobardorum cit, I, 15.

23 Leges Langobardorum cit., Roth. c. 386. Sull'assemblea delle lance cfr. Jarnut 1982, pp. 50-51. 
contus, una lancia, "ut moris est"24. Sulla base del racconto di Paolo, incrociato con i dati del mito, possiamo supporre che la trasmissione della lancia sia stata presente in tutta la storia longobarda.

\section{La prima influenza romana}

L’influenza militare romana si esercitò sui Longobardi a partire dal momento in cui essi divennero federati di Costantinopoli, dapprima con il re Wacone, intorno al 530 - dopo quindi il loro ingresso nella Pannonia settentrionale, tra il Danubio e la Drava (poco dopo il 510) -, e poi con l'altro re Audoino, al quale Giustiniano concesse la Savia, tra la Drava e la Sava, e la parte orientale del Norico mediterraneo (547/8). Quest'influenza produsse effetti rilevanti sul piano dell'organizzazione interna dell'exercitus e modificò anche la natura del potere regio, rafforzandolo ${ }^{25}$. La politica romana e poi bizantina, infatti, sul fronte balcanico come su quello renano, aveva sempre teso ad appoggiare alcuni capi barbarici, sui quali puntava con la stipulazione di foedera, al fine di creare poteri militari autorevoli che si esercitavano su poche concentrazioni tribali ampie, più facilmente controllabili di un pulviscolo instabile di micro-unità tribali. E in effetti il pieno sviluppo della regalità longobarda, dall'avvento della famiglia dei Gausi fino al punto più alto rappresentato da Alboino, che estese la sua autorità su vasti gruppi di Gepidi, Sassoni, Sarmati, Bulgari e Norici, coincise con il dispiegarsi dell'influenza romana federata e ne fu, in parte, il frutto; pure se tale sviluppo seguì anche logiche diverse, legate alla politica dei capi barbarici dell'età delle migrazioni 26 .

Il re longobardo, dunque, prima dell'invasione della penisola italiana univa ai tratti arcaici del re-eroe quelli molto concreti del re-capo federato di Bisanzio. Ancora in Italia la natura "federata" del comando longobardo emerge bene, anche se forse meglio al livello dei duchi - si veda il caso di Ariulfo di Spoleto che chiede a Gregorio Magno di assicurare lui gli stipendi per i suoi seguaci, un tempo pagati dai Bizantini27 - che a quello del re, ma non molto diversa doveva essere la natura di quest'ultimo, almeno agli occhi delle autorità bizantine: un capo federato occasionalmente ribelle, da ricondurre sotto controllo con l'oro o, se resisteva, con l'assassinio; fu questa la sorte di Alboino e del suo successore Clefi. Lo stesso racconto del primissimo inse-

24 Paolo Diacono, Historia Langobardorum cit, VI, 55.

25 Vecchio ma sempre valido è Bognetti 1967, pp. 1-46; sulle vicende della migrazione, Delogu 1980, pp. 3-4 e Jarnut 1990, pp. 26-27 (che tra l'altro modifica la datazione tradizionale del 526/7 riferita all'occupazione longobarda della Pannonia settentrionale).

26 Pohl 1992, pp. 165-207 e Gasparri 1997, pp. 73-77.

27 Gregorio Magno, Registrum Epistolarum, in MGH, Epistolae, t. I, ed. P. Ewald - L. M. Hartmann, Berolini 1891, II, 45 (luglio 592). 
diamento longobardo fatto dall'abate trentino Secondo di Non, costruito intorno ai concetti di tertia e di hospitalitas, con tutti i suoi limiti di prospettiva geografica provinciale (ma non dimentichiamo che si tratta di un testimone oculare), rende chiaro che siamo in presenza di ex-federati che agiscono in maniera autonoma e violenta. $\mathrm{E}$ tutto ciò si riverbera sulla natura del potere regio, che è mista, federata e barbarica, fin dai primi tempi italiani ${ }^{28}$.

Dopo i dieci anni di interregno seguiti all'assassinio di Clefi, che sono da interpretare come una fase nella quale l'oro bizantino recupera all'obbedienza federata i capi longobardi e non certo come un'esplosione di anarchia germanica primitiva, con Autari (584) inizia timidamente una fase nuova. Il prenome Flavius assunto allora da Autari, di chiara tradizione romano-gotica, era l'espressione di una regalità che intendeva rivolgersi anche ai Romani, ponendo le premesse almeno ideologiche per un esercizio territoriale del potere. La cessione di metà delle substantiae dei duchi al re pose inoltre, nella stessa epoca, le prime basi per la creazione di un supporto economico della regalità, sia che sotto il termine di "sostanze" ducali Paolo Diacono, qui come spesso nostra unica fonte, intendesse ricchezze fondiarie oppure solo beni mobili, frutto del bottino dei primi anni di disordinato e violento insediamento dei Longobardi in Italia ${ }^{29}$.

Con Autari lo schema che, per semplicità, potremmo definire "tribale" della regalità longobarda comincia a mostrare le prime crepe. Ma una forzatura molto maggiore di questo schema si verifica poco più tardi, con Agilulfo, sua moglie Teodolinda e suo figlio Adaloaldo (590-626). Un periodo questo che Gian Piero Bognetti definì "estate dei morti" e che, secondo la sua interpretazione, avrebbe rappresentato una sorta di estate di s. Martino della romanità italica, durante la quale alla corte longobarda fu vigorosa l'influenza politica di un gruppo residuale di Romani colti. Come spesso capita, qui e altrove le interpretazioni di Bognetti sono viziate dal poderoso sviluppo cui la sua fantasia - partendo da intuizioni non di rado geniali - le sottopone, allontanandole sempre più dalle fonti e dunque da una loro attendibilità 30 . Ma in questo caso un qualche nucleo di veridicità è possibile riscontrarlo, in quanto, come vedremo, il regno di Agilulfo appare in effetti segnato da una certa impronta romanizzante.

L'azione di Agilulfo si inserì in un contesto interno ed esterno favorevole, segnato dalla pace con Franchi e Avari, dalle guerre vittoriose contro Bisanzio - allora impegnata duramente in oriente - e dalla crisi religiosa della Chiesa italica dell'Italia del nord, in rotta con Bisanzio a causa della condanna impe-

28 Alla base di Paolo Diacono, Historia Langobardorum cit, II, 31-32 e III, 16, c'è infatti l'historiola, purtroppo scomparsa, di Secondo di Non (ibid., III, 29 e IV, 40).

29 Paolo Diacono, Historia Langobardorum cit, III, 16.

30 Sulla storiografia di Bognetti v. Gasparri 2003, pp. 3-28. 
riale della dottrina dei Tre Capitoli. Quest'ultima circostanza consentì al re di inserirsi nel dissidio, puntando a creare dei punti di riferimento alternativi per il clero cattolico, che fossero a lui legati da rapporti di sottomissione politica: il risultato modesto, ma non del tutto insignificante, fu la creazione di una nuova sede patriarcale in territorio longobardo, ad Aquileia, che limitò l'autorità della vecchia sede di Grado, progressivamente sospinta verso un destino lagunare ${ }^{31}$.

Questa complessa costellazione di eventi ebbe come effetto quello di rafforzare la monarchia. Ne è un'ottima prova la sottomissione con le armi di numerosi duchi ribelli, un fatto che scandì i primi anni del regno di Agilulfo e il cui esito non fu solo quello di ripristinare l'autorità del re allo stadio precedente alla decennale crisi della monarchia, ma fu anche quello di portare il suo potere all'interno della gens a livelli fino ad allora inusitati e sconosciuti a qualsiasi più antico capo germanico dell'età delle migrazioni 32 .

In un simile contesto, lo sviluppo dell'influenza romana agì come rafforzamento dell’immagine della regalità e come sviluppo delle sue potenzialità di rapporti con forze diverse. Si spiega così la politica di collegamento con gli ecclesiastici (il vescovo Agnello di Trento, inviato dal re in Francia a riscattare dei prigionieri; il patriarca Giovanni ad Aquileia, che chiede ad Agilulfo di intervenire per porre fine allo scisma dei Tre Capitoli; l'abbate Secondo di Non, attivo a corte) e con un monastero come Bobbio, fondato dall'irlandese Colombano in pieno accordo con Agilulfo. Proprio in relazione a Bobbio, inoltre, si conserva il testo del più antico diploma regio longobardo tramandato, sia pure in una copia successiva: un testo che risulta essere fortemente interpolato, ma non falso, e che dunque prova che in quest'epoca - a cavallo fra VI e VII secolo - era già attiva una cancelleria regia ${ }^{33}$. Una testimonianza evidente dell'influenza romana, che è rafforzata dal predicato di vir excellentissimus utilizzato nel diploma dal re Agilulfo: un predicato che tutti i re longobardi adotteranno dopo di lui e che in età imperiale romana era stato riferito a personaggi di rango elevatissimo quali consoli, patrizi, prefetti. L'uso di questo titolo, così come di quello di vir gloriosissimus da parte dei duchi, non corrisponde ad una volontà dei capi longobardi di inserirsi in modo ordinato in una gerarchia di dignità riconosciute dall’imperatore, così come sarà il caso dell'impiego di titolature bizantine in età più tarda da parte di funzionari imperiali periferici semi o del tutto autonomi o di altri sovrani barbarici; in questo contesto, ancora tardo-antico, si tratta invece del tentativo di duchi e

${ }^{31}$ Sul regno di Agilulfo cfr. la nota successiva, Bognetti 1966, pp. 179-302 e Gasparri 1997², pp. 48-52.

32 Delogu 1980, pp. 36-44.

33 C. Brühl, Codice Diplomatico Longobardo, III,1, in Fonti per la Storia d'Italia, 64, Roma 1973, 1 (24.7. 613?). Si tratta di una copia della metà circa del IX secolo. 
re di rivestirsi di titoli di onore e di dignità espressi in forme romane e tali perciò da essere riconoscibili - ed entro certi limiti accettabili - dalla popolazione della penisola e dai pochi membri superstiti della sua classe dirigente ${ }^{34}$. Non è un caso, allora, che alcuni fra questi ultimi appaiano essere attivi a corte durante il regno di Agilulfo, Teodolinda e Adaloaldo: oltre a Secondo, i notai Aureo e Stabliciano, forse anche - ma qui il terreno si fa già più scivoloso - il misterioso Paolo e suo figlio Pietro, studiati da Gian Piero Bognetti ${ }^{35}$.

I sovrani sfruttavano come residenze i palazzi dei funzionari romani, soprattutto a Pavia e a Milano, una città quest'ultima di forte tradizione imperiale romana e che viene a lungo privilegiata da Agilulfo e Teodolinda rispetto alla barbarica Ticinum, legata invece ai ricordi di Teodorico e della monarchia ostrogota. Ma in questi anni inizia anche una politica edilizia dei re: a Monza viene costruito un palazzo da parte della regina Teodolinda - ed è l'unica notizia di un'operazione di questo tipo per l'età longobarda in senso stretto - oltre ad una basilica dedicata a s. Giovanni. In quest'ultimo caso, si tratta solo della prima di una lunga serie di fondazioni religiose da parte dei sovrani. Nella chiesa di S. Giovanni Battista venne battezzato Adaloaldo, figlio dei due sovrani longobardi 36 .

Il contesto romanizzante del regno di Agilulfo è provato anche da due episodi entrambi collegati alla romana Milano: lì Agilulfo scelse di farsi eleggere una seconda volta, dopo che la sua prima elezione era avvenuta in modo fortemente contestabile, forse addirittura con la forza. La scelta di Milano potrebbe far sospettare l'uso di forme rituali romane, come avvenne con maggiore certezza in occasione del secondo episodio, l'associazione al potere del figlioletto Adaloaldo, che ebbe luogo nel circo di Milano, con una chiara, seppur pallida, imitazione delle cerimonie imperiali che avvenivano nel'Ippodromo di Bisanzio ${ }^{37}$.

La romanizzazione del potere regio longobardo in questo periodo è sempre temperata dalle robuste radici barbariche della regalità. La famosa lamina di Valdinievole ci presenta l'immagine di un sovrano, che l'iscrizione presente sulla lamina ci dice essere proprio Agilulfo, in trionfo su nemici di varia natura: dunque una scena in sé tipicamente romana, ma che nei particolari unisce dettagli appunto romani, come le figure alate con la scritta victuria, ad

34 Wolfram 1967, sui titoli d'onore in età barbarica, e Ravegnani 1992, pp. 19-29, che, partendo dal caso veneziano, esamina il problema più generale delle dignità bizantine conferite a principi stranieri.

35 Cfr. nota 30, Bognetti 1966, cit. alla nota 29 e Gasparri 1987, pp. 39-41.

36 Paolo Diacono, Historia Langobardorum cit, IV, 21-22 e 27 per Teodolinda; altre fondazioni religiose opera di regine, ricordate da Paolo Diacono: Gundiperga fa costruire S. Giovanni a Pavia (IV, 47) e Rodelinda S. Maria delle Pertiche, sempre a Pavia (V, 34). Sui palazzi: Brühl 1968, pp. 357-377, e Harrison 1998, pp. 247-248.

37 Paolo Diacono, Historia Langobardorum cit, III, 35 e IV, 30. 
altri fortemente germanici, come l'acconciatura del re e le figure dei due portalancia che attorniano quest'ultimo ${ }^{38}$. Proprio la presenza di costoro, che è confermata da notizie di Paolo Diacono riferibili al tardo VII e all'VIII secolo, ci potrebbe suggerire che, nonostante tutta l'influenza romana dispiegata in questo periodo, l'arma fondamentale del re sia rimasta sempre la lancia dell'antica tradizione pagana, pure se la spada - che qui appare nelle mani del re - aveva anch'essa un suo ruolo ${ }^{39}$. Contro gli entusiasmi interpretativi suscitati dalla lamina, comunque, non va dimenticato che si tratta di un oggetto non solo unico, e dalla funzione originale niente affatto chiara, ma che ha oltretutto origini quanto meno dubbie. Insomma, l'immagine della regalità che essa ci presenta è senz'altro attendibile e si collega perfettamente - forse anche troppo - a ciò che sappiamo per altra via dell'età di Agilulfo e Teodolinda, ma la lamina in sé rappresenta ancora un punto interrogativo ${ }^{40}$.

È possibile che un'altra insegna del potere regio fosse la corona, visto che sappiamo dell'esistenza di corone sia di Agilulfo che di Teodolinda. Su quella di Agilulfo, oggi perduta, era scritto "Agilulf grat(ia) D(e)i vir glor(iosissimus) rex totius Ital(ie)”. Al di là del dilemma, non risolvibile, se tale corona sia stata veramente un'insegna regia e non solo una corona votiva - sappiamo che fu donata a S. Giovanni di Monza, così come quella di Teodolinda -, è interessante il titolo portato dal sovrano: "re di tutta l'Italia". L'accentuazione dei tratti romanizzanti della regalità si sposava quindi ad una rivendicazione di sovranità su tutta la penisola, con una concezione territoriale che superava largamente l'angusto schema di riferimento etnicopolitico costituito dalla gens Langobardorum. Al tempo stesso, la nuova dimensione romana assunta dal potere monarchico poneva il re in una situazione di forte concorrenzialità con Bisanzio nei confronti della popolazione indigena della penisola, verso cui Agilulfo voleva presentarsi come l'esponente di un potere legittimo, adorno di tratti romani e cattolici ${ }^{41}$.

38 Frugoni 1998, pp. 719-729.

39 Cfr. più avanti, testo e note 63 e 64 (portalancia) e 68 e 69 (spada).

40 La riflessione su questo punto è ancora agli inizi e la sto portando avanti insieme a Cristina La Rocca, nell'ambito di una ricerca comune e più vasta dal titolo "I Longobardi e l'identità italiana: riflessione storiografica, prove materiali, memoria locale e falsificazioni tra ' 800 e ' 900 ". Per il momento si veda, per la bibliografia recente sulla lamina e per i riferimenti alle circostanze del ritrovamento avvenuto nel 1893 "fra le rovine di un castello in Val di Nievole", Frugoni 1998 , cit. a nota 38.

41 Elze 1980, pp. 393-400: la corona ci è nota da un disegno del 1717; l'iscrizione, dopo il titolo di Agilulfo, prosegue con le parole: "offeret s(an)c(t)o Iohanni Baptiste in eccl(esia) Modicia". V. poi Gasparri $1997^{2}$, per il rapporto fra romanizzazione della monarchia longobarda e conflittualità con i Bizantini. 


\section{La lenta elaborazione del secolo VII}

Il secondo venticinquennio del secolo VII, fino al 650 circa, è la fase più oscura della storia longobarda, caratterizzata dalla mancanza quasi assoluta di fonti. Lo stesso Paolo Diacono, l'unico a fornirci qualche notizia, scrive a proposito di un sovrano come Arioaldo (626-636) che "delle gesta di questo re non è pervenuto nulla alla nostra conoscenza" 42 . In questo stesso periodo si completa il ricambio della classe dirigente all'interno del regno: spariti, con l'esaurirsi dell'esperienza di Agilulfo e Teodolinda al momento della deposizione di Adaloaldo nel 626, gli ultimi "ministri” romani, si affaccia allora sulla scena un gruppo di funzionari la cui fisionomia culturale, espressa dall'onomastica, appare nettamente longobarda ${ }^{43}$. Tuttavia continua l'intreccio tra influenza romana e tradizione barbarica. Come è stato già ricordato, è nel 643 che Rotari emana le prime leggi scritte, che ad una vaga patina di cristianizzazione uniscono evidenti influenze del diritto romano, ad esempio nel prologo, che rimanda alle Novellae di Giustiniano; l'intera operazione di passaggio dall'oralità alla scrittura rappresenta in realtà il trasferimento entro schemi culturali romani del patrimonio giuridico della gens Langobardorum, corroborato dalla figura del notaio Ansoald, autore del testo scritto, che ne certifica l'autenticità 44 .

Ma nel prologo e nell'epilogo dell'editto Rotari si ricollega in modo consapevole alla tradizione storico-mitica, dapprima inserendo un catalogo dei re, a partire dal leggendario Agilmundo, e poi affermando esplicitamente la sua subordinazione davanti alla forza di quella stessa tradizione. Infatti il re fa scrivere nell'epilogo: "il presente editto da noi disposto, che abbiamo composto con il favore di Dio [...] ricercando e ricordando le antiche leggi dei nostri padri che non erano scritte"; e ancora: "riservandoci questa condizione, di dover aggiungere a questo editto quanto ancora saremo in grado di ricorda-

42 Paolo Diacono, Historia Langobardorum cit, IV, 41.

43 Gasparri 1987, pp. 41-42.

44 Leges Langobardorum cit., Roth. c. 388: il re afferma che non c'è altro editto valido "nisi quod per manus Ansoald notario nostro scriptum aut recognitum seu requisitum fuerit, qui per nostram iussionem scripsit". Come osserva Azzara 1992, in nota (p. 106), "in tutto il prologo riecheggiano motivi, formule, tecnicismi desunti dal linguaggio giuridico giustinianeo ed impiegati talora anche in modo improprio". Letterale invece è il calco da Novellae, VII, pr. III, dell'anno 535, quando Rotari, sempre nel prologo, afferma di rinnovare la legge aggiungendo ciò che mancava e togliendo ciò che era superfluo. Su questo punto cfr. anche Wormald 1977, pp. 105-138, il quale, oltre a sottolineare che questo passo delle Novellae è presente anche in altre legislazioni barbariche (p. 113), mette in evidenza le difficoltà dell'intero passaggio dall'oralità alla scrittura, affermando che, anche dopo la messa per iscritto, in molti casi (però con l'eccezione quasi totale delle leggi visigote e longobarde) la parola del re rimaneva la vera fonte della legge. Di recente, sullo stesso argomento e sempre in chiave comparativa, v. Wormald 2003, pp. 21-53. 
re, consentendolo la divina clemenza, con un'accurata ricerca delle antiche leggi longobarde, effettuata sia da noi stessi sia grazie a uomini anziani" 45 . Almeno in teoria, dunque, la legge va cercata nel passato, testimoniato dalla memoria degli antiqui homines, e l'autorità del re (sempre in teoria) è debole di fronte ad essa; pure se Rotari si riserva, nel prologo, la capacità di modificare per il bene dei suoi sudditi le leggi tramandate. Ugualmente debole e un po' esterno appare il richiamo all'ispirazione divina. Qui in campo sono solo il re e la tradizione tribale, impersonata dagli anziani e garantita dal popolo-esercito (con i suoi capi, gli iudices), che approva l'editto. Rotari inoltre si intitola "re dei Longobardi": cade così il riferimento all'Italia introdotto da Agilulfo, anche se nel prologo si parla della provincia Italiae come ambito concreto, in senso territoriale, di esercizio del dominio longobardo ${ }^{46}$.

Con il regno di Rotari si definiscono anche, per la prima volta, le basi economiche della regalità e al tempo stesso si delinea la fisionomia del sovrano come detentore della giustizia suprema. Il sistema delle multe presente nell'editto incrementa infatti il fisco regio, la curtis regia, che appare la base materiale del potere del re: il fisco rappresenta il mezzo per rimunerare gli ufficiali pubblici - fra i quali i gastaldi si presentano come i referenti privilegiati dei sovrani - e per mantenere la stessa corte (il palatium), oltre che un utile strumento per la costruzione di una clientela pubblica attorno al sovrano ${ }^{47}$.

La seconda metà del secolo VII vede una novità significativa, lo stabilizzarsi sul trono della cosiddetta dinastia bavarese, ossia una serie di sovrani cattolici discendenti sia da Teodolinda sia da suo fratello Gundoaldo, duca di Asti; di essi parleremo diffusamente più avanti ${ }^{48}$. Ora conviene piuttosto sottolineare come già con Ariperto I (653) si arrivi all'abolizione dell'arianesimo, un fatto che si accompagna alla conversione coatta degli Ebrei ed alla prima donazione-restituzione di patrimoni alla chiesa romana (il patrimonium Alpium Cottiarum). È evidente come il cattolicesimo professato dalla nuova dinastia produca effetti su due piani, da una parte in direzione di una più ricca concezione della regalità come garante dell'ortodossia religiosa, sviluppando i primi accenni che si erano avuti all'età di Agilulfo, dall'altra inducendo i sovrani a ricercare nuovi collegamenti e ad avvicinarsi dunque al potente centro politico-religioso rappresentato da Roma e dal papa. Come spia evidente di questo processo si può segnalare la presenza pressoché ovunque, nel regno, di una regolare gerarchia cattolica: a partire dagli anni 650-68o circa, dopo un vuoto nelle fonti che in alcune sedi si prolungava da quasi un seco-

45 Leges Langobardorum cit., Roth. prol. e c. 386.

46 Harrison 1998, pp. 242-243.

47 Gasparri, 1990, pp. 254-256. Wormald 1977, p. 111, ricorda come il sistema di multe compensative dei delitti era presente presso i Germani fin dall'età di Tacito (Germania, c. 12).

$48 \mathrm{Cfr}$. sotto, paragrafo 5 . 
lo, vediamo riapparire un vescovo anche nelle numerose città nelle quali non sappiamo se vi fosse stato nel periodo immediatamente precedente ${ }^{49}$.

Questa crescita generale della regalità longobarda si inserisce in un quadro pacifico, solo brevemente interrotto dall'età di Grimoaldo (662-672). Si giunge così alla prima vera e propria pace con Bisanzio nel 680, ai margini del concilio di Costantinopoli convocato in funzione antimonotelita dall'imperatore Costantino IV ${ }^{50}$. In un simile contesto diventa possibile un'affermazione come quella fatta da Mansueto di Milano e dai vescovi suoi suffraganei, che nella sinodo milanese del 679-80, preparatoria di quel concilio, scrivono allimperatore di trovarsi "sub felicissimos et christianissimos a Deo custodiendos principes, dominos nostros, precellentissimos reges Christiane religionis amatores"; un'affermazione impensabile fino a qualche decennio prima, visto che i due principi cristianissimi ai quali alludono i vescovi sono Pertarito (672-688) e suo figlio Cuniperto (678-700), due re longobardi ${ }^{51}$.

\section{Il pieno sviluppo della monarchia cattolica}

Il regno di Cuniperto è particolarmente ricco di spunti, che provano la sempre più matura elaborazione di un'ideologia regia tesa a imitare la dignità imperiale bizantina, che rappresentava il modello indiscusso di ogni sovranità cattolica. Il dato più vistoso è rappresentato dalla convocazione nel 698 di una sinodo a Pavia, per stroncare una volta per sempre l'eresia dei Tre Capitoli: assiso nel suo palazzo, il re assiste alla composizione del dissidio in un'atmosfera di chiarissima imitazione costantinopolitana ${ }^{52}$. Un altro fatto che va nella medesima direzione è costituito dall'emissione di monete d'oro che, per la prima volta, al posto del nome dell'imperatore di Bisanzio portavano quello del re longobardo; a questa esplicita imitazione imperiale andava unita un'altra innovazione, l'apparizione sempre sulle monete dell'effigie di s. Michele, il cui culto lo stesso Cuniperto, in particolare dopo la vittoriosa battaglia di Coronate contro il rivale Alahis, sosteneva con un vigore anche maggiore di quello tradizionale presso i Longobardi. Stando alla lettera del racconto fatto da Paolo Diacono, anzi, al re longobardo veniva prestato un giuramento militare (solo da parte dei

49 Delogu 1980, pp. 86-90, sottolinea l'importanza della costruzione di una chiesa dedicata al Salvatore, subito fuori Pavia, da parte di Ariperto, che esprime l'ortodossia del re in materia cristologica e dunque rappresenta "la prima espressione monumentale della dignità e insieme della fede di un re longobardo" (p. 88). Per la conversione degli Ebrei si veda il Carmen citato alla nota 48.

$5^{0}$ Delogu 1980, pp. 90-101.

51 J. D. Mansi, Sacrorum conciliorum nova et amplissima collectio, XI, rist. anastatica Graz 1960, col. 205.

$5^{2}$ Carmen de synodo Ticinensi, in MGH, Scriptores rerum Langobardicarum cit., pp. 189-191. 
grandi del regno?) in presenza proprio dell'immagine dell'arcangelo guerriero, forse all'interno dell'omonima chiesa pavese ${ }^{53}$.

Dimensione cattolica e proiezione territoriale del potere, inoltre, si intrecciano nuovamente con chiarezza sotto Cuniperto, come già quasi cento anni prima con Agilulfo. La sua epigrafe infatti presenta l'Italia che lo piange come signore, padre, pastore e marito; l'Italia, e non la gente longobarda: "Cunigpert florentissimus ac robustissimus rex quem dominum Italia patrem atque pastorem inde flebile maritum iam viduata gemet" 54 .

Tutti questi elementi si ritrovano con Liutprando (712-744), Ratchis (744-747) e Astolfo (747-756). Le prove sono numerose: si va dal prologo delle leggi da Liutprando aggiunte per la prima volta all'editto nel 713, dove egli si definisce, sia pure in modo indiretto, "christianus ac catholicus princeps" - espressioni simili torneranno con evidenza negli anni successivi - e dove si afferma che la legge è opera del sovrano ispirato da Dio, al prologo di Ratchis del 746, che inizia con l'affermazione secondo la quale "Christi Iesu et Salvatoris nostri adsidue nos convenit precepta conplere". In quell'occasione il re, pur parlando della "nostra stirpe dei Longobardi", intitola se stesso soltanto "precellentissimus et eximius princeps", senza adoperare il consueto genitivo etnico ${ }^{55}$. La massima apertura della titolatura regia avviene però con Astolfo, che nel prologo delle sue leggi del 750 si definisce, nel nome di Gesu Cristo, "rex gentis Langobardorum, traditum nobis a domino populo Romanorum". Più che alludere a fantastiche mire imperiali, è corretto sostenere che mediante questa complessa titolatura Astolfo volesse certo presentare il suo come un potere monarchico successore di quello dell'impero, ma solo in quanto ne aveva con piena legittimità preso il posto nell'ambito della penisola italiana, ponendo così fine - almeno negli intenti del re - a quasi due secoli di rivalità fra Longobardi e Bizantini. Il fatto che il prologo fosse prece-

53 Paolo Diacono, Historia Langobardorum cit, V, 41, racconta che l'immagine di s. Michele, apparsa fra le file dei guerrieri del re, avrebbe impaurito il ribelle Alahis, avversario di Cuniperto nella battaglia di Cornate d'Adda: Alahis afferma infatti di non poter accettare la sfida di Cuniperto a battersi a duello perché "inter contos suos sancti archangeli Michaelis, ubi ego illi iuravi, imaginem conspicio" (sul giuramento, Delogu 1980, p. 101). L'aneddoto rispecchia evidentemente la versione ufficiale che della battaglia e della vittoria del re si dava a corte, pure se Cuniperto costruì in seguito, sul luogo dello scontro, un monastero dedicato non a s. Michele ma a s. Giorgio, altro santo militare di origine orientale (Paolo Diacono, Historia Langobardorum cit, VI, 17). Sulla monetazione: Delogu 1980, pp. 106-107 e Harrison 1998, pp. 246-247 e 251252. Infine, v. Delogu 1994, pp. 19-20, che inquadra la monetazione aurea di Cuniperto nell'insieme delle nuove emissioni del periodo, mettendo in rapporto la ripresa economica che esse esprimono con la nuova fisionomia istituzionale assunta dal potere longobardo dopo la stipulazione della pace del 680 con l'impero.

54 Panazza 1953, n. 58, pp. 250-251 e Consolino 1987, pp. 161-162.

55 Leges Langobardorum, Liut. prol. 713 e Ratch. Prol. 746. 
dente di un anno circa alla caduta di Ravenna non ci autorizza dunque a dilatarne il significato: Ravenna, l'Esarcato, il cuore stesso insomma dell'Italia bizantina erano ormai un frutto maturo che stava per cadere nelle mani del re; e perciò i Romani del prologo sono senza dubbio i Bizantini d'Italia, o meglio gli abitanti di Esarcato e Pentapoli56.

Non ci stupiamo quindi che la monetazione di Astolfo assuma tratti ancora più esplicitamente romanizzanti, e che il re intenda la superiorità che pretende ormai di esercitare sulla città stessa di Roma nella forma, anch'essa di chiara imitazione imperiale, di un prelievo fiscale individuato nella misura di un solido per caput ${ }^{57}$. E se l'autorappresentazione romanizzante è quella prevalente in Astolfo, da tratti evidenti traspare una più profonda matrice cattolica nella legislazione, più antica di qualche anno, di Liutprando, il re che legifera in materia di matrimonio in base alle decisioni ecclesiastiche e ai suggerimenti papali, che fa costruire chiese e monasteri, che, infine, invia una spedizione in Sardegna per recuperare le reliquie di s. Agostino minacciate dai Saraceni e le fa trasportare a Pavia, nella chiesa di S. Pietro in Ciel d'Oro attigua al monastero da lui stesso fondato -, a protezione di essa e della sua città-capitale. La causa Dei è, per Liutprando, il fine ultimo di una legislazione nella quale la protezione economica e la tutela fisica di donne e minori si accompagna a quella delle chiese ${ }^{58}$. Lo stesso sovrano, nell'epigrafe dedicatoria del monastero di Corteolona, costruito dopo il 729, delinea un'immagine dei Longobardi come nuovo Popolo Eletto: siamo in piena crisi iconoclastica e dunque in un momento ricco di potenzialità per la monarchia longobarda, alla quale allora guardavano anche le popolazioni dell'Italia bizantina come a un fattore di protezione. Il momento passò, e l'Esarcato i Longobardi dovettero prenderlo con le armi, circa venti anni più tardi; ma l'impostazione teorica rimaneva ${ }^{59}$.

56 Leges Langobardorum, Ahist. Prol. 750. Harrison 1993, p. 189, presenta, sia pure in forma dubitativa, l'ipotesi (peraltro insostenibile) che Astolfo "might have had - the sources are hard to interpret - Roman imperial ambition" (tra l'altro l'autore fraintende sia Delogu 1980, pp. 169170, che Jarnut 1982, p. 111, i quali entrambi vedono - correttamente - nell'adozione di una simbologia e di una politica "imperiale" da parte di Astolfo il tentativo del re di legittimarsi pienamente agli occhi degli abitanti dell'Italia bizantina).

57 Liber Pontificalis, ed. L. Duchesne, I, Paris 1886, p. 441; per un commento dell'episodio, Gasparri 1990, p. 267. Harrison 1998, pp. 250-251, sottolinea come, con tutta probabilità, Astolfo fu l'unico re longobardo a coniare solidi d'oro; ma, riguardo alla monetazione, il dato importante, a mio avviso, non è tanto questo, ma il fatto che già da Cuniperto i sovrani longobardi facessero rappresentare la propria effigie su monete d'oro, sia pure di minore valore dei solidi (tremissi): cfr. sopra, nota 49. Inoltre, già il duca di Benevento Gisulfo I (689-706 circa) aveva coniato dei solidi: cfr. Delogu 1994, p. 19.

58 Paolo Diacono, Historia Langobardorum cit, VI, 48 (traslazione delle reliquie a Pavia) e 58 (fondazione del monastero - ma forse anche della chiesa - di S. Pietro in Ciel d'Oro). Sui contenuti cattolici della legislazione di Liutprando, v. GASPARRI 1983, pp. 113-120.

59 Tituli saec. VIII, in MGH, Poetae Latini Aevi Carolini, I, p. 105 sgg. 
I tratti romanizzanti e cattolici si univano ad una più matura consapevolezza dell'ambito territoriale di riferimento del potere regio. Se dal punto di vista pratico contano le numerose operazioni di chiarificazione confinaria di confini interni ed esterni al regno - eseguite durante il regno di Liutprando 60 , è con Ratchis che nelle leggi si esprime il modello di un governo costruito su un efficace e imparziale esercizio della giustizia radicato su base territoriale: " che ciascun giudice debba ogni giorno risiedere in giudizio nella sua civitas", scrive il re, laddove civitas rappresenta la circoscrizione territoriale, centrata sulla città, dove agisce lo iudex, ossia il funzionario pubblico al massimo livello, duca o gastaldo ${ }^{61}$. Contemporaneamente, nella pratica si perfeziona la struttura materiale di funzionamento del potere pubblico, basata sullo sfruttamento del patrimonio fiscale e articolata nel palatium, al centro, e nelle curtes in periferia, oltre che accompagnata da un sistema peraltro molto imperfetto e mal conosciuto di tributi62. Anche con questi limiti, il progresso civile e la sia pur pallida imitazione imperiale bizantino-cattolica confermano la trasformazione del potere monarchico longobardo nella sua età matura.

Si precisa infine anche il potere di mobilitazione militare da parte del re, espresso mediante un bando che, almeno a partire da Astolfo, appare esteso a tutti i liberi possessori indipendentemente dalle loro origini etniche, con distinzioni fra loro fatte esclusivamente sulla base della ricchezza. Tale potere va inteso sia come convocazione all'esercito generale sia come semplice obbligo alla caballicatio accanto al sovrano o ad uno iudex ${ }^{63}$. Fatto significativo, alla convocazione non sfuggono nemmeno i vescovi, pure se forse non tutti saranno stati mobilitati dal re come accadde al vescovo lucchese Walprando, probabilmente morto in guerra contro i Franchi di Pipino nel 754. Il coinvolgimento degli ecclesiastici nella gestione del potere all'interno del regno longobardo si verificò però sulla base dei loro legami personali e familiari - Walprando era figlio del duca di Lucca, così come Pietro vescovo di Pavia era parente di Liutprando - e non a causa di una compenetrazione strutturale tra publicum ed ecclesia, come avvenne invece nel coevo regno franco guidato dai Pipinidi-Arnolfingi ${ }^{64}$.

60 Gasparri 1990, pp. 241-249 e Gasparri 19923, pp. 5-8.

${ }^{61}$ Leges Langobardorum, Ratch. c. 1 (anno 745).

62 Gasparri 1990, pp. 256-268.

63 Leges Langobardorum, Ratch. c. 4 (anno 745) per la caballicatio e Ahist. cc. 2-3 (anno 750) per la mobilitazione generale dell'esercito.

64 Su quest'argomento, fino a comprendere tutta l'età carolingia, vedi Tabacco 1993, pp. 45-94 e 165-208. 


\section{Re e regine: la continuità del potere}

L'accenno al regno franco invita a effettuare una comparazione fra i due regni, che erano i più forti dell'occidente ex-romano e che, come si accennava più sopra, si scontrarono fra di loro nei decenni centrali del secolo VIII, finché i Franchi non si impadronirono del regno longobardo. Di recente sono state avanzate delle proposte di interpretazione che presentano la maggior forza dei Franchi come il prodotto, oltre che del sostegno strutturale del clero, di una maggiore ricchezza e attitudine guerriera dell'aristocrazia ${ }^{65}$. Si tratta di interpretazioni importanti. Ma accanto ad esse va considerato anche il problema, che coinvolge direttamente il nostro tema, rappresentato dalla mancata stabilizzazione in senso dinastico della regalità longobarda.

Quest'ultimo problema va però affrontato senza schemi precostituiti. Ł̀ vero che i Franchi furono fronteggiati da sovrani longobardi di origine friulana di recente giunti sul trono, e in ultimo addirittura da un homo novus qual era, molto probabilmente, Desiderio. Ma questo non consente di affermare che non vi sia stata, in precedenza, una stabilizzazione secolare della regalità longobarda all'interno di un gruppo familiare. Non fu una stabilizzazione dinastica, se a quest'ultimo aggettivo diamo il valore di successione diretta padre-figlio in senso maschile; ma se allarghiamo la nostra prospettiva, considerando l'elemento femminile di pari importanza di quello maschile, allora si può affermare con ragionevole certezza che un medesimo gruppo familiare abbia gestito il potere regio fra il 589 e il 712 .

Si tratta della "dinastia bavarese" alla quale si è accennato più sopra66. Teodolinda, figlia del duca bavarese Garipald ma discendente del re longobardo Wacone, un lethingio, diviene regina dei Longobardi nel 589, sposando Autari. Rimane regina alla morte di questi, nel 590, sposando Agilulfo (e qui il suo ruolo nella trasmissione della regalità è trasparente); a loro succede sul trono il figlio Adalaloaldo, fra il 616, anno della morte di Agilulfo, e il 626. A questo punto, però, non avviene una vera frattura, perché una sorella di Adaloaldo, Gundiperga, sposa in successione i sovrani successivi, quali e quanti è impossibile dirlo con sicurezza; combinando i dati delle fonti (Paolo Diacono, Giona e Fredegario), le si potrebbero attribuire come mariti sia Arioaldo che Rotari e Rodoaldo, i tre sovrani succeduti, nell'ordine, ad Adaloaldo ${ }^{67}$. Pure se appare abbastanza improbabile che li abbia sposati tutti e tre, tuttavia è evidente che anche Gundiperga, come già sua madre, ha rappre-

65 Wickham 1988, pp.153-170.

66 Sopra, testo a nota 48.

67 Paolo Diacono, Historia Langobardorum cit., IV, 47; Giona, Vita Columbani, in MGH, Script. rer. Mer., IV, Hannoverae et Lipsiae 1902, II, 24, e Fredegario, Chronicon, in MGH, Script. rer. Mer., II, Hannoverae 1888, IV, 50. 
sentato un elemento di continuità familiare (e in quanto tale è stata ricordata) all'interno della regalità, nel periodo di transizione seguito alla scomparsa di Adaloaldo, fra il 626 e il 653; il filo, dunque, non si era spezzato del tutto.

Nel 653 diviene re Ariperto I, figlio di Gaidoaldo duca d'Asti fratello di Teodolinda. Siamo di fronte ad un passaggio (comunque interno al medesimo gruppo parentale) che forse è meno netto di quanto appaia a prima vista. Infatti il figlio di Ariperto, Pertarito, re nel 661 insieme al fratello Godeperto, ebbe una moglie di nome Rodelinda ${ }^{68}$. Su di lei, Paolo non ci dà alcuna informazione genealogica, però ci soccorre l'epitaffio di Cuniperto, figlio di Pertarito e Rodelinda e re dal 678 insieme al padre (e dal 680 da solo). In esso si scrive che Cuniperto, se da parte paterna discendeva da un padre e un nonno re (Pertarito e Ariperto), "alia de parte", ossia da parte materna, "[...] rex fuit avus, mater gubernacula tenuit regni”. A parte l'accenno ad un ruolo attivo di Rodelinda nella gestione del potere regio, una circostanza verificatasi forse nel primissimo periodo di regno di Cuniperto, subito dopo la morte del padre, colpisce il fatto che si dica che anche il padre della regina era stato re. Non può trattarsi di un fatto inventato, il tono panegiristico non potrebbe consentire un falso che ai contemporanei sarebbe apparso evidente ${ }^{69}$. E allora, l'unica spiegazione possibile è che la regalità paterna di Rodelinda vada ricercata nell'altro ramo della famiglia bavarese; qui ci può soccorrere il suo nome, dove la seconda parte, - linda, rinvia appunto a Teodolinda, e la prima, Rode -, a uno dei sovrani che avrebbero sposato Gundiperga figlia di Teodolinda, più verosimilmente Rotari, il cui figlio maschio si chiamava Rodoaldo. Rodelinda, insomma, potrebbe essere stata sorella di quest'ultimo e figlia di Rotari e Gundiperga. In questo modo le due linee si salderebbero: e il prestigio di Rodelinda, dovuto al suo carisma familiare, spiega sia la sua accennata "reggenza", sia il fatto che - come le sue presumibili antenate - sia stata ricordata come regina costruttrice. A lei si deve infatti la fondazione di S. Maria delle Pertiche a Pavia. Sul nome di Rodelinda, infine, è costruito quello di sua figlia Wigilinda, sposa del duca di Benevento Grimoaldo $\mathrm{II}^{70}$.

Alla morte di Cuniperto, nel 700, suo figlio Liutperto regnò per breve tempo, deposto ben presto da Ragimperto, duca di Torino e cugino di suo padre. Seguì poi il figlio di Ragimperto, Ariperto II, che fu re fino al 712. Nell'ultima fase della dinastia bavarese, quindi, salì al potere una ulteriore diramazione del ramo familiare discendente da Gundoaldo, questa volta tramite Godeperto, fratello di Pertarito e padre di Ragimperto. Fu solo nel 712, con Ansprando e Liutprando, che ci fu un cambio vero e proprio della fami-

68 Paolo Diacono, Historia Langobardorum cit., IV, 51 e V, 34.

$69 \mathrm{Il}$ testo dell'epigrafe è riportato in Consolino 1987, pp. 161-162 (l'autrice del saggio sembra ritenere invece il passo puramente encomiastico).

70 Paolo Diacono, Historia Langobardorum cit., VI, 2. 
glia al vertice del regno; iniziò allora un'altra storia, che doveva portare al potere qualche decennio più tardi (744) i Friulani, alla vigilia ormai dello scontro con i Franchi. Ma in precedenza, è bene ribadirlo, un unico gruppo familiare aveva gestito il regno, quello bavarese, caratterizzato da una struttura interna più forte in senso orizzontale che verticale, cognatizia - visto il ruolo delle donne - più che agnatizia. Del resto, lo stesso matrimonio bavaro di Liutprando potrebbe essere forse letto come un desiderio di ricollegarsi alla precedente stirpe regia: infatti Guntrut, sua moglie, era discendente di una famiglia che potrebbe essere ricollegata a quella di Garipald, padre di Teodolinda e Gundoaldo ${ }^{71}$.

Il ruolo forte dell'elemento femminile non deve affatto stupire. Anche solo restando in ambito regio, è presumibile ad esempio che nella famiglia del re Ratchis, primo dei Friulani, fosse la madre Ratperga - nonostante ciò che dice Paolo sul suo aspetto rozzo (la definisce infatti facie rusticana) - a rappresentare la linea più importante, e non suo padre Pemmone, almeno se si dà la giusta importanza alla trasmissione onomastica ${ }^{72}$; e questa stessa circostanza la si può verificare, con maggiore certezza, nel caso dell'ultimo re Desiderio e di sua moglie Ansa: gli antenati della regina, che erano dei ricchi proprietari, ci sono noti, al contrario degli avi di Desiderio ${ }^{73}$.

Nel chiudere questa parentesi dinastica, ne va sottolineata l'importanza per una comprensione delle vicende del potere regio longobardo. Non furono infatti la fragilità dei meccanismi di trasmissione del potere e i frequenti cambiamenti al vertice - e meno che mai la presunta, e non dimostrabile, lotta fra re ariani e cattolici ${ }^{74}$ - a indebolire la regalità longobarda, rimasta al contrario ancorata per oltre un secolo entro un gruppo familiare abbastanza ben definito, ma il passaggio, avvenuto troppo tardi, da questo gruppo radicato nell'area nordoccidentale ad un altro, che aveva le sue basi nel nordest friulano e veneto. I Friulani in prospettiva erano più forti, ma non ebbero il tempo sufficiente per rinsaldarsi al potere ed estendere le loro reti clientelari, in modo tale da poter reggere in modo efficace l'urto dei Franchi compattati intorno ai Pipinidi, esponenti questi ultimi di una dinastia teoricamente anch'essa "nuova", ma che in realtà al momento della conquista dell'Italia aveva già alle spalle quasi un secolo di esercizio del potere all'interno del regno franco 75 .

\footnotetext{
71 Paolo Diacono, Historia Langobardorum cit., VI, 43.

72 Paolo Diacono, Historia Langobardorum cit., VI, 26.

73 Bruhl, Codice Diplomatico longobardo cit., 38 (766).

74 È questa la teoria di Boguetti, da considerare però ormai del tutto superata: cfr. Gasparri 2001, pp. 219-247.

75 Gasparri 1999, pp. 105-128 per i Friulani.
} 


\section{Dalla lancia alla spada}

L'evoluzione in senso bizantino-cattolico del potere regio si espresse in modo più contraddittorio sul piano dei simboli. Quest'affermazione non è del tutto vera, certo, se all'interno della simbologia del potere comprendiamo la costruzione di edifici sacri, un'azione in cui si distinsero non solo i sovrani, a partire da Ariperto I alla metà del VII secolo, ma anche le regine a partire da Teodolinda. In alcuni casi l'imitazione bizantina appare chiara, basti pensare alla costruzione dell'oratorio palatino di S. Salvatore da parte di Liutprando ${ }^{76}$. Ma l'esempio di Desiderio, ultimo sovrano longobardo, che insieme alla moglie Ansa fondò il monastero bresciano di S. Salvatore, autentico monastero di famiglia eretto sul patrimonio ereditario di Ansa (pure se in seguito arricchito di ampi beni fiscali), mostra come, nel tardo VIII secolo, l'erezione di chiese e monasteri non appaia più una prerogativa regia, bensì possa sposarsi senza mediazione alcuna ad una politica aristocratica di tipo dinastico e patrimoniale ${ }^{77}$.

Altri dunque sono i simboli specifici della regalità in senso stretto. E in questo campo dobbiamo registrare una certa resistenza al cambiamento, dovuta ad un saldo radicamento della regalità longobarda nella tradizione anche nei momenti della sua massima trasformazione. Infatti la lancia rimase sempre il simbolo principale del potere del re, sanzionata anche dalla presenza, fino sul campo di battaglia, di portatori ufficiali della lancia regia. Quest'ultima, secondo il racconto di Paolo Diacono, appare un elemento capace di rappresentare il re qualora questi sia fisicamente lontano e persino di condurre l'esercito alla vittoria, come avvenne nella battaglia di Forino del $663^{78}$. Un portalancia lo troviamo pure accanto a Ratchis quando era ancora duca del Friuli, cosicché dobbiamo pensare che anche il potere ducale si esprimesse con un linguaggio simbolico non dissimile da quello regio. $\mathrm{E}$ del resto, come è già stato osservato, nella lamina del Bargello Agilulfo ha una spada sulle ginocchia ma è comunque raffigurato attorniato da due portalancia ${ }^{79}$.

Enigmatico, al contrario, appare il contenuto degli obsequia palatina e della regia dignitas che - sempre sulla base del racconto di Paolo - si fecero incontro al re Pertarito allorché questi ritornò a Pavia nel 672, dopo un esilio decennale. Il primo termine può forse essere tradotto con "seguito" o "corteggio di palazzo", identificando cioè il personale di corte; il secondo con maggiore verisimiglianza può essere inteso come "simboli del potere regio",

\footnotetext{
76 Paolo Diacono, Historia Langobardorum cit, VI, 58, e Delogu 1977, pp. 17-19, dove esamina in generale le fondazioni regie longobarde, e pp. 21-25 per i possibili rapporti fra le fondazioni pavesi (S. Salvatore e anche S. Michele ad palatium, quest'ultima chiesa fatta costruire da Grimoaldo) - e la S. Sofia del principe beneventano Arechi II.

77 Gasparri 1980, pp. 436-440.

78 Paolo Diacono, Historia Langobardorum cit, V, 10.

79 Paolo Diacono, Historia Langobardorum cit, VI, 52. Cfr. sopra, testo e nota 36.
} 
purtroppo non meglio specificati 80 . Dal racconto di Paolo, comunque, traspare con evidenza il ruolo centrale, come sede fisica del potere regio, del palatium, che rimane tale anche quando il re è lontano: il possesso del palazzo equivale in un certo senso al possesso del regno, il palazzo occuperebbe cioè lo stesso ruolo giocato dal tesoro regio nel mondo franco ${ }^{81}$.

I simboli menzionati in modo vago da Paolo Diacono - la regia dignitas - rimagono oscuri, per cui non sappiamo se, accanto alla lancia, fra essi vi fosse anche una corona. Di corone regie longobarde abbiamo menzione qua e là nelle fonti - e quella della regina Tedolinda si è addirittura conservata -, ma ignoriamo se si trattasse di vere e proprie manifestazioni della regalità o (ipotesi in linea di massima più probabile) di semplici oggetti donati alle chiese in segno di devozione. Certo, il fatto che nel 728 Liutprando, dopo aver rinunciato ad attaccare Roma, donasse a S. Pietro una corona e una spada con il suo cinturone, accanto agli altri regalia insignia, parla a favore dell'ipotesi che la corona fosse ormai entrata a far parte del corredo normale dei simboli regali. Ma il fatto che si tratti di una fonte come il Liber pontificalis a riportare l'episodio, di un testo cioè anche culturalmente esterno al mondo longobardo, induce a qualche cautela ${ }^{82}$. Se la notizia fosse totalmente esatta saremmo veramente all'alba di un'epoca nuova, quella che si delineerà compiutamente con i nuovi dominatori franchi, padroni del regno longobardo a partire dal 774. Nel 781, Pipino fu consacrato rex Langobardorum a Roma da papa Adriano I tramite l'unzione, in chiesa, secondo il modello impostosi trent'anni prima nel regno franco. Circa sessant'anni più tardi, nell'844, anche il futuro imperatore Ludovico II fu fatto re dei Longobardi a Roma - si tratta delle uniche due elezioni regie longobarde di età carolingia a noi note nel loro svolgimento rituale -, stavolta da papa Sergio II ${ }^{83}$. In questa circostanza, il papa unse Ludovico con l'olio santo e lo incoronò con una preziosa corona; poi, "consegnandogli la spada regia, il papa gli ordinò di cingerla". L'idea carolingia della militia regia simbolizzata dal gladius e dal cingulum militiae, secondo la quale il dovere principale del sovrano era quello di proteggere (servire) il popolo cristiano e la chiesa, aveva cancellato le ultime vestigia della monarchia "odinica" dei Longobardi, che erano convissute fino a quel momento ambiguamente, tramite la lancia, con la nuova configurazione cattolica e romanizzante del potere ${ }^{84}$. Ora tali vestigia erano svanite definitivamente, e insieme con esse era svanito il ruolo svolto dai guerrieri longobardi nella cerimonia di elezione regia. La nuova regalità cattolica cercava altrove la base legittimante del suo potere.

80 Paolo Diacono, Historia Langobardorum cit, V, 33.

81 Gasparri 2004, pp. 47-67.

82 Liber pontificalis, par L. Duchesne, I, Paris 1981, (rist. anastatica), p. 408.

83 Liber pontificalis cit., p. 89.

84 Sull'idea di militia in età carolingia v. Keller 1982, pp. 59-117. 


\section{Bibliografia}

Amory P., 1997, People and identity in Ostrogothic Italy, 489-554, Cambridge

Azzara C., 1992, Introduzione al testo, in Azzara C. - Gasparri S., Le leggi dei Longobardi. Storia, memoria e diritto di un popolo germanico, Milano, pp. XXIII-XLI

Bognetti G., 1966, S. Maria foris Portas di Castelseprio e la storia religiosa dei Longobardi, in ID., L'età longobarda, II, Milano

Bognetti G., 1967, L'influsso delle istituzioni militari romane e la natura della fara, in ID., L'età longobarda, III, Milano, pp. 1-46

Brühl C., 1968, Fodrum, Gistum, Servitium Regis. Studien zu den wirtschaftlichen Grundlagen des Königtums im Frankenreich und Italien vom 6. Bis zur Mitte des 14. Jahrhunderts, Köln - Graz

Consolino F. L., 1987, La poesia epigrafica a Pavia longobarda nell'VIII secolo, in Storia di Pavia, II, L'Alto Medioevo, Milano, pp. 159-176

Delogu P., 1977, Mito di una città meridionale (Salerno, secoli VIII-XI), Napoli

Delogu P., 1980, Il regno longobardo, in Delogu P. - Guillou A. - Ortalli O., Storia d'Italia, I, Longobardi e Bizantini, Torino, pp. 1-216

Delogu P., 1994, La fine del mondo antico e l'inizio del medioevo: nuovi dati per un vecchio problema, in Francovich R. - Noyé G. (ed.), La Storia dell'Alto Medioevo italiano (VI-X secolo) alla luce dell'archeologia, Firenze, pp. 7-29

Elze R., 1980, Per la storia delle corone di Monza, in Atti del VI Congresso internazionale di studi sull'alto medioevo, II, Spoleto, pp. 393-400

Frugoni C., 1998, Immagini fra tardo antico e alto medioevo: qualche appunto, in Morfologie sociali e culturali fra Tarda Antichità e Alto Medioevo, Settimane di studio del CISAM, 45, II, Spoleto, pp. 703-742

Gasparri S., 1980, Grandi proprietari e sovrani nell'Italia longobarda dell'VIII secolo, in Atti del VI Congresso internazionale di studi sull'Alto Medioevo, II, Spoleto, pp. 429-442

Gasparri S., 1983, La cultura tradizionale dei Longobardi. Struttura tribale e resistenze pagane, Spoleto

Gasparri S., 1987, Pavia longobarda, in Storia di Pavia, II, L'Alto Medioevo, Milano, pp. 19-65

Gasparri S., 1990, Il regno longobardo in Italia. Struttura e funzionamento di uno stato altomedievale, in Gasparri S. - Cammarosano P., Langobardia, Udine, pp. 237-305 (ora ristampato, con modifiche, in 
Gasparri S. (ed.), Il regno longobardo in Italia. Archeologia, società e istituzioni, pp. 1-92, Spoleto 2004)

Gasparri S., 1992, La memoria storica dei Longobardi, in Azzara C. Gasparri S., Le leggi dei Longobardi cit., pp. V-XXII

Gasparri S., $1992^{2}$, Le tradizioni germaniche nell'Italia dei Goti, in Teoderico il Grande e i Goti d'Italia, Atti del XIII Congresso internazionale di studi sull'Alto Medioevo, I, Spoleto 201-226

Gasparri S., 19923, Venezia fra i secoli VIII e IX. Una riflessione sulle fonti, in Studi veneti offerti a Gaetano Cozzi, Venezia, pp. 3-18

Gasparri S., 1997, Prima delle nazioni. Popoli, etnie e regni fra Antichità e Medioevo, Roma

Gasparri S., $1997^{2}$, Bisanzio e i Longobardi. I rapporti fra l'impero e una stirpe barbarica al tramonto del sistema tardo-antico, in Europa medievale e mondo bizantino. Contatti effettivi e possibilità di studi comparati, Nuovi Studi Storici, 40, Roma, pp. 43-58

Gasparri S., 1999, Istituzioni e poteri nel territorio friulano in età longobarda e carolingia, in Paolo Diacono e il Friuli altomedievale (secc. VI-X), Atti del XIV Congresso internazionale di studi sull'alto medioevo, Spoleto, I, pp. 105-128

Gasparri S., 2001, Roma e i Longobardi, in Roma nell'alto Medioevo, Settimane di studio del CISAM, 48, Spoleto, I, pp. 219-247

Gasparri S., 2003, I Germani immaginari e la realtà del regno. Cinquant'anni di studi sui Longobardi, in I Longobardi dei ducati di Spoleto e Benevento, Atti del XVI Congresso internazionale di studi sull'alto medioevo, Spoleto, I, pp. 3-28

Gasparri S., 2004, Il tesoro del re, in Gelichi S. - La Rocca C. (ed.), Tesori. Forme di accumulazione della ricchezza nell'alto medioevo (secoli V-XI), Roma, pp. 47-67

Geary P., 1988, Before France and Germany. The Creation and Transformation of the Merovingian World, Oxford - New York

Goffart W., 1988, The Narrators of Barbarian History (A.D. 550-80o), Princeton

Härke H., 1998, Archeologists and Migrations. A Problem of Attitude?, in "Current Anthropology", XXXIX,1, 19-24

Harrison D., 1993, The Early State and the Towns. Forms of Integration in Lombard Italy AD 568-774, Lund

Harrison D., 1998, Political rethoric and political ideology in Lombard Italy, in Pohl W. - Reimitz H. (eds.), Strategies of Distinction. The Construction of Ethnic Communities, 30o-80o, Leiden - Boston - Köln, pp. 241-254

Höfler O., 1952, Germanische Sakralkönigtum, I, Berlin

Höfler O., 1956, Der Sakralcharakter der germanischen Königtums, in Mayer T. (ed.), Das Königtum. Seine geistigen und rechtlichen 
Grundlagen, Vorträge und Forschungen, 3, Konstanz, 1956, pp. 75-104

Keller H., 1982, Militia. Vasallität und frühes Rittertum im Spiegel oberitalienischer Miles-Belege des 10. und 11. Jahrhunderts, "Quellen und Forschungen aus italienischen Archiven und Bibliotheken”, LXII, pp. 59-117

Jarnut J., 1982, Geschichte der Langobarden, Stuttgart - Berlin - Köln Mainz

Jarnut J., 1990, I Longobardi nell'epoca precedente all'occupazione dell'Italia, in Gasparri S. - Cammarosano P. (ed.), Langobardia, Udine, pp. 3-33

Modzelewski K., 1997, Europa romana, Europa feudale, Europa barbara, "Bullettino dell'Istituto Storico Italiano per il Medio Evo e Archivio muratoriano", C, pp. 377-409

Orsucci 1998, Ariani, indogermani, stirpi mediterranee: aspetti del dibattito sulle razze europee (1870-1914), "Cromohs", 3, <http://www.unifi.it/riviste/cromohs/3_98/orsucci.html>

Panazza G., 1953, Lapidi e sculture paleocristiane e pre-romaniche di Pavia, in Arte del Primo Millennio, Atti del II Convegno per lo Studio dell'Arte dell'Alto Medio Evo, Torino, pp. 211-301

Pohl W., 1991, Conceptions of ethnicity in early medieval studies, "Archeologia Polona", XXIX, pp. 39-49

Pohl W., 1992, I Goti d'Italia e le tradizioni delle steppe, in Teoderico il Grande e i Goti d'Italia, Atti del XIII Congresso internazionale di studi sull'Alto Medioevo, I, Spoleto 227-251

Ravegnani G., 1992, Dignità bizantine dei dogi di Venezia, in Studi veneti offerti a Gaetano Cozzi, Venezia, pp. 19-29

Schlesinger W., 1956, Das Heerkönigtum, in Mayer T. (ed.), Das Königtum. Seine geistigen und rechtlichen Grundlagen, Vorträge und Forschungen, 3, Konstanz, 1956, pp. 105-142

Tabacco G., 1993, Le ambiguità delle istituzioni nell'Europa costruita dai Franchi, e Il volto ecclesiastico del potere in età carolingia, in Sperimentazioni del potere nell'alto medioevo, Torino, pp. 45-94 e pp. 165-208

Ward D., 1968, The divine Twins. An Indo-Europea Myth in Germanic Tradition, Berkeley - Los Angeles

Wenskus R., 1961, Stammesbildung und Verfassung. Das Werden der frühmittelalterlichen Gentes, Köln - Graz

Wickham C., Aristocratic Power in Eight-Century Lombard Italy, in Calander Murray A. (ed.), After Rome's Fall. Narrators and Sources of Early Medieval History. Essays presented to Walter Goffart, Toronto 1998, pp. 153-170

Wolfram H., 1967, Intitulatio, Mitteilungen des Instituts für Österreichische Geschichtsforschung”, Ergbd. 21 
Wood I., 1995, Defining the Franks, in Forde S. - Johnson L. - Murray A. V. (eds.), Concepts of Nationale Identity in the Middle Ages, Leeds, pp. 47-57

Wormald P., 1977, Lex scripta and Verbum regis: Legislation and Germanic Kingship, in Sawyer P. H. - Wood I. (eds.), Early Medieval Kingship, Leeds, pp. 105-138

Wormald P., 1986, Celtic and Anglo-Saxon Kingship: Some Further Thoughts, in Szarmach P. E. (ed.), Sources of Anglo-Saxon Culture, Studies in Medieval Culture, 20, Kalamazoo, pp. 151-183

Wormald P., 2003, The Leges barbarorum: Law and Ethnicity in the PostRoman West, in Goetz H.-W. - Jarnut J. - Pohl W. (eds.), Regna and Gentes. The Relationship between Late Antique and Early Medieval Peoples and Kingdoms in the Transformation of the Roman World, Leiden-Boston, pp. 21-53

\section{Fonti}

Carmen de synodo Ticinensi, in MGH, Scriptores rerum Langobardicarum et Italicarum saec. VI-IX, ed. L. Bethmann - G. Waitz - O. Holder-Egger, Hannoverae 1878, pp. 189-191

Codice Diplomatico Longobardo, ed. C. Brühl, III,1, in Fonti per la Storia d'Italia, 64, Roma 1973

Gregorio Magno, Registrum Epistolarum, in MGH, Epistolae, t. I, ed. P. Ewald - L. M. Hartmann, Berolini 1891

Leges Langobardorum 643-866, Germanenrechte Neue Folge, Westgermanisches Recht, bearb. von F. Beyerle, Witzenhausen 1962 (rist. anast. D..i Weimar 1947)

Liber Pontificalis, par L. Duchesne, I, Paris 1981 (rist. anast.)

Origo gentis Langobardorum in MGH, Scriptores rerum Langobardicarum cit., pp. 1-16

Paolo Diacono, Historia Langobardorum, in MGH, Scriptores rerum Langobardicarum cit., pp. 12-187

Sacrorum conciliorum nova et amplissima collectio, ed. J. D. Mansi, XI, Graz 1960, col. 205 (rist. anast.)

Tituli saec. VIII, in MGH, Poetae Latini Aevi Carolini, I, ed. C. Dümmler, pp. 105 sgg. 


\title{
Capitali e residenze regie nell'Italia longobarda*
}

\author{
Gian Pietro Brogiolo
}

Carlrichard Brühl ha sostenuto in un famoso articolo che le sole città dei regni barbarici che possano essere definite "capitali" furono la visigota Toledo e la longobarda Pavia, città che imitano un modello "inégalé et inégalable qu'est Costantinople (et en Italie, peut-être aussi Ravenne)”.

In realtà, la situazione dell'Italia longobarda è più complessa. Pavia, come del resto riconosce lo stesso Brühl, non divenne effettiva capitale che negli anni '20 del VI secolo, dopo che i re avevano preferito nell'ordine Verona e Milano. La scarsa coesione del regno rese autonomi, di fatto e a lungo, alcuni ducati (Friuli, Tuscia, Spoleto, Benevento), trasformando le sedi ducali in piccole capitali. Una di queste, Benevento, dopo la conquista franca del 774, fu il capoluogo di un fiorente stato longobardo, destinato a sopravvivere fino alla conquista normanna. E ancora: negli ultimi vent'anni del regno, il re Desiderio, coltivando il sogno di fondare una propria dinastia, fece di Brescia una residenza regia.

Tratterò dunque non solo di Pavia, ma anche di Verona, Milano, Brescia e Benevento, privilegiando, tra gli approcci possibili, quello dei simboli di una capitale, rintracciabili nell'evoluzione della topografia e dell'architettura, cercando peraltro di interpretarne le motivazioni ideologiche e culturali².

\section{Alla ricerca di una capitale}

Fino alla scelta da parte di Arioaldo di Pavia come capitale, avvenuta nel 626, i re longobardi s’insediarono dapprima a Verona, in attesa e con la speranza andata delusa di poter conquistare Ravenna, la vera capitale italiana, e poi a Milano, già capitale dell'Impero nel IV secolo e maggiore città italiana al pari di Roma.

\footnotetext{
* Questo saggio è già apparso nel volume Sedes regiae (anni 400-80o), eds. G. Ripoll e J.M. Gurt, Barcellona 2000, pp. 135-162.

${ }^{1}$ Bruhl, 1967, p. 215.

2 Ewig, 1963; Duval, 1992.
} 
L'eredità ostrogota, che i Longobardi si apprestavano parzialmente a raccogliere, consisteva peraltro non solo di una rete di residenze regie, ma anche di un modello ideologico che le valorizzava. Al tempo di Teodorico, capitale e residenze costituivano infatti un misto di tradizione antica (Roma, Milano, Ravenna) e di nuove esigenze strategiche (Pavia, Verona, Monza). Se Ravenna era la sede ufficiale in quanto fin dall'età di Onorio (dal 405) l'ultima capitale, Roma era il simbolo dell'Impero antico che il re goto intendeva emulare con il suo programma di "renovatio urbium". Le effigi di Roma e Ravenna, poste a fianco di Teodorico nel mosaico della porta del palazzo di Ravenna, simboleggiano questa eredità. Rimase invece in ombra, durante il regno goto, Aquileia, altra residenza imperiale destinata ad una ineluttabile decadenza.

Gli interventi architettonici che le fonti, Cassiodoro e l'Anonimo Valesiano in prima fila, si incaricarono di tramandare creando il mito del re goto, riguardano prevalentemente le nuove residenze. Vengono anche ricordati restauri di edifici di spettacolo, ma la cura maggiore è dedicata ai palazzi, sede delle amministrazioni dipendenti dal re, e alle mura. In particolare, Verona, Pavia e Monza, dove il re fa costruire palazzi pubblici e, nel caso di Verona e Pavia, migliorare le fortificazioni, rivestono un'importanza strategica nel quadro del sistema difensivo apprestato nel IV-V secolo e rinforzato in età gota, tutto rivolto a bloccare le infiltrazioni di barbari attraverso le Alpi. È probabile che il messaggio ideologico abbia fatto da velo amplificando realizzazioni civili di modesta portata ${ }^{3}$, ma l'impegno destinato a Pavia e Verona fu incisivo e duraturo.

La politica di Teodorico fallì, come è noto, per ragioni interne (il regno, socialmente bipartito tra romani e goti, rimase sempre in attesa di una sintesi che non fece in tempo a giungere a maturazione) e per la minaccia dall'esterno: l'attacco mosso da Giustiniano nel 535. I Goti, che avevano impostato la loro strategia nella difesa delle Alpi, erano del tutto impreparati a resistere all'invasione da $\mathrm{Sud}^{4}$. Il processo di frammentazione del territorio italiano, prodotto dalla guerra e accompagnato da un'ulteriore selezione in funzione strategica dei capoluoghi ${ }^{5}$, non verrà ricomposto dalla conquista bizantina. L'Italia, fino al 1861, non avrà più una capitale politica ed amministrativa, ma una pluralità di sedi. L'entrata dei Longobardi in Italia nel 568, sia essa un'invasione o l'effetto di una trama di Narsete, acuisce la frammentazione della penisola. La loro incapacità, alla fine del VI secolo, nel completare la conquista non deriva solo dalla forte resistenza bizantina, ma anche dalla frammentarietà della loro struttura sociale e politica. Una società divi-

3 La Rocca, 1993.

4 Settia, 1993.

5 Gasparri, 1990, p. 279. 
sa in gruppi tribali (fare), comandati da un capo, che spesso si muovono in modo autonomo se non di fatto indipendente dal re, ridisegna la geografia del potere delle regioni conquistate. Venti castelli e venti città di nuova fondazione diverranno le nuove sedi di potere, tante piccole capitali di ducato tutte accomunate dalla centralità della guerra contro i Bizantini ed i Franchi loro alleati. Mentre il re, che non ha una sede fissa, si sposta tra Pavia, Milano e Verona?.

Il messaggio ideologico del potere non è più affidato alla monumentalità di una capitale e all'evergetismo del re, ma ai valori della stirpe e ai rapporti di clientela con il capo militare. L'esercito è al centro della società. La sua coesione è rinsaldata dalle assemblee che si tengono a Pavia presso la grande necropoli "ad perticas", e dai riti della morte, che sottolineano il rango sociale del defunto\%.

Verona, tra le capitali occupate nella prima fase della conquista, fu la prediletta da Alboino, probabilmente più per la sua rilevanza strategica che per il valore simbolico di città di Teodorico, significato che assunse solo più $\operatorname{tardi}^{10}$. Era la città più vicina a Ravenna ${ }^{1}$, cui era collegata da un percorso fluviale, utilizzato da Rosmunda e dall'amante Elmichi, quando, dopo l'assassinio del re, su una nave fornita dai Bizantini, fuggirono portando con sé il tesoro regio conservato nel palazzo ${ }^{12}$. Il tesoro, costituito non solo dagli oggetti preziosi frutto del bottino di guerra ma anche da manufatti carichi di significati simbolici, come la coppa ricavata dal cranio di Cunimondo, padre di Rosmunda, era una delle componenti essenziali della regalità, una sorta di memoria storica del proprio passato e di testimonianza della ricchezza e del prestigio attuali, da ostendere come testimonianza della legittimità del pote$\mathrm{re}^{13}$. Verona era anche la chiave di volta del sistema difensivo centro alpino, lungo l'asse Adige-Garda, minacciato dai Franchi. Superata la crisi del periodo dell'interregno (574-584), Autari tornerà a fissarvi una residenza regia, salvo ritirarsi nella più sicura Pavia nel momento più acuto dell'offensiva nemica (590).

La presenza regia longobarda è concentrata nel palazzo, eretto da Teodorico sulla collina di S. Pietro, al di là dell'Adige. Alboino vi venne sepolto, come ricorda Paolo Diacono, sotto una attigua scalinata, con un corredo

\footnotetext{
6 Gasparri, 1990, pp. 279-83.

7 Gasparri, 1987, pp. 25-27 e 35-37.

8 Infra, p. 197.

9 La Rocca, 1998.

10 La Rocca, 1993, pp. 451-453.

${ }^{11}$ Che costituiva plausibilmente l'obiettivo del re: Ewig, 1963, p. 36.

12 P.D., H.L., II, 29.

$13 \mathrm{Su}$ questi temi, cfr. Gelichi e La Rocca, 2004, in particolare il saggio di Stefano Gasparri (Gasparri 2004).
} 
che comprendeva la spada ed altri oggetti ${ }^{14}$. Nulla sappiamo, dal punto di vista archeologico, di questa residenza, che compare ancora nell'iconografia rateriana, un disegno della città, redatto tra il IX e il X secolo, che mostra due torri affiancate, che ne costituiscono forse l'ingresso monumentale.

A differenza del palazzo, la città, naturalmente protetta dall'ansa dell'Adige, era in via di trasformazione. Rinserrata nella doppia cinta difensiva, quella di età repubblicana, rinforzata nel III e V secolo, e quella costruita ex novo da Teodorico ${ }^{15}$, una sorta di antemurale secondo le nuove tecniche difensive elaborate dalla trattatistica militare bizantina ${ }^{16}$, offriva all'esterno un'immagine di continuità. Una certa continuità della compagine urbana è desumibile anche dalla straordinaria persistenza del tessuto viario, ma all'interno degli isolati la ricca edilizia antica stava lasciando il posto a case più umili intervallate ad orti, che talora invadevano anche il tracciato stradale ${ }^{17}$. Alla fine del VI secolo, un grande incendio, forse quello del 589 ricordato da Paolo Diacono ${ }^{18}$, determinò la crisi della città e la rinuncia di Agilulfo a risiedervi ${ }^{19}$, anche se è più plausibile interpretare in positivo la scelta di Milano con una duplice chiave di lettura.

Da un lato i Longobardi avevano rinunciato alla conquista di Ravenna e dopo le vittoriose offensive del 602-603, condotte con l'aiuto degli Avari contro Cremona, Mantova, Padova e Monselice, si era venuta stabilizzando una linea di frontiera lungo il Po, che rendeva meno strategica la posizione della città del Veneto, non più minacciata del resto dalle incursioni franche da Nord. Dall'altro il re, influenzato dalla cattolica Teodolinda, intendeva porsi come punto di riferimento delle due componenti etniche del regno: le aristocrazie romane, che nonostante le stragi e le fughe patite al tempo di Clefi e dell'interregno, annoveravano ancora, almeno in alcune città, esponenti di prestigio ${ }^{20}$, e l'“exercitus", di cui perseguì l'unità colpendo duramente i tentativi di indipendenza dei duchi.

L'obiettivo era quello di fondare un regno secondo modelli sperimentati dalla monarchia franca e visigota, nel quale Milano, simbolo della tradizione antica, offriva una forte e specifica evocazione. Nel suo territorio, Monza, dove Teodorico aveva fatto erigere un palazzo, si prestava altresì per una "esaugurazione" in senso nazionale. Elementi simbolici tardo antichi, dell'e-

\footnotetext{
14 P.D., H.L., II, 28.

15 Cavalieri Manasse, 1993.

16 Ravegnani, 1983, pp. 37-46.

17 Hudson, 1985; La Rocca Hudson, 1986; Brogiolo, 1987.

18 Hudson, \#1989.

19 P.D., H.L., III, 23; cfr. Gasparri, 1987, p. 35.

20 Che troviamo tra i collaboratori di Agilulfo, come Paolo, reggente alla morte di Autari, Stabliciano, inviato come ambasciatore all'imperatore Foca, Pompeo, mandato con il medesimo incarico al re franco Clotario.
} 
tà gota e altri direttamente derivati dal cerimoniale di corte bizantino, come l'associazione al trono del figlio Adaloaldo, proclamata nel 602 nel circo di Milano alla presenza degli ambasciatori franchi ${ }^{21}$, formavano un coacervo simbolico da rappresentare attraverso manufatti, probabilmente oggetto di dono da parte del re, di semplice comunicazione ideologica del messaggio accanto ad interventi di evergetismo regio più complessi e dispendiosi.

Tra i manufatti, è da ricordare la lamina di Valdinievole, un oggetto in cui la politica di Agilulfo è felicemente sintetizzata ${ }^{22}$. Corrisponde forse alla parte anteriore di un elmo e raffigura Agilulfo che, in posizione centrale, siede su un trono ed è affiancato, ai lati ed in stringente simmetria, da due guerrieri con armi (elmo con pennacchio, armatura in lamelle, scudi rotondi, lance) che simboleggiano l'esercito longobardo, da due vittorie con labaro e cornucopia, da quattro offerenti, due romani e due longobardi. La scena è incorniciata da due torri, immagine compendiaria della città o del palazzo dove il re risiede. Derivata da schemi iconografici propri dell'arte tardo romana e bizantina, vi innesta una visione realistica della foggia del vestire, delle acconciature e delle armi dei longobardi. Sintetizza assai bene dunque il programma politico di Agilulfo, teso a stabilizzare il regno facendo leva sulle due componenti etniche (quella romana e quella longobarda), fatta peraltro salva l'esclusività del potere basato sul controllo dell'esercito.

Tra le testimonianze di evergetismo regio, sono menzionati a Milano il rifacimento della copertura della grande basilica di S. Simpliciano, comprovati dalle tegole con bollo di Adaloaldo; a Monza, la ricostruzione, o più plausibilmente il restauro, promosso dalla regina Teodolinda, del palazzo e l'edificazione dell'annessa basilica dedicata a S. Giovanni. Il programma decorativo del palazzo comprendeva episodi tratti dalle gesta dei Longobardi. Era una vera e propria residenza regale, a dodici miglia da Milano, dove la regina diede alla luce il figlio Adaloaldo ${ }^{23}$, battezzato poi da Secondo di Non ${ }^{24}$ nella chiesa intitolata a S. Giovanni e adornata da molti oggetti d'oro e d'argento ${ }^{25}$. Un vero e proprio tesoro di cui alcuni oggetti, compresi i doni del papa Gregorio Magno, sono ancora conservati. Un santo e una chiesa destinati ad assurgere, rispettivamente, a protettore e santuario nazionale dei Longobardi ${ }^{26}$, o almeno di quella componente cattolica stretta attorno alla dinastia bavarese che, come vedremo, saprà coniugare al meglio i simboli laici del potere con quelli offerti dalla religione.

21 PD, H.L., IV, 30.

22 Accettando Kurze, 1980, ma sul problema interpretativo, vedi Harrison, 1993, p. 188, nota 59.

23 P.D., H.L., IV, 25.

24 Ibidem, IV, 27.

25 Ibidem, IV, 21.

26 Ibidem, V, 6. 
Purtroppo, la sconsiderata distruzione dell'intero deposito archeologico a est della basilica, avvenuta nel 1992, non ci consente di datare le fondazioni degli ambienti absidati presumibilmente appartenenti al palazzo ${ }^{27}$. A fianco della chiesa sopravvive invece in alzato un'imponente torre realizzata con materiale di spoglio che si presume appartenesse al complesso.

Monza era peraltro solamente una residenza regia; la capitale era Milano, una città che nel IV secolo domina un vasto territorio in funzione economica, militare ed ecclesiastica. Pur privata, all'inizio del V, della sede imperiale, non subisce contraccolpi fino almeno alla metà del secolo. Dalla fine del V, l'abbandono dell'insediamento extraurbano, il disuso degli ambienti periferici del palazzo, la trasformazione, urbanistica ed architettonica dei centri di potere, sono sintomi di un incipiente cambiamento, che si radicalizza a partire dalla guerra greco-gotica, allorché la centralità della metropoli tardo antica lascia il posto ad una pluralità di centri periferici (i castelli, Monza, la stessa Pavia), che si avvalgono delle risorse ancora parzialmente integre assicurate dalla continuità di villaggi e di aziende rurali sparse 28 .

La frammentazione è acuita, alla fine del VI secolo, dal lungo scontro tra Bizantini e Longobardi e dalla concorrenza tra potere regio e potere ducale, che ha il massimo conflitto al tempo di Agilulfo, a causa delle mire espansionistiche del duca di Bergamo verso l'enclave bizantina del lago di Como.

La fuga del vescovo e di "quei maggiorenti che costituivano l'élite stretta da secoli attorno al vescovo" 29 , che ancora nel 593, come riferisce Gregorio Magno, "Illic (...) coacti barbarica feritate consistunt"30, è stata considerata un evento determinante per spiegare la sostituzione della classe dirigente romana.

Le attività edilizie che abbiamo ricordato (il restauro della chiesa di $\mathrm{S}$. Simpliciano, l'evergetismo regio a Monza), la possibile presenza, nel battistero presso la cattedrale, di monetazione bronzea ancor circolante alla fine del VI secolo ${ }^{31}$, le restituzioni di beni e le donazioni a favore di chiese, ricordate da Paolo Diacono, indicano peraltro livelli di ricchezza pubblica e un certo dinamismo economico e sociale, propri di una capitale, che contrastano con l'immagine di impoverimento materiale restituita dagli scavi di Piazza Duomo, dove nella seconda metà del VI compaiono edifici in legno che lasciano il posto, nel secolo successivo, ad un'area ruralizzata.

Dati così diversificati possono forse essere spiegati ammettendo che fosse in atto una forte frammentazione della società e conseguentemente delle sue

27 Brogiolo, 1996.

28 Brogiolo 1997a.

29 Tabacco, 1986, p. 23.

30 Gregorii I Papae Registrum, I, III, ep. 30 (a. 593), in M.G.H., Epistolae, I, p. 188.

$3^{1}$ Arslan, 1997, p. 66. 
manifestazioni materiali. La capitale era tale perché vi risiedeva il re, con il tesoro e con il suo entourage, nei palazzi antichi o in quelli fatti costruire a modello degli antichi, ma al suo interno si andavano affermando, come a Verona, modi di vita del tutto innovativi e decisamente più poveri rispetto all'età precedente.

Il tentativo di Agilulfo e Teodolinda, proseguito dal figlio Adaloaldo, di costruire uno stato romano-barbarico, nel quale le due componenti si fondessero, è destinato al fallimento per la reazione anti cattolica coagulata attorno a Arioaldo e poi a Rotari. Questa svolta determina anche l'emergere, come capitale, di Pavia, già luogo di riunione dell'esercito, anti romana e anti cattolica.

Nodo fluviale strategico per i rapporti tra la Pianura occidentale e Ravenna, era stata uno dei capisaldi del sistema difensivo a protezione di Milano capitale dell'impero. Oggetto di particolari cure da parte di Teodorico ${ }^{32}$ e di Atalarico nel 528-2933, aveva giocato un ruolo importante nel 538-40 e nelle fasi finali della guerra greco-gotica ${ }^{34}$.

Alboino, dopo un lungo assedio durato tre anni, la conquistò, riservando peraltro clemenza verso la popolazione ${ }^{35}$. In tal modo assicurava il persistere della sua complessità sociale e della sua struttura urbana.

\section{Una capitale "longobarda": Pavia nella prima metà del VII secolo}

Cattedrale ariana, palazzo regio, necropoli "ad perticas" sono gli elementi topografici che contraddistinguono la capitale Pavia nella prima metà del VII secolo.

Paolo Diacono ${ }^{36}$ ricorda che ancora ai suoi tempi, ossia sullo scorcio dell'VIII secolo, era identificabile il luogo ove era stato costruito il battistero del vescovo ariano. Si trovava presso la cattedrale, esaugurata poi con il titolo di Sant'Eusebio. I pochi resti del luogo di culto altomedievale, sopravvissuti alla ricostruzione romanica, non sono peraltro di facile lettura e ne hanno sinora impedito una sicura collocazione cronologica ${ }^{37}$. La sua posizione centrale rispetto alla compagine urbana testimonia la forza del clero ariano, risalente presumibilmente all'età gota. Nelle vicinanze, documenti del X

\footnotetext{
32 An.Val.,p.234: 'Item Ticino palatium thermas amphiteatrum et alios muros civitatis fecit' . Per quanto riguarda le mura, forse semplici riparazioni all'esistente cinta romana: Hudson, 1987, p. 242, oppure di un'estensione del quartiere sud-orientale: Boullogh, 1966, p. 88).

33 "Has sedis spectaculi anno regni sui tertio fieri feliciter precepet": Panazza, 1953, n.10.

$34 \mathrm{Nel} 538$ città saldamente fortificata, con una guarnigione agguerrita di goti: Procopio, Guerra gotica, II, 12; III, 1,3; IV,33,34,35.

35 P.D., H.L.,II, 27.

36 Ibidem, IV,42.

37 Peroni, 1984, p. 258.
} 
e XI secolo indicano la presenza della "faramannia", termine che pare designare il nucleo di popolazione longobarda acquartierato in un'area distinta ${ }^{38}$, secondo un modello che è stato ipotizzato anche per altre città39. I Longobardi si erano infatti insediati in prevalenza nell'angolo nord-orientale della città, sul sito della probabile zona monumentale romana 40 immediatamente a nord del palazzo reale. È da rilevare come in questa zona siano state rinvenute le uniche sepolture longobarde all'interno delle mura ${ }^{4}$.

Del palazzo regio non restano avanzi archeologici, ma solo la menzione delle fonti fino al X secolo, quando venne distrutto. Fatto costruire da Teodorico 42 nel quartiere nord-orientale della città, comprendeva oltre agli edifici palaziali, anche un viridarium, esistente ancora nel $915^{43}$. È probabile che, dopo la conquista longobarda, quando ancora per Pavia non si profilava un destino da capitale, vi si sia insediato il duca Zaban ${ }^{44}$.

Nella prima metà del VII secolo estremamente rare sono le fonti scritte su Pavia ${ }^{45}$ : damnatio dopo la vittoria dei cattolici sugli ariani o indicazione che l'evergetismo pubblico non era più un modello ideologico da propagandare?

I simboli del potere delle società germaniche sembrano più legati ai ritmi della morte, nei quali si esprime il rango e la fidelitas rispetto al capo. In tal senso, nella prima metà del VII secolo, luogo simbolo dei Longobardi a Pavia appare il cimitero alle Pertiche, così denominato perché vi erano stati eretti dei pali sulla cui sommità i familiari ponevano, a ricordo di un parente morto lontano, una colomba di legno, volta verso la direzione dove era morto il loro congiunto, perché si potesse sapere in quale parte del mondo fosse sepolto ${ }^{46}$. In questo luogo si tenevano le adunanze annuali dell'esercito longobardo e ancora nel 740 vi sarà eletto re Hildebrando ${ }^{47}$.

Cattedrale ariana, Palazzo Regio, necropoli alle Pertiche sono i simboli di una cultura tradizionale chiusa in se stessa per difendere la propria sopravvivenza nel lungo conflitto con i Bizantini.

38 Boullogh,1966, pp. 95-96; Hudson,\#1987, pp. 245-247; Gasparri, 1987, p. 31.

39 Cagiano De Azevedo, 1974, p. 298.

40 Hudson, 1987, p. 246.

${ }^{41}$ Ibidem, pp. 245-46.

42 An.Val., p.234.

43 Sul palatium: Hudson, 1987, pp. 242-45.

44 P.D.H.L., II,32.

45 Scarsissime sono pure le testimonianze archeologiche della Pavia longobarda: solo tre sepolture con corredo, due nella zona dell'arimannia (supra), la terza ad ovest della città (Hudson, 1987, p. 247).

46 P.D., H.L., V, 34.

47 Ibidem, VI, 55 . 


\section{Pavia dal 650 al 750: la cristianizzazione di una capitale}

Pavia offre prospettive di ricerca quanto mai interessanti sulla topografia cristiana di una capitale altomedievale. A partire dalla metà del VII secolo vi vengono infatti sostituiti i simboli legati all'ideologia nazionale dei Longobardi con nuovi messaggi, che vanno progressivamente a localizzarsi nei luoghi di culto cattolico, costruiti da re e regine. Nuovi simboli di un potere che si accompagna alla cristianizzazione della società longobarda.

\section{a) Le chiese mausoleo}

Rotari fu il primo re ad essere sepolto a Pavia nella chiesa di San Giovanni Battista ${ }^{48}$. Paolo Diacono afferma che la basilica fu fatta erigere dalla regina Gundiperga ${ }^{49}$. Non è tuttavia chiaro se il re sia stato sepolto in una chiesa ariana, poi ricostruita e esaugurata da Gundiperga al tempo del re Radoaldo, nel 648/652-65350, oppure se Rotari, benché ariano, sia stato inumato nella basilica cattolica di Gundiperga ${ }^{51}$. Non si trattava peraltro di un mausoleo dinastico stabile ${ }^{52}$. Solo con Ariperto I (653-661) la monarchia assume un modello sperimentato in Gallia fin dal tempo di Clodoveo: la fondazione di una cappella funeraria, dove si riassumono le tradizioni della dinastia, "in parte alternative a quelle puramente elettive dell'assemblea degli armati" 53 . Il re fa infatti erigere il mausoleo dinastico di San Salvatore, chiesa suburbana presso la porta Marengo, nella quale troveranno sepoltura i re della dinastia bavarese: Pertarito (morto nel 688), Cuniperto (morto nel 700) e Ariperto II (morto nel 712).

Il re Grimoaldo, inseritosi violentemente con l'uccisione del re Godeperto e l'esilio inflitto a Pertarido, nella successione della dinastia bavarese, fonda a sua volta una chiesa mausoleo ariana, più tardi esaugurata con il titolo di Sant'Ambrogio ${ }^{54}$.

La cristianizzazione del luogo simbolo della tradizione longobarda, il cimitero alle Pertiche, è opera della regina Rodelinda, moglie di Pertarito, che vi fece edificare una basilica dedicata alla Madonna ${ }^{55}$. Della chiesa che opere mirabili condidit ornamentisque mirificis decoravit, demolita nel 1815 , rimane il disegno della pianta a schema centrale ${ }^{56}$. Divenne in seguito

\footnotetext{
48 Ibidem, IV, 47.

49 Ibidem, V,40.

50 Ewig, 1963, p. 38.

51 Gasparri, 1987, p. 44.

52 Ibidem, p. 44.

53 Ibidem, p. 42.

54 P.D., H.L., V, 33.

55 Ibidem, V,34.

56 Peroni, 1984, p. 259.
} 
mausoleo regio, ospitando le tombe dei re Ansprado (morto 712), Liutprando (morto 744) e della regina Regintrude.

Il proliferare dei mausolei regi riflette il dinamismo dell'istituto monarchico, caratterizzato da dinastie di breve durata in lotta tra loro, particolarmente nella seconda metà del VII secolo.

\section{b) Monasteri e fondazioni religiose}

La cristianizzazione della società longobarda trova ulteriore espressione nei monasteri e nelle fondazioni religiose promosse dai re sia nelle città che, più sovente, nelle campagne ${ }^{57}$, imitate, dalla fine del VII, ma soprattutto nell'VIII secolo, da un gran numero di aristocratici che edificano chiese ed istituiscono monasteri in ogni angolo del regno.

La fine dello scisma dei Tre Capitoli, sancito dalla sinodo convocata a Pavia nel 698, e l'alleanza tra i re e le gerarchie cattoliche ${ }^{58}$, consolidano il regno attraverso messaggi ideologici che, particolarmente nella capitale, trovano compiuta espressione.

Non sono sopravvissuti gli apparati a fresco e a mosaico che decoravano le fondazioni regie, ma non è da dubitare che anche a questi fossero affidati i messaggi che il re e la gerarchia ecclesiastica intendevano diffondere tra i sudditi. A giudicare dalla scultura, la sola testimonianza storico artistica conservata, alto è il livello raggiunto dagli artigiani che operavano nella capitale Pavia e nelle altre città legate di volta in volta alla presenza regia: Milano, Cividale e Brescia.

I testi metrici delle epigrafi presuppongono d'altra parte la presenza di maestri di retorica. Paolo Diacono ricorda il diacono e grammatico Felice, zio del suo precettore Flaviano, molto stimato da re Cuniperto che gli regalò un bastone lavorato d'oro e d'argento ${ }^{59}$. Lo stesso re si fece comporre un carme dal grammatico Stefano 60 in cui veniva celebrata la sua dinastia, protetta da Dio per meriti nella difesa della fede. Un diacono, filosofo di grande fama, è infine ricordato in altra epigrafe pavese, forse dell'VIII secolo ${ }^{61}$.

c) Corteolona: il palazzo suburbano di Liutprando

Paolo Diacono ricorda la fondazione da parte di Liutprando di un palazzo suburbano e della chiesa e del monastero di S. Anastasio ${ }^{62}$. Un testo epigrafico racconta così l'episodio: il re, andato a Roma a pregare sulla tomba di s.

57 Ewig, 1963, pp. 41-42.

58 Delogu, 1980, p. 115 .

59 P.D., H.L., VI, 7.

60 Carmen de Synodo ticinensi, pp. 190-91.

61 Panazza 1953, n. 90.

62 P.D., H.L., VI, 58. 
Anastasio, rinuncia alla costruzione di terme regali e, al loro posto, fonda una chiesa al santo, adornandola del materiale di spoglio portato da Roma. L'impresa renderà gloria in eterno al re che, desiderando celebrare i trionfi della sua gente, ha onorato con questa fondazione la patria intera63.

Il re, celebrato da questo testo epigrafico in quanto fondatore di un luogo di culto, passerà alla storia con tale nomea ${ }^{64}$; era peraltro ben attento ad utilizzare la gerarchia ecclesiastica a sostegno del suo potere ${ }^{65}$.

Alla fine del regno longobardo, la religione cristiana ha preso il sopravvento nell'ideologia del potere: il re raccoglie meriti e gloria più per le fondazioni dei luoghi di culto che per la costruzione del palazzo, un'impresa che dal tempo di Teodolinda non veniva più tentata da un re longobardo.

\section{Brescia: una capitale mancata alla fine della dominazione longobarda?}

La conclusione, nel 743, con Ildeprando delle stirpi regie pavesi porta all'affermazione di uomini nuovi la cui base del potere si trova in altri ducati. La capitale rimane Pavia, centro dell'amministrazione del regno, ma l'investimento ideologico viene realizzato nella patria d'origine, ove vengono edificati edifici simbolo, messaggi destinati a infondere una forte immagine di sé e a rinsaldare la corte dei propri seguaci locali.

Alla metà dell'VIII secolo è Cividale ad esprimere due re: Ratchis (744757) e Astolfo (749-756). È soprattutto quest'ultimo, con la costruzione di quel gioiello architettonico e decorativo che è S. Maria in Valle, a testimoniare l'alto livello raggiunto alla metà dell'VIII secolo66 dalle maestranze che operavano al servizio della committenza regia.

Se nel caso di Cividale si può parlare soltanto di un investimento ideologico nella patria di origine, il caso di Brescia al tempo di re Desiderio è più complesso e può essere forse considerato il tentativo di costruire l’immagine di una città alternativa alla capitale Pavia.

Brescia è una città nella quale si è scavato molto negli ultimi vent'anni e per la quale è stato proposto un modello complessivo delle trasformazioni tra

63 MGH, PAC I, Tituli saeculi VIII, X-XII, pp. 105-106: Capo 1992, p. 608 .

64 Anche Paolo Diacono (P.D., H.L., VI, 58) celebra la figura del re come fondatore di chiese (tra le quali rammenta quelle pavesi di S. Pietro in Ciel d'oro, S. Salvatore nel palazzo, S. Anastasio a Corteolona) e del monastero di Berceto. Il concetto viene ripreso anche nelle Laudes mediolanensis civitatis (MGH, PAC, Tituli saecc. VIII, pp. 24-26; PIGHI 1980; Orselli 1985; La Rocca 1989) e nel prologo delle leggi di Ratchis (Capo 1992, p. 610). 65 A Pavia e a Milano i vescovi, rispettivamente Pietro e Teodoro, sono suoi parenti; interviene pesantemente a favore del suo protetto Callisto nella questione della sede di Cividale, contesa tra questo ed il vescovo (H.L., VI, 51).

$66 \mathrm{Si}$ accettano le datazioni dell'architettura e degli affreschi proposte da L'Orange, Thorp, 1977. 
tarda antichità e altomedioevo ${ }^{67}$. La cristianizzazione delle aree cimiteriali suburbane, tra la fine del IV e gli inizi del V secolo, anticipa presumibilmente la riorganizzazione urbanistica, genericamente datata tra V e metà VI secolo, che ne fece una città "munita", efficacemente protetta da un rinsaldato sistema difensivo. La riorganizzazione comporta l'abbandono degli isolati meridionali, la ricostruzione delle mura, allargate verso ovest, la riqualificazione della sommità del colle, ove era un tempio romano, in luogo di culto cristiano forse collegato ad una funzione militare. La costruzione del palatium e l'insediamento del complesso episcopale ad occidente, hanno come conseguenza lo spostamento del baricentro politico-religioso e la marginalizzazione dei quartieri centro-orientali, più direttamente coinvolti in un processo di destrutturazione sia urbanistica che architettonica.

In questo settore urbano degradato, di pertinenza del fisco regio, si insedia un gruppo di artigiani probabilmente di condizione servile le cui manifestazioni di cultura materiale comprendono, oltre ad un'edilizia residenziale povera e alla deposizione dei morti presso le abitazioni, numerose attività che spaziano dalla lavorazione del ferro a quella delle ceramiche e dell'osso. Alcuni isolati del comparto orientale della città vengono inoltre ridotti a coltura, mentre sul lato opposto, in un grande edificio ad ali (forse il palazzo tardo antico), si insedia la corte ducale longobarda.

L'area suburbana, fino a 5 chilometri dalla città, era invece caratterizzata da un insediamento sparso, probabilmente di aziende agricole e di attività produttive, ove risiedevano personaggi di rango elevato, almeno a giudicare dalle sepolture di VII secolo con ricco corredo longobardo 68 .

Come a Pavia, l'insediamento pubblico occupa dunque porzioni importanti della città, estendendo su di essa una forte immagine di potere, mentre l'aristocrazia sembra privilegiare le aziende rurali dell'hinterland e della ricca pianura. In questo contesto sociale ed urbanistico, definitosi alla fine del VI secolo e che sembra perdurare a lungo, almeno per tutto il secolo successivo, si sviluppa il piano di Desiderio di fondare un potere dinastico, donando importanti beni del fisco, sia regio che ducale, al monastero di S. Salvatore, da lui fondato unitamente alla moglie Ansa e affidato alle cure della figlia Anselperga. La chiesa omonima, che sulla base di recenti ricerche 69 si può tornare a datare alla metà dell'VIII secolo, diviene, come nelle basiliche regie pavesi, il simbolo della grandezza della nuova dinastia. Viene costruita, come S. Maria alle Cacce a Pavia, con una pianta basilicale, sulla quale si innesta poi una cripta per ricevere le reliquie di S. Giulia e di alcuni martiri romani. La presenza, nella navata meridionale, di una tomba con arcosolio costruita

67 Brogiolo, 1993.

68 Brogiolo 1997b.

69 Brogiolo, 1993 e 1998. 
in fase con la muratura, sepoltura attribuita da una tradizione antica alla regina Ansa ${ }^{70}$, la presenza nella navata centrale di tre sepolture privilegiate, la menzione, nelle iscrizioni che accompagnano gli affreschi della navata, del re Desiderio, suggeriscono l'ipotesi che il San Salvatore sia stato progettato come mausoleo e luogo di celebrazione della nuova dinastia.

\section{Benevento e Salerno: capitali della "Langobardia minor"}

L'attacco sferrato da Carlomagno, d'accordo con il papa, porrà fine tragicamente al sogno di Desiderio. Solo il ducato di Benevento, governato dal genero Arechi II (757/758-787), sopravviverà alla catastrofe. Il duca, dopo la caduta del regno longobardo, si era autoproclamato principe, proponendosi come punto di riferimento dei Longobardi che non si erano sottoposti a Carlomagno $^{71}$. Nella capitale del principato e a Salerno, città portuale di nuova fondazione, Arechi II evocherà, attraverso la costruzione di importanti monumenti (la chiesa di S. Sofia a Benevento, il palazzo e la cappella palatina a Salerno), i simboli di rappresentazione di una capitale altomedievale. La chiesa di S. Sofia di Benevento, ispirata nel nome e nella pianta alla omonima basilica di Costantinopoli, rivela l'orizzonte ideologico nel quale il principe longobardo voleva collocare la propria capitale. Analogamente gli elementi decorativi della cappella palatina di S. Pietro a Corte recentemente scoperti, in particolare i frammenti di pavimento o rivestimento parietale in porfido e serpentino a quadrati, losanghe, esagoni, elementi a goccia, a dischi ${ }^{72}$ e in tessere vitree policrome per mosaico e "a forma di listelli e di piramidi tronche rivestite a foglia d'oro"73, richiamano livelli qualitativi propri di una dimora imperiale, anticipando altresì modelli della fioritura artistica documentata alla fine del secolo nel grande monastero di San Vincenzo al Volturno ${ }^{74}$.

\section{Conclusioni}

Nel territorio italiano conquistato da Alboino si trovava una delle capitali tetrarchiche (Milano), ma il re preferì come sua sede abituale Verona, città più vicina a Ravenna e dunque giudicata strategicamente più importante nel conflitto in corso con i Bizantini.

$70 \mathrm{Si}$ è conservato anche l'epitaffio composto da Paolo Diacono (Epitaphium).

${ }^{71}$ Fonseca,1984, pp. 140-41.

72 Peduto e al., 1988, figg. 3-6.

73 Dell'Acqua, 1997, p. 250.

74 Mitchell, 1995, pp. 47-64. 
Solo con Agilulfo i luoghi simbolo dell'antica capitale (il palazzo ed il circo) torneranno ad avere una centralità nell'ideologia del potere basata sulla fusione tra romani e barbari.

La reazione della componente più tradizionale della società longobarda farà optare per una terza città (Pavia), al pari di Verona ristrutturata come caposaldo strategico in età gota. Nella nuova capitale, i centri del potere dell'età precedente, il palazzo e la cattedrale ariana, divengono i punti di riferimento dell'insediamento longobardo. Ma a questi si aggiunge, con una fortissima carica simbolica, il cimitero "ad perticas", presso il quale si tengono le annuali assemblee dell'esercito e quelle straordinarie per l'elezione del re.

La cristianizzazione della società longobarda e l'affermarsi, alla metà del VII secolo, della dinastia bavarese, fautrice del cattolicesimo fin dal tempo della regina Teodolinda, introducono nella capitale nuovi luoghi simbolo, le basiliche-mausoleo regie e i nuovi luoghi di culto fondati dal re: monumenti che con la ricchezza del loro apparato decorativo danno la misura del suo prestigio e del suo potere.

Questi modelli, propri ormai di una capitale cristiana, verranno imitati, alla fine della dominazione longobarda, dai re che provengono dai ducati del Friuli e di Brescia e che, anziché a Pavia, investono in immagine nel territorio di origine, dove si trova la loro base di potere. Ad essi si ispirerà anche l'ultimo principe longobardo, Arechi II, un friulano assurto al ducato di Benevento in quanto genero di Desiderio, che farà del capoluogo e della nuova città di Salerno, due sedi degne di un re.

Accanto alla capitale si mantiene, nell'età longobarda, il modello della residenza regia di campagna, senza peraltro che venga messa in discussione la centralità della città come sede del potere. A Monza Teodolinda fonda sul palazzo di Teodorico un luogo simbolo del nuovo ruolo italiano della gens langobardorum. A Lomello, Liutprando ripropone un'iniziativa analoga, caricandola ulteriormente dell'incontro ormai consolidato tra religione e potere civile.

Palazzi urbani e residenze regie rurali, chiese-mausoleo e basiliche o monasteri fondati dalla coppia reale, ossia i monumenti simbolo della regalità e di una capitale nell'avanzata età longobarda. La basilica regia, con la sua magnificenza decorativa e grazie alle reliquie dei santi e agli oggetti preziosi tratti dal tesoro regio, assume essa stessa il valore di un "tesoro celeste", un valore da ostentare, così come nell'età precedente lo erano stati i ricchi corredi tombali deposti pubblicamente nelle sepolture ${ }^{75}$. Il nuovo modello, proposto dal re, trova imitazione nell'aristocrazia, dando il via ad una straordinaria fioritura in ogni parte del regno di cappelle funerarie, basiliche e monasteri privati. 
Se l'evoluzione dei simboli e dei monumenti che l'incarnano sembra sufficientemente chiara, meno evidenti sono le conseguenze sull'economia e sulla società, sull'urbanistica e sull'architettura delle città che vennero privilegiate dalla presenza del re.

Per l'età tetrarchica e ancora per il periodo goto siamo informati, dai contemporanei e dalle testimonianze archeologiche, della ricaduta positiva sull'economia della città-capitale ${ }^{76}$. Milano nel IV e Ravenna nel V-VI vedono un notevole sviluppo nella città e nelle campagne, marcato dalla presenza di un'edilizia "aulica" di grande qualità. Nulla di tutto questo è avvertibile per la fine del VI e per gran parte del VII. Il circolante bronzeo rinvenuto nel battistero di Milano attesta certamente che non si era passati al baratto e che le transazioni quotidiane avvenivano sulla base della moneta. Ma le testimonianze archeologiche, a Milano come a Verona, in questo non distinguendosi dalla situazione delle altre città, registrano degrado e abbandono delle infrastrutture e degli edifici antichi, sostituiti da abitazioni in legno. L'immagine di una capitale, pur con l'incognita rappresentata da Pavia ove mancano del tutto informazioni archeologiche, sembra dunque calibrarsi, tra fine VI e almeno metà del VII, su un deciso contrasto tra i luoghi del potere, che mantenevano od imitavano gli standard edilizi antichi, ed un tessuto urbanistico ed architettonico fortemente rinnovato con tecnologie molto più povere che in passato.

Una struttura sociale più articolata traspare dalla fonti scritte a partire dalla fine del VII secolo. Milano viene descritta al tempo di Liutprando come una città dove si trovano merci di varia specie e dove è possibile arricchirsi con $\mathrm{i}$ commerci. A Pavia risiedono artigiani abili nel realizzare produzioni artistiche di alta qualità e uomini di cultura in grado di scrivere testi epigrafici e letterari. Essi lavorano per una committenza estesa all'aristocrazia: il privilegio non è più circoscritto, come nel periodo precedente, alla ristretta cerchia di chi esercita il potere. Le capitali tornano ad essere, come nella tarda antichità, centri nei quali vive un'aristocrazia che è tornata ad investire nei monumenti e non soltanto nelle sepolture. Tuttavia si tratta forse di un cambiamento limitato ai livelli più alti della società. Non prima del grande giro di boa dell'anno Mille, l'archeologia è infatti in grado di registrare mutamenti di rilievo nell'urbanistica e nell'architettura, parametri che misurano, in ogni tempo e luogo, il livello economico e la complessità sociale di una città, e dunque anche delle capitali.

76 Scagliarini Corlaita, 1990; Cantino Wataghin, 1996. 


\section{Bibliografia}

An. Val.=Anonimi Valesiani pars posterior, a cura di T. Mommsen, in Chronica minora saecc. IV, V, VI, VII, MGH, Auctores antiquissimi,9, Monaco 1981

Arslan E., 1997, La testimonianza della moneta, in AA.VV., La città e la sua memoria. Milano e la tradizione di sant'Ambrogio, Milano, pp. 63-67

Brogiolo G.P., 1987, A proposito dell'organizzazione urbana nell'altomedioevo, "Archeologia medievale", XIV, pp.27-46

Brogiolo G.P., 1993, Brescia altomedievale. Urbanistica ed edilizia dal IV al IX secolo, Documenti di archeologia, 2, Mantova

Brogiolo G.P., 1996, Aspetti economici e sociali delle città longobarde dell'Italia settentrionale, in G.P. Brogiolo (a cura di), Early medieval towns in the western Mediterranean, Atti conv. internaz., Ravello 1994, Mantova 1996, pp. 77-88

Brogiolo G.P. (1997a,) "Ricerche archeologiche su Tardo Antico e Alto Medioevo tra Ticino e Adda", in Archeologia della Regione insubrica.Dalla preistoria all'Alto Medioevo, Como 1997, pp. 67-88

Brogiolo G.P. (1997b), "Sepolture a Brescia tra tarda antichità e prima età longobarda (ex IV-VII secolo)", in L. Paroli (a cura di), L'Italia centro-settentrionale in età longobarda, Atti convegno Ascoli Piceno, 6-7 ottobre 1995, Firenze 1997, pp.413-424

Brogiolo, G.P. (1998), "La sequenza altomedievale della cripta di San Salvatore in Brescia", in M. Exner (a cura di), Wandmalerei des frühen Mittelalter. Bestand, Maltechnik, Konservierung, Lorsch 1996, (München), pp. 35-39

Bruhl C., 1967, Remarques sur les notions de"capitale "et de "residence" pendant le haut Moyen Age, Journal des savants (s.n.), pp. 193-215

Bullough D.,1966, Urban change in Early Medieval Italy. The example of Pavia, Papers of the British school at Rome, 34, pp. 82-130

Cagiano De Avezedo M., 1974, Esistono una architettura e un'urbanistica longobarde?, in La civiltà dei Longobardi in Europa, (Atti del convegno internazionale, Roma-Cividale 1971), Roma, pp. 289-329

Cantino Wataghon G.,1996, Quadri urbani nell'Italia settentrionale: Tarda Antichità e Alto Medioevo, in Lepelley C. (a cura di), La fin de la cité antique et le début de la cité médiévale, (Nanterre 1933), Bari, pp. 239-272

Capo L., 1992 (a cura di), Paolo Diacono. Storia dei Longobardi, Milano.

Carmen de synodo ticinensi, in MGH, SS.RR. Lang. saec. VI-IX, Hannoverae 1964, pp. 190-91) 
Cavalieri Manasse G., 1993, Le mura di Verona, in Atti conv. Mura delle città romane in Lombardia, (Como 1990), Como, pp. 179-215

Degani A. 1981," Il tempietto longobardo di Cividale”, Udine.

Dell'acqua F., 1997, Nota sui reperti vitrei del monastero di San Vincenzo al Volturno e della cappella palatina di Arechi II a Salerno, Rassegna storica salernitana, XIV, fasc. 1, pp. 243-257

Delogu P., 1980, Il regno longobardo, in AA.VV, Longobardi e Bizantini, vol I della 'Storia d'Italia', a cura di G. Galasso, Torino, pp. 1-216

Duval N., 1992, Le palais de Milan parmi les residences imperiales du BasEmpire, in Sena Chiesa G., Arslan E. (a cura di), Felix Temporis Reparatio. Atti conv. archeologico internaz. "Milano capitale dell'Impero romano", (Milano 1990), Milano, pp. 137-146

Ewig E., 1963, Résidence et capiatle pendant le haut Moyen Age, Revue Historique, 230, pp. 25-72

Fonseca C. D., 1984, Langobardia Minore e Longobardi nell'Italia meridionnale, in Magistra Barbaritas. I Barbari in Italia, Milano, pp. 127-184

Harrison D., 1993, The Early State and the towns. Forms of Integration in Lombard Italy, Lund

Hudson P., 1985, La dinamica dell'insediamento urbano nell'area del cortile del tribunale di Verona. L'età medievale, Arch. Med., XII, pp. 281-302.

Hudson P., 1987, Pavia: l'evoluzione urbanistica di una capitale altomedievale, in Storia di Pavia, II, pp. 237-315

Hudson P., 1989, Contributi archeologici alla storia dell'insediamento urbano veneto (IV-XI secolo), in Castagnetti A.-Varanini G.M. (a cura di), Il Veneto nel medioevo. Dalla 'Venetia' alla Marca Veronese, II, pp. 329-348

Gasparri S., 1987, Pavia longobarda, in Storia di Pavia, Pavia, II, pp. 19-65.

Gasparri S., 1990, Il regno longobardo in Italia. Struttura e funzionamento di uno stato altomedievale, in Gasparri S. Cammarosano P. (a cura di), Langobardia, Udine, pp. 237-305

Gasparri S., 2004, "Il tesoro del re”, in S. Gelichi e C. La Rocca, Tesori, forme di accumulazione della ricchezza nell'alto medioevo (secoli $V-X I$ ), Roma, pp. 47-67

Kurze W., 1980, La lamina di Agilulfo: usurpazione o diritto?, in "Atti 6 congresso internaz. di studi sull'alto medioevo”, Milano 1978, Spoleto, II, pp. 447-456

La Rocca Hudson C., 1986, Dark ages a Verona: edilizia privata, aree aperte e strutture pubbliche in una città dell'Italia settentrionale," Arch. Med.", XIII, pp. 31-78

La Rocca C., 1989, Trasformazioni della città altomedievale in "Langobardia”, Studi storici, n. 4, pp. 993-1011

La Rocca C., 1993, Una prudente maschera "antiqua” . La politica edlizia di Teoderico, in Teoderico il grande e $i$ Goti d'Italia,Atti del XIII congresso internaz. di studi sull'alto medioevo, Milano 1992, Spoleto, pp. 451-515

La Rocca C. 1998, "Donare, distribuire, spezzare. Pratiche di conservazione 
della memoria e dello status in Italia tra VIII e IX secolo", in G.P. Brogiolo, G. Cantino Wataghin (a cura di), Sepolture tra IV e VIII secolo, $7^{\circ}$ seminario sul tardo antico $\mathrm{r}$ l'alto medioevo in Italia centrosettentrionale, Gardone Riviera 1996, Mantova, pp. 77-87

La Rocca, 2004, "Tesori terrestri, tesori celesti, in S. Gelichi e C. La Rocca, Tesori, forme di accumulazione della ricchezza nell'alto medioevo (secoli $V$-XI), Roma, pp. 123-141

L'Orange H.-Thorp H., 1977, Il tempietto di Cividale, II, Roma

Mitchell J., 1995, Arichis und die Künste, in Meier H.R., Jaggi C., Butner P. P. (a cura di), Für irdischen Ruhn und himmlischen Lohn, Berlin, pp. 47-64

Orselli A.M., 1985, Il santo patrono cittadino tra Tardo Antico e Alto Medioevo, in EAD, L’immaginario religioso nella città medievale, Ravenna, pp. 415-435

Panazza G., 1953, Lapidi e sculture paleocristiane e preromaniche di Pavia, in Arte del Primo Millennio, (Atti del II convegno per lo studio dell'arte dell'Alto Medioevo, Pavia 1950), Torino, pp. 211-302

Paulus Diaconus, Epitaphium Ansae Reginae, MGH, Scriptores rerum Langobardicarum et italicarum saec. VI-IX, ed. G. Waitz, Hannover, 1878, pp. 191-92

P.D., H.L.=Pauli Diaconi, Historia Langobardorum, MGH, Scriptores rerum langobardicarum et italicarum saec. VI-IX, a cura di G. Waitz, Hannover, 1878

Peduto P., Romito M., Galante M., Mauro D., Pastore I., 1988, Un accesso alla storia di Salerno: stratigrafie e materiali dell'area palaziale longobarda, Rassegna storica salernitana, V, 10, pp. 9-63

Peroni A., 1984, L'arte in età longobarda. Una traccia, in Magistra Barbaritas. I Barbari in Italia (coll. Antica Madre), pp. 229-297

Perring, D. (1991), "Lo scavo di piazza Duomo: età romana e altomedievale", in Caporusso D. (a cura di), Scavi MM3. Ricerche di Archeologia urbana a Milano durante la costruzione della linea 3 della metropolitana. 19821990, (Milano), pp. 105-161

Pighi G.B.,1960, Versus de Verona, versus de Mediolano civitate, Bologna

Procopio, Guerra gotica, in Procopius, Opera omnia, a cura di J Haury, voll. 3, Leipzig 1905, 1906, 1913, (rist. 1963), trad. it. (Le guerre persiana vandalica gotica), a cura di M. Craveri, Torino, 1977

G. Ravegnani, 1983, Castelli e città fortificate nel VI secolo, Ravenna

Scagliarini Corlaita D., 1990, Le grandi ville di età tardo-antica, in AA.VV., Milano capitale dellimpero romano (286-402 d.C.), Milano, pp. 257-58

Settia A.A., 1993, Le fortificazioni dei Goti in Italia, in Atti XIII Congr. internaz. di studi sull'Alto Medioevo, Milano 1992, Spoleto, pp. 101-131

Tabacco G. 1986, Milano in età longobarda, in Atti X congr. internaz. di studi sull'alto medioevo, Spoleto, pp. 19-43 


\title{
“... quod cawerfeda antiqua usque nunc sic fuisset". Consuetudine e codificazione nell'Italia longobarda
}

\author{
Claudio Azzara
}

Il 22 novembre del 643, nel suo palazzo di Pavia, il re dei longobardi Rotari (636-652) promulgò l'Editto che da lui prese il nome e che raccoglieva il patrimonio normativo della stirpe longobarda: si trattava della prima codificazione scritta - a quasi settantacinque anni dalla fondazione del regno longobardo in Italia - di leggi che sino ad allora erano state trasmesse solo oralmente, secondo la tradizione, per mezzo di uomini esperti in grado di svolgere il ruolo di veri e propri codici viventi, ricordando a memoria l'intero complesso di norme. A tali «antiqui homines» il monarca aveva dovuto fare ricorso - come si dichiarava esplicitamente nel capitolo 386 dello stesso

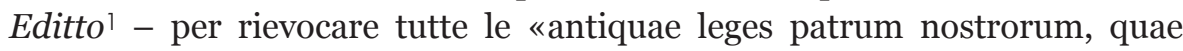
scriptae non erant»; il recupero di tale cospicua quantità di norme, avvenuto per iniziativa del re, «pari consilio parique consensum cum primatos iudices cunctosque felicissimus exercitum nostrum», aveva dato vita al testo edittale, che, secondo il costume longobardo, era stato ratificato per gairethinx, cioè dall'assemblea degli uomini liberi della gens Langobardorum.

L'Editto così costituitosi non raccoglieva, peraltro, tutte le norme che regolavano la società longobarda. Nel già citato capitolo 386, Rotari prevedeva espressamente la possibilità per i re longobardi suoi successori di aggiungere in futuro altre leggi, «quod adhuc annuentem divinam clementiam per subtilem inquisitionem de antiquas legis Langobardorum [...] memorare potuerimus». Di questa facoltà si avvalse per primo - com'è noto - Grimoaldo (662-671), nell'anno 668, seguito da Liutprando (713-744), che aggiunse una vasta quantità di norme tra il 713 e il 735, e poi da Ratchis (744-749), da

\footnotetext{
${ }^{1}$ Edizione critica: Leges Langobardorum, ed. F. Bluhme, in Monumenta Germaniae Historica, Leges, IV, Hannoverae 1868 (ristampa anastatica Stuttgart 1965). Cfr. anche Leges Langobardorum 643-866, ed. F. Beyerle, Weimar 1947 (ristampa anastatica Witzenhausen 1962). Una versione italiana delle leggi dei longobardi è disponibile in Le leggi dei Longobardi. Storia, memoria e diritto di un popolo germanico, a c. di C. Azzara e S. Gasparri, Milano 1992; nuova edizione Roma 2004.
} 
Astolfo (749-756) e - infine - dai principi di Benevento Arechi II (758-787) e Adelchi (853-878), i quali raccolsero nella Langobardia meridionale l'intera eredità politica dei longobardi dopo la fine del regno indipendente nel nord per mano di Carlo Magno, nel 774.

Le integrazioni all'Editto dei successori di Rotari non si configuravano concettualmente quali innovazioni o modifiche rispetto alla normativa precedente (anche se talora lo erano di fatto, come nel caso di alcune disposizioni di Liutprando in materia matrimoniale, ricettive del diritto canonico)2 ${ }^{2}$; piuttosto, esse si proponevano quali aggiunte di leggi che venivano percepite come già esistenti nel patrimonio tradizionale della stirpe e che erano di volta in volta "ricordate" dal re e dall'assemblea dei liberi e messe per iscritto. Per la cultura longobarda, infatti, il diritto affondava le proprie radici nella tradizione e nella memoria collettiva della stirpe e solo in queste trovava fondamento e legittimità. Nel momento della codificazione la norma, preesistente, veniva ricordata e convenuta tra il re e il popolo-esercito (cioè, l'insieme dei detentori dei diritti politici) per cooperazione spontanea, e non veniva per niente affatto "creata", "data", da un monarca che si proponesse quale fons legum, secondo il modello romano. La legge codificata non innovava, bensì fissava attraverso il mezzo scritto quanto già sussistente e "affiorato" nel ricordo collettivo.

Tale diritto tradizionale non venne dunque messo per iscritto in modo completo da Rotari, né lo fu dai suoi successori: molte norme continuarono ad avere vigore accanto all'Editto ma restando al di fuori di esso, nella forma di consuetudini, orali, dette in lingua longobarda cawarfidae. Solo episodicamente il legislatore intervenne a fissare nel codice una cawarfida di malsicura o controversa applicazione, per darle maggior certezza, dichiarando tale suo intento in maniera esplicita ${ }^{3}$. Piuttosto, a riprova della persistente forza della consuetudine, capitava più spesso, al contrario, che il re dovesse lamentare la propria impotenza di fronte a una specifica cawarfida di cui non condivideva il contenuto, ma che non era in grado di cassare o modificare. Il caso forse più celebre a questo proposito è quello della vana perplessità di Liutprando di fronte alla pratica del duello giudiziale, vale a dire l'istituto che in sede processuale induceva l'accusato e l'accusatore (o dei campioni da

${ }^{2}$ Liutp. 32 e 33, che fanno aperto riferimento ai canoni e a una lettera del papa Gregorio II e che recepivano, nel vietare le nozze fra cugini, una costituzione del Codex Theodosianus (III,10), pure abrogata da Giustiniano (Institutiones, I, 10).

3 Liutp. 73 (donazioni avvenute in assenza di launegild e thingatio), 77 (successioni a individui manomessi per thinx e privi di figli), 133 (investimenti realizzati con mezzi propri su immobili presi in affitto). In quest'ultimo capitolo, ad esempio (e la formula è del tutto analoga pure negli altri due) si dice: «hoc autem ideo nunc adfiximus, quia tantumodo causa ista in hoc modo semper et antecessorum nostrorum tempore et nostro per cawarfida sic iudicatum est; nam in edicto scripta non fuit». 
costoro designati) a battersi con le armi per stabilire da che parte stesse la ragione. Pur esprimendo senza riserve la propria totale sfiducia circa il valore probatorio di tale pratica (peraltro in buona misura già rimpiazzata dal giuramento di sacramentales convocati da ciascuna delle parti), il re ammetteva di non poter affatto vietarla, «propter consuitutinem gentis nostrae Langobardorum» ${ }^{4}$.

La consapevolezza del carattere bipolare, tra codificazione (scritta) e usi consuetudinari (orali), del diritto longobardo (così come anche del diritto di tutte le altre gentes coeve) non sempre ha evitato negli studiosi moderni, tuttavia, il rischio di una percezione impropria e anacronistica dei meccanismi di funzionamento di tale sistema giuridico. In particolare ci si riferisce qui all'indebita pretesa, ricorrente in molti approcci critici, che l'Editto dei longobardi si possa configurare nei termini di un codice di leggi moderno, parametro unico in cui poter automaticamente e necessariamente rintracciare il criterio di risoluzione di ogni singolo caso, aspettandosi quindi uno svolgimento del negozio di volta in volta considerato per forza di cose conformato in toto sulla norma scritta; salvo, qualora ciò non avvenga, meravigliarsi, per l'appunto, dell'esistenza di "anomalie", di "divaricazioni”, che si sente il bisogno di spiegare in qualche modo. Invece, come si va vieppiù chiarendo sulla scorta degli studi maggiormente avvertiti e rinnovati circa il diritto altomedievale $^{5}$, si deve tener fermo il concetto che il sistema giuridico longobardo era un modello complesso, di cui il codice costituiva solo una parte, accanto a una vitalissima tradizione di consuetudini; e le forme stesse di risoluzione dei conflitti seguivano percorsi diversificati - arbitrali, consuetudinari, extragiudiziali - senza necessariamente aderire in modo meccanico ed esclusivo alle disposizioni edittali. Inoltre, la natura medesima dell'Editto di Rotari si dimostra del tutto peculiare, rendendone complesso il significato e difficoltosa la corretta interpetazione.

Sin dal celebre studio condotto in merito da Gian Piero Bognetti (pubblicato nel 1957)6 è stato ampiamente sottolineato come la codificazione eseguita per volere di Rotari dell'antichissimo patrimonio normativo della stirpe longobarda fosse avvenuta sotto la spinta di istanze molteplici, in larga misura di

4 Liutp. 118: «quia incerti sumus de iudicio Dei, et multos audivimus per pugnam sine iustitia causam suam perdere; sed propter consuitutinem gentis nostrae Langobardorum legem ipsam vetare non possumus».

5 Per un giro d'orizzonti complessivo e aggiornato su simili tematiche, cfr. almeno i contributi raccolti nelle due recenti Settimane (rispettivamente, XLII e XLIV) del Centro Italiano di studi sull'alto medioevo: La giustizia nell'alto medioevo (secoli V-VIII), Spoleto 1995, e La giustizia nell'alto medioevo (secoli IX-XI), Spoleto 1997.

6 G. P. Bognetti, L'Editto di Rotari come espediente politico di una monarchia barbarica, in Studi in onore di G. De Francesco, II, Milano 1957, pp. 235-256, ripubblicato in ID., L'età longobarda, IV, Milano 1968, pp. 115-135. 
carattere politico-ideologico. Accanto alla necessità di dare certezza, tramite la scrittura, alle leggi della gens, in un frangente di incisive trasformazioni delle antiche strutture politiche e sociali tribali, come conseguenza del progressivo e rapido stabilizzarsi dello stanziamento dei longobardi in Italia, centrale appariva l'intento del re (il suo «espediente politico» nella formula bognettiana) di rafforzare la base del proprio potere attraverso l'atto della codificazione, in concomitanza con la rischiosa campagna militare diretta contro i capisaldi imperiali della costa ligure e della Venetia. Con la promulgazione dell'Editto Rotari avrebbe guadagnato a sé la devozione degli exercitales, maggiormente tutelati da un codice scritto rispetto alle prevaricazioni di coloro «qui maiore virtute habentur», e al contempo, attraverso un esplicito richiamo alla tradizione della stirpe, di cui il diritto costituiva un'espressione fondamentale, avrebbe ricompattato l'intero populus-exercitus, politicamente disperso nei vari rivoli della conquista. Inoltre, la stessa proposizione di se stesso in veste di re codificatore (pur se con tutti i condizionamenti visti), ispirata al grande esempio giustinianeo (e a una secolare tradizione cristiano-ellenistica della regalità), rappresentava un elemento di forte suggestione nello sforzo di creare un modello eterogeneo e più saldo del potere monarchico, tradizionalmente debole presso i longobardi di fronte ai vincoli posti dall'aristocrazia tribale e dall'assemblea del populus-exercitus ${ }^{7}$.

È stato parimenti rimarcato da molti (ma è idea non condivisa da tutti) come la codificazione del 643, proprio perché in larga misura recupero a fini "ideologici" dell'ancestrale tradizione di stirpe, fosse in un certo senso già arcaica, almeno in alcuni suoi tratti, all'epoca della propria redazione, specchio cioè di una società longobarda più antica e in buona parte diversa, per cultura e istituzioni, da quella che abitava l'Italia attorno alla metà del secolo VII; anche se si deve sottolineare a questo proposito come il codice fosse in ogni caso effettivamente applicato e non costituisse certo una mera reliquia, pura testimonza di assetti passati. Comunque, di molti istituti tradizionali, pur mantenuti fermi in quanto radicati nel costume della gens e quindi elemento costitutivo della sua stessa identità, si avvertiva appieno il carattere inadeguato rispetto alle mutate esigenze di una nuova struttura sociale, oltre che la dissonanza nei confronti delle suggestioni provenienti da altri modelli giuridici, di ascendenza romana e canonica.

La necessità di un "aggiornamento", pur nel rispetto sostanziale di una tradizione dalla quale non si poteva prescindere perché in essa trovava la propria legittimità la legge stessa, venne avvertita con forza ancor maggiore come si è già accennato - con i successori di Rotari, e specialmente con

7 Per un quadro di sintesi sulle trasformazioni della società longobarda in Italia e lo specchio del diritto, cfr. da ultimo C. Azzara, L'Italia dei barbari, Bologna 2002, pp. 93-134. 
Liutprando. Le soluzioni esperite in età liutprandina appaiono fortemente empiriche, con una tensione irrisolta fra l'ossequio alla tradizione e la ricognizione del nuovo; per cui se, per esempio, come s'è detto, nulla si poté fare contro il duello giudiziale, vennero all'opposto introdotti significativi cambiamenti in campo matrimoniale, con un'ampia ricezione della norma canonica che vietava le unioni fra consanguinei, anche spirituali, o in quello delle trasmissioni patrimoniali, con il riconoscimento, tra l'altro, della pratica della donatio pro anima ${ }^{8}$.

Sin dalla sua origine l'Editto longobardo si presentò, dunque, come una raccolta scritta di norme che erano certamente di sicuro riferimento e applicazione, ma che restavano pur sempre in viva dialettica con la consuetudine, con il complesso delle cawarfidae. Esso mostrava, dunque, una struttura non conchiusa in sé, ma al contrario "aperta" all'interazione costante con la prassi. L'Editto non può essere inteso, pertanto, come una realizzazione onnicomprensiva e sicura regolatrice di ogni negozio: prodotto rievocando mnemonicamente -per concorso collettivo del re, degli iudices (vale a dire, dei maggiorenti) e dell'assemblea del populus-exercitus- il patrimonio normativo tradizionale, orale, "preesistente" nella tradizione della gens, esso era ben consapevole, come s'è detto, della propria incompiutezza, prevedendo esplicitamente la possibilità di aggiungere nel corso del tempo altre tra quelle leggi che gli restavano esterne e che di volta in volta sarebbero state "ricordate" dal re e dall'assemblea dei liberi.

Altre norme, oltre agli usi consuetudinari, dovevano rimanere escluse dall'Editto e solo eccezionalmente essere recepite nel testo di questo: si trattava di specifiche disposizioni regie, originate da situazioni contingenti e perciò dotate di vigore transitorio. Tracce di simili norme sarebbero rintracciabili in alcune sopravvivenze di testi più ampi, recepite solo in un secondo tempo dalla tradizione manoscritta dell'Editto, come è il caso dei capitoli noti con i titula di Memoratorium de mercedes commacinorum e Notitia de actoribus regis, rispettivamente ascrivibili al regno di Grimoaldo (662-671) o di Liutprando il primo e dello stesso Liutprando il secondo. Il Memoratorium (otto capitoli in tutto) rappresenta una sorta di prontuario di istruzioni (quasi l'estratto di un capitolato d'appalto) per i maestri commacini operanti nelle corti regie, mentre nel caso della Notitia (sei capitoli, di cui uno frammentario) si tratta probabilmente della sopravvivenza di un più esteso preceptum emanato dal re per i propri actores.

La vitale trama di usi propri del diritto longobardo, forse improntati anche a varietà locali e non privi di interazioni con la prassi giuridica della

8 Per le donationes pro anima, cfr. Liutp. 6, 19, 65, 101; per il duello giudiziale, cfr. qui sopra, la nota $4 \mathrm{e}$ il testo ad essa corrispondente; per la normativa sulle unioni illecite, cfr. qui sopra la nota 2 e il testo ad essa corrispondente. 
popolazione romana del regno, appare oggi solo in minima parte ricostruibile. A tale scopo sembra percorribile la via di una ricognizione integrale ancora da compiere - delle notizie a tal fine rilevanti contenute nei documenti d'età longobarda, la testimonianza delle quali va assunta come significativa in sé e non solo secondo il parametro della loro aderenza o meno alla normativa scritta. Il sistema giuridico longobardo nella sua interezza sembra doversi ricostruire, pertanto, con un'operazione esegetica che parta dalla molteplicità dei casi concreti, attraverso un esame sistematico e un'interpretazione critica delle norme applicate nei documenti, piuttosto che - come fin qui si è per lo più fatto - muovendo dal solo Editto.

Un'analisi di tale fatta è suscettibile di perfezionare le nostre conoscenze circa il sistema giuridico dei longobardi, offrendo verosimilmente un quadro di forte articolazione, a seconda della cronologia e dei contesti. A puro titolo d'esempio, se sondaggi condotti su di un case-study quale quello costituito dai documenti relativi alla famiglia longobarda dei da Campione, che iniziano dal 721 e che riguardano diversi negozi di diritto privato, sembrano mostrare la disponibilità a derogare dalla norma edittale in talune materie qualora le parti concordino liberamente in tal $\mathrm{senso}^{9}$; altre ricerche - ancora allo stadio iniziale - su documenti della Langobardia meridionale paiono suggerire invece una più stretta aderenza delle soluzioni giuridiche esperite nei casi testimoniati dalle singole carte alla lettera dell'Editto ${ }^{10}$.

Un'immagine di sintesi del sistema normativo dei longobardi che più propriamente sembra rispecchiare la realtà (anziché uniformarsi ad astrazioni impropriamente "modernizzanti") appare dunque non certo quella di un modello fisso e uniformante, fondato sulla prevalenza del codice scritto, rispetto al quale isolare le "eccezioni"; ma, piuttosto, quella di un meccanismo plurale e dialettico, in cui largo peso conservava la tradizione consuetudinaria, capace di adattamenti ed evoluzioni, che, pur nel rispetto dei principi fondamentali, lasciava spazio a soluzioni flessibili, più adatte a una società in rapida trasformazione, nelle sue strutture e nella sua stessa identità, qual era quella del regnum Langobardorum in Italia.

9 Cfr. C. Azzara, Le nozze di Anstruda. Codice e prassi nell'Italia di diritto longobardo, in Carte di Famiglia. Strategia, rappresentazione e memoria del gruppo familiare di Totone da Campione (721-877), a cura di S. Gasparri e C. La Rocca, Roma 2005 (in corso di stampa). Sulla facoltà riconosciuta dall'Editto di derogare dalla norma nel caso di un accordo in tal senso fra privati, che sarebbe desumibile dal celebre Liutp. 91, cfr. S. Caprioli, Satura Lanx 11. Per Liutprando 91, in Studi in memoria di Giuliana D’Amelio, I: Scritti storico giuridici, Milano 1978, pp. 203-217.

${ }^{0} \mathrm{Cfr}$. E. Chiariello, Codificazione e prassi nel diritto della Langobardia meridionale (secc. VI-XI). Tesi di Laurea, a.a. 2001/02, facoltà di Lettere e Filosofia, Università di Venezia. 


\section{Bibliografia}

Azzara C. e Gasparri S. (a cura di ), Le leggi dei Longobardi. Storia, memoria e diritto di un popolo germanico, Milano 1992

Azzara C., L'Italia dei barbari, Bologna 2002

Azzara C., Le nozze di Anstruda. Codice e prassi nell'Italia di diritto longobardo, in Carte di famiglia. Strategie, rappresentazione e memoria del gruppo familiare di Totone di Campione (721-877), a cura di S. Gasparri e C. La Rocca, Roma 2005, pp. 223-236

Bognetti G. P., L'Editto di Rotari come espediente politico di una monarchia barbarica, in Studi in onore di G. De Francesco, II, Milano 1957, pp. 235256, ripubblicato in Id., L'età longobarda, IV, Milano 1968, pp. 115-135

Caprioli S., Satura Lanx 11. Per Liutprando 91, in Studi in memoria di Giuliana D’Amelio, I: Scritti storico giuridici, Milano 1978, pp. 203-217

Chiariello E., Codificazione e prassi nel diritto della Langobardia meridionale (secc. VI-XI). Tesi di laurea, a.a. 2001/o2, Facoltà di Lettere e Filosofia, Università di Venezia 